$$
\text { كلية الآداب و العلوم الاجتماعية محمد خيضر -بسكرة- وزارة التعليم العالي و البحث الجية الديمقر اطية الثعبية }
$$

$$
\begin{aligned}
& \text { التدبن و علافته ببعضث المثتير اتث التفسية } \\
& \text { الاجتماعية (الثو افق الاجثماعي، ثقدير الذاث) }
\end{aligned}
$$

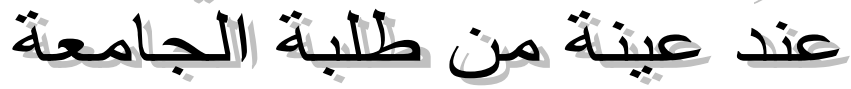

مذكرة مكملة لنيل شهادة الماجستير في علم النفس تخصص علم النفس المرضي الاجتماعي

$$
\text { من إعداد الطالبة: }
$$

أعضاء اللجنة:

مشرفا و مقررا

رئيسا

مناقشا

مناقشا
أ.د لوكيا الهاشمي: جامعة قسنطينة أ.د جابر نصر الاين: جامعة بسكرة أ.د دبلة عبد العالي: جامعة بسكرة

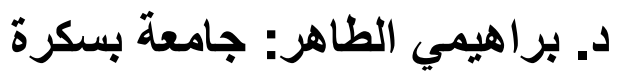




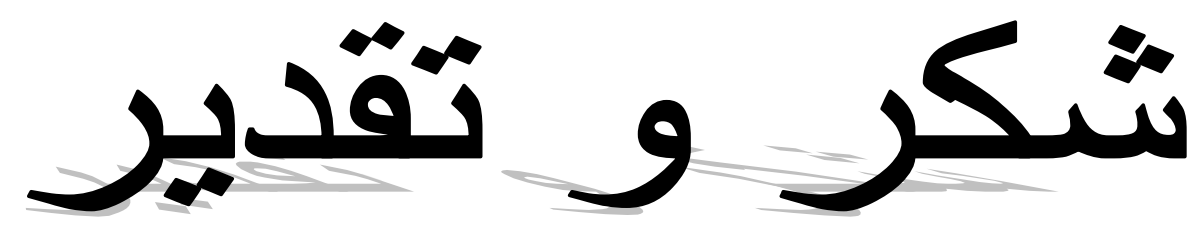

أبدأ أو لا بحمد الله تعالى العلي القدير الذي وفقني و أعانتي على إنجاز هذه الدر اسة (و ما كنا لنهتدي لولا أن هدانا الله)، فلك اللهم الحمد حتى ترضى و للك الحمد إذا رضبيت. ثم أتقدم بالثكر الجزيل و العرفان إلى الأستاذ المشرف (أ. د. لوكيا الهاشمي)، الذي تفضل بقبول الإشر اف على هذه المذكرة، و على النصائح و التوجيهات القيمة التي أحاطني بها و التي كانت سندا كبير الي طو ال إنجاز هذه المذكرة. كما لا يفوتني أن أتقدم بالثكر الجزيل إلى كل من ساعدني في إنجاز هذه

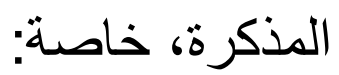
أ. بلقاسم، أ. صالح، جهيدة. و أخير ا أتقدم بالثكر الجزيل إلى لجنة الأساتذة الذين تفضلو ا مشكورين على مناقشة هذه المذكرة.

الصفحة

فهرس المحتويات

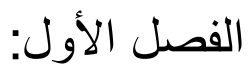


الفصل التمهيدي:

2 - مقدمة.

6. -

9. ـ أهمية الدر اسة

11

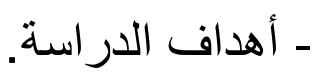
12

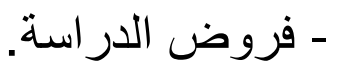
12 . ـ المفاهيم الرئيسية للار اسة. 13 - حدود الدر اسة. 15 ـ الدر اسات السابقة... الفصل الثاني: فصل التدين - تمهيد. 1- تعريف الدين. 29 2- تعريف التدين. 30 . 3- تفسير ظاهرة التدين. 31 4- أبعاد التدين (جو انبه). 5- أنماط التدين. 34 5-1- التدين المعرفي "الفكري". 34. 2-5-التدين الحماسي. 34 3-5- التدين السلوكي (تدين العبادة). 5-4- التدين النفعي. 5-5- التعصب 35 6-6- التطرف. 35 5-5- التصوف. 6- أهمية التدين و التدين. 
7- وجهة النظر الغربية و الإسلامية في العلاقة بين التدين و الصحة النفسية...38 38. 1-7- - 1- - المنظور الغربي. 40.

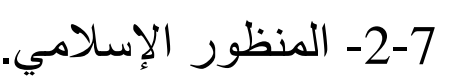
8- كيف يؤثر الدين -فيزيولوجياو نفسيا- على الصحة الإنسانية (الصلاة، الصيام 43. كنموذج). 44. 1-8- الصلاة. 46. 2-8- الصيام. -خاتمة. - خلاصة الفصل. الفصل الثاني: التو اقق. - تمهيد.

54

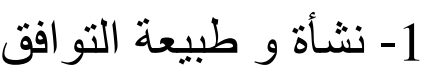
54 ـ التو افق و التكيف. 56. ـ التو افق و الصحة النفسية. 2- تعريف التو افق

60. 3- أنو اع التو افق. لقرئ.

62 4- العو امل الديناميكية في عملية التو افق. 62. 4-1-4 الإحباط. 62 1-1-4 تقسيم الإحباط. 62 أـ الإحباط الأولي و الثانوي. 63. ب- الإحباط السلبي و الإيجابج. 63. ج- الإحباطات الخارجية و الداخلية. 64. 4-1-4- الآثار التي يتركها الإحباط. 64 أ- تحسين الأداء. - ألع. 65.

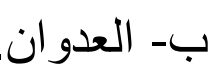


65.

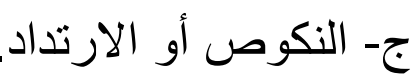

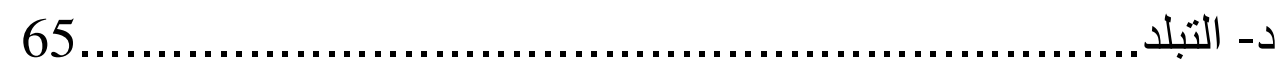

65.

هـ-التخيل (أحلام اليقظة).

66.

2-4 - 2-4 الصراع.

66

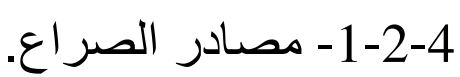

66

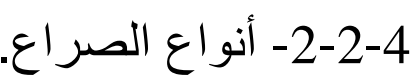

66

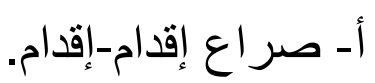

67

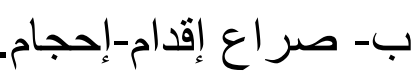

67.

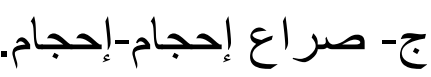
67 د- صر اع إقدام-إحجام مزدوج.

68 4-3-4 القلق 68 1-3-4- القلق الموضوعي أو الواقعي. 69

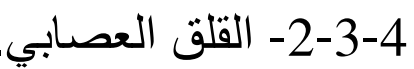
69 3-3-4- القلق الخلقي. 70 5- الآليات النفية الدفاعية. 71 6- أساليب التو افق. - البال 72 6-1-6 المعالجة أو المو اجهة المباثرة. 72

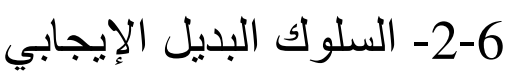
72 . 3-6- السلوك البديل السلبي. 72 4-6- مر احل متقدمة من الأساليب التو افقية الثاذة.. 73. 7- الاستجابات العصابية و الذهانية كأساليب للتوافق الثاذ. 73 1-7- إقدام شاذ. 73.

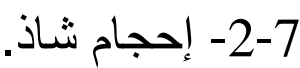

74 3-7- انتظار شاذ. 74 4-7- الاستعطاف الثاذ.. 

8- الاتجاهات الأساسية في تفسير التوافق 1-8 المقاربة الفيسيولوجية. 75 2-8- المقاربة السيكولوجية. 3-8- المقاربة الاجتماعية و الثقافية. 76. 4-8- الدقاربة الدينية (الروحية).. - خاتمة.

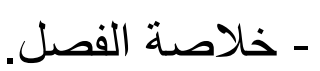

الفصل الثالث: تقدير الذات.

86. - الفرق بين مفهومي "الأنا" و "الذات". 88. I-1- - تعريف الذات

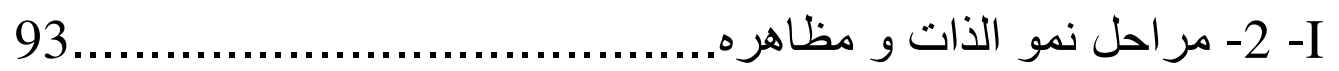
1-2-I الطفولة المبكرة (3-0 سنوات).............................................. -2-2-I مرحلة ما قبل المدرسة (4-6 سنوات)................................... 3-2-I 94.

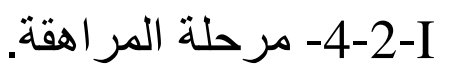

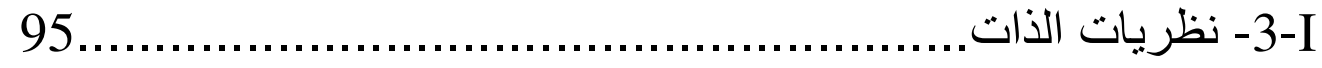

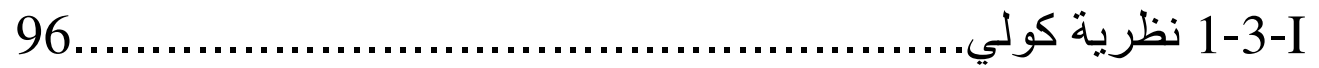

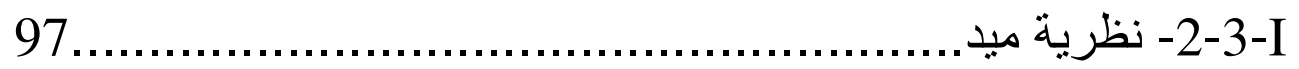

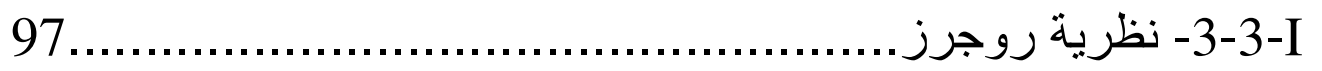

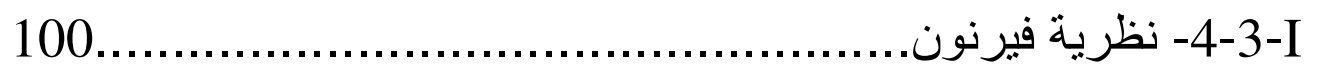
-4-I وجهة النظر الإسلامية في النفس (الذات)......................................

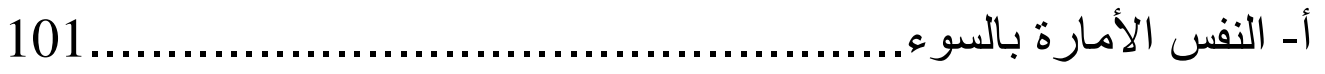

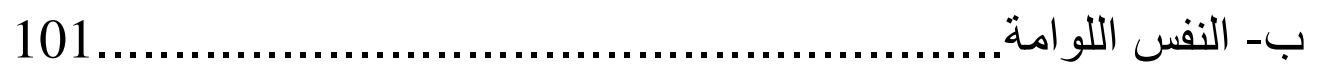




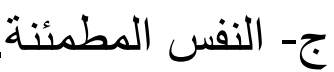

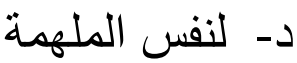

104........................" بعض الدفاهيم التي لها علاقة بمفهوم "تقدير الذات -1I

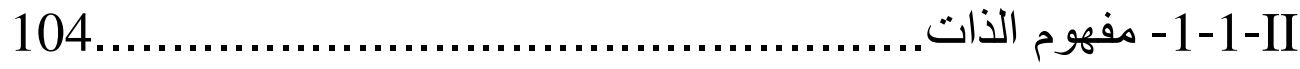

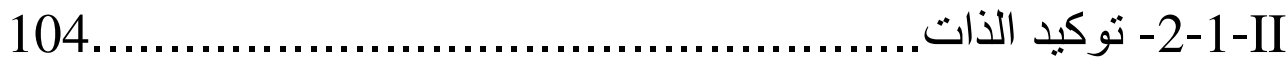

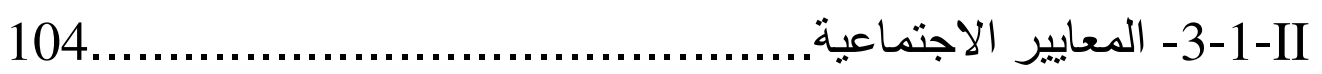

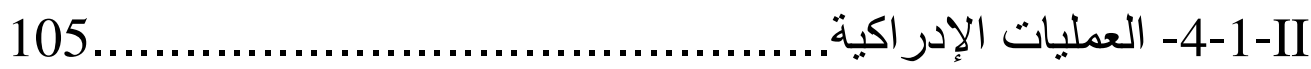
105

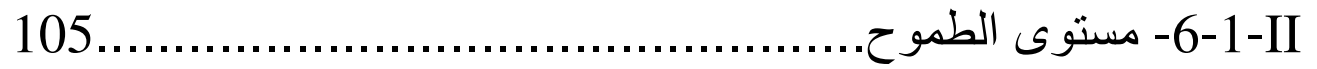

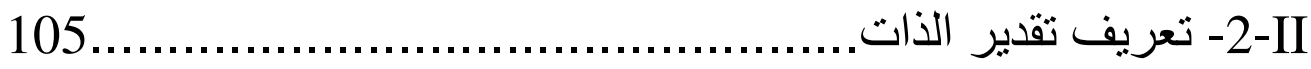

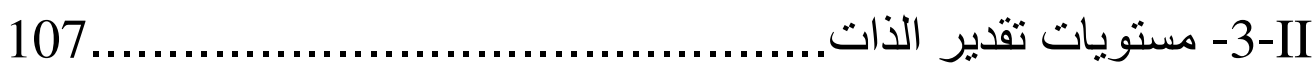
1-3-II

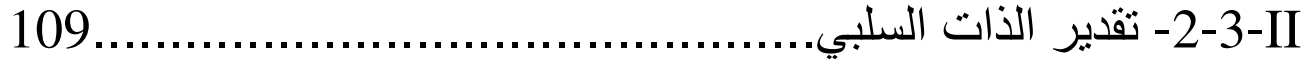

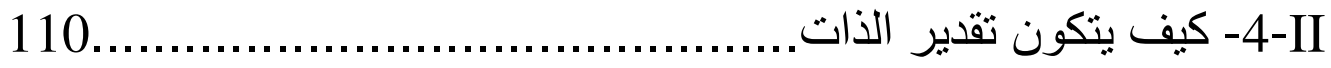

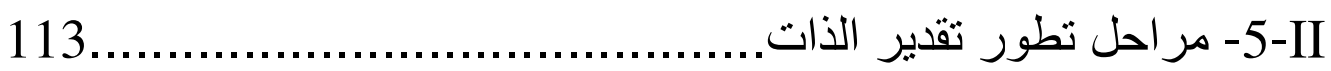
115. 6-II - تقدير الذات من وجهة نظر إسلامية

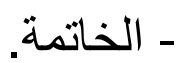

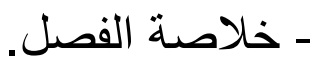
الفصل الخامس: منهج الدراسة و إجراءاتها. 120.

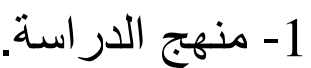

120.

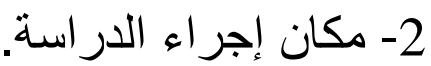

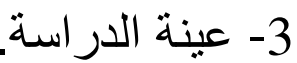
120

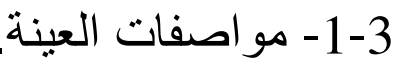




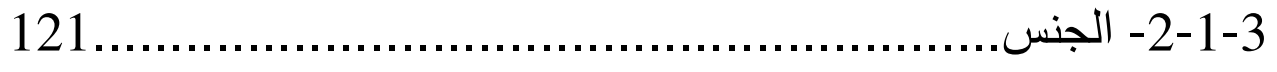

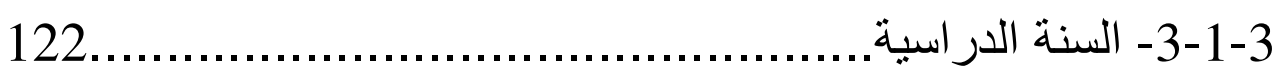

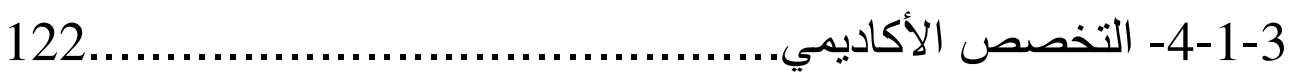

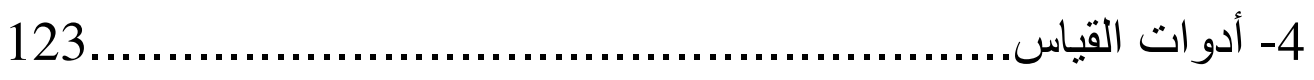

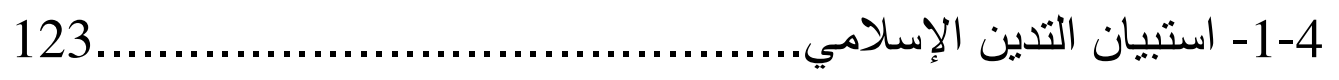

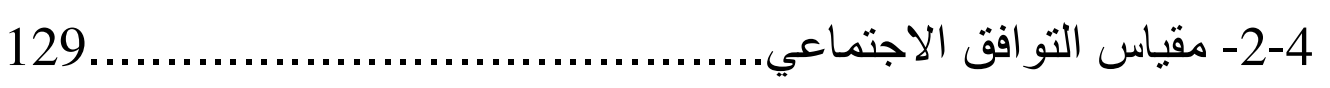

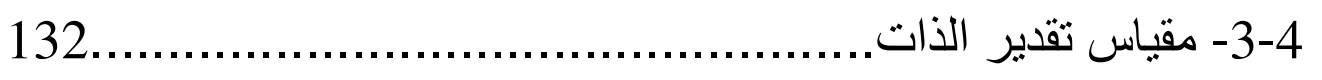

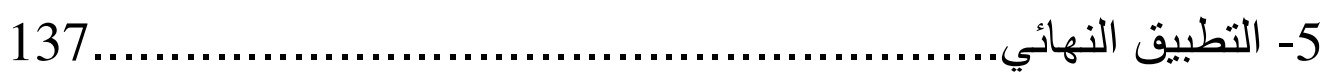

الفصل الساد: نتائج الدراسة و مناقتشها.

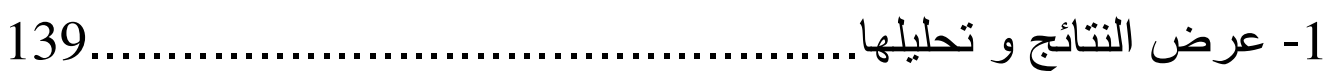

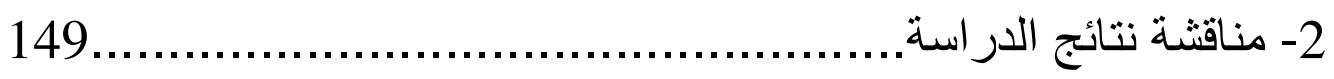

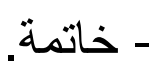

- التوصيات و المقترحات.

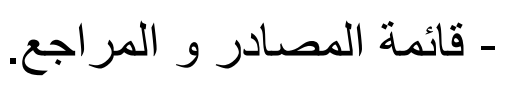

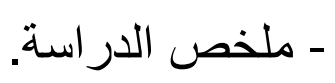

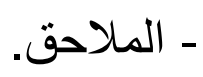




\section{قائمة الجداول:}

\begin{tabular}{|c|c|c|}
\hline الصفحة & عنوان الجدول & رقم الجدول \\
\hline 121 & عدد الذكور و الإناث و النسبة المئوية لكل منهما في العينة & جدول (1) \\
\hline 122 & عدد أفراد العينة حسب التخصص النينة الدراسي (ديني / غير الكئ منهما & 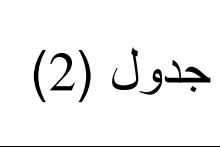 \\
\hline 126 & توزيع البنود على محاور الاستبيان & جدول (3) - ج) \\
\hline 128 & يمثل أرقام الفقرات الموجبة و السالبة و طريقة التصحيح & جدول (4) \\
\hline 131 & يمثل الفقرات الموجبة و السالبة في مقياس التوافق و الجاه تصحيا & 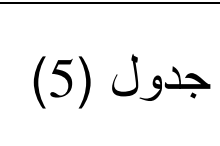 \\
\hline 135 & أرقام العبار ات الموجبة و السالبة و اتجاه تصحيحها & 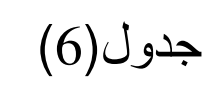 \\
\hline 141 & الطرق الإحصائية المستخدمة & جدول (7) \\
\hline
\end{tabular}




\begin{tabular}{|c|c|c|}
\hline 142 & الارتباط بين كل من التدين و التوافق الاجتماعي & جدول (8) \\
\hline 143 & الارتباط بين التدين و تقدير الذات. & جدول (9) \\
\hline 144 & الفروق في مستوى التدين حسب نوع التخصص الدر اسي & جدول (10) \\
\hline 146 & الفروق بين الذكور و الإناث في مستوى التدين & جدول (11) \\
\hline 147 & الفروق بين الذكور و الإناث في التوافق الاجتماعي & جدول (12) \\
\hline 148 & الفروق بين الذكور و الإناث في مستوى تقدير الذات. & جدول (13) \\
\hline
\end{tabular}

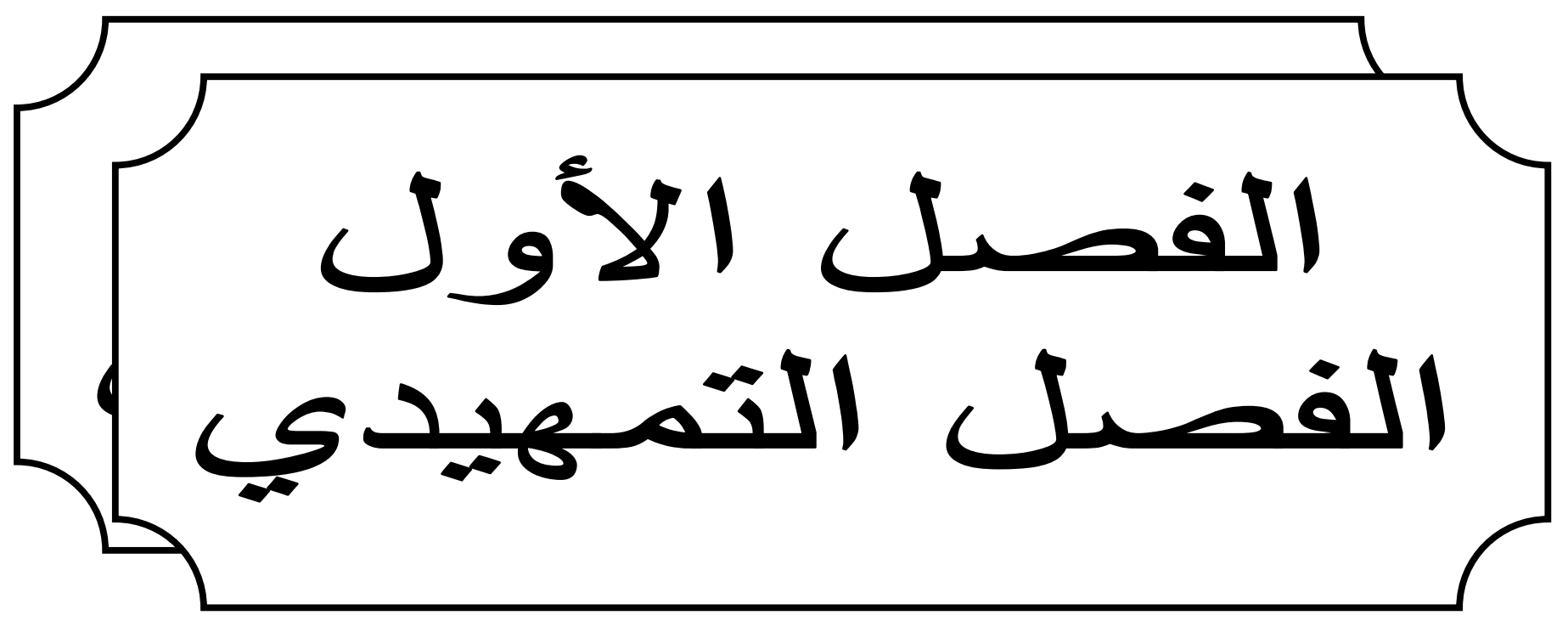




\section{المقدمة:}

إن التدين حاجة نفسية و غريزة فطرية لدى كل إنسان على وجه الأرض، و هو ظاهرة نفسية إجتماعية تضرب بجذور ها في الماضي البعيد. بل إن كثير ا من مؤرخي الأديان يجمعون على أنه لا يوجد جماعة إنسانية عاشت على له

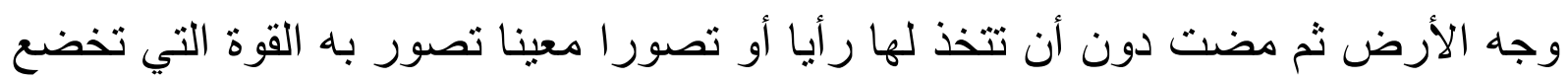
لها و المسؤولة عن خلق الإنسان و موته و مآله بعد الموت، و ظواهر الكون و

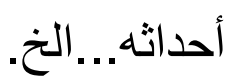
و يعد التدين ظاهرة أساسية في حياة الثعوب، استمدت مبررات وجودها من عوامل و اقعية داخل المجتمعات، و من الظروف الخاصة بالتحو لات الاجتماعية و الاقتصادية و و و المشكلات العميقة التي تو اجه الإنسان. و بالرغم من التمييز الذي يقوم به العلم بين الدين(و بالتالي الإيمان)، و النفس (و بالتالي

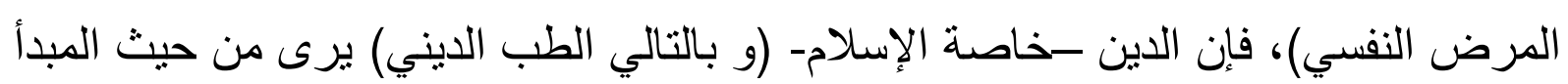

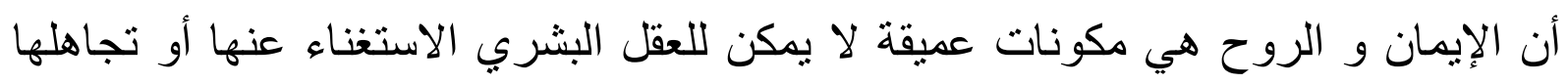


(د.إحسان كارافاس المسار الإنساني التاريخي للطب النفسي في الإسلام، مجلة الثقافة

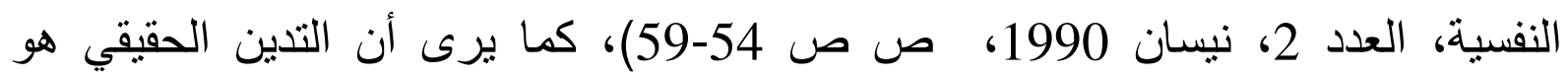
الطريق إلى بناء الثخصية السوية المتزنة و المتمتعة بالصحة النفسية، فالدين بمنظومته الفكرية المنطقية و بصلاته الوقائية و العلاجية يعمل على تزويد الأفراد المؤمنين بطاقة نفسية هائلة كما يمدهم بالإضافة إلى ذلك بمعنى حقيقي للحياة و بأهداف سامية يكرسون لأجلها حياتهم إلى جانب أنه بملؤ قلوبهم بالحب لله و رسوله و الناس من حولهم و للإنسانية عامة و هو فوق ذلك يبعث فيهم الثعور بالأمن و الطمأنينة. و هذه حقيقة يؤكدها الواقع المعاش، فالحضارة السائدة اليوم و التي تقوم على مبادئ

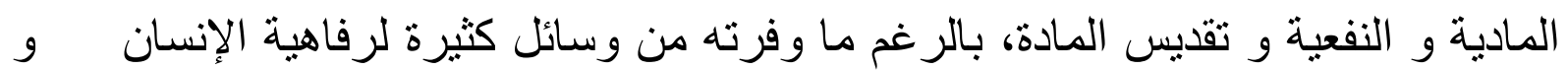

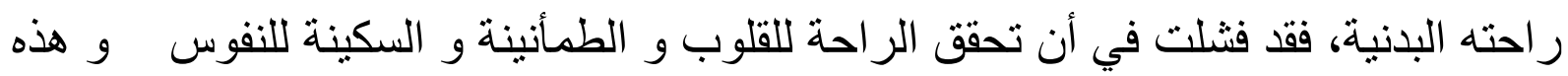

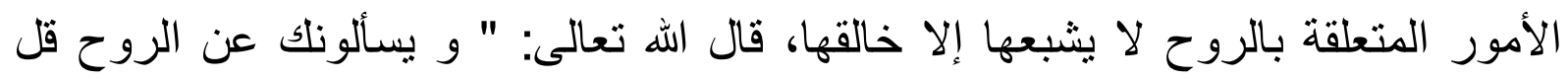
الروح من أمر ربي، و ما أوتيتم من العلم إلا قليلا " [ الإسر اء: 85 ].

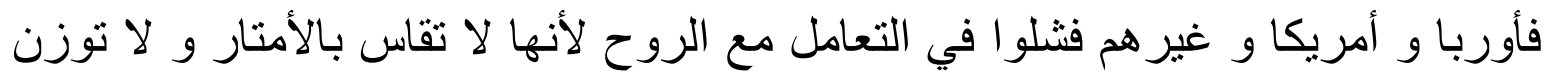

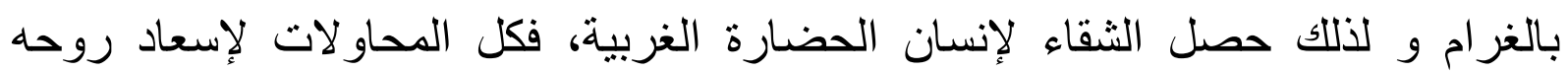
الثنقية عن غير طريق خالقها باءت بالفشل، و لن تسعد هذه الروح إلا بمنهاج ربها و عبادته و الإتصال به و الأنس بحضرته و جلاله، قال الله تعالى: " الذين آمنوا و تطمئن قلوبهم بذكر الله، ألا بذكر الله تطهئن القلوب" [ الرعد: 28 ]. و لذللك ظهرت الإتجاهات النفسية في الغرب الني تنادي بأهمية الدين و ضرورة العودة

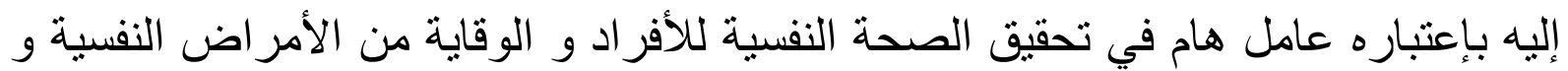

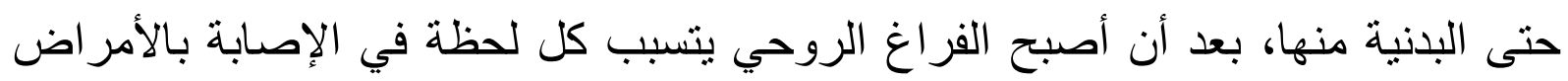
النفسية و إنتشار الجر ائم و حالات الإنتحار بشكل وبائي. و هذا الثقاء الذي يعاني منه الأفراد في الغرب قد امتد إلى المجتمعات العربية

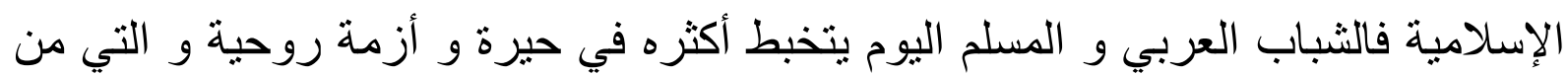

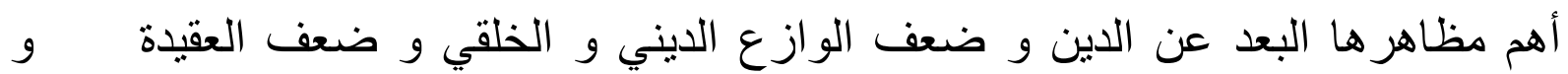


الابتعاد عن مبادئ الدين الإسلامي و في أحسن الحالات حصر الدين في إطار ضيق من أداء للعبادات دون اتخاذه (الدين) منهجا للحياة. و كان نتيجة ذلك انتنار الأمر اض النفسية الباطنة و الظاهرة بين هؤلاء الثباب و. و

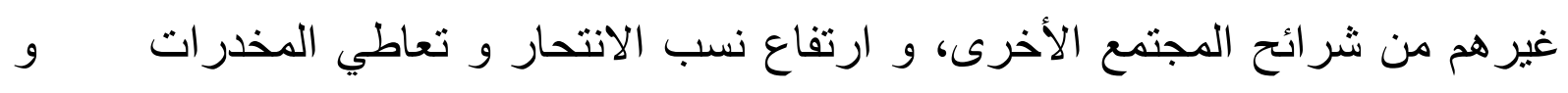
أنكال الجريمة بشكل مخيف. إن الدين -خاصة الإسلام- أصلح سبيل للإنسان المعاصر الذي غدا يعاني من فقدان روح الطمأنينة، و تغتاله أمر اض التغير و التكنولوجيا و البيئة الملوثة، فهو خير منقذ له من سوء لإهي المصير المرضي الذي تسببه عجلة الحياة الخالية من القيم و عجلة التكنولوجيا بتلوثها

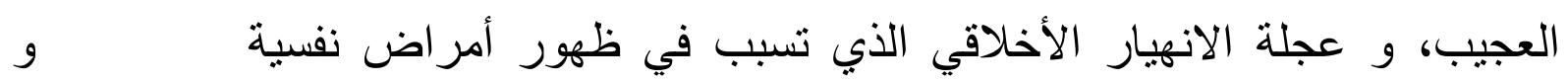
نفسجمية لا حصر لها. فالدين (خاصة الإسلام) هو طب للنفس و الجسم معا، و مصداقيته تتبع من مناسبته السابقة و حتى اليوم و لكل الظروف و المتغيرات و المستجدات على مستوى الحياة البشرية، و كأنه وضع علاجا طبيا قبل كل شيء للجسم و العقل و الروح. و انطلاقا من هذا ارتأت الباحثة تناول موضوع (التدين) في علاقته ببعض المتغيرات النفسية الاجتماعية لتقف على حقيقة العلاقة بين هذا المتغير و بعض المتغيرات النفسية الاجتماعية (التوافق الاجتماعي، تقدير الذات) و ذلك عند عينة من طلبة الجامعة. و قد قسمت الباحثة دراستها إلى سبعة فصول، حيث تتاولت في الفصل الأول: المقدمة،

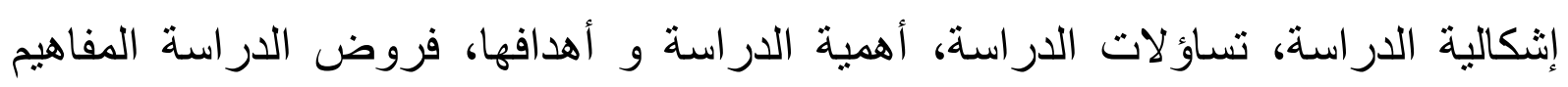
الأساسية للاراسة،حدود الدراسة، و أخيرا الدراسات السابقة التي لها علاقة بموضوع

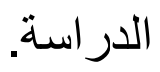
أما الفصل الثاني، فقد تناولت فيه الباحثة موضوع "التدين"، حيث تطرقت في هذا الفصل إلى تعريف الدين، ثم تناولت تعريف التدين من وجهة نظر غربية و إسلامية، ثم تفسير ظاهرة التدين و بعدها تطرقت إلى أبعاد التدين و أنماطه و أهميته، ثم وجهة النظر الغربية و الإسلامية للتدين و ختمت الباحثة هذا الفصل بتوضيح كيفية تأثثر الدين فزيولوجيا و نفسيا على الصحة الإنسانية من خلال نموذجين روحيين علاجيين (الصلاة و الصوم). 
أما الفصل الثالث: فقد تناولت فيه الباحثة موضوع التو افق، حيث تطرقت في البداية إلى

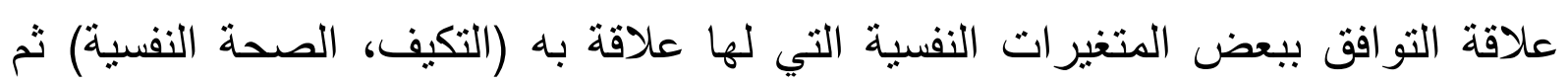

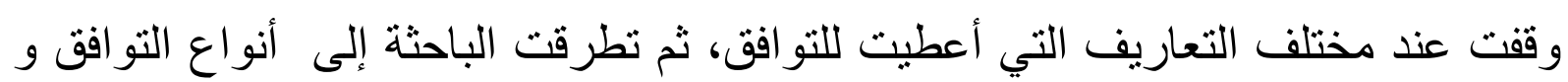

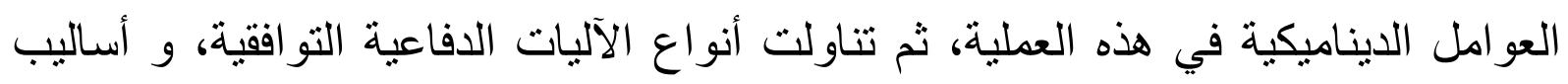

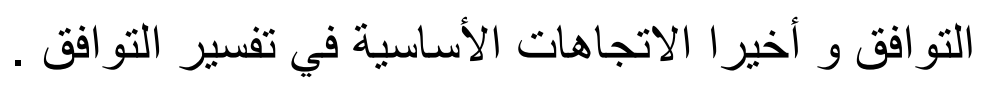

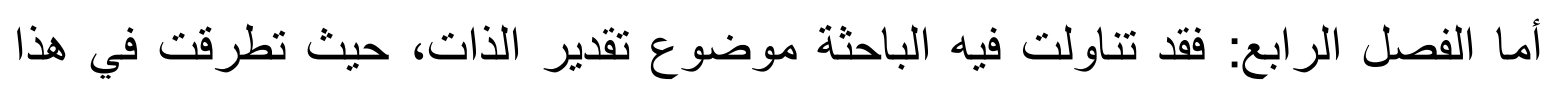
الفصل إلى تعريف الذات، و مراحل نمو الذات و مظاهره، و نظريات الذات، كما تناولت الته وجهة النظر الإسلامية في النفس (الذات). ثم تناولت متغير تقدير الذات حيث تطرقت فيه إلى بعض الدفاهيم التي لها علاقة بهذا

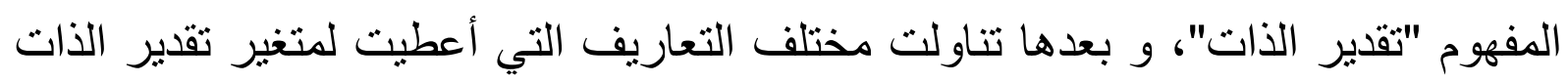

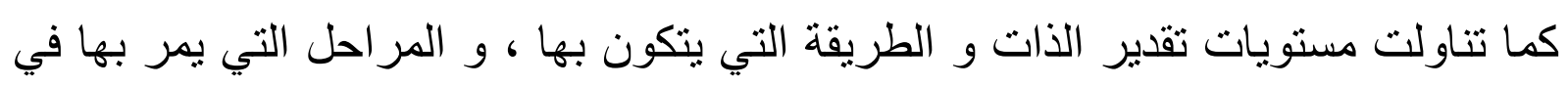
تطوره عند الإنسان و أخيرا تتاولت الباحثة تقدير الذات من وجهة النظر الإسلامية.

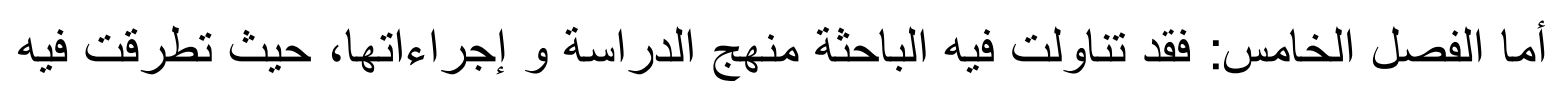

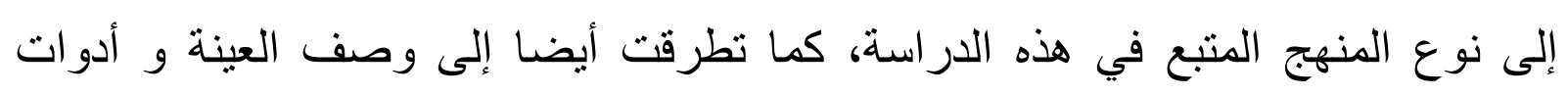
القياس المستخدمة في هذه الدراسة. أما الفصل السادس: فقد خصصنه الباحثة لعرض نتائج الدراسة التي نم التوصل إليها و تفسير ها. و ختمت الباحثة هذه الدراسة بخاتمة، تطرقت فيها إلى أهم ما توصلت إليه من نتائج في هني هذه الدراسة. و أخير ا، قامت الباحثة بعرض مجموعة من المقترحات و التوصيات المستبطة من نتائج 


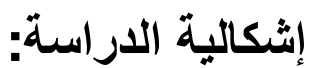

لقد تعددت وجهات النظر و اختلفت حول تفسير الأمراض النفسية و منشؤها و أسباب

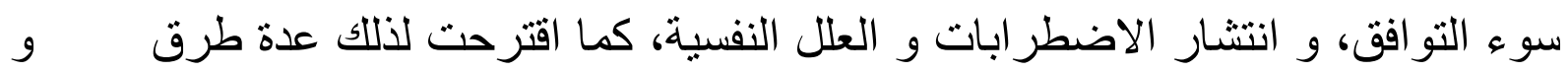
أساليب لعلاج هذه العلل و الأمر اض أو الوقاية منها، و قد تم كل ذلك و في معظم الأحيان

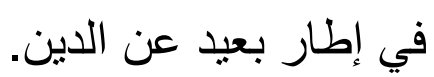
و لم تتمكن هذه النظريات على كثرتها و تنوعها من الوصول إلى فهم حقيقي للإنسان و لا إلى علاج مشكلاته و علله النفسية أو حتى وقايته من الوقوع فيها.

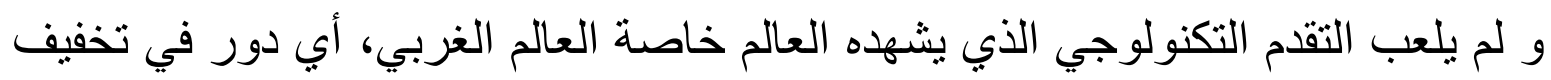
هذه الأزمة بل إنه أصبح سببا لظهور مشاكل جديدة في سعيه لحل المشكلات القديمة.

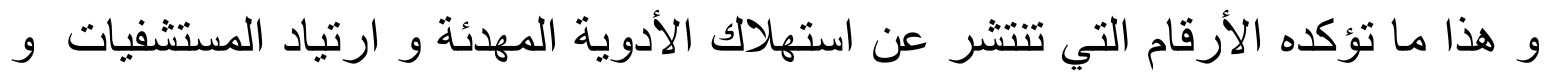

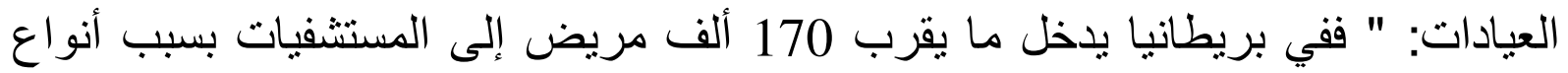
مختلفة من الأمراض العقلية و ما يقرب عن 16 ألف من المعوقين عقليا. و استهلكت فرنسا سنة 1982 أكثر من مليون علبة دواء من المنومات و المهئئات.

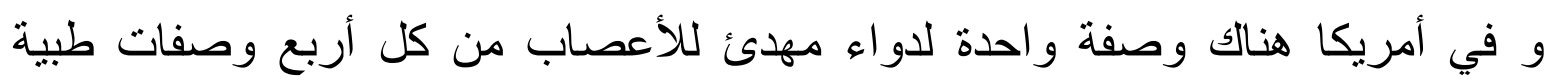
عادية، و يباع ما يزيد عن 60 ألف صنف من العقاقير و الأدوية الأخرى. و في إحصائيات فرنسية لعام 1986 هناك 17 ألف حادثة انتحار ناجحة بين المراهقين

$$
\text { فقط" (محمد نوفيق، 2002: 227-228). }
$$


و قد كان هذا الثقاء النفسي أهم الأسباب التي أدت إلى انتشار العيادات النفسية بكثرة في أوربا و البلاد المتقدمة. و في مقابل هذا ظهرت تيار ات نفسية تنادي بأهمية الدين في الصحة النفسية و ضرورة إعادة تفعيل دوره من جديد ليتولى الدور الرئيسي في الوقاية و العلاج النفسي، بعد أن نم إدر الك ما للدين من أهمية عظيمة في تحقيق الصحة النفسية. و هو ما تبناه بعض النفسيين العرب و المسلمين فيما بعد، و الذي ظهر جليا في المؤتمر الدولي للصحة النفسية الذي عقدته الجمعية الإسلامية للصحة النفسية في لاهور بباكستان (سنة 1985)، رغم أن علماء النفس المسلمين قد أدركوا ذلك منذ زمن بعيد لكن بحكم 9 سيطرة الغرب على علم النفس بمختلف فروعه، فقد تم تجاهل آرائهم اجتهاداتهم و لم بتم الأخذ بها مطلقا. و عموما تحدد مشكلة البحث سموضوع الدراسة- انطلاقا مما يلي: إذا كان بعض علماء النفس الغربيين ينادون بضرورة العودة إلى الدين لكن بنية نفعية

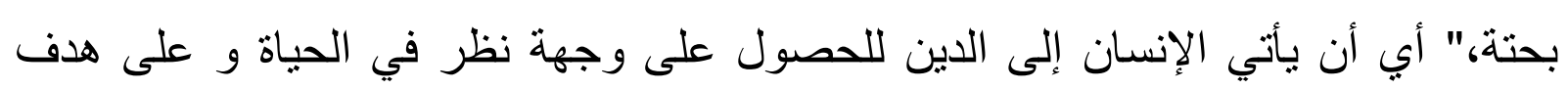
يكرس لأجل حياته و أن يجد أجوبة للأسئلة التي تحيره حول أصل الخلق و خالق الكون و

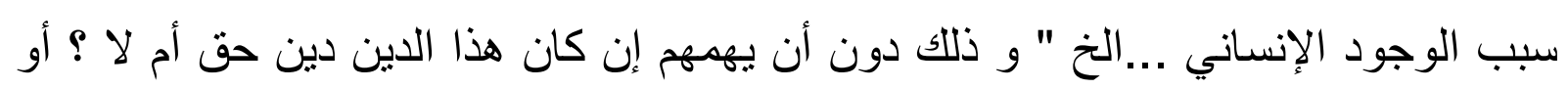
أن يلتزم الإنسان بمقتضى عقيدته و أحكام دينه. فإن كان الأمر كذلك فهل ذلك يكفي فعلا للوصول إلى تحقيق الصحة النفسية و تحصيل

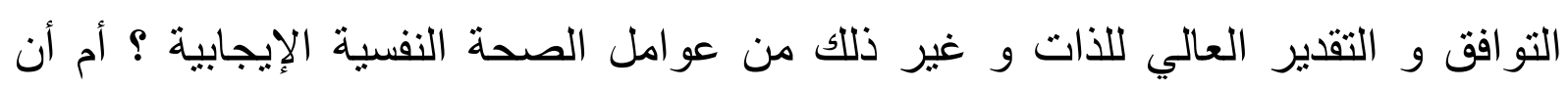
الوصول إلى تحقيق هذه الأخيرة يتطلب أكثر من ذلك بكثير، أي الالتز ام بأحكام الدين و بمقتضياته العملية التز اما حقيقيا؟ كذللك ما يلاحظ في المجتمعات العربية و الإسلامية التي يعتنق معظم أفرادها الدين

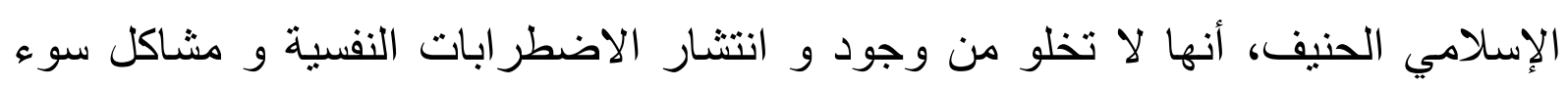

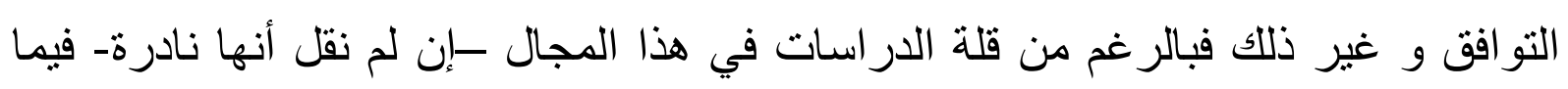
يتعلق بالمجتمعات العربية و الإسلامية، إلا أنه من خلال بعض الإحصائيات التي يتم 
إجراؤها من حين لآخر يتضح أن هذه المجتمعات غير مستقلة عما يجري في العالم فيما يخص انتشار الاضطر ابات النفسية. و هو ما يدفعنا للتساؤل حول السبب الحقيقي ور اء هذا، خاصة ما يلاحظ على المسلمين 9 اليوم من أن أكثرهم يعاني من ضعف التمسك بالدين و قلة الالتزام به بمقتضياته العملية و التأثر بالمادية الغربية. و أخيرا، فإن الاعتماد على نتائج الدراسات الغربية التي تناولت متغير التدين في علاقته ببعض المتغير ات النفسية و الاجتماعية، و الاكتفاء بما توصلت إليه هذه الدر اسات من نتائج ثم تعميم ذلك على جميع أنشكال الدين و التدين من الخطأ بمكان، خاصة و أن هذه الدراسات أجريت على أديان تختلف ضمنيا و شكليا عن الدين الإسلامي الحنيف الذي تعتتقه مجتمعاتنا العربية، و خاصة المجتمع الجزائري -الذي يمثل مجتمع بحث الدراسة الحاليةلذلك من الضروري در اسة التدين الإسلامي و الوقوف على حقيقته و حقيقة علاقته بالجانب النفسي و الاجتماعي للثخص. و بناء على ذلك كان التحمس لدراسة التدين الإسلامي، و يكون ذلك من قبيل التعرف على بعض المتغير ات النفسية الاجتماعية للأفر اد باختلاف مستوى تدينهم (مرتفعي التدين / منخفضي التدين) و ذلك من خلال محاولة الإجابة عن أسئلة الدراسة التالية: السؤال الرئيسي للاراسة: ما طبيعة العلاقة بين التدين و بعض المتغيرات النفسية الاجتماعية (التو افق الاجتماعي تقدير الذات) عند طلبة الجامعة؟

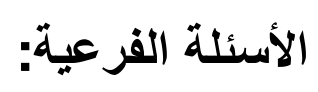

ما هي طبيعة العلاقة بين التدين و التو افق الاجتماعي عند طلبة الجامعة ؟

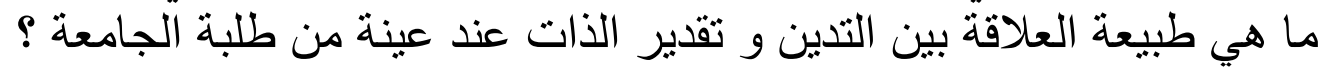
هل توجد فروق ذات دلالة إحصائية في مستوى التدين حسب نوع التخصص الدراسي

$$
\text { (ديني/غير ديني) }
$$

- هل نوجد فروق ذات دلالة إحصائية في مستوى التدين حسب متغير الجنس (ذكور / 
هل توجد فروق ذات دلالة إحصائية في التوافق الاجتماعي حسب متغير الجنس (ذكور

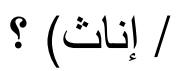

هل توجد فروق ذات دلالة إحصائية في مستوى تقدير الذات حسب متغير الجن؟؟

\section{أهمية الدراسة:}

إن وجود الأمراض النفسية وأنثال سوء التوافق و اضطرابات الثخصية هي مسألة طبيعية للحياة و تكيفاتها مع تغيرات البيئة الخارجية و البيئة النفسية، و لكن حين تتعدى

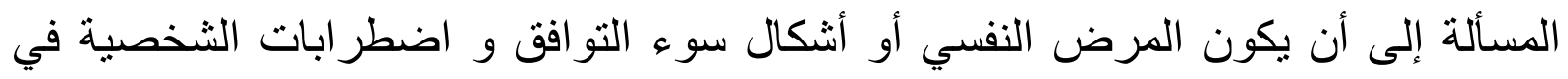
مساحة انتثار ها أثنبه بالوباء فإن المسألة تتجاوز حدودها الطبيعية، و هو ما تؤكده الأرقام الإحصائية و التي تم الإثشارة إليها -سابقا-. وقد ظهرت اتجاهات نفسية تنادي بأهية الدين و التدين في الوقاية أو علاج الأمر اض و الإناريا. أشكال سوء التوافق التي تتخبط فيها المجتمعات المعاصرة، و التي أصبح الجانب المادي فيها يطغى على كثير من الإشباعات الأخرى حيث أصبح الكثبر من الأشخاص لا يربطون بين متغير ات الحياة المادية و الجانب الروحي أو المعنوي الذي يعنى به الدين.

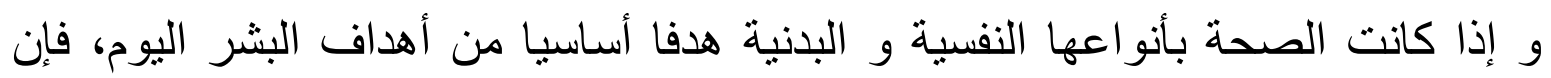

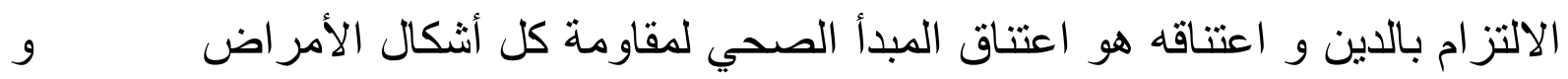
الاضطر ابات النفسية و الجسدية التي أخذت تزداد زيادة وبائية تنوعا و ولينة عددا (د. سامي

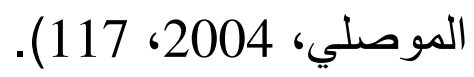
و لقد أصبح من الواضح اليوم أن التدين (الإسلامي) سسواء ما أثنتته الدراسات الميدانية

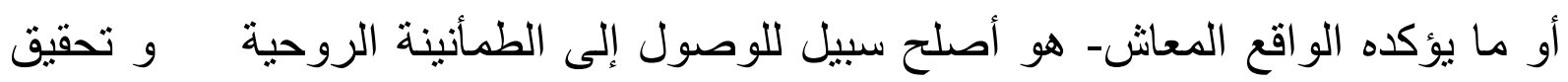
الصحة النفسية و التو افق بمختلف مستوياته.

و في هذا الإطار فإن أهمية الدراسة تتضح في النقاط التالية: - تعتبر هذه الدراسة إضافة جديدة إلى الدراسات التي تناولت متغير "التندين" كعامل إيجابي ــوقائياو علاجيا- في الصحة النفسية. 
- كما تعتبر هذه الدراسة إضافة إلى الدراسات التي تناولت منغير "التدين" في علاقته ببعض المتغير ات النفسية الاجتماعية. - كذللك فإنه أملا و سعيا في سبيل إنثاء "علم نفسي ديني" نابع من ديننا الإسلامي الحنيف و من بيئتنا الحضارية فإن أهمية الدراسة تتمثل في كونها إحدى الخطوات ـالتي نرجو أن تكون مهمة- في سبيل تحقيق ذللك. ـ أيضا و بحكم الانتماء الديني و الحضاري و الثقافي إلى الأمة الإسلامية التي أوكل الله

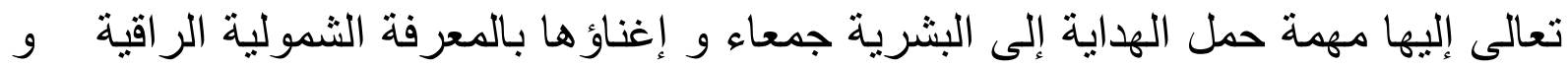
سبل الوصول إلى السعادة في الدنيا و الآخرة و ذللك مصداقا لقوله تعالى: " كنتم خير أمة أخرجت للناس تأمرون بالمعروف و تتهون عن المنكر و تؤمنون بالله" [آل عمران: 110] و تأسيا بقوله صلى الله عليه وسلم: "بلغوا عني و لو آية" فإن أهمية الدراسة تكمن في كونها توضح أهمية الدين و التدين في حياة الناس و في تحصيل السعادة و الطمأنينة للنفوس. - كذللك فإنه مع ظهور التيارات الفكرية اللددينية و الدينية المنطرفة التي شوهت صورة الدين و ضللت الفهم الصحيح له، فإنه يصبح من الضروري إجراء هذا النوع من الدراسات و البحوث في محاولة لتقديم الصورة الحقيقية للدين و إرساء المفهوم الصحيح له. ـ كذللك فإن أهمية الدر اسة تتضح أيضا من خلال ما تتاولته هذه الدراسة من متغير ات نفسية اجتماعية (التو افق الاجتماعي و تقدير الذات)، حيث و حسب (د. كمال دسوقي) فإن علم النفس هو علم دراسة التو افق و أن كل جوانب علم النفس و فروعها و تفريعاته تعنى بدر اسة

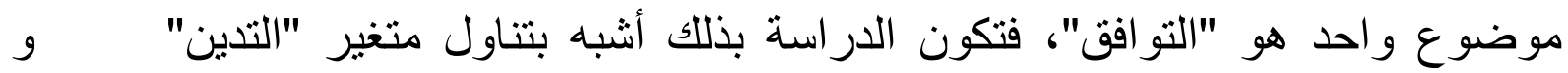
در استه في علاقته مع علم النفس ككل (بكل فرو عهد و تفريعاته). - كذللك فإنه إذا كان التوافق هو الموضوع الجوهري في علم النفس، فإن الثخصية أو "الذات" هي محل در اسة هذا الموضوع، فبدون الذات لا يمكن دراسة التوافق أو غيره من المتغيرات الأخرى و تتضح من خلال هذا أهمية در اسة الذات "و ما يتعلق بها من تقدير الذات أو غيره". 
هذا من الناحية النظرية، أما من الناحية التطبيقية فيمكن التوصل إليها من خلال ما تسفر

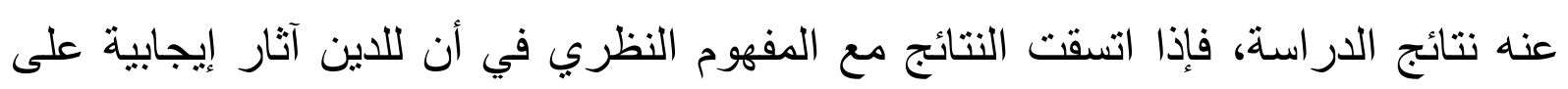

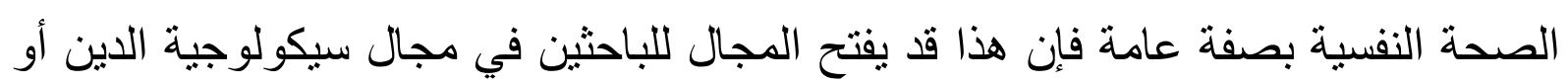

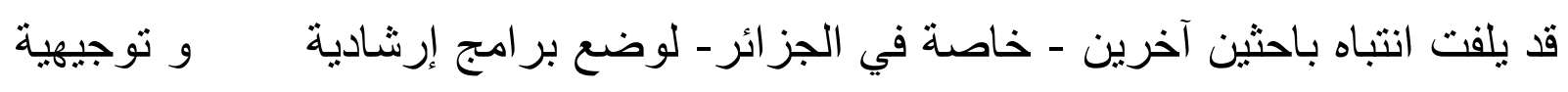
للكبار و الصغار مستوحاة من الدين بهدف تصحيح الدفاهيم الخاطئة السائدة عن الدين، بالإضافة إلى زيادة الوعي الديني و إعادة إرساء قيم الدين الإسلامي خاصة لإى الأجيال

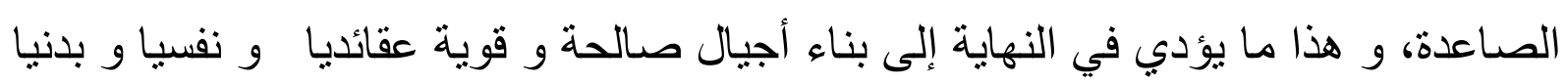
و بالتالي مجتمعات فعالة و منتجة. أهداف الار اسلة: تتلخص أهداف الدراسة الحالية فيما يلي:

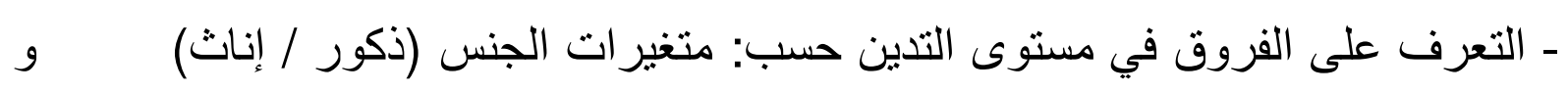
حسب نوع التخصص الدراسي (ديني / غير ديني). ـ التعرف على الفروق في بعض المتغيرات النفسية الاجتماعية (التوافق الاجتماعي تقدير الذات) عند طلبة الجامعة حسب مستوى تدينهم. - التعرف على الفروق في بعض المتغيرات النفسية الاجتماعية عند طلبة الجامعة حسب متغير الجنس (ذكور / إناث). - الكثف عن طبيعة العلاقة بين التنين و بعض الدتغيرات النفسية الاجتماعية (التوافق

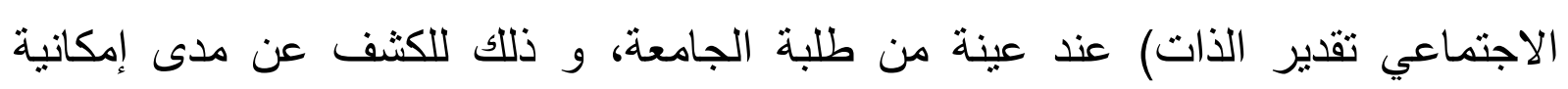
اعتماد التدين كعامل أساسي نحو تحسين الصحة النفسية للأفراد.

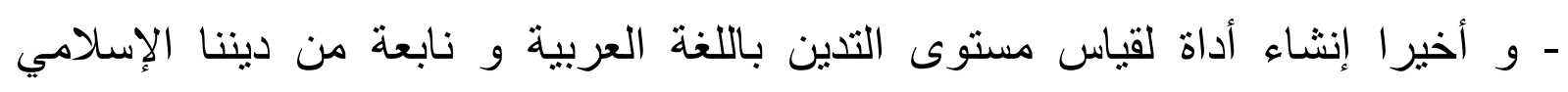
الحنيف. - 20 - n 


\section{ـ الفرضية الرئيسية:}

توجد علاقة ارتباطيه موجبة بين كل من التدين و المتغيرات النفسية الاجتماعية (النت اقق الاجتماعي تقدير الذات) عند طلبة الجامعة.

ـ الفروض الفرعية:

توجد علاقة ارتباطيه موجبة بين كل من التدين و التوافق الاجتماعي عند طلبة الجامعة

توجد علاقة ارتباطيه موجبة بين كل من التدين و تقدير الذات عند طلبة الجامعة. - توجد فروق ذات دلالة إحصائية في مستوى التدين حسب نوع التخصص الدراسي

$$
\text { (ديني / غير ديني). }
$$

- توجد فروق ذات دلالة إحصائية في مستوى التدين حسب متغير الجنس (ذكور /

توجد فروق ذات دلالة إحصائية في التوافق الاجتماعي حسب المتغير الجنس

$$
\text { (ذكور /إناث). }
$$

- توجد فروق ذات دلالة إحصائية في مستوى تقدير الذات حسب متغير الجنس (ذكور / إناث).

المفاهيم الرئيسية للاراسة:

التدين:

يقصد به ما يقوم به الفرد المتدين من ممارسات دينية ـتنبع من إيمان عميق بالله- تتمثل في العبادات و المعاملات و الأخلاق، و ذلك في محاولة إرضاء خالقه و تحسين علاقته بالآخرين و تمثله بالأخلاق الحميدة التي يدعو إليها الدين (د. رشاد موسى 1999، 678). و يقاس مستوى التدين بالدرجة التي يحصل عليها الفرد في مقياس التدين (الإسلامي). 
هو عملية تفاعل مستمرة بين الفرد و البيئة، و يقصد به عملية المواعمة بين الفرد بما له من مطالب و حاجات وبين البيئة بمالها من مؤثرات طبيعية و اجتماعية، و يقاس بمدى

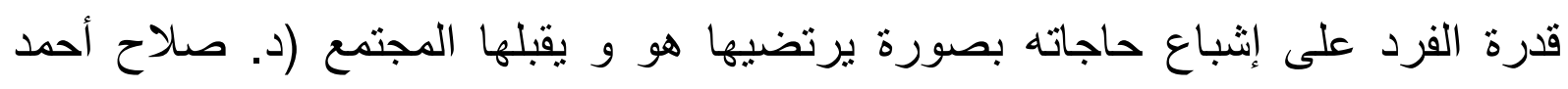

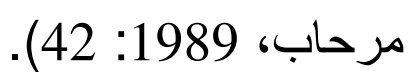

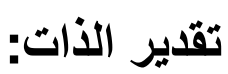
يقصد به تقييم صريح للنقاط الحسنة و السيئة في الفرد، و هو حكم شخصي عن الاستحقاق أو عدم الاستحقاق التي يتم التعبير عنها في الاتجاهات التي يحملها الفرد نحو نفسه و هو يرتبط بدرجة كبيرة بمدى تقبل الآخرين (د. إبراهيم أحمد أبو زيد، 1987

\section{حدود الاراسة:}

تتحدد الدر اسة الحالية ب:

1- المتغير ات موضوع الدر اسة و المتمثلة في:

التدين، التو افق الاجتماعي، تقدير الذات.

2- العينة المستخدمة في الدراسة و المكونة من 204 طالبا و طالبة من الذين تتجاوز أعمارهم ال 20 سنة، فهم أكثر استقرارا في توجهاتهم الدينية و خصائصهم النفسية ونه الاجتماعية (التوافق الاجتماعي، تقدير الذات). و قد أخذت عينة من طلاب جامعة (فرحات عباس بسطيف)، و ذلك لتمثل طلابا طابع تعليمهم غير ديني (عام)، في مقابل طلاب من الجامعة الإسلامية (جامعة الأمير عبد القادر بقسنطينة) و ذلك لتمثل طلابا طابع تعليمهم ديني، كما روعي متغير الجنس (ذكور ا / إناثا) في الدراسة. 3- نوع الأدوات التي طبقت على العينة لجمع بيانات البحث سموضوع الدراسة- و التي

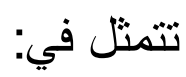

1- استبيان مستوى التدين الإسلامي من إنثاء الباحثة. 2- مقياس التوافق الاجتماعي المأخوذ من مقياس التوافق النفسي ل (د. زينب محمود 
3- مقياس تقدير الذات ل (د. حسين عبد العزيز الدريني و آخرون). 4- نوع الأساليب الإحصائية التي استخدمت في استخلاص نتائج البحث.

نظر الحداثة تناول موضوع التدين من الجانب النفسي (نوعا ما) خاصة في الجزائر في حدود علمنا- ، كنتيجة للخلفية غير الدينية للكثير من الباحثني النفسانيين إلى جانب قداسة 
الدين و مكانته عند معظم الناس، فقد ترتب عن ذللك قلة البحوث (خاصة في الجزائر) التي تناولت متغير الدين من الجانب النفسي بالرغم من أنه عامل يتسع لدراسات عديدة قد تؤدي إلى إثراء المجال النفسي أكثر سواء فيما تعلق بالجانب النظري أو الجانب التطبيقي (وقاية و علاجا). و في هذا الإطار تقوم الباحثة بطرح قسمين من الدراسات:

أولا: بعض الدر اسات التي تناولت التدين في علاقته بالصحة النفسية. ثانيا: بعض الدراسات التي تتاولت التدين في علاقته ببعض المتغيرات النفسية الاجتماعية

$$
\text { (التو افق الاجتماعي، تقدير الذات). }
$$

\section{أولا: الدراسات التي تناولت التدين في علاقته بالصحة النفسية.}

تظهر الدراسات التالية العلاقة الوطيدة بين الدين و الصحة النفسية، و تتمثل فيما يلي:

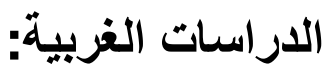

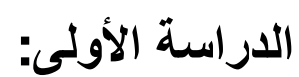

تناول شيفر و ساد (Shaver \& Sadd) سنة 1980 التنين و الصحة النفسية للمر أة الأمريكية الحديثة، بهدف التعرف على طبيعة التدين بين النساء، و ما إذا كان التدين الحديث يتفق مع مفهوم (وليم جيمس) من حيث أنه يرتبط بالصحة النفسية. و كان من بين أسئلة الدر اسة ما يلي:

ما طبيعة التدين لدى النساء الأمريكيات حاليا؟. إلى مدى يرتبط التدين بالصحة النفسية و البدنية؟ و قد استخدمت طريقة إرسال الاختيار ات للنساء عن طريق البريد، و تمثلت الاختبار ات المطبقة في هذه الدر اسة في: اختبار التدين (يحتوي على 97 عبارة) و يتكون من ثلاثة أبعاد و هي: المعتقدات الخبرة، ما تقوله الأمهات لأو لادهن عن حقيقة الإله. و اختبار الصحة النفسية (يشتمل على 12 مشكلة مثل: الصراع الداخلي، الثعور بالوحدة...الخ). 
و شملت الدراسة 250 مفحوصة، و كن من النساء البيض بالو.م.أ يعشن في بيئات اقتصادية-اجتماعية منباينة، كانت نسبة الكاثوليك 23\%، البروتنتانت 70\%، اليهود 2\%، و \% \% ع بر متدينات.

كما وصفت 27\% أنفسهن كمندينات جدا، 52\% معتدلات التدين، 12\% منخفضات التدين 4\% غير متدينات، 1\% ضد الدين. و تظهر الدراسة أن للدين دور إيجابيا في الصحة النفسية و الصحة البدنية، بالإضافة إلى دوره في الأمن و الاستقرار النفسي و السعادة، كما تظهر توجهات المرأة الأمريكية نحو

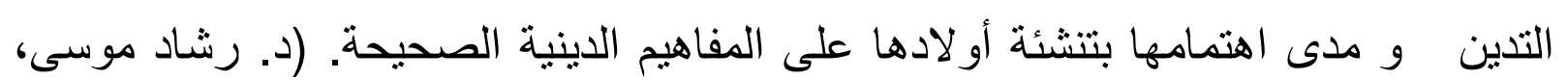

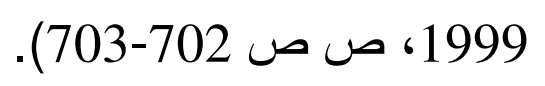
الاراسة الثاتية: تناول كرول و شيهان (Kroll and Sheehan) سنة 1989 المعتقدات و الممارسات الدينية لدى عينة من المرضى النفسانيين بهدف التعرف على العلاقة بين المعتقدات الممارسات الدينية و بين بعض الأمراض النفسية منها: الاكتئاب الخصام، اضطر ابات

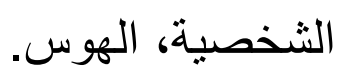
و شملت العينة 52 من المرضى الذين يعانون من الأعراض السابقة و يعالجون في إحدى المستشفيات. و قد استخدم الباحثان المقاييس التالية: مقياس بيك للاكتئاب، و مقياس المعتقدات و الممارسات الدينية و قائمة كاليفورنيا للثخصية. و قد أظهرت الدراسة أهمية المعتقدات، و بعد الممارسات في تدين الأفراد، و تبدو الممارسات في حضور الكنيسة و التردد عليها و الاشتراك في الأنشطة الدينية و البعد عن المشروبات الكحولية، الصلاة...الخ.

و قد أظهرت النتائج أن المتدينين تدينا مرتفعا كانوا أقل في الاضطر ابات النفسية بينما ارتفعت الأمر اض أكثر مع أصحاب التدين المنخفض (مرجع سابق، 1999، ص ص 709- 
قامت (إسعاد البنا) سنة 1990 بدر اسة دور الأدعية و الأذكار في علاج القلق

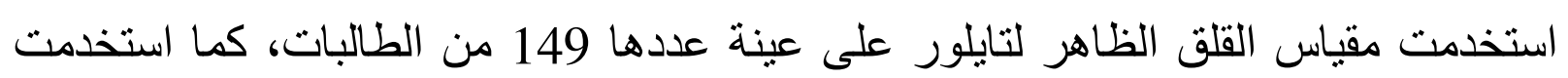
استمارة المستوى الاقتصادي الاجتماعي. قامت الباحثة بتطبيق مقياس القلق على مجموعة من الطالبات، كما قامت بإلقاء محاضرة عليهن تعرفهن بمخاطر القلق النفسي ثم تم دخولهن في جلسات علاجية، كل جلسة لمدة ساعة و ذللك لمدة أسبوع، كانت تعالج خلالها عن طريق القرآن الكريم و الأذكار و الحديث النبوي الثريف، مع إعطاء مساحة للطالبات للتعبير عن مشاكلهن التي تسبب لهن القلق بالكتابة، و كذلك القيام بخلق مو اقف للاعاء الجماعي. و أعادت الباحثة تطبيق مقياس (تايلور للقلق) بعد 5 جلسات من العلاج. و قد نوصلت الدراسة إلى وجود فروق ذات دلالة إحصائية بين درجة الطالبات في التطبيق الأول و درجاتهن في التطبيق الثاني عند مستوى دلالة (0,01) لصالح الاختبار القبلي أي كانت درجاتهن على مقياس القلق أكثر ارتفاعا في الاختبار القبلي عنه في التطبيق البعدي، مما يثير إلى أهمية الدين في العلاج النفسي (مرجع سابق، 1999 ص 711).

\section{الار اسة الثاتية:}

قام مسفر عامر أحمد عسيري (1411هـ) بدراسة مقارنة للفروق بين الاضطرابات النفسية العصابية و الأسوياء في مستوى التدين في الإسلام و لاختبار صحة الفرضيات قام

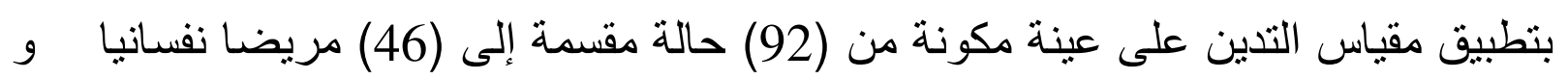
(46) سويا من المترددين و زوار مستشفى الملك عبد العزيز بمكة المكرمة. و استخدم الأساليب الإحصائية التالية لمعالجة النتائج:

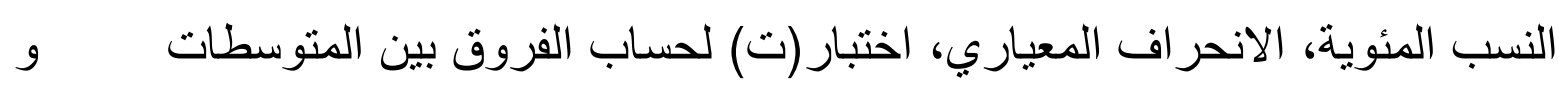

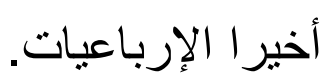
و انتهت النتائج إلى ما يلي: 
وجود فروق ذات دلالة إحصائية في مستوى التدين في الإسلام بين الأسوياء العصابيين عند مستوى دلالة (0,01) لصالح الأسوياء.

تعقيب:

يتضح من الدر اسات السابقة ما يلي:

ـ أهمية الدين في تحقيق الصحة النفسية للأفر اد.

- دور الدين الإيجابي في علاج الاضطر ابات النفسية و العقلية أو الوقاية منها.

- يعمل الدين على توفير الصحة العقلية و النفسية و الجسدية للأفراد.

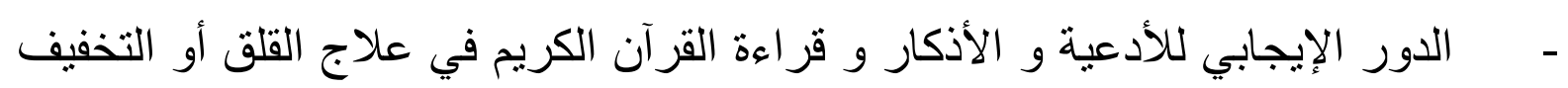

منه.

ثانيا: الدراسات التي تناولت التدين في علاقته ببعض المتغيرات النفسية الاجتماعية:

الدر اسات التي تناولت متغير التدين في علاقته بالتوافق الاجتماعي:

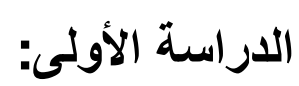

قامت باكيناز حسيب سنة (1988) بدراسة القيم الدينية و الخلقية و علاقتها بالتوافق

النفسي الاجتماعي لدى طلاب الجامعة، بهدف التعرف على الصحة النفسية للمتدينين و غير المتدينين و قد استخدمت عدة مقاييس هي: مقياس ألبورت للقيم (القيمة الدينية)، مقياس كورنل للنواحي العصابية و السيكوسوماتية، و قائمة كورنل للتو افق النفسي. و قد قسمت الباحثة العينة إلى (مرتفعي التدين / منخفضي التدين).

و قد أنشارت النتائج إلى وجود ارتباط موجب بين درجات الطلاب على مقاييس القيم الدينية و والخلقية و بين درجاتهم على مقياس التوافق النفسي الاجتماعي.

الاراسة الثانية:

قام عبد الله بن محمد الخراز و منصور بن سفر الزهراني (1412 هـ) بدر اسة العلاقة بين التدين و الصحة النفسية، و كان هدف الدراسة التعرف على طبيعة العلاقة بين التدين و كل من الصحة النفسية، و عدد من أنواع التو افق منها التو افق الاجتماعي. و استخدم الباحثنان مقياسين لقياس كل من: التدين و الصحة النفسية. 
و تكونت عينة الدراسة من (64 طالبا) من طلاب كلية العلوم الاجتماعية تتراوح

$$
\text { أعمار هم بين (19 إلى } 29 \text { سنة) بمتوسط حسابي قدره (21,55) سنة. }
$$

و قد أسفرت الدراسة عن وجود علاقة ارتباطيه موجبة بين التنين و كل من الصحة

النفسية و التو افق الاجتماعي إلى جانب أنواع التو افق الأخرى (التحصيلي الانفعالي...) (مرجع سابق 1999، ص ص (589-589).

الداسات التي تناولت التدين في علاقته بتقدير الأات:

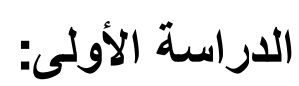

قام هولترز (1980، Hoelters) بدراسة العلاقة بين التنين و تقدير الذات و متغيرات أخرى و لاختبار صحة الفروض تم تطبيق الأدوات النفسية التالية: مقياس التدين و مقياس تقير الذات و مقاييس أخرى تتعلق بالمتغيرات الأخرى. و تكونت عينة الدراسة من طلبة و طالبات الجامعة.

و قد انتهت النتائج إلى وجود ارتباط موجب بين التدين و تقدير الذات المرتفع (مرجع سابق 1999، ص ص 287-287) - 287).

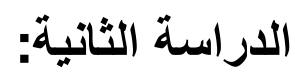

قام فيهر و هنتزلمان (FEHR AND Heintzelman، 1997) بدر اسة الثخصية و و

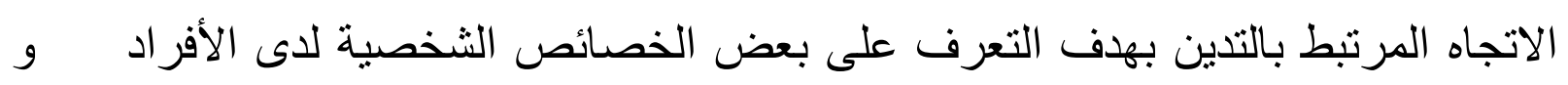
توجهم نحو التدين، و كان من بين المتغيرات النفسية المستخدمة في الدراسة: تقدير الذات. و قد قام الباحثان بتطبيق المقاييس التالية: مقياس القيم لألبورت، مقياس كاليفورنيا للثخصية و مقياس النزعة الإنسانية. و تكونت عينة الدراسة من (120) مفحوصا. و قد أشنارت النتائج إلى عدم وجود ارتباط دال إحصائيا بين درجات الطلاب على لقانى

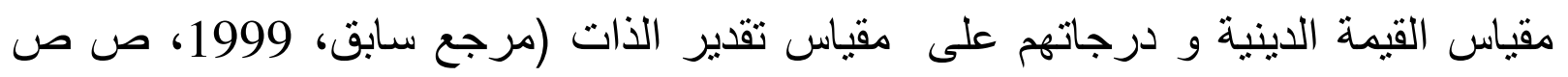
.(715-714 
من خلال الدر اسات السابقة التي تم التطرق إليها يتبين ما يلي: - يوجد ارتباط موجب بين كل من التدين و التوافق الاجتماعي، أي أن التدين له دور إيجابي في تحقيق التو افق الاجتماعي للأفر اد. ـ تختلف النتائج التي توصلت إليها الدر اسات السابقة في نوع العلاقة التي نربط بين التدين و تقدير الذات، فيينما تشير بعض الدراسات إلى وجود علاقة إرتباطية موجبة بين كل من التدين و تقدير الذات، نجد أن دراسات أخرى تتفي هذه العلاقة و ترى أنه لا نوجد علاقة بين التدين و تقدير الذات و هذا ما سوف تؤكده الباحثة أو تنفيه من خلال هذا البحث موضوع الدراسة-.

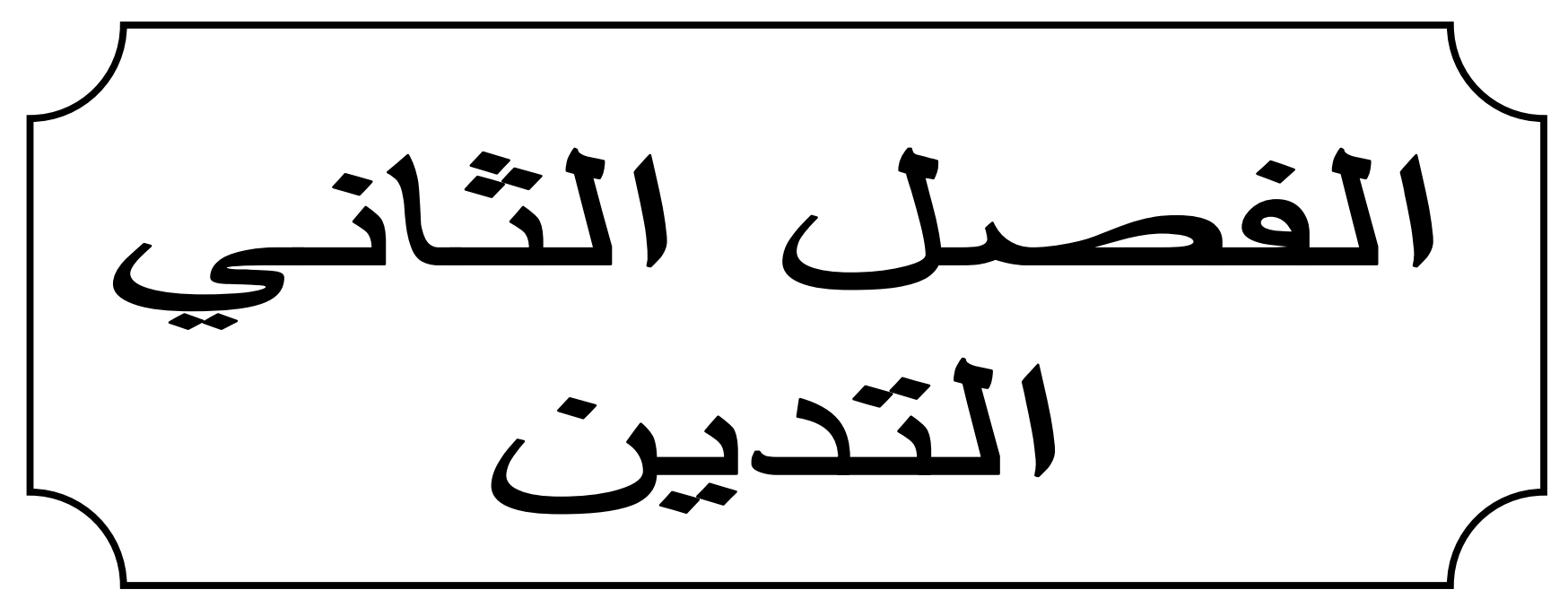




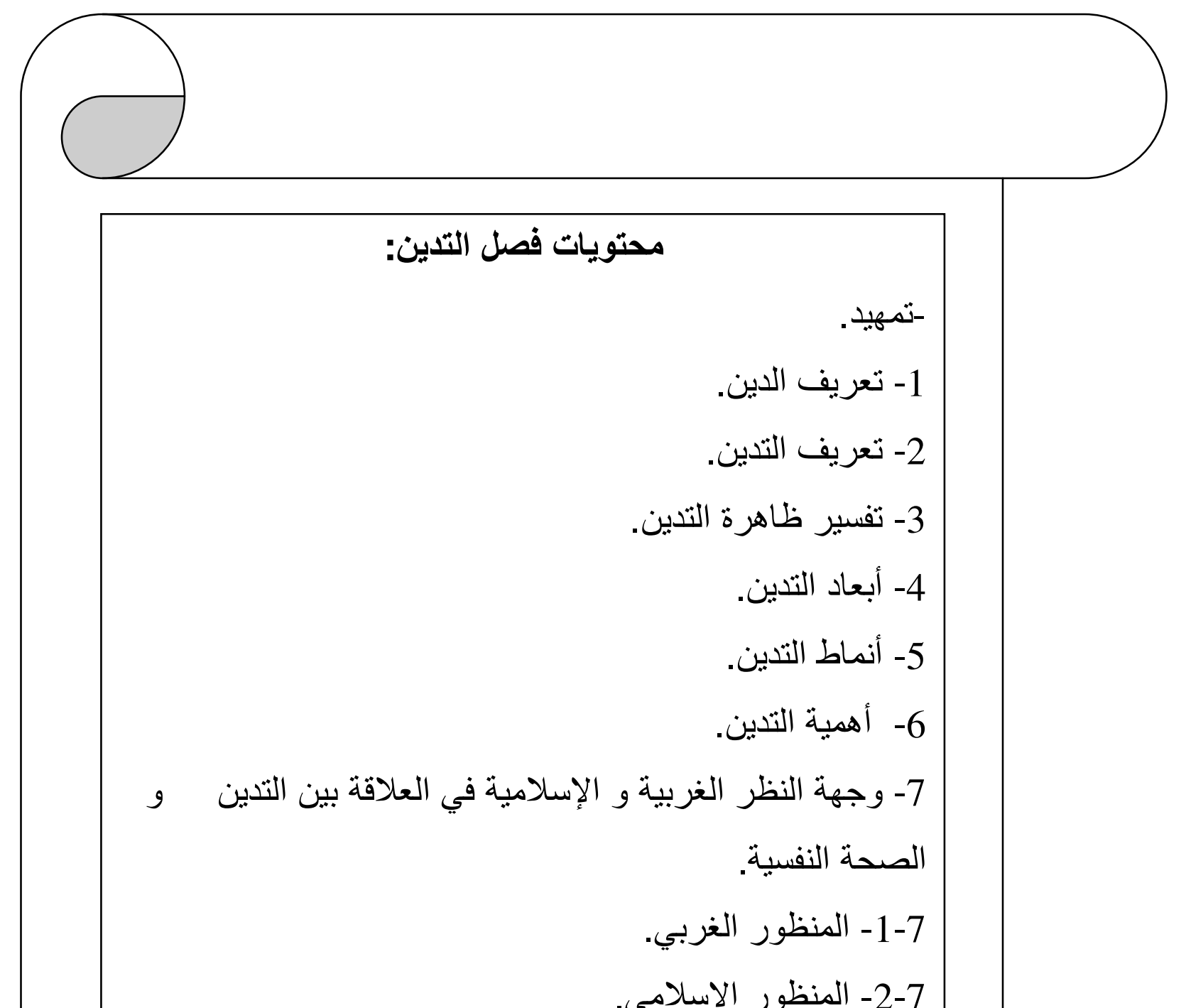




\section{فصل التديـن}

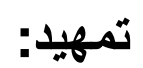

كان للاين و لا يزال أثر كبير في حياة الأمم و الثعوب، و كما يقال: "الإنسان مدني بطبعه" نستطيع أن نقول أن: " الإنسان متدين بطبعه". و الدين هو مسألة طبيعية للإنسان، فثيء ثابت لا يتردد فيه الباحثون الآن مهما يكن لون

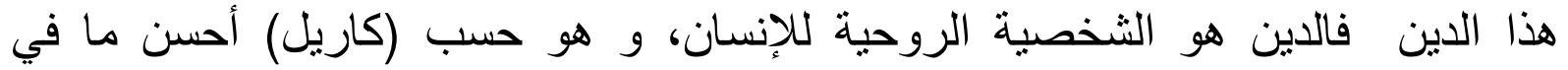

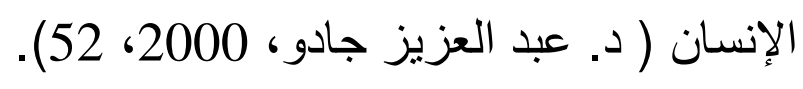
و تعرف الأديان على أنها: أنساق للمعتقدات و الممارسات و التنظيمات، تشكل الجانب التبان

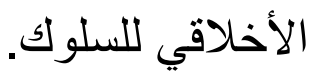
و المعتقدات الدينية: هي تفسيرات أو تأويلات للخبرة المباثرة بالرجوع إلى البناء المطلق للعالم و إلى القوة فوق الطبيعية التي تسيطر على الكون و ظواهره. 
أما السلوك الديني: فهو سلوك مقد و طقوس يقوم بها الثخص على شكل ممارسات

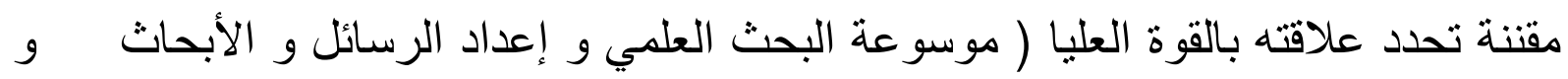

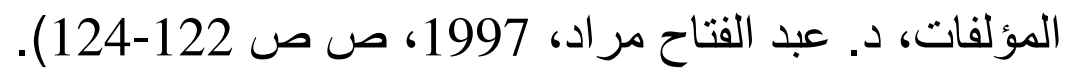

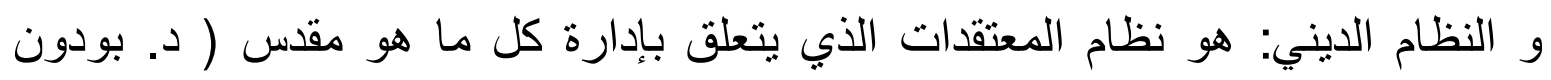

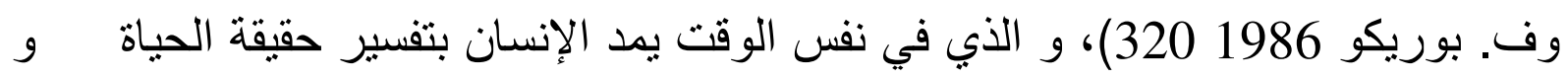
الوجود، و حقيقة الإنسان و مركزه من هذا الكون و مصيره و غاية الوجود و الكون (نبيل

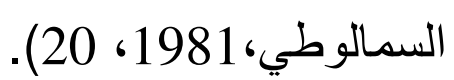

و يعرف الإيمان الديني: بأنه الإيمان بقوة أسمى تتحكم في القدر (د. عبد الدنعم الحفني،

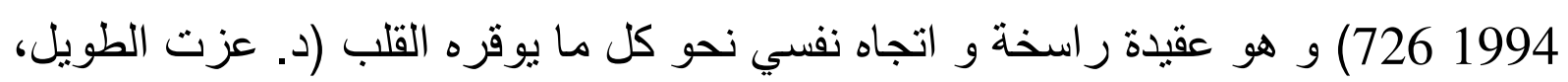

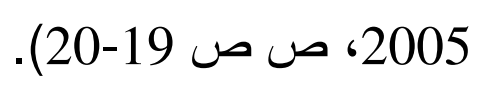

و يتكون الاتجاه الديني من عناصر مثل: الاتجاه نحو الصلاة و الصوم و المؤسسات الدينية أو النشاطات المرتبطة بها، و الاتجاهات الدينية مثلها مثل الاتجاهات النفسية تحتاج إلى وقت طويل حتى ينم بناؤها و غرسها في الإنسان و إلى خبرة و تجارب عملية (د. عمر الثينابي، بدون سنة: 637). و تساهم في تتكيلها عدة عو امل و التي تمثل في:

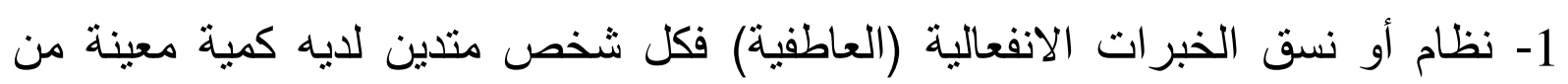
الخبر ات الانفعالية المرتبطة بدينه. - الئ. 2- العوامل الفكرية التي تكون (رشيدة/عقلانية).

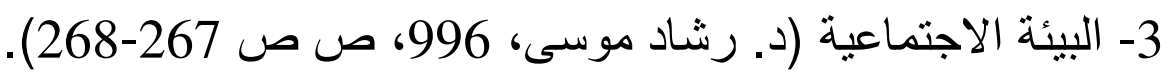
و قد أوضحت (ماريا كورنوال،Cornwal Marie 1989) أن السلوك و المعتقد الديني

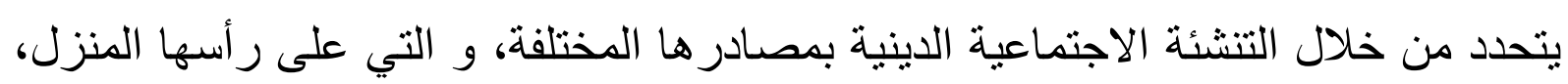
و دور العبادة ... فالأسرة تلعب دورا كبيرا في إكساب الأبناء الاتجاهات الدينية كما يقول

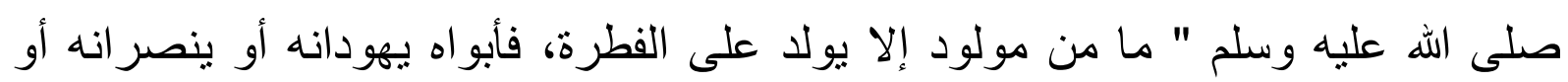
يمجسانه" (رواه البخاري). 
و يأتي بعد ذلك دور باقي مؤسسات التنتئة الاجتماعية، كدور العبادة و وسائل الإعلام 1... الخ، في إكساب الاتجاهات الدينية للأفر اد.

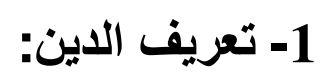

حسب (د. محمد عبد اللهدراز) فإن كلمة الدين عند العرب تثشير إلى علاقة بين طرفين

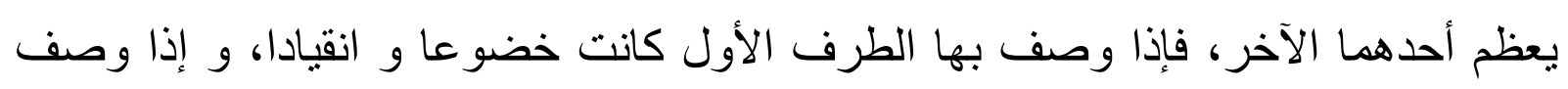

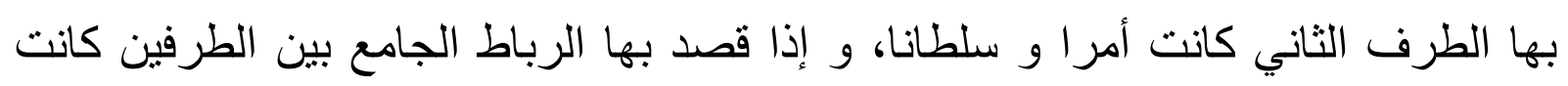
هي الدستور المنظم لتلك العلاقة أو المظهر الذي يعبر عنها (د. نبيل السمالوطي، 1981 .(19-18

أما كلمة الدين (Religion) فهي مشتقة من الفعل اللاتيني (Religiere) و هي تعني:

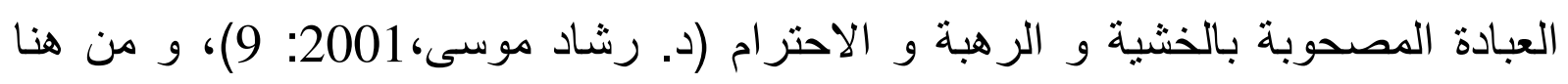

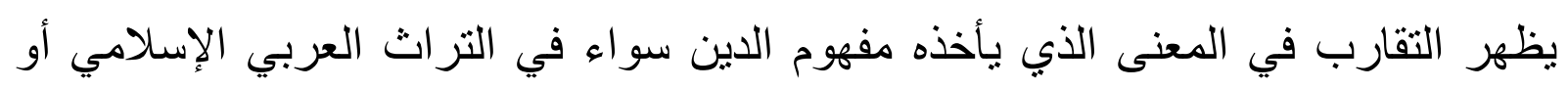

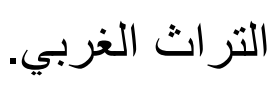

و نجد أن الباحثين الغربيين يستعملون مفاهيم الروحية أو الروحانية (Spirituality)

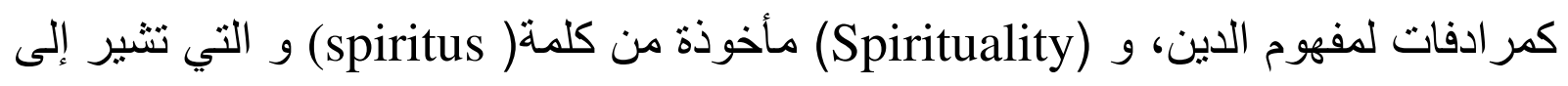

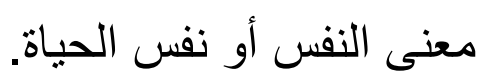
و الدين بمفهومه الذي يدرس في العلوم الاجتماعية، يقصد به ظاهرة نفسية اجتماعية لها

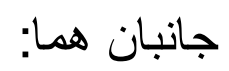

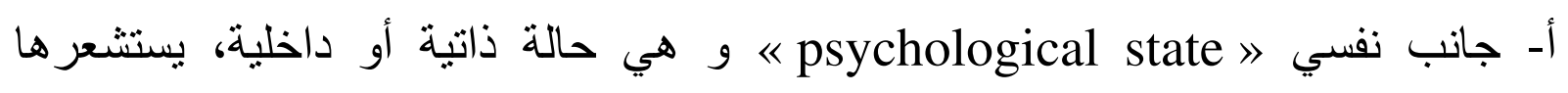
المندين تسمى "حالة التنين" (حالة الانقياد و الإذعان للمعبود) (د. نبيل السمالوطي، 1981

ب- جانب اجتماعي \$ social state « و يتضمن ما يشترك فيه الفرد مع الجماعة أو

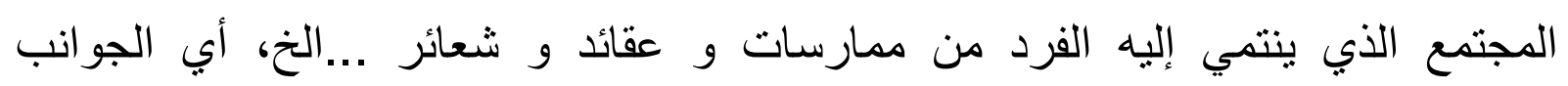
الموضو عية أو الخارجية لحالة التندين. 
و إذا كان الدين يشير إلى الخشية و الرهبة و الخضوع و التبعية، فإن لبس كل انقياد

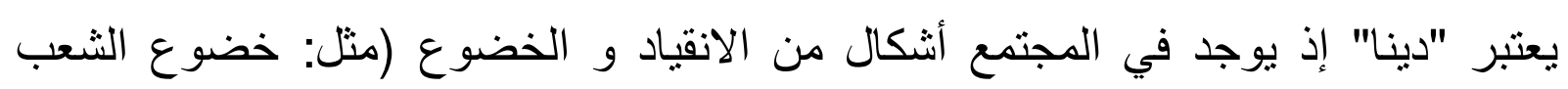

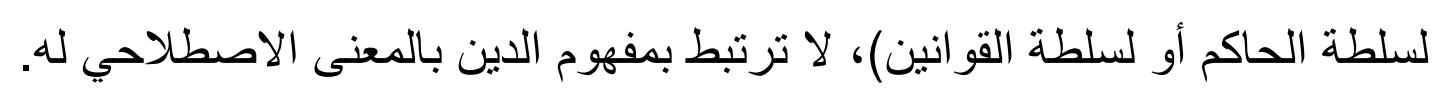

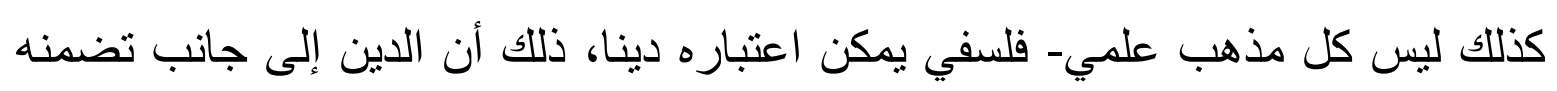

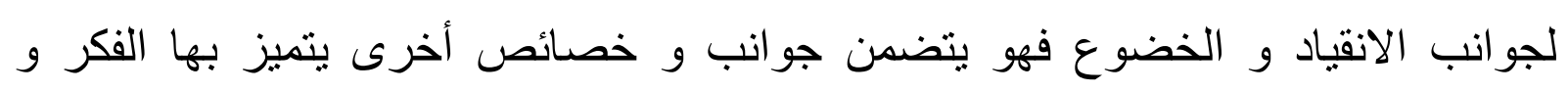
السلوك و الثعور الديني. و قبل التطرق إلى التعريفات التي تتاولت مفهوم الدين، من المهم الإنشارة إلى أن تعريف

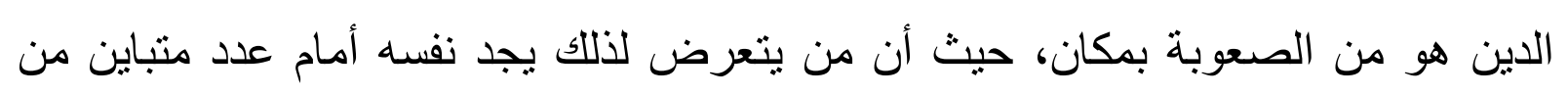

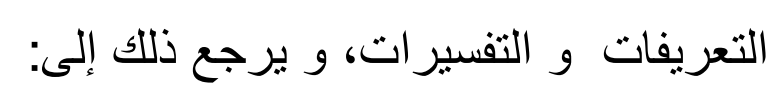
- أن الدين يتضمن علاقة بين الفردو و بين شيء و كائن مقدس غير مطوع للتعريف بالألفاظ

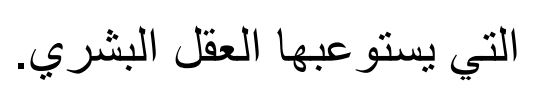
- مرمة و قداسة و حساسية ظاهرة الدين. - وجود العديد من الديانات لكل منها فرقاو مذاهبا و ملانلا...الخ (د. حسين رشوان 2004، .03

و اعتبار الذلك فإن الباحثة سوف تعمد إلى إدراج تعريفات الدين التي تثترك فيها معظم الديانات كما سوف تعدد إلى إدراج التعريفات التي تخدم الدراسة.

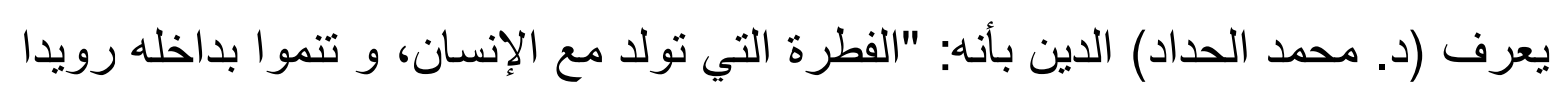
رويدا حتى يدرك ما يحيط به في العالم و يعرف الفرق بين الحق و الباطل" (د.محمد بلدية

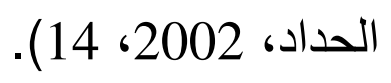
و حسب (د. الهادي سريط) فإن الدين يعبر به عن العقيدة، فالدين بمفهومه العام مجموعة

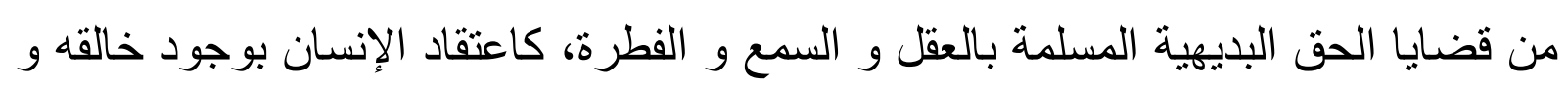

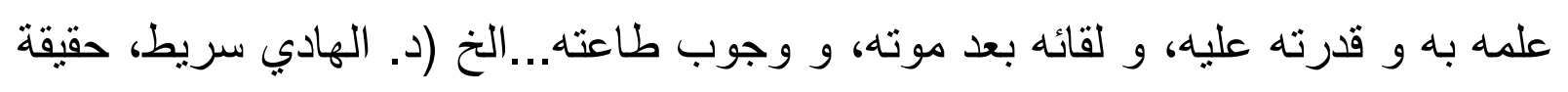

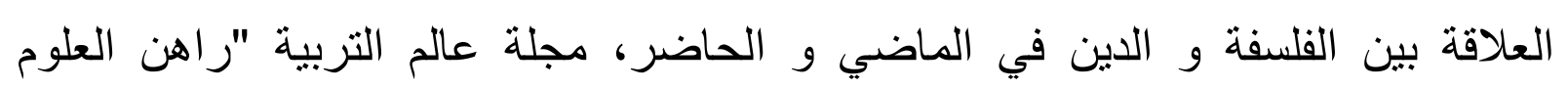

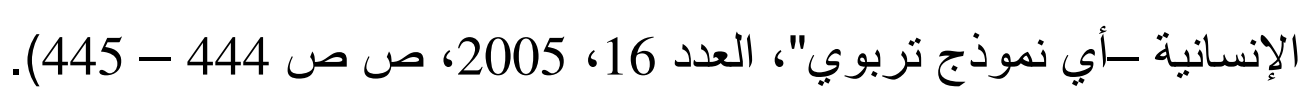


و يبين كل من (محمد شرف و العيسوي، 1974) أنه من خلال الدين يكون الفرد فلسفته في الحياة، و هو ـالدين- يلعب دور ا مهما في طرد مشاعر اليأس و القنوط لدى الأفراد.

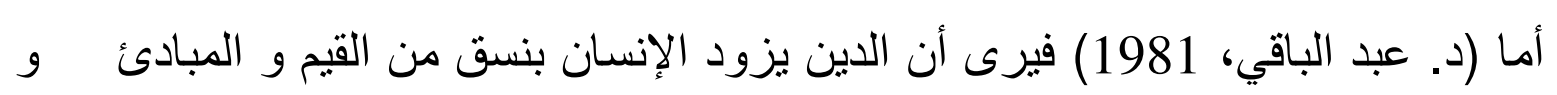

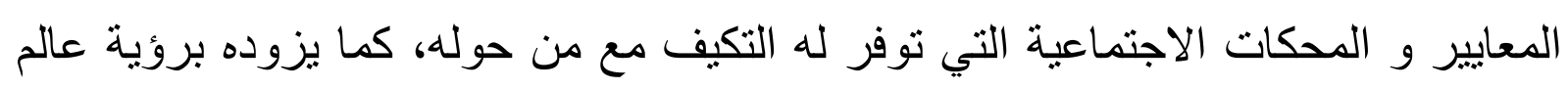
آخر غير محسوس فوق هذا العالم فيه الخلاص و الرحمة (د. رشاد موسى، 2001 09). يعرف (جون ويلسون Johon Wilson) الدين على أنه: "السعي للحصول على بعض فر في الصيغ أو المفاهيم كالاعتقادات و القيم و الطقوس التي تتظم علاقته بكائن أو قوة فوق طبيعية قوية" (Michaelle Man, 1983 (M28).

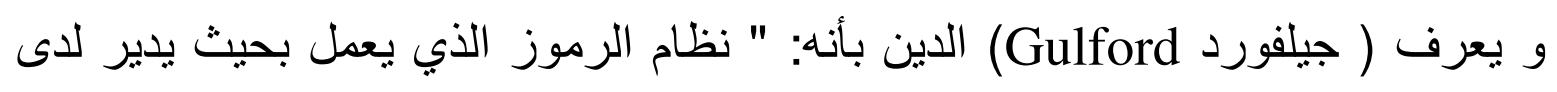
البشر حوافز قوية و مستديمة عبر صياغة مفاهيم عامة حول الوجود، و عبر إعطاء هذه

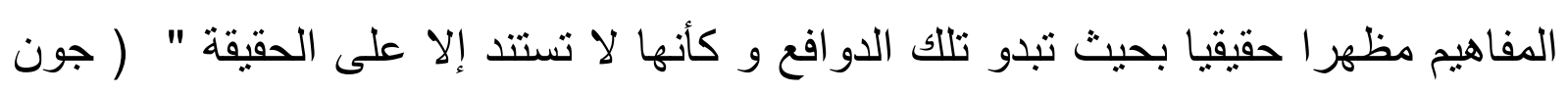
بول وليم، 2001، 176-176). و يعرفه (yung) بأنه: " الخضوع لقوى أكبر من أنفسنا، هذا الخضوع له أهمية في حياة الفرد و المجتمع لما يضفي عليه من استقرار نفسي " (د. رشاد موسى، 2001

و حسب (روسو Rousseau) فإن الدين لا يزود الناس فقط بحو افز ليسلكو اسلوكا حسنا أو يتجمعوا معا في جماعة دينية أو من أجل تقويتهم عندما يتألمون، بل إنه يزودهم أيضا بمفهوم مكانهم في هذا العالم و الذي يجعل الحياة سعيدة -حسبه- ( د. صالح فيلالي، الدين

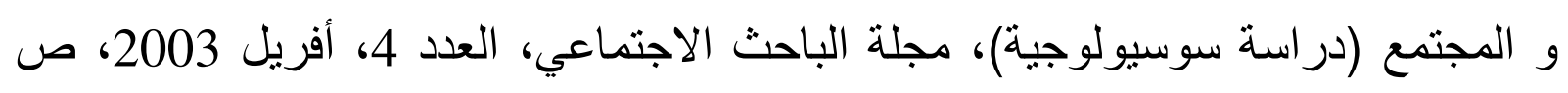
ص (239-238.).

و لعل أثنهر التعريفات عند الغربيين ما قاله الفيلسوف (كانت kant) بأن الدين هو :

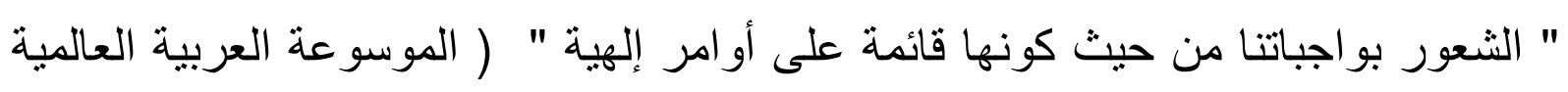
-10-6، بدون مؤلف، 1996، 85 ) ).

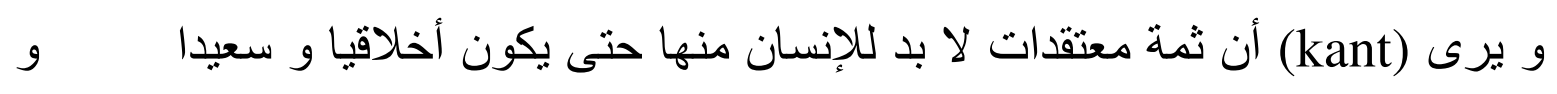
أولها الإيمان باله تعالى (د. إسماعيل سعد، 2002، 287). 
و خلافا لهذا فإن (فرويد) يعتبر الدين وهم من الأوهام التي ابتكرها الإنسان ليحمي نفسه من قوى الطبيعة المتفوقة عليه، و هو يعتبر أن الدين شكل من أشكال العصاب الجماعي تسببت في ظهوره عوامل تشبه العوامل المسببة لعصاب الطفولة، كما ير اه عائقا في وجه تقدم الإنسان و تحضره، لذلك فإن العلم و ما يشهده من تطور سوف يتجاوز هذه الطفولية - مالدين-. و إذا كانت وجهة نظر فرويد صحيحة و تنطبق على بعض الأديان فإن الأمر ليس كذلك بالنسبة للإسلام دين الحق و الفطرة. و نظرا أن هذا البحث ينطلق من منظور نفسي ديني إسلامي بالدرجة الأولى فإن التعريف الذي تعتمده الباحثة يجب أن يتو افق مع ذلك. فمن أثهر التعريفات الإسلامية للدين، ما يلي: " وضع إلهي سائق لذوي العقول السليمة باختيارهم إلى الصلاح في الحال و الفلاح في المآل " ( د. عبد اله دراز، 1980، 34-

و من خلال التعريفات السابقة يتضح ما يلي:

ـالدين فطري عند الإنسان يؤثر في نموه عند الفرد عدة عوامل. ـ الدين تشريع إلهي يعنى بتوجيه الناس إلى ما فيه خيري الدنيا و الآخرة. - يساعد الدين الناس على تحديد مكانتهم في العالم و غاية الوجود و الكون و مصيرهم

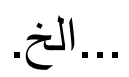
- يمثل الدين صلة روحية بين الإنسان و قوة عليا (الله)، هذه القوة يستمد منها الإنسان الطاقة و القوة اللازمين لتكيفه في الحياة و سعادته. - تؤثر العلاقة الني تجمع الإنسان بخالقه على ضمير الإنسان و وجدانه و سلوكه حيث تصبح هي الدافع في مختلف توجهاته. ـ الدين عامل أساسي في الصحة النفسية للأفراد، يعمل على تنمية الجوانب الإيجابية عندهم. - تثترك معظم الديانات - خاصة الصحيحة منها - في الجوانب أو الأبعاد المكونة للدين و التي تتمثل في: الاعتقادات- الطقوس (العبادات)- و الممارسات. 
و أخيرا نلاحظ أن التعريفات و المعاني السابقة حصرت الدين في نطاق الأديان

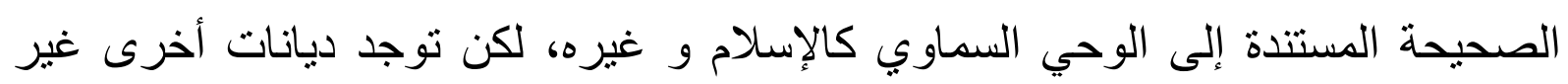

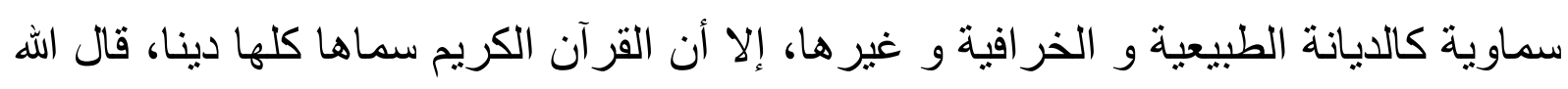

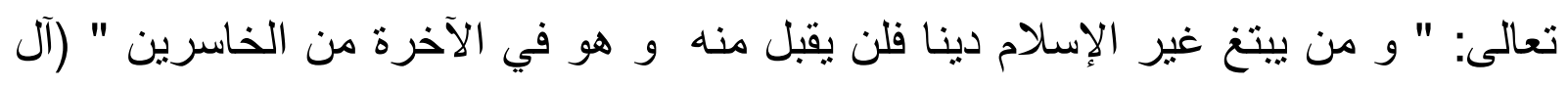

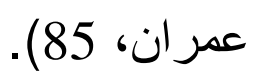
و نظرا للأسباب التي تطرقت إليه الباحثة آنفا و المتعلقة بصعوبات تعريف الدين

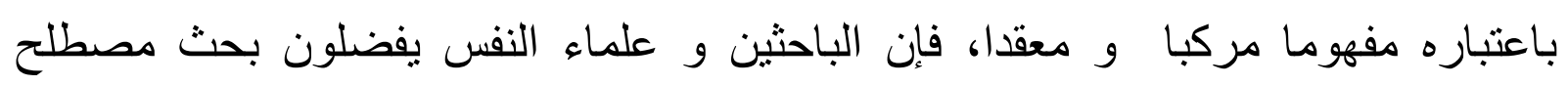

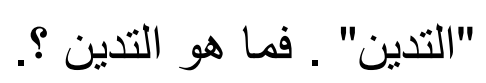
2- 2- 2 - تعريف التدين:

التدين تجربة إنسانية عالمية و تاريخية، فلم يوجد شعب يخلو تر اثه من الأدب الديني.

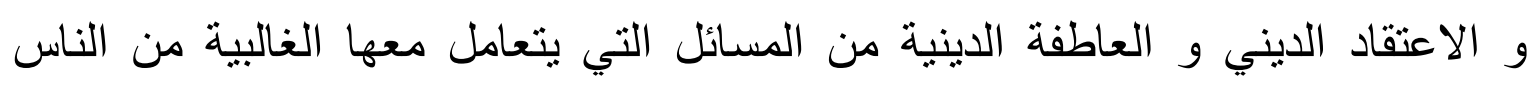

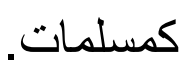
و يشير (Moberg,1965) إلى أن التندين يأخذ معنى التبعية، فهو نزعة عاطفية للاحتر ام بإجلال و تعظيم لقوة عليا (Nicolas Zay,1981,p 450). و يعرف التدين في مفهومه الضيق على أساس التردد على دور العبادة و العضوية في

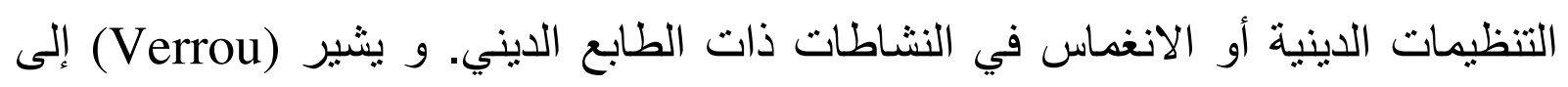

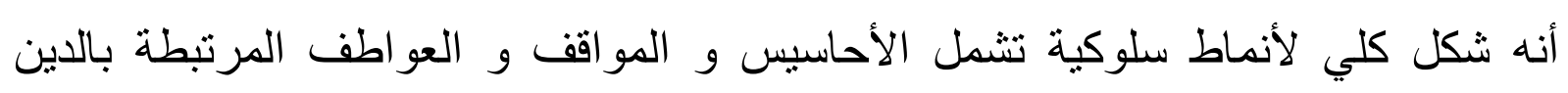

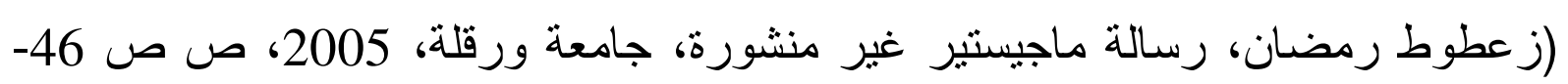

و يعرفه الباحث عبد المحسن حمادة على أنه: " ما يقوم به الفرد من ممارسات دينية تتبع

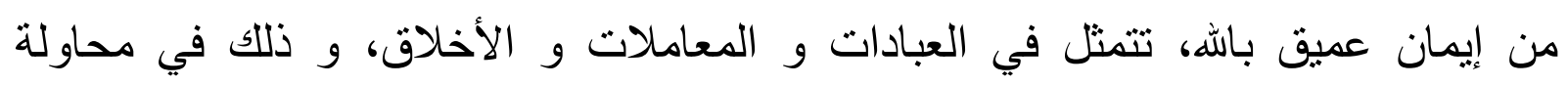
إرضاء خالقه و تحسين علاقاته بالآخرين و تمثلك الأخلاق الحميدة التي يدعو إليها الدين

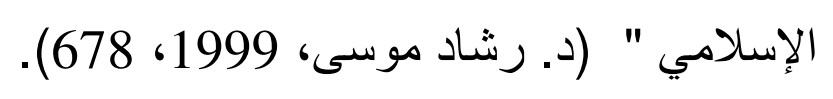

و نلاحظ أن هذا التعريف الأخير يعرف التدين انطلاقا من المنظور الإسلامي، و يرى أن التدين يجب أن يشتمل على الاعتقادات و العبادات و الأخلاق و المعاملات. 
و التعريف الذي تعتمده الباحثة يجب أن يكون نابعا من ثقافة مجتمع الدراسة، كما يجب أن ير اعي التوجه النفسي الإسلامي الذي تنطلق منه الدراسة - بالدرجة الأولى - ـ و هو كما بلي:

تعرف (طريفة الثويعر) التدين بأنه: " إتباع الفرد لكل تعاليم المنهج الإسلامي الحنيف

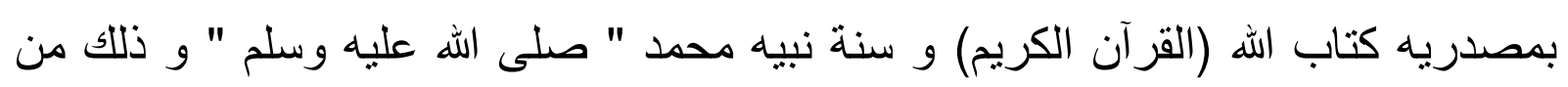
خلال علاقته بربه و معاملاته مع الآخرين، و يقاس مستوى تدين الفرد دينيا بالدرجة

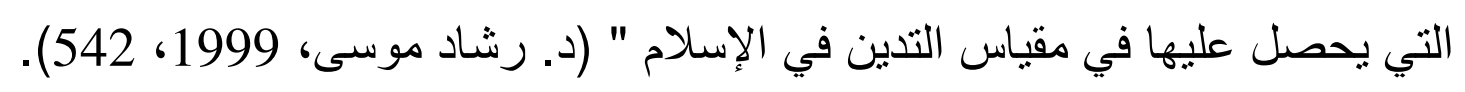
3- تفسير ظاهرة التدين: لقد أثتتت الدراسات الأنثروبولوجية على أن النزعة للندين هي نزعة فطرية عند الإنسان، بدليل عدم خلو أي مجتمع قديم أو حديث بدائي أو متحضر من شكل ما من أشكال الدين (د. نبيل السمالوطي، 1986، 55). و هذا ما ذهب إليه كل من (ف. مري،F.Merry ) و (ر. مري، آن. R.Merry ) في آرائهما حيث يفترضان أن ظاهرة التدين ظاهرة غريزية، بمعنى وجود غريزة دينية لدى الدى

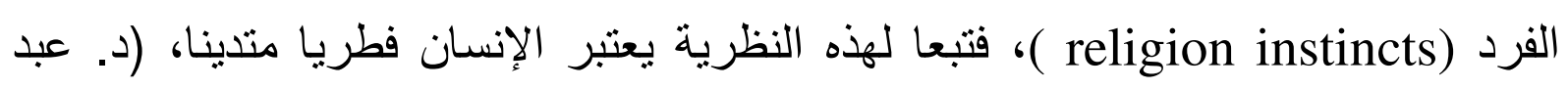
الرحمن عيسوي1992، ص ص 132-133)، فالإنسان يشعر في أعماق نفسه بدافع يدفعه إلى البحث و التفكير لمعرفة خالقه و خالق الكون و سبب وجوده في هذه الحياة و مآله بعد الممات، و هو فوق كل ذلك يحتاج إلى قوة عليا يلتجئ إليها أوقات الحاجة و و يجد في ولي حمايتها و رعايتها الأمن و الطمانينة. و الدين يقدم إجابات عن كل القضايا التي تحير الإنسان و تشغل باله و التي تتعلق بأصل

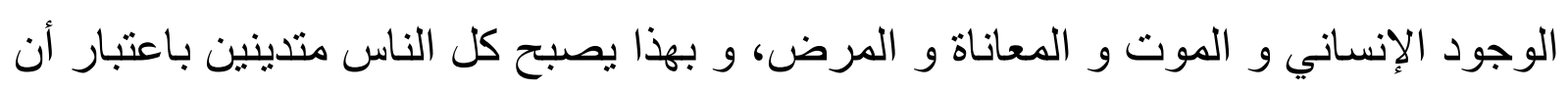

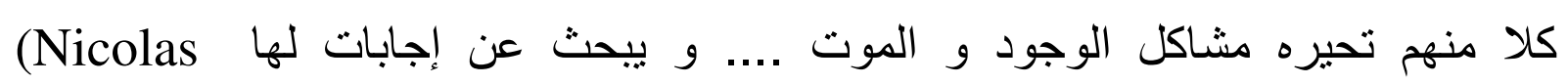
.Abecrombie et al, 2000 )

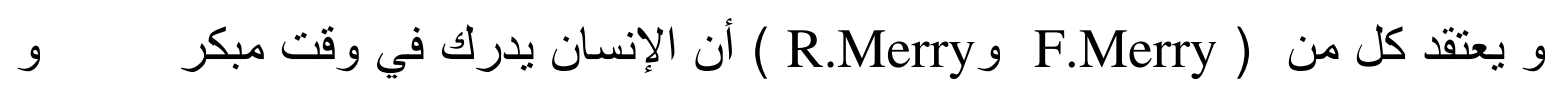

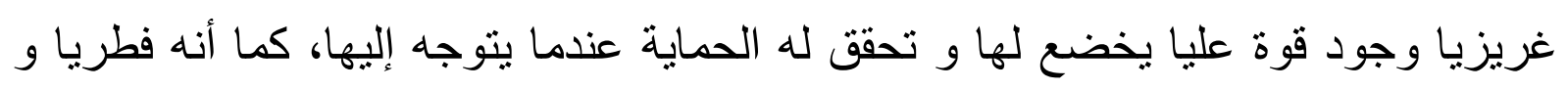
غريزيا لديه ميل نحو العبادة. 
و في نفس السياق يذهب علماء الدين المحثثين أن الإنسان يولد باستعدادات هي التي يوجهها المجتمع (بدءا من الأسرة) إلى القنوات الصالحة أو الفاسدة، و هذا ما ذهب إليه (سكينر) الذي أوضح أن الإنسان يولد باستعدادات تسمح بتوجهه نحو التدين أو نحو معارضة التدين. و لعل الحقيقة الكاملة هي كما أوضحها سيدنا محمد "صلى الله عليه وسلم" و التي تتضح جليا في قوله : " ما من مولود إلا يولا على الفطرة، فأبواه يهودانه أو ينصرانه أو يمجسانه" (رو اه البخاري). 4- أبعاد التدين (جوانب التدين): تختلف الآراءو تتباين في تناولها لجو انب التدين أو أبعاده. حيث نجد أن كل من (ستارك، Stark) و غيره يحددون الجوانب الأساسية في التدين في (العقيدة) و (المعرفة)، إلا أنه قد يكون للفرد إطلاع واسع و معرفة خصبة عن نظام ديني معين و لكنه لا يؤمن به و لا يعتقد فيه (و هو ما يصطلح على تسميته بالتدين المعرفي)، كذلك (الطقوس أو الممارسات) و التي نظهر من خلال أداء الأفر اد للثعائر المتعلقة بدينهم، ثم (النتائج) التي تتعكس على الفرد المتدين و هي ذات علاقة بالجوانب و الأبعاد السابقة و تتأثز بها. و يرى كل من (رويتر و بونس، Rutter , Bance، 1989) أن أبعاد التدين تتلخص في: المعتقدات و الاتجاهات و المقاصد و السلوك. أما (شارل.إ. غلوك،Charles.y. Glock) فقد ميز بين خمسة أبعاد للتدين: بعد تجريبي (الحياة الدينية، التجربة الدينية، المشاعر أو العاطفة الدينية)، و بعد شعائري (الممارسات الدينية)، و بعد إيديولوجي (يظهر في العقائد أكثر من الثعور الديني)، بعد معرفي (معرفة العقائد أو النصوص المقدة)، و بعد نتائجي (النتائج في المجالات المختلفة من الحياة التجريبية و ممارسات الأفر اد و عقائدهم الدينية) . (Nicolas Zay, 1981, p 450-451) و نلاحظ أن الأبعاد التي حددها (Glock) تقترب من التي جاء بها (ستارك). 
و المتتبع لآيات القرآن الكريم (باعتباره المصدر الأساسي للتشريع الإسلامي) يجدها

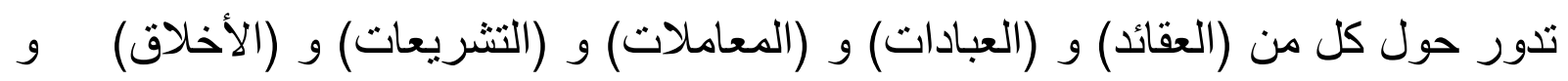
كما تبين السنة النبوية ما ذكره القرآن الكريم من هذه الجوانب. فالعقيدة هي المنهج و الأساس الذي تقوم عليه شخصية المسلم و حياته، و من حسنت عقيدته يكون قد أسس بنيانه على تقوى من الله تعالى و هذه العقيدة تتمثل في: الإيمان بالهه و ملائكته و كتبه و رسله و اليوم الآخر و الإيمان بالقضاء و القدر خيرهو شره ...الخ. أما العبادات فهي في الواقع صلات بين العبد و ربه، و خضوع و خشوع لله سبحانه فبأدائها تطمئن القلوب و يقترب الإنسان من غايته، فيرضي ربه سبحانه و يصبح بأدائها راضيا و سعيدا و هي تشمل: الصلاة، الصيام، الزكاة، الحج ... الخ (د. سعد رياض .26-23، 2003 أما الأخلاق و المعاملات فهي تعتبر إطار المرجعيا لسلوك الفرد و أسلوب حياته و و هي الدعامة الأولى لحفظ كيان المجتمع من خلال تنظيم العلاقات الاجتماعية بين الأفراد، كما تنظم السلوك و تنمي في الثخصية ضمير ا حيا يحاسب الفرد إذا أخطأ أو انحرف عن الطريق المستقيم، و لعل من أهمها: الاستقامة، الصدق، الأمانة، التواضع حفظ الفرج عن الحرام، الابتعاد عن الرباو الرشوة التعاون، الإيثار ...الخ (د. حامد عبد السلام زهران، 2002 ، ص ص ص (307-305 ). و يقوم منهج الإسلام في تحقيق الصحة النفسية على تقوية هذه الأبعاد الأربعة في الإنسان (العقيدة، العبادات، الأخلاق، المعاملات)، و ذلك من خلال ثناثة أساليب من التربية، تتلخص فيما يلي: الأسلوب الأول: يعنى بتقوية الجانب الروحي في الإنسان، عن طريق الإيمان بالله و عبادته و توحيده و أداء العبادات المختلفة من صلاة و صيام و زكاة و غير ذللك، و قد أثنتت الدر اسات الحديثة ما لذلك من آثار جد إيجابية على الصحة النفسية و البدنية للإنسان. الأسلوب الثاني: يعنى بالسيطرة على الجانب البدني في الإنسان و ذللك بالتحكم في الدوافع بإثباعها عن طريق الحلال و تحريم إثباعها عن طريق الحرام، مثل: إثباع الدافع الجنسي عن طريق الزواج و تحريم إثباعه عن طريق الزنا. 
كذلك التحكم في الانفعالات بالسيطرة عليها و كظمها، يقول النبي محمد (صلى الله عليه و سلم): " لا تغضب ...." (حديث شريف)، و معروف وفقا لعلم النفس الحديث أن تعرض الإنسان للانفعالات الثنديدة و لمدة طويلة من شأنه أن يتسبب له في مجموعة من الأمر اض تسمى الأمراض النفسجدية (السيكوسوماتية) ومنها: ضغط الدم، السكري، الربو الثعبي ........ الأسلوب الثالث: يعنى بتعليم الإنسان مجموعة من الخصال و العادات الضرورية لنضجه الانفعالي و الاجتماعي، و لنمو شخصيته، و لإعداده لتحمل مسؤولياته في الحياة، و للقيام بدوره في تقدم المجتمع و عمارة الأرض بحيوية و فعالية و لتهيئته لكي يحيى حياة سوية تتحقق فيها الصحة النفسية، و من هذه الخصال و العادات: القناعة، الرضا حب الآخرين، الصبر...الخ (د. محمد نجاتي، 1993، 297). 5- أنماط التدين:

يفرق علماء النفس بين الخبرة الباطنة الصادقة و السلوك الديني الروتيني، و الذي مجاله مظهر الشخصية و ليس مخبر ها، و أطلق بعضهم على هذا التمايز اسم: الباطن و الظاهر أو في شخصية الإنسان المتدين، أو الأولي و الثانوي فيها و من ثم يتمايز في التجربة

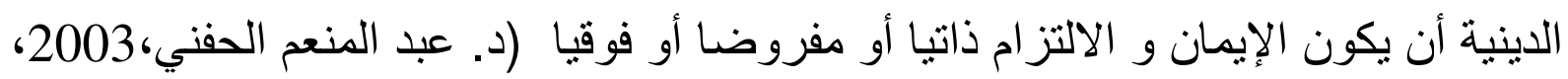

و يقترب هذا المفهوم من المفهوم الذي قدمه (آلبورت Allport، 1966) للتدين، أسماه التوجه الديني ينقسم إلى قسمين رئيسيين هما: التوجه الديني الداخلي Intrinsic) (Extrinsic religious و و religious orientation) (orientation) الفرد مع معتقداته، أما النوع الآخر فيتمثل في استخدام الدين للأغراض و الأهدئ لأهداف الخاصة، هذا بالإضافة إلى فئة الجاحدين (Nonreligious) (د. رشاد موسى، 1999 .$(673-672$ و يميز (ويليام جيمس William James) بين ما يسميه ديانة الأصحاء عقليا و نفسياو 
و يفرق آخرون بين التعبد الموضوعي الذي يسلك بمقتضاه المتدين سلوكا ليس عن اقتناع بأهدافه و لكن لأن الدين يأمره به، و التعبد الذاتي الذي غاية العابد منه أن يصنع ذاته و تكون التعاليم الدينية جزءا من كمالاته الثخصية، و العابد يهمه في المقام الأول حقيقته

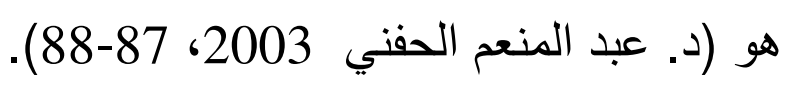

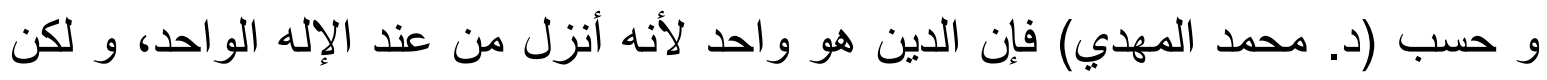

عند تناول البشر له و تطبيقه في حياتهم يختلف مأخذ كل منهم له و طريقة تطبيقه، و لا بد أن نعرف أن نشاطات الإنسان النفسية يمكن حصر ها في ثلاثة دو ائر و هي:

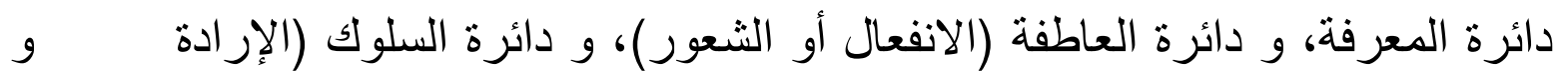
الفعل)، و من هذا التعدد ـأيضا- جاءت النماذج التالية من الخبرة الدينية: 1-5 التدين المعرفي " الفكري": من مدرئ

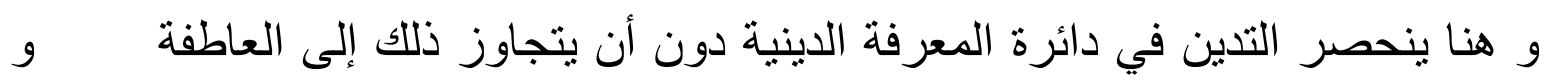
السلوك.

2-5 التدين الحماسي: 2-5 في هذا النوع يظهر الثخص حماسا و عاطفة كبيرين اتجاه الدين دون أن يدعم ذلك بمعرفة جيدة بأحكام الدين و لا سلوكا ملتزما بقو اعده. 3-5 التدين السلوكي (تدين العبادة): و هنا تنحصر مظاهر التدين في دائرة السلوك، أي دون معرفة كافية بأحكام الدين و حكمته و بدون عاطفة دينية تعطى لهذه العبادات معناها الروحي.

4-5 التدين التفعي:

و الذي يسخر فيه الثخص الدين لمصلحته من أجل تحقيق أهداف دنيوية شخصية (د. محمد المهدي، أنماط التدين، مجلة النفس المطمئنة، العدد 65، يناير، 2001). هذا بالإضافة إلى أنماط أخرى من التدين كالتدين التفاعلي (تدين رد الفعل) و التدين الدفاعي (العصابي) و التدين الإنسحابي و التدين الذهاني ...الخ، و أيضا: 


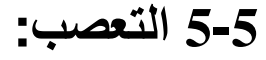

الذي يمثل اتجاه نفسي جامد مشحون انفعاليا لدذهب أو لدين معين، مع عدم التقبل و

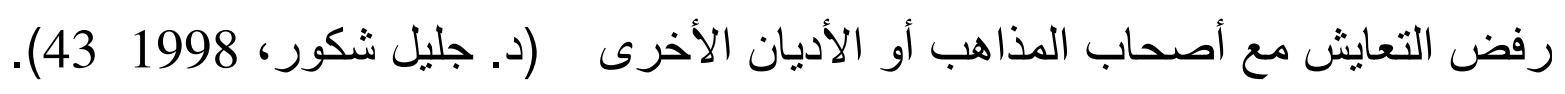

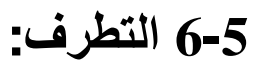
الذي يعني المبالغة و الغلو الذي يبديه الثخص نحو جانب دون الجوانب الأخرى من الدين، الأمر الذي يبعده عن حدود المعقول. 7-5 التصوف: الذي يمثل تجربة خاصة يمر بها عدد قليل من الناس دون غير هم. و أخير التندين -الأصيل- المعتدل: و الذي يمثل النوع الأمثل من الخبرة الدينية، حيث

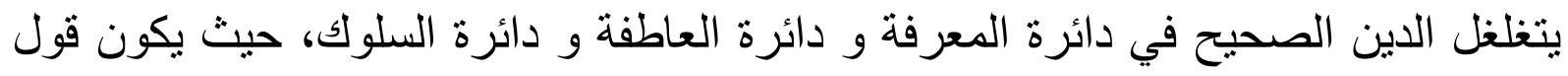

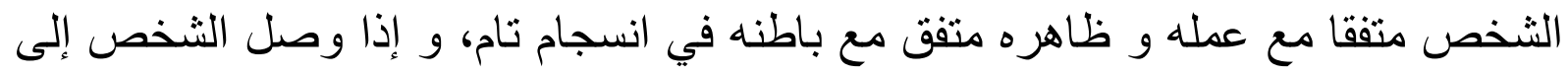
هذا المستوى من التدين يشعر بالأمن و الطمأنينة و السكينة و يصل إلى درجة من التوازن النفسي (د. محمد الدهدي، أنماط التدين، مجلة النفس المطيئنة، العدد 65، يناير 2001).

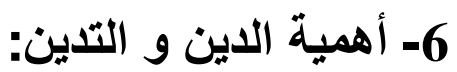

تتضح أهمية الدين و التنين جليا عند علماء النفس الكبار، فهذا (يونغ،بung) برى أن النيان التنين يمكن أن يشفي أقوى مما تثفي نظريات (فرويد) و (أدلر)، كما يمكن أن يكون علاجا أكثر فاعلية من العقاقير، و يؤكد عالم النفس (مور) أن علة النفس في الحياة

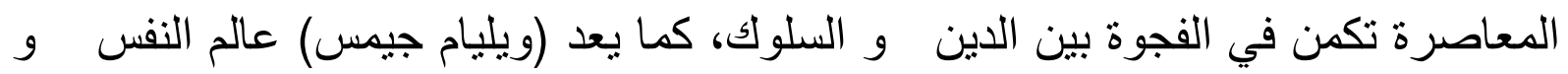
الفيلسوف الأمريكي الكبير، الدين أساس علاج القلق و التوتر و الخوف، هذه الأخيرة التي تعد مصدر لنصف أمر اض هذا العصر (دايل كارينجي، 1998 179).

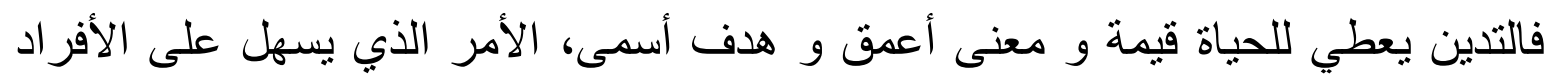
المندينين إيجاد طرق و إستراتيجيات فعالة لتحقيق تكيفهم مع ظروف الحياة و مشاكلها

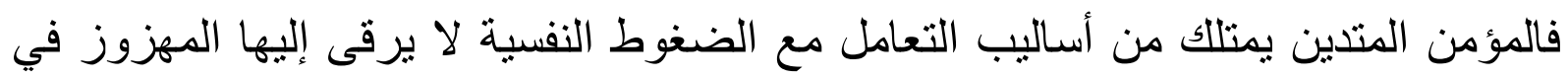

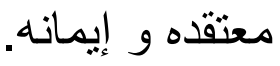


و قد أجريت دراسات على متدينين من مختلف الديانات - غير الإسلام- و وجدت هذه الدر اسات أن المتدينين يتصفون بما يلي: 1- يقل لديهم احتمال إصابتهم بالأمر اض النفسية خاصة القلق و الاكتئاب، لما يقدمه الدين

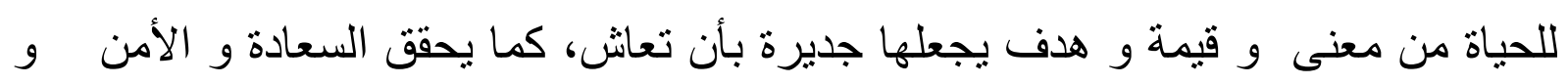
السكينة.

2- يقل وقو عهم في هاوية الإدمان، ذلك أن الددمن يلجأ إلى الإدمان فرارا من القلق و الاكتئاب.

3- وجدت الدراسات أن المتدينين تقل في أسرهم التصدعات و الخلاف و الطلاق بشقيه (العاطفي/و المادي)، مما ينعكس ذللك إيجابا على نفسية الأبناء، و كما نعلم أن علماء النفس يركزون على ضرورة توفير الجو الأسري السوي و الصالح حتى يكبر الأبناء متو افقين مع أنفسهر و مع مجتمعهم. 4- وجدت الدراسات أن المتدينين أقل ترددا على الأطباء العضويين، و هذا يتفق مع ما توصلت إليه الدراسات حول إسهام القلق النفسي في إصابة أعضاء الجسم. 5- وجدت الدراسات أن المتدينين لا ينتشر بينهم الإقدام على الانتحار أو حتى التفكير فيه،

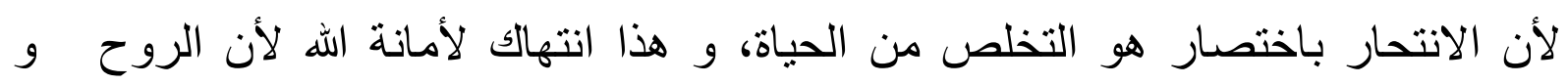
الوجود أمانة يجب أن المحافظة عليها. 6- وجدت الدراسات أن المتدينين أكثر الناس قبو لا لفكرة الموت و هذا ما وجد خاصة عند كبار السن باعتبار أن الموت هو قضاء الله و حكمته في أن يعيش الإنسان عمر از ائلا في الدنيا و عمر ا خالدا في الآخرة. 7- يقل انحر افهم و ارتكابهم للجر ائم، ذلك أن أسباب الإجر ام متعددة إلا أنها تصب جميعا في نفسية قلقة غير راضية، حاقدة على الآخرين و بالتالي تقدم على الجريمة (أ.د.محمد حسين غانم، الأمر اض النفسية من وجهة نظر الدين الإسلامي، مجلة النفس المطمئنة العدد 82، (8) سبتمبر 2005).

كما نجد أن هذه النتائج التي نوصلت إليها الدراسات التي أجريت على أديان أخرى غير الإسلام تنطبق مع نتائج الدراسات التي أجريت على الإسلام و الملتزمين بتعاليمه كدر اسة 
(صالح الصنيع) و (جمال ماضي أبو العزايم) و دراسة (د. محمد شريف) د دراسة

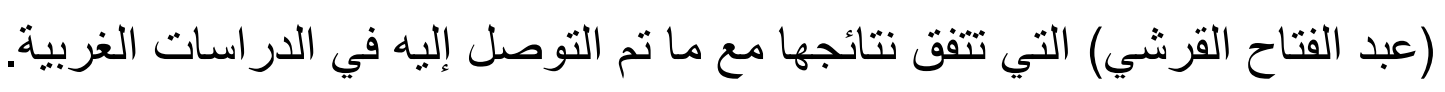

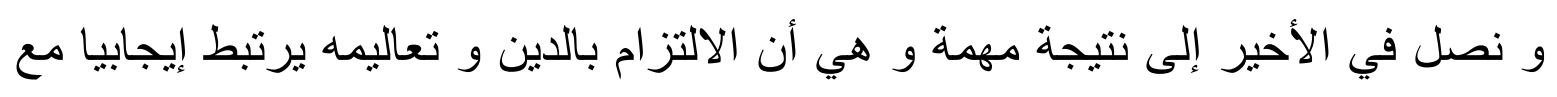
الصحة النفسية و البدنية للأفر اد. 1-6 علاقة التنين بالصحة النفسية: قد اختلف الباحثون في تفسير علاقة التندين بالسعادة و الصحة النفسية، فأنشار فريق منهم

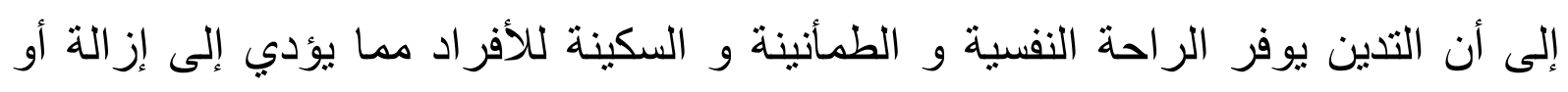

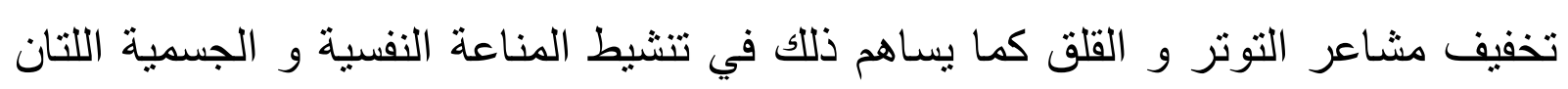

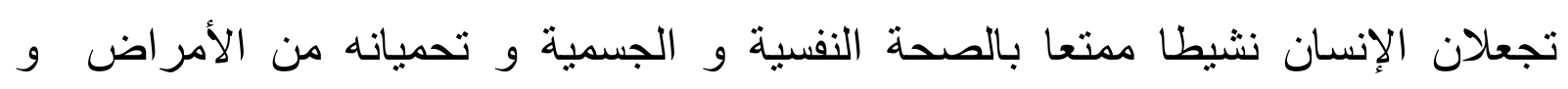

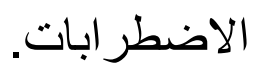

و أشار فريق ثان إلى الدعم النفسي و الاجماعي الذي توفره أماكن العبادة للمترددين

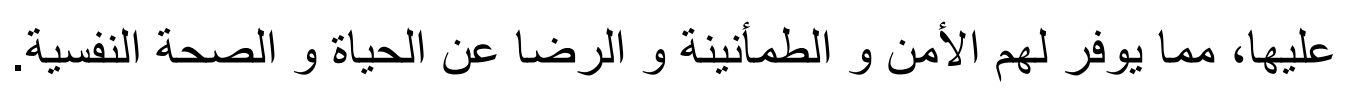

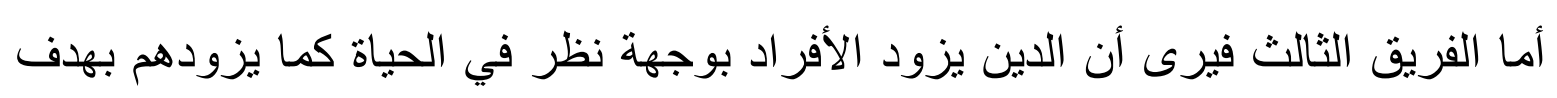

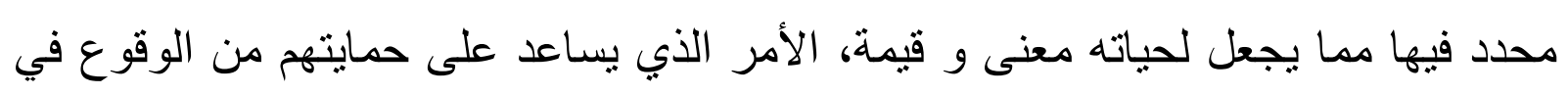
الاضطر ابات النفسية.

7- وجهة النظر الغربية و الإسلامية في العلاقة بين التدين و الصحة النفسية: 1-7 المنظور الغربي: إن الدراسات التي اهتمت بدور الإيمان أو التنين في الصحة النفسية داخل ما يسمى في الغرب بعلم النفس الديني تمثل اتجاهين: الأول: يرى أن الدين يسبب الأمر اض النفسية.

\section{الثناني: يرى أن الدين له دور في التخلص من هذه الأمراض الن}

\section{النفسية (د. محمد توفيق 002 ، 332).}


فلقد شاع إلى زمن غير بعيد فكرة أن الأديان على العموم -خصم للحياة- لأن الحياة لم

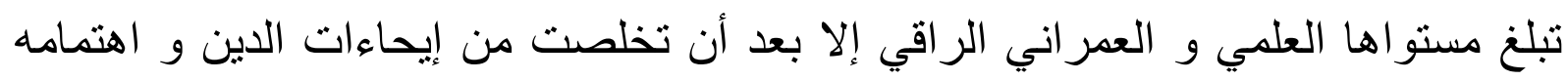

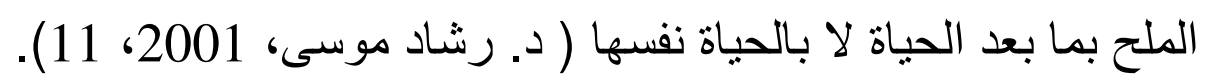

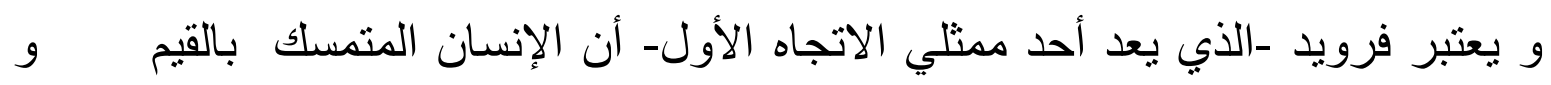

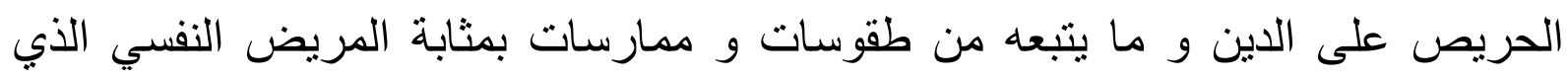

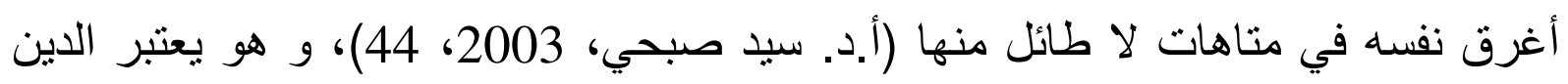

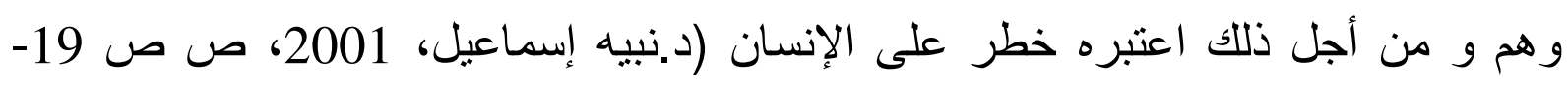

كذلك نجده يربط بين التجربة الدينية و بين الأمراض الوسواسية القهرية، و هو يشبه

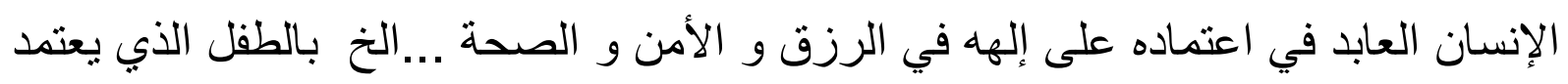

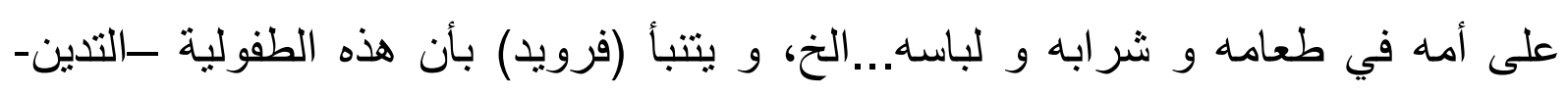
سيتم تجاوز ها بالعلم و الدور الذي كان يقوم به الدين سوف يقوم به التحليل النفسي.

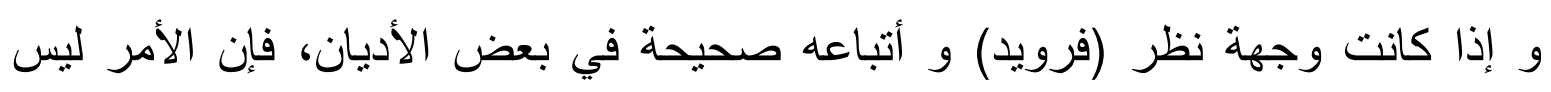

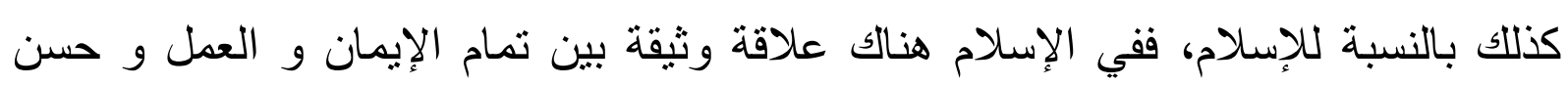
النظر في الكون و الحياة و أن الإيمان الصحيح يتم من عناصر تؤخذ من التفكير في الكون.

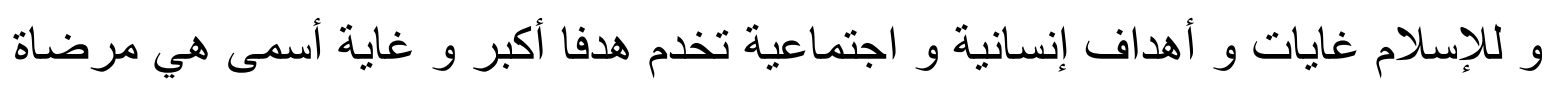
الله سبحانه و تعالى و حسن الصلة به، و تكون نتيجة ذلك معرفة غاية الوجود الإنساني و

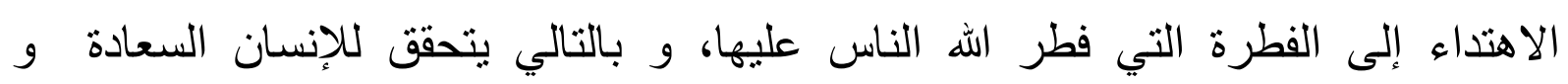

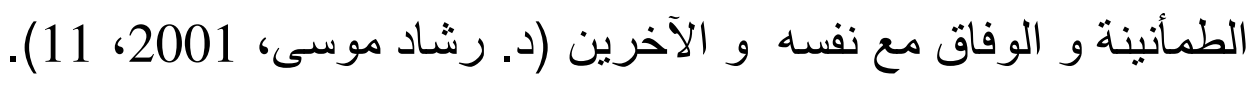

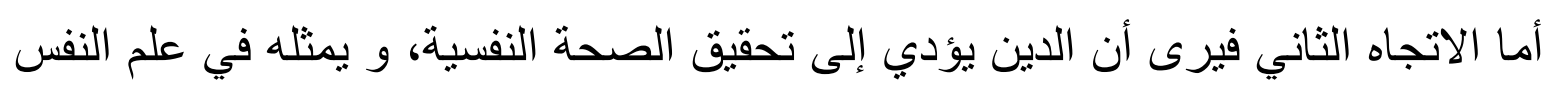
الغربي صنفان هما: علماء النفس و رجال الدين.

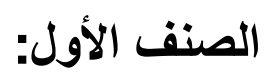

هم علماء النفس الذين يقرون بدور الإيمان في الصحة النفسية، لكن هؤلاء لا يهتمون

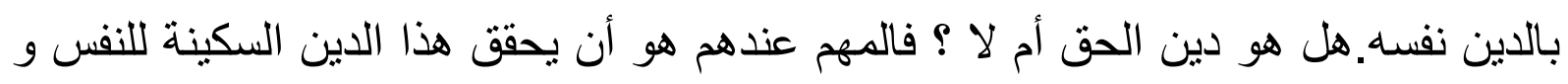

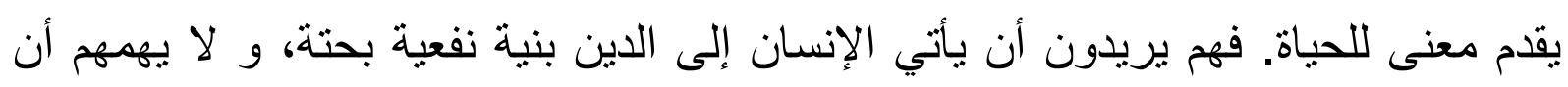


يكون الدين دين حق أو أن يلتزم الثخص بمقتضى عقيدته الدينية و أحكام دينه، بل إنهم هم

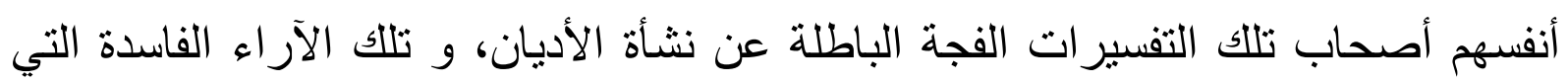

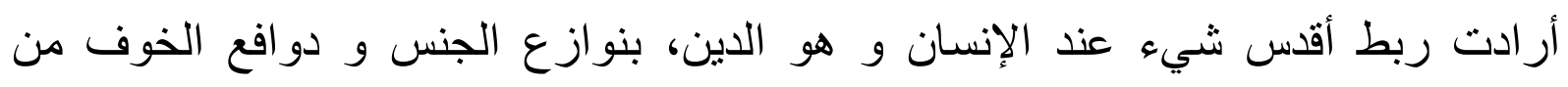

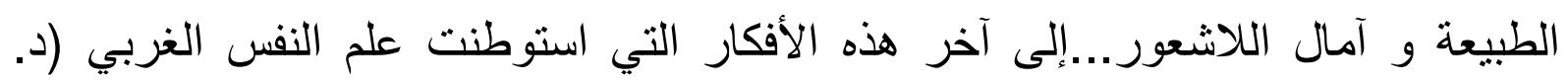

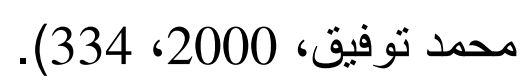
و يمثل هذا الاتجاه بعض علماء النفس أمثال: كارل يونغ، ويليام جيمس، إيريك فروم

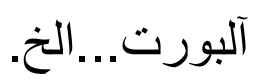
و ييقى على الفرد أن يبحث عن الدين الحق ليجعله إطارا للتوجه و موضو عا يكرس من التهن

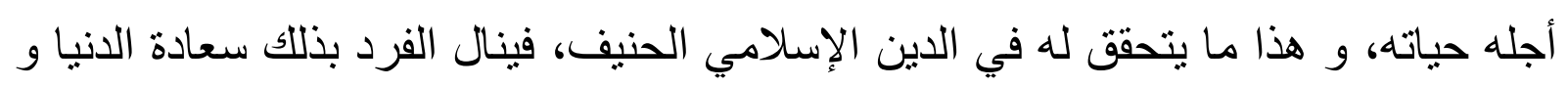

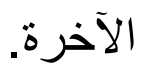

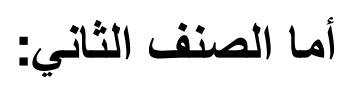
الذي يرى بأن للاين دورا أساسيا في الصحة النفسية، فيمثله رهبان متخصصون في علم النفس. فلقد أخذ رجال الدين البروتستانت في أوربا و أمريكا على عاتقهم مهمة إعداد و تأهيل

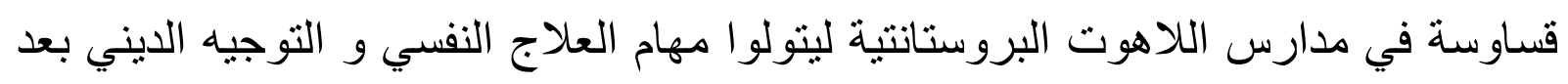

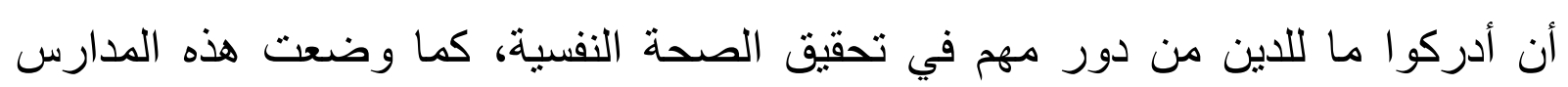

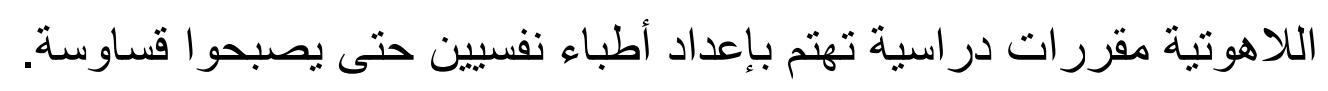

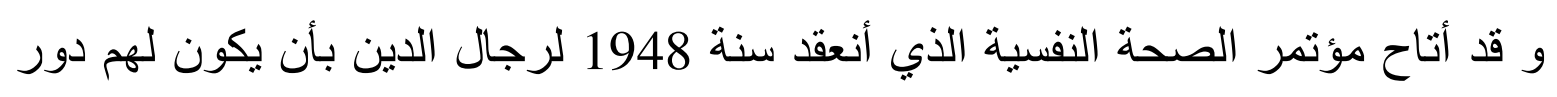
في العلاج النفسي، فقد أقر المؤتمرون بالدور الكبير الذي يقوم بهاته الإيمان في علاج

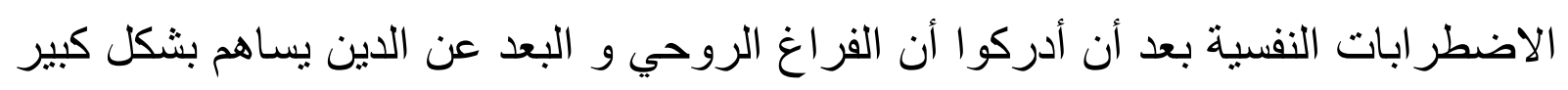

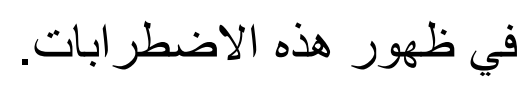
2-7- - 2- - المنظور الإسلامي: باعتبار أن الإسلام هو دين الإنق و دين الفطرة التي فطر اله الناس عليها، فإن علماء

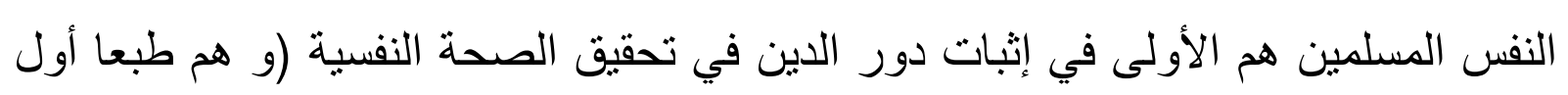

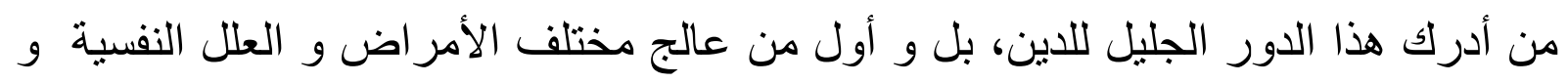


البدنية باستخدام الدين) و قد يظن البعض أن البديل الإسلامي يهدف إلى جعل الإيمان

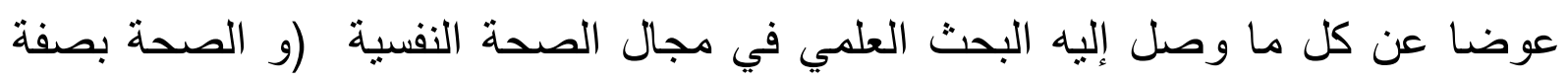

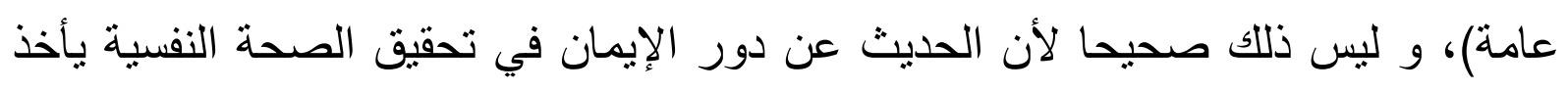
بعين الاعتبار الأمور التالية: مالية أولا: من خلال الأبحاث التي قام بها علم المناعة النفسية، ليست الششاكل التي نواجه هي

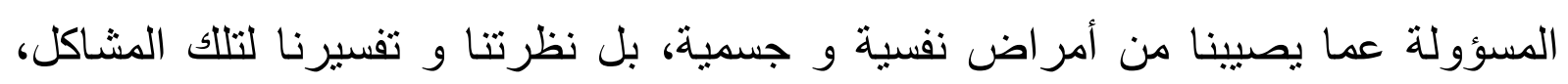

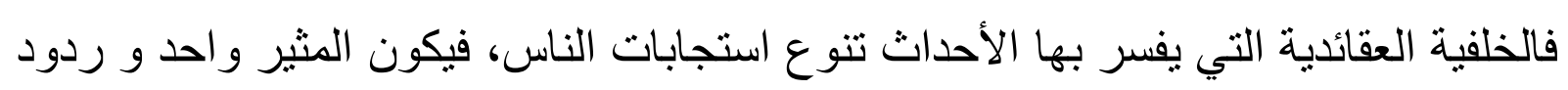

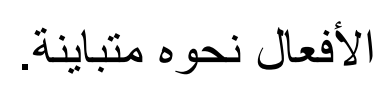

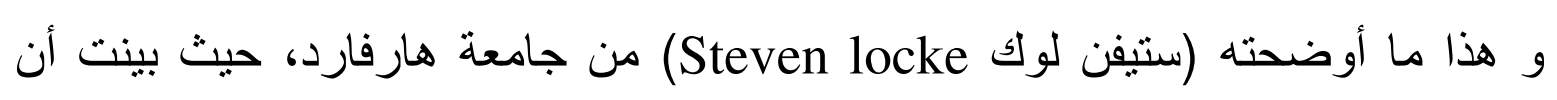

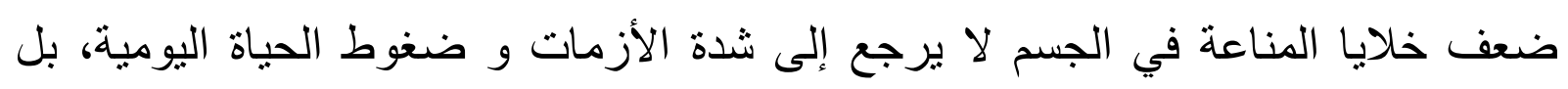

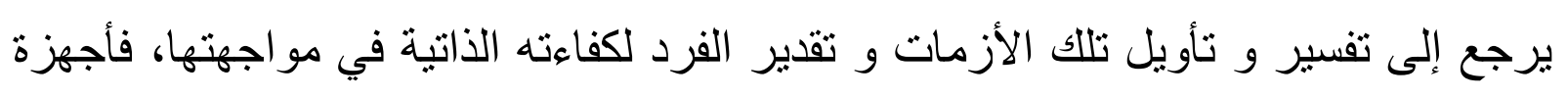

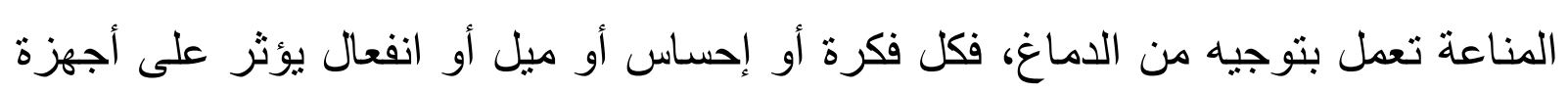

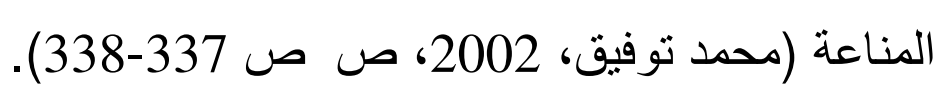

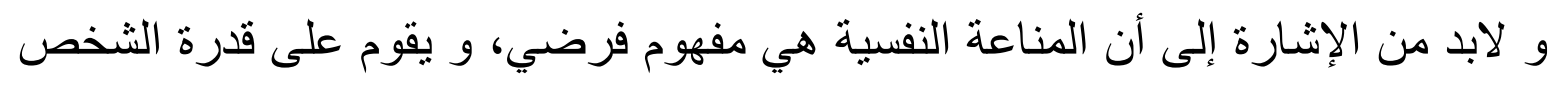

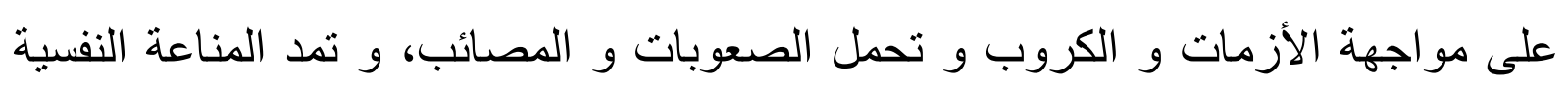
الجسم بمناعة إضافية " Super immunity " تتشط أجزة المناعة الجسمية (د. كمال مرسي، 2000، 96).

و هناك عمليات نساهم في تنشيط و تنمية المناعة النفسية و هي تسمى ب "رياضة النفس أو ترويض النفس أو إدارة الذات (Self management) "، و تتمثل هذه العمليات في: الرضا و ترك السخط، التفاؤل و ترك التشاؤم، الصبر و ترك الجزع، الثنكر و ترك

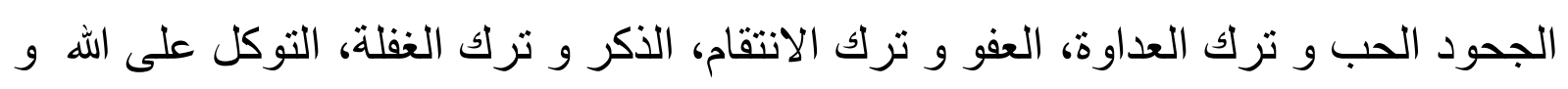

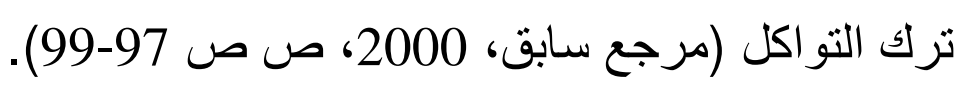
و قد أثبتت العديد من الدراسات العلاقة بين هذه العمليات و تنثيط المناعة النفسية. و من الملاحظ أن هذه العمليات تنطبق مع ما يدعو إليه الدين الإسلامي الحنيف. 
إذن فدور الدين في مجال الصحة -سواء النفسية أو البدنية- هو أنه يقوي تلك المناعة ( المناعة النفسية) و من ثم المناعة البدنية من خلال ما تحث عليه تعاليمه من تحلي بالصبر و التوكل و الرضاو التفاؤل...الخ، أي العمليات التي سبق و أن أنثارت إليها الباحثة من قبل فيل

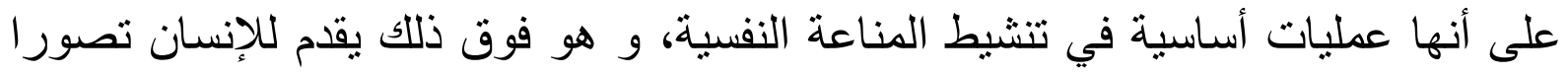
للحياة يجعله يصبر على البلاء و يشكر على النعماء، و ينظر إلى مشاكل الحياة و تقلباتها بنظرة تفاؤلية على أساس أنه بعد كل عسر يكون يسر و فرج .....الخ.

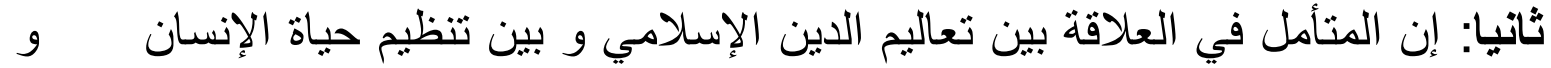

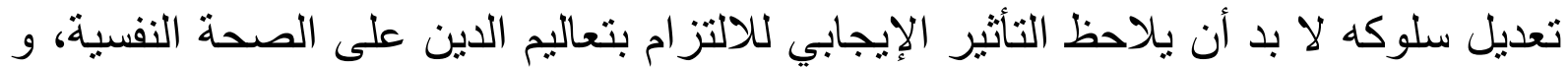
يتضمن ذلك الوقاية -و هو ما بسمى بلغة العصر: الطب الوقائي- العلاجي ، و مثال ذلكائ

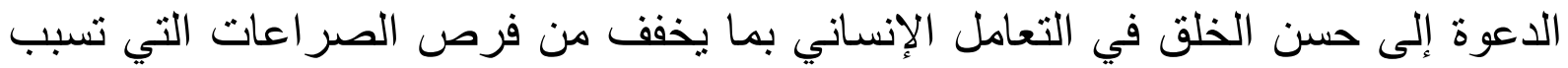

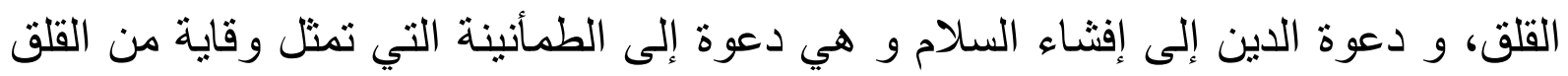
و الاكتئاب، كذللك العبادات الإسلامية لها تأثير إيجابي على الصحة النفسية كما تؤكد

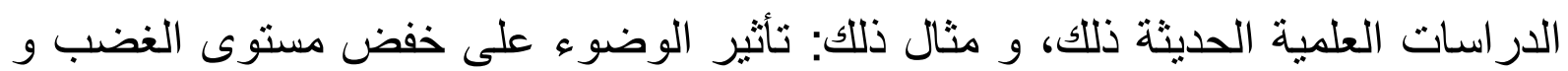

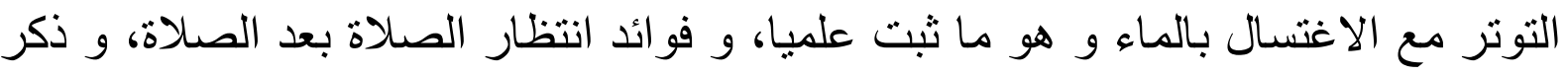

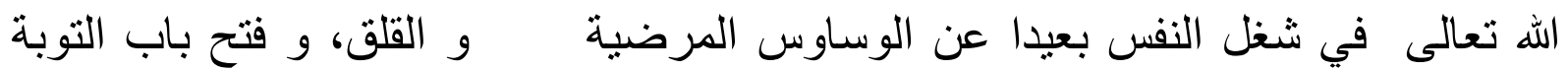
للإنسان مما يساعده على التخلص من تأنيب الضمير و مشاعر الذنب التي تؤدي إلى اليأس

$$
\text { و الاكتئاب (لطفي الثربيني، 2003، 256). }
$$

بالإضافة إلى الجانب النفسي فقد حرص الدين الإسلامي على الجانب البدني للإنسان و و ذللك من خلال أمور عديدة منها: الحث على ممارسة الرياضة البدنية و الفروسية و ركوب الخيل و عدم الإسراف في تناول الطعام، يقول الرسول صلى الله عليه و سلم: " نحن قوم لا نأكل حتى نجوع و إذا أكلنا فلا نثبع " كذللك تحاثي الإصابة بالأمراض المعدية و البعد عن الأوبئة، يقول

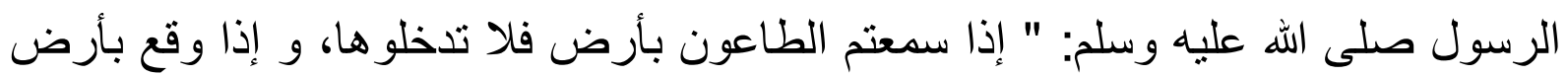

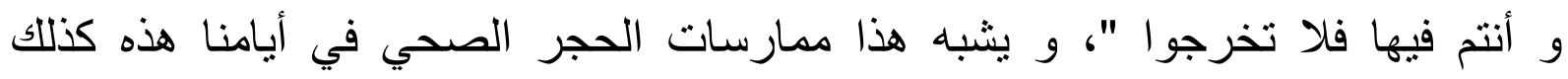


يحرص الإسلام على نظافة بيئة المسلم، و ذلك من خلال الحث على إماطة الأذى عن الطريق و غير ذلك (د. عبد الرحمن العيسوي، 2005، 44). بالإضافة إلى الجوانب النفسية و الجسمية فقد حرص الإسلام أيضا على السلامة العقلية و الفكرية لأبنائه لذلك حرم السحر و الثعوذة و الدجل، و التطير و التشاؤم و الفأل، يقول الرسول صلى الله عليه و سلم: " لا عدوى و لا طيرة " ( صحيح الإمام مسلم ) (مرجع سابق، 2005، ص ص 44-45). و لابد من الإشارة إلى أن الاعتقادات و العبادات الإسلامية و الأخلاق التي يدعو إليها الدين الإسلامي هي عوامل وقائية في نفس الوقت الذي تعد فيه علاجية.

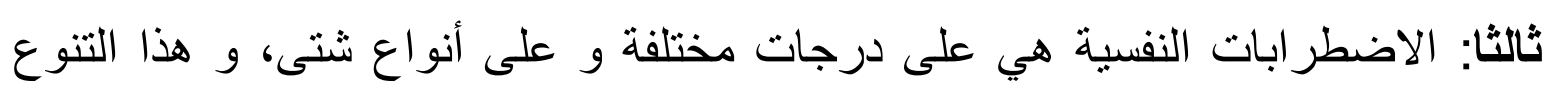

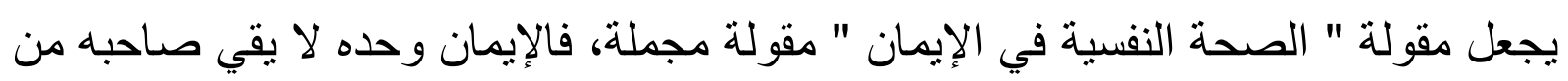

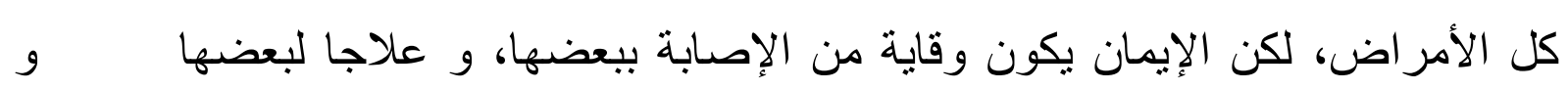

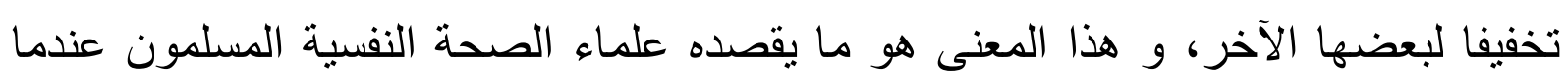
يربطون بين الإيمان و الصحة النفسية.

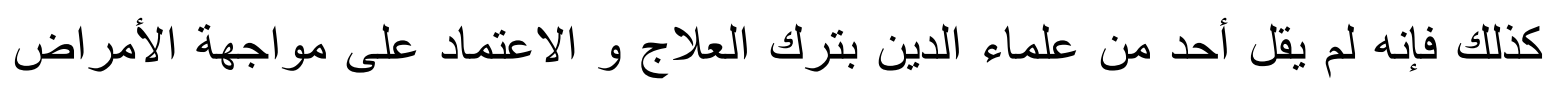

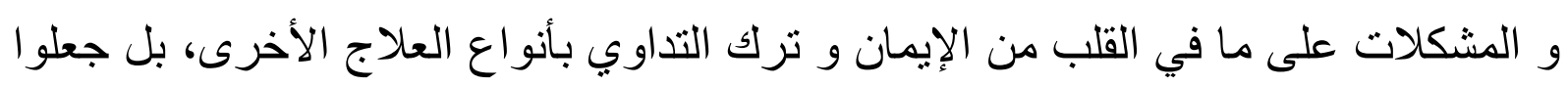

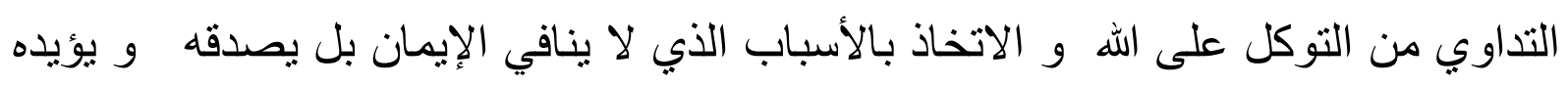

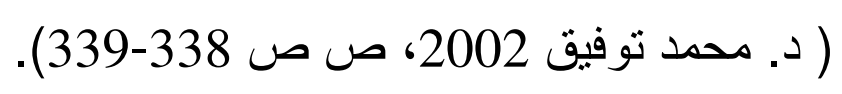

رابعا: إن الإيمان الذي يحفظ صاحبه من الاضطر ابات النفسية، و يمده بالقدرة على الدقاومة إذا أصيب بشيء منها هو الإيمان المستكمل لثروطه، وليس الإيمان الباهت

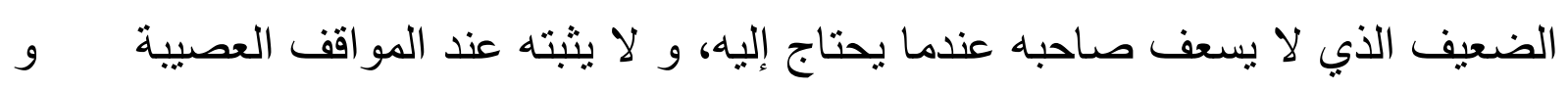

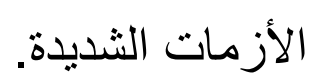
و هاهم المسلمون اليوم يعاني الكثير منهم من الأمراض النفسية الباطنة و الظاهرة رغم انتسابهم للإسلام السبب هو ضعف إيمانهم، و ضعف التز امهم بمقتضياته العملية ( مرجع سابق، 2002341 ). 
8-كيف يؤثر الدين -فيزيولوجيا و نفسيا- على الصحة الإنسانية (الصلاة، الصيام

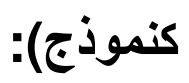

إذا كان الحديث بشكل عام عن علاقة الصحة النفسية بالإيمان و التدين، قد أصبحت أكيدة عند علماء النفس، و إذا كان الإيمان فعلا هو مناعة و علاج نفسي في الوقت نفسه فإن العلم يأبى أن بسلم بهذه الحقائق قبل البرهنة على آليتها و ميكانيزم حركتها الفيزيولوجية ( د. سامي الموصلي 2004، 77)، و هو ما سوف تحاول الباحثة توضيحه من خلال عرضها لآليات بعض النماذج التي تعد علاجات نفسية روحية و كيفية نأثيرها على الصحة الإنسانية.

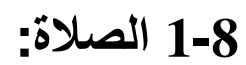

تعد الصلاة من أهم الطقوس الدينية أو العبادات في جميع الديانات على اختلافها و

معناها:

وجود صلة بين الإنسان و خالقه، وهي عبارة عن مناجاة روحية بين العبد و خالقه

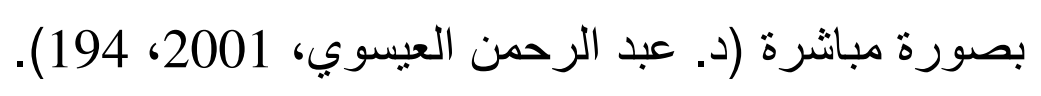

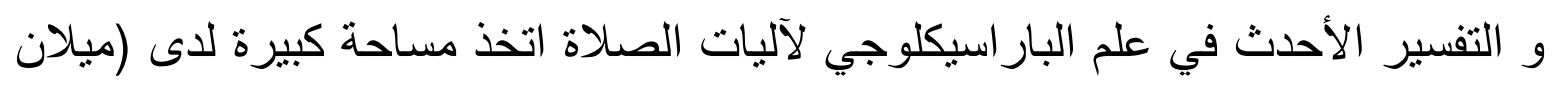

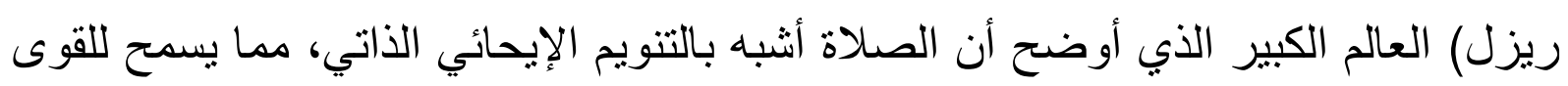

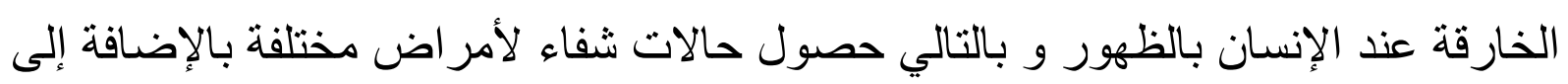
أنها تحقق تغيير ا أساسيا في الثخصية من خلال أنها تخلق استعدادا عاليا لقبول الإيحاءات.

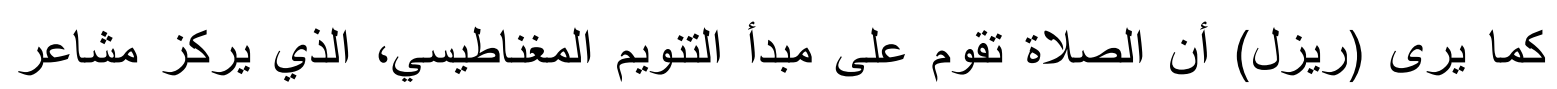

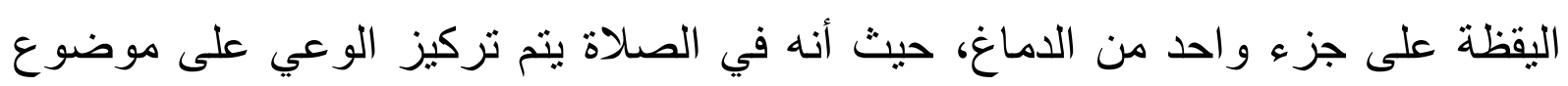
واحد ذي طابع شعوري (و هو الاتجاه إلى الرب الخالق) مما يسمح باستلام التأثيرات

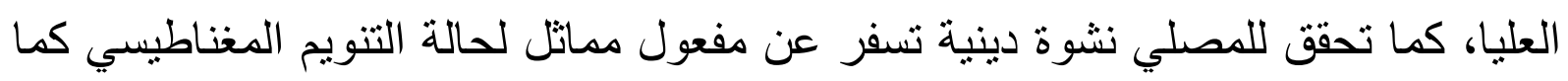

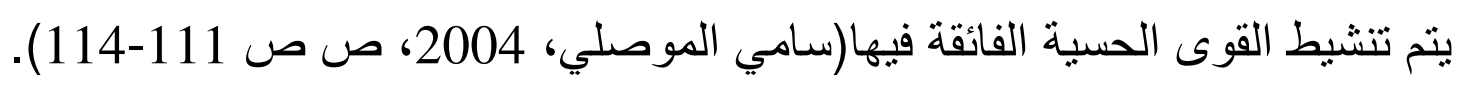
فالاتصال الروحي بين الإنسان و ربه أثناء الصلاة يمده بطاقة روحية تجدد فيه الأمل و يقوي فيه العزم و تطلق فيه قدرات هائلة تمكنه من تحمل المشاق و القيام بجلائل الأعمال.

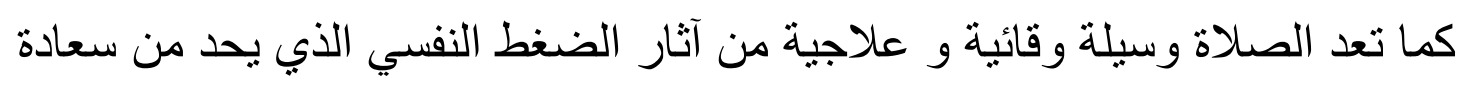


الفرد و راحة باله، كما يتسبب في إصابته بالكثير من الاضطر ابات النفسية و الجسدية (أ.د.

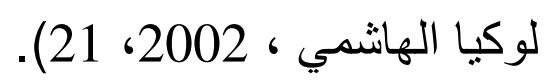
كذلك مجرد التوجه إلى الله تعالى بالدعاء، و أمل الإنسان في استجابة الهه تعالى له يؤدي عن طريقه الإيحاء الذاتي باحتمال استجابة الله تعالى له دعاءه إلى تخفيف من حدة قلقه

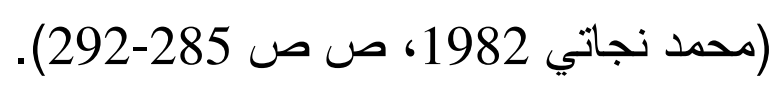
أيضا فلقد أثبتت الدراسات التجرييية ما نوصل إليه (بنسن) من أن المشاركين في المجمو عات التي تمارس تقنية الاسترخاء بانتظام، لديهم عدد قليل من أيام المرض و. انخفاض في ضغط الدم، كما أن أداءهم العملي متقدم بالنسبة للمجموعات الأخرى غير

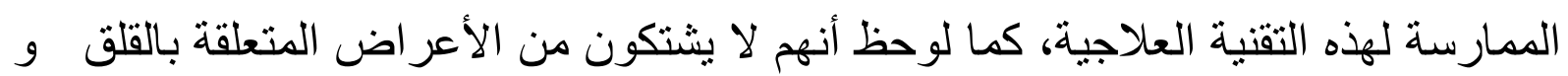
الصداع و صعوبة النوم....الخ. فالصلاة إذا حتى و إن كانت تأملية استرخائية فقط، فهي ذات تأثنير كبير على الصحة فكيف إن كانت الصلاة هي الصلاة الإسلامية التي لا تقتصر على التأمل فقط و إنما الإحساس بالسعادة الكبيرة عبر الكلام الإلهي العظيم الذي يردد و ما يخلق من إيحاءات شفائية كبيرة تطبع النفس و الجسد بطابع الصحة (سامي الموصلي، 2004، 110). و حول مدى تأثير سماع آيات القر آن الكريم في نفوس عدد من المرضى، أجرت مؤسسة العلوم الطبية الإسلامية في ولاية فلوريدا الأمريكية دراسة حول ذلك، حيث أسفرت نتائج هذه الدراسة على أن استماع آيات القرآن الكريم يؤدي إلى تخفيف نوتر الجهاز العصبي التلقائي في 97\% من الحالات. و التوتر النفسي كما هو معروف يؤدي إلى نقص المناعة النفسية، و بالتالي فإن استماع

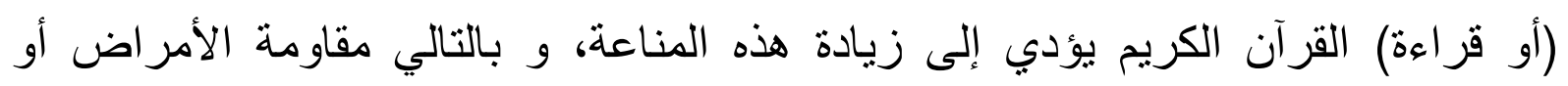
الوقاية منها. كذلك بالنسبة للحركات التي تؤدى في الصلاة الإسلامية، فقد بينت الدراسات أن هذا

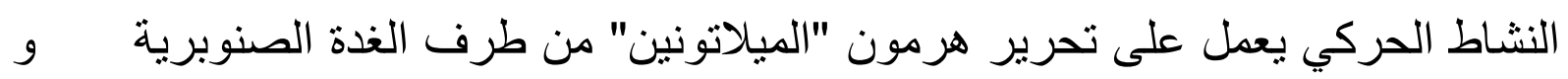
الذي يتسبب في جلب السعادة للأشخاص كما يعطل مسار الدخول في الثيخوخة. 
و من المعروف أن الصلاة (و تحديدا الصلاة الإسلامية) لا تصح إلا إذا توفرت

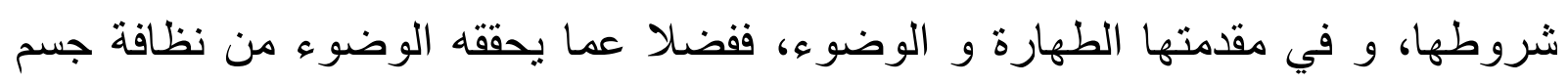
المسلم و طهارته و حمايته من الجراثيم و مصادر العدوى، فإن له معنى رمزيا، حيث يشعر المسلم بطهارة قلبه و خلاصه من الذنوب و المعاصي و بذلك يشعر المسلم بأنه يمثل ونل أمام الله تعالى دون حجب. و علاوة على ذلك فقد أثنتت الدراسات الحديثة في الصحة النفسية أن الاغتسال بالماء يساعد على الثعور بالهدوء و الاسترخاء و السكينة، و يزيل مشاعر التوتر و القلق و و التأزم النفسي و العصبي و العضلي (د. عبد الرحمن العيسوي، بدون سنة، 141).

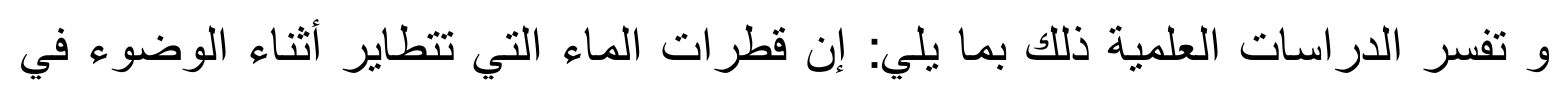
الهواء تولد طاقة ضوئية منها "أيونات سالبة الثحنة" لها قوة كهرومغناطيسية تسبب استرخاء نفسيا عاليا يزيل التوتر العصبي و القلق.

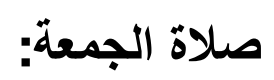
إن لصلاة الجمعة دور وقائي و آخر علاجي، فدورها الوقائي يتمثل في كونها تمد الفرد بأنواع من المعلومات الدينية و الإرشادات العملية التي توجه سلوكه في الحياة توجيها سليما، و تزيد قدرته على مو اجهة مشكلات الحياة. أما دورها العلاجي فيرجع إلى التأثثر الذي تحدثه خطب الجمعة في زيادة استبصار الفرد لذاته و ما يعانيه من بعض مشكلات الحياة و في تقوية إر ادته في مواجهتها مقاومتها و التغلب عليها. إن الدور الذي تقوم به صلاة الجمعة يشبه إلى حد كبير الدور الذي يقوم به العلاج

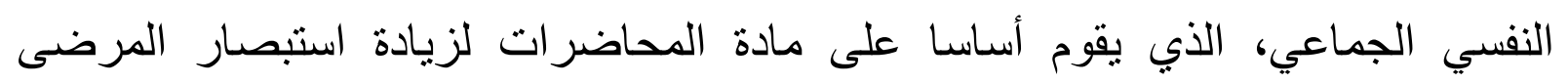
لمشكلاتهم و مساعدتهم للتغلب عليها (د محمد نجاتي، 1982، ص ص ص 285-292). 2-8

لا شك أن فريضة الصوم موجودة في جميع الأديان، كما أنها موجودة في مختلف

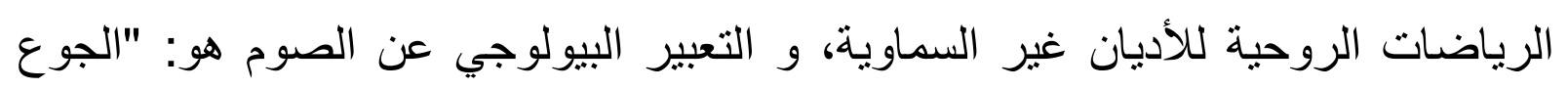
البدني"، و يعرف الصوم على أنه: "الإمساك عن الطعام و الثراب و المتع الحسية لمدة 
معينة تختلف هذه الدة من ديانة إلى أخرى و من مذهب إلى آخر (د. رمضان القذافي

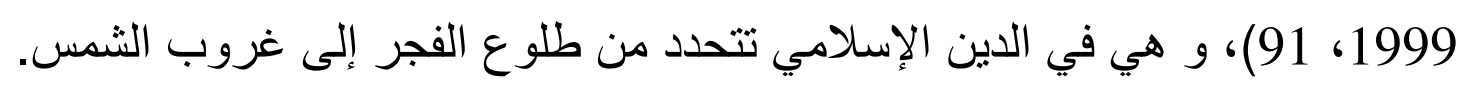

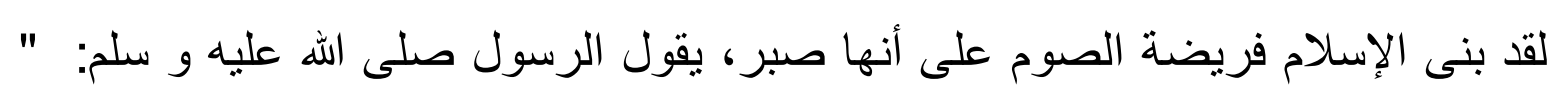

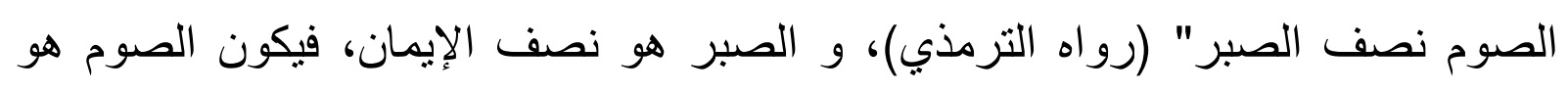

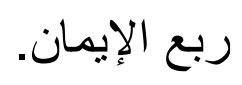

أما أجر الصائم فهو كبير يوم القيامة لأنه ينسب إلى الله نعالى، كما يقول الله نعالى في الهي

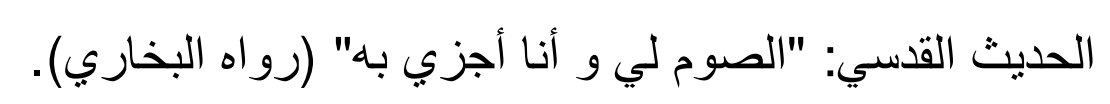

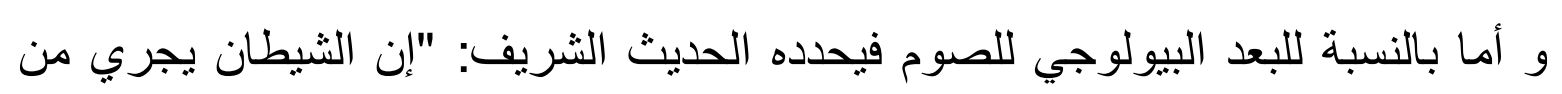

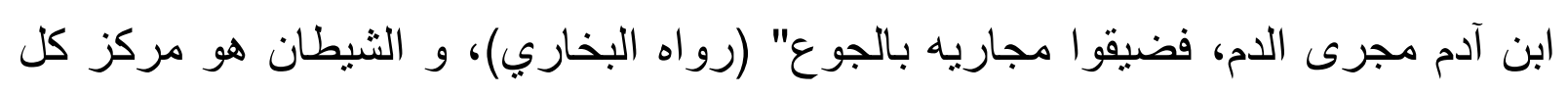

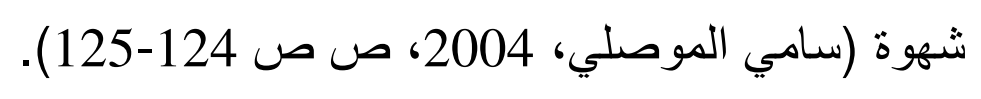

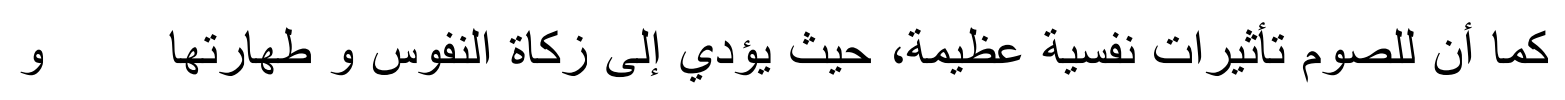

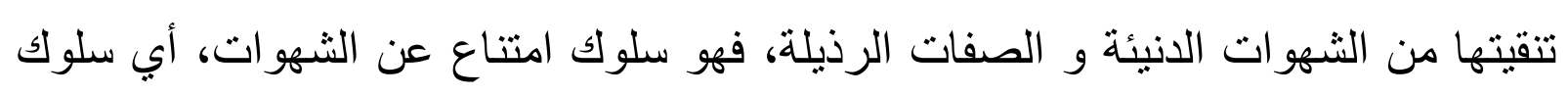
للكف عن النشاطات التي تؤدي إلى المتع الحشوية أو الحسية مما يؤدي إلى إعطاء الإنسان

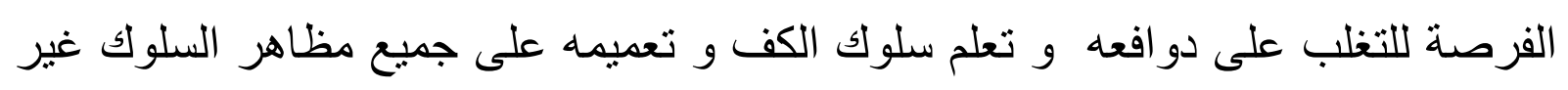

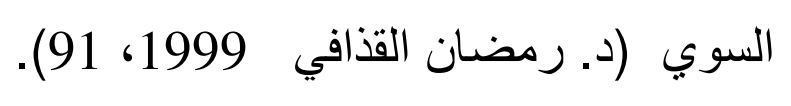

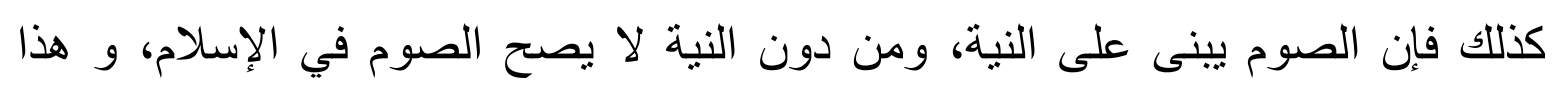

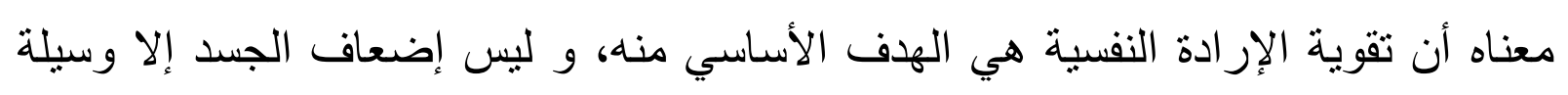

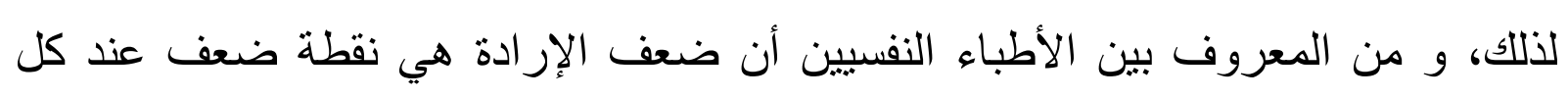

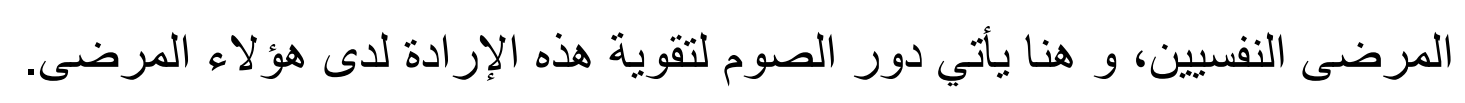

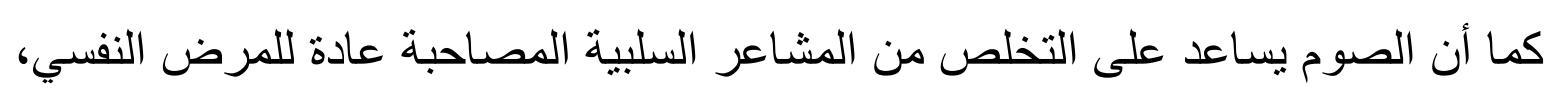

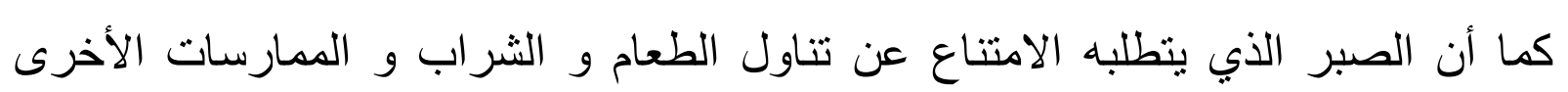

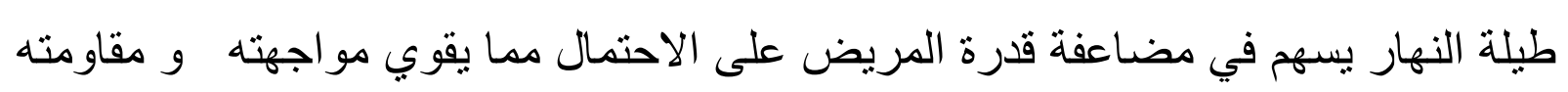

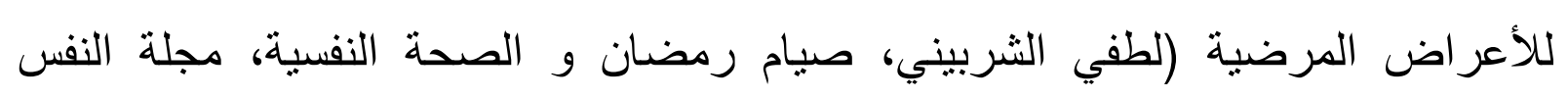

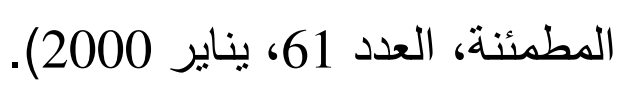


و قد أوضحت الدراسات العلمية أن آلية أو دافع أو غريزة الجوع تتحكم بها وظائف

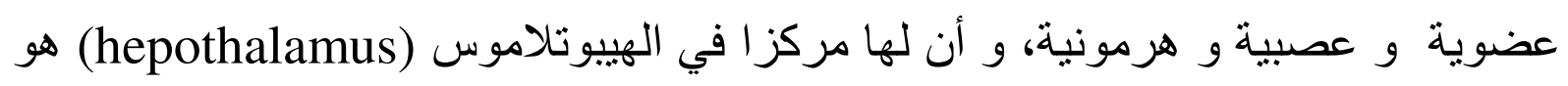
الدؤول عن تنظيم كافة الآليات التي تتحمم في الجوع و الثبع على السواء (سامي

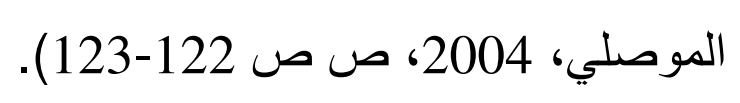
و نخدم آلية الصوم -الجوع آليات فيزيولوجية من آليات الكف نفسها، و تعمل هذه

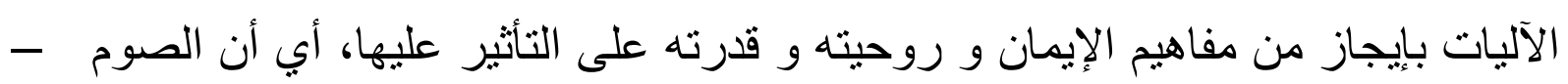

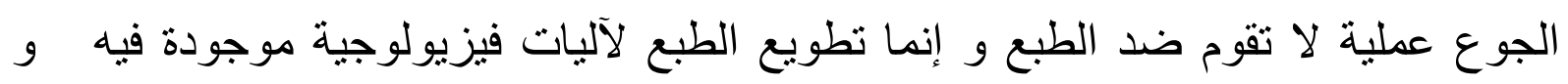

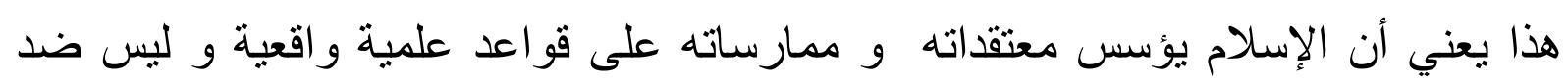

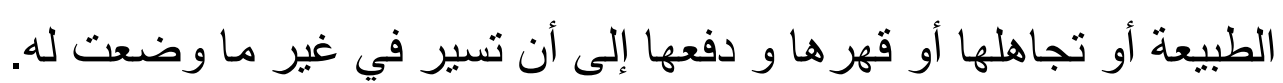

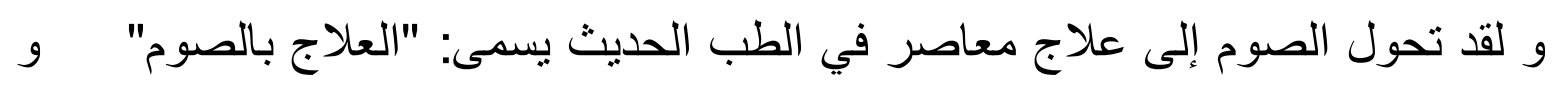

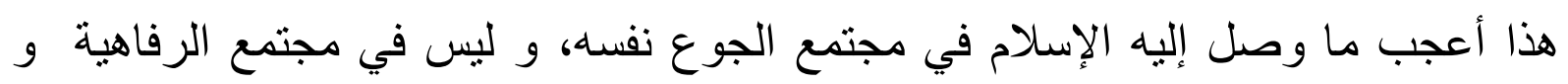

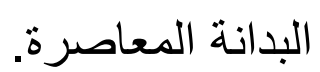
فذخول المكننة و طبيعة الحياة العصرية بما فرضته و تفرضه من عادات غذائية و و

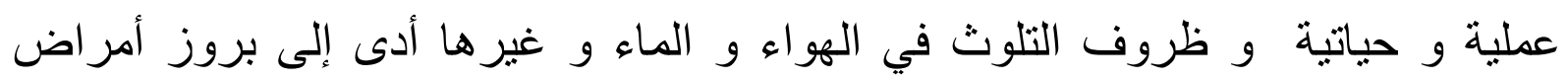
مستعصية مثل: البدانة، مرض السكري، الكولسترول...الخ، على الرغم من التقدم الكبير الذي تشهده التكنولوجيا الجر احية التشخيصية.

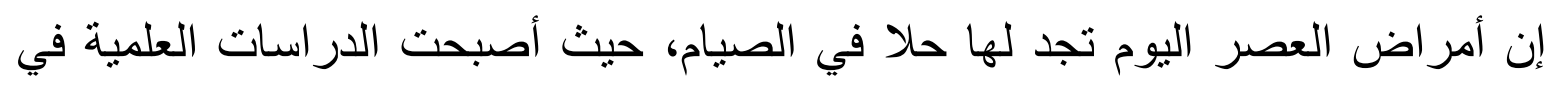

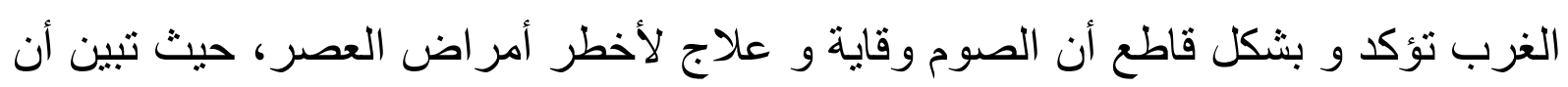

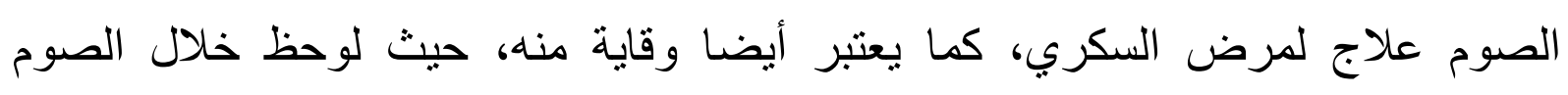

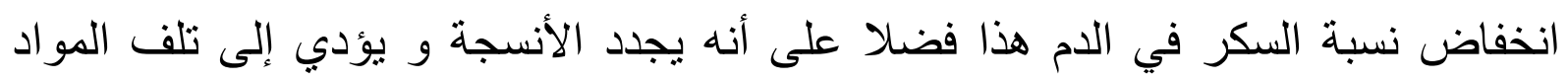

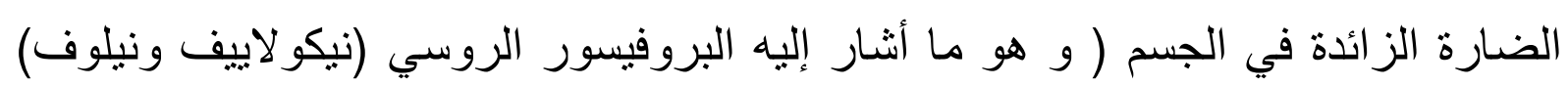

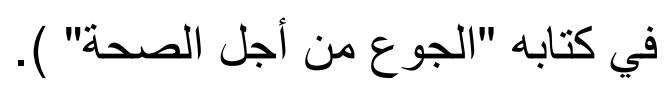
كذلك يعد الصوم فرصة للمعدة و الأمعاء أن تظل خالية من أي طعام، مما يسهل شفاء الهاء

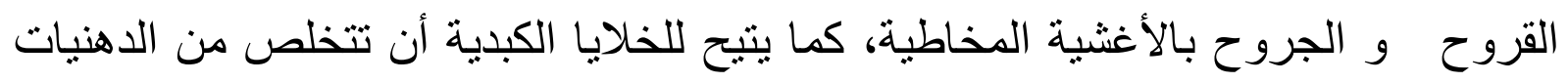


كما أن الصيام يقاوم الثيخوخة التي لا دواء لها، و هذا ما أثتتته الجمعية الأمريكية

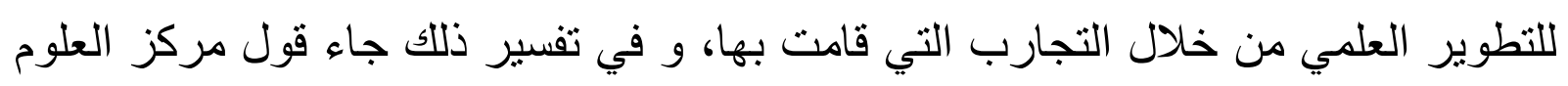

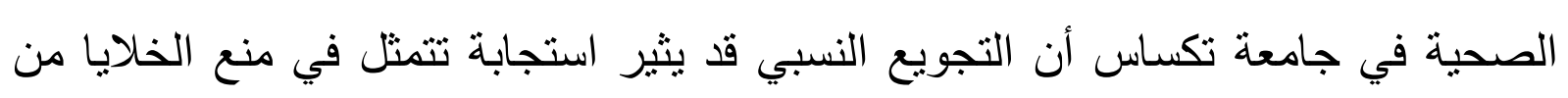

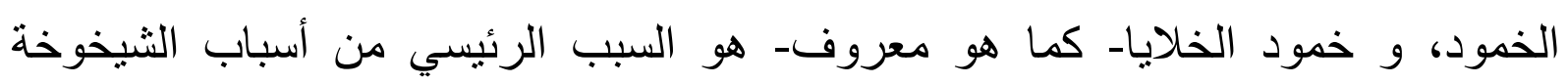
(سامي الموصلي، 2004، ص ص 124-140)، و غير ذلك من فو ائد الصيام.

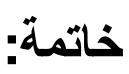

إن ما تعرضت له الباحثة من خلال هذين العلاجين الروحيين و من خلال باقي العناصر

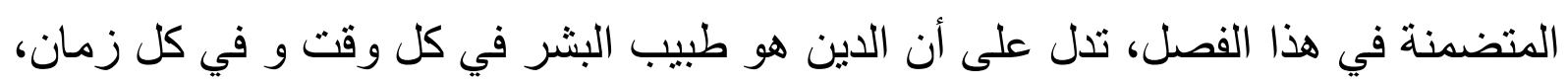

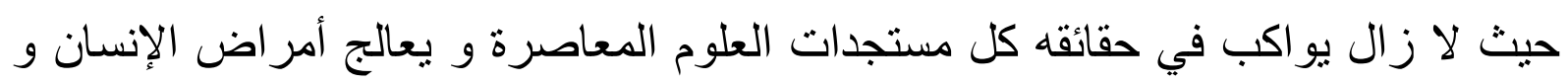

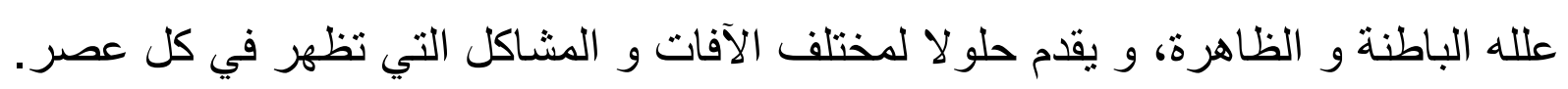
و يعجز الإنسان عن تخفيف الكثير منها فضلا عن إيجاد حلول لها.

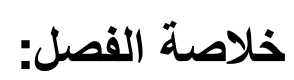

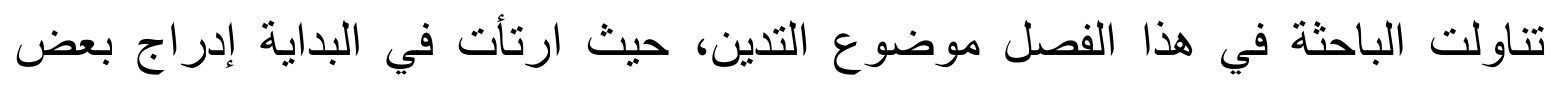

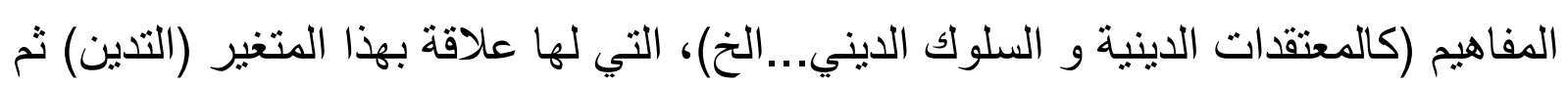

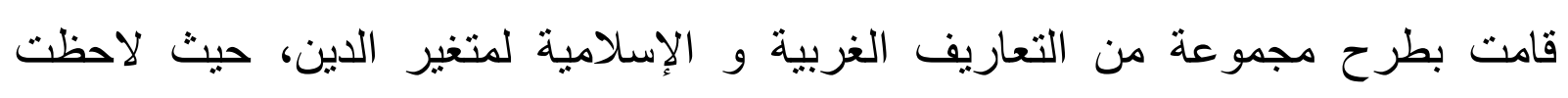


الباحثة من خلال هذه التعاريف أن التعاريف الإسلامية تقترب من التعاريف الغربية للدين، كما خرجت بمجموعة من الاستنتاجات الأخرى.

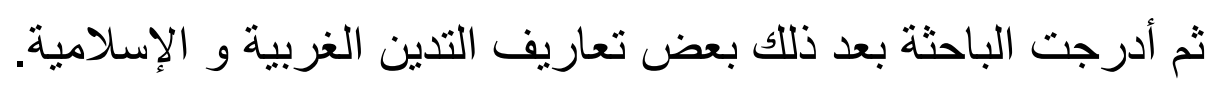

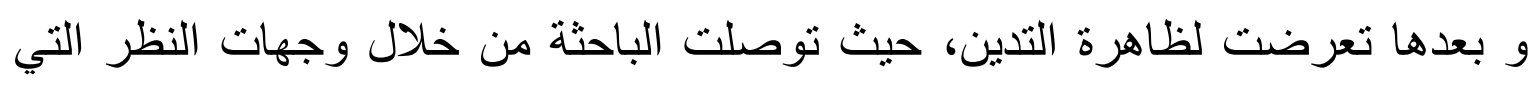
قامت بطرحها إلى معظم الباحثين و الدفكرين يجمعون على فطرية التدين عند الإنسان. و بعد هذا تتاولت الباحثة أبعاد التدين، حيث تبين من خلال ذلك أن معظم الأديان تثترك الإنس

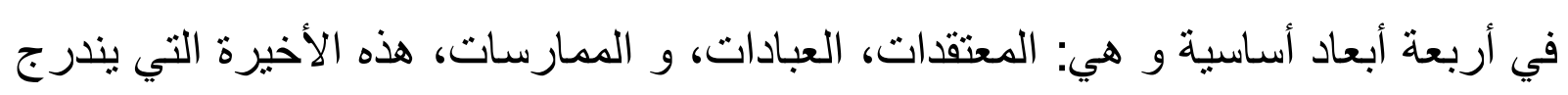
تحتها كل من الأخلاق و المعاملات (بالتعبير الإسلامي).

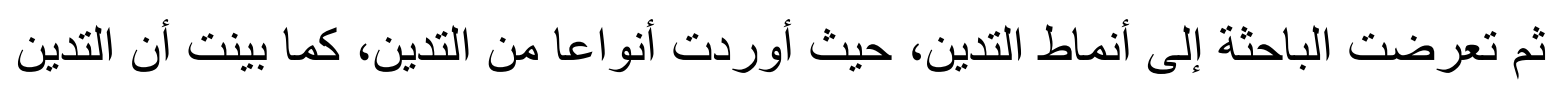

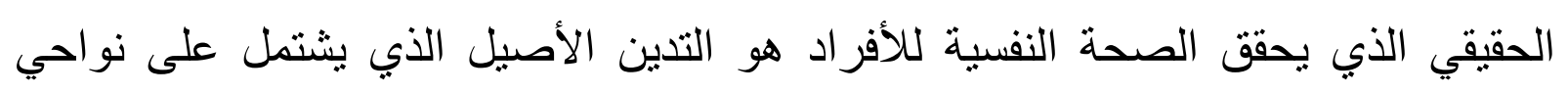
المعرفة و السلوك و العاطفة و الإخلاص و اليقين.

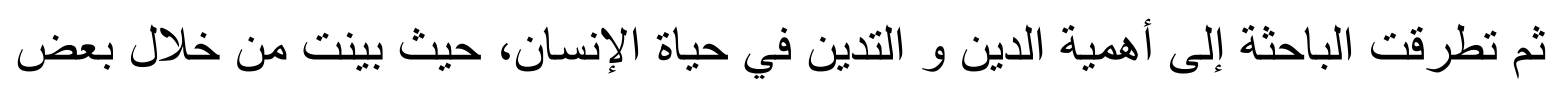

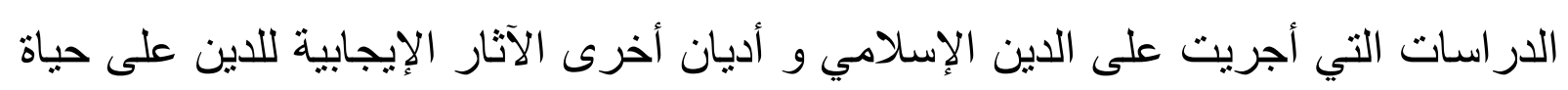
الأفراد و صحتهم النفسية.

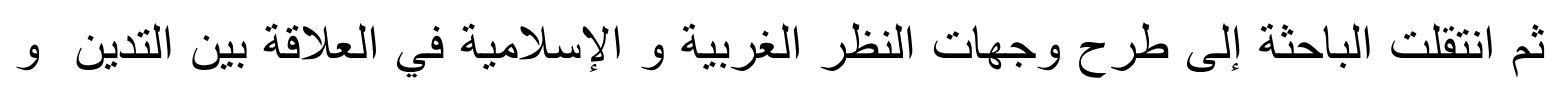
الصحة النفسية، حيث خرجت من هذا العنصر بوجهات نظر مختلفة أهمها:

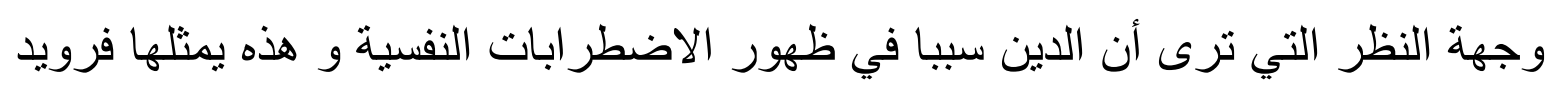

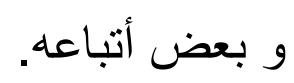

و وجهة النظر التي ترى أن الدين عامل مهم في تحقيق الصحة النفسية للأفراد و هذه

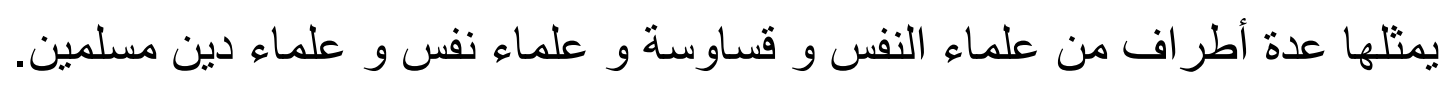

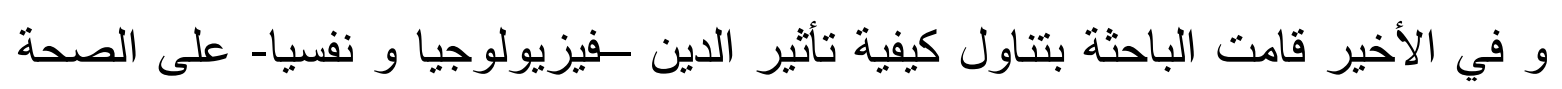

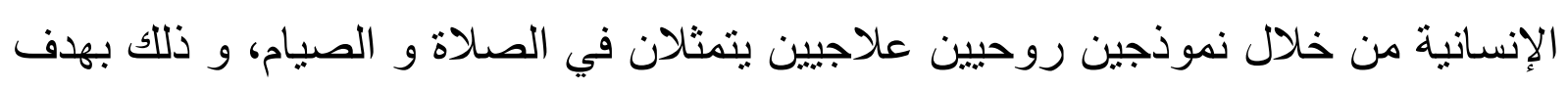

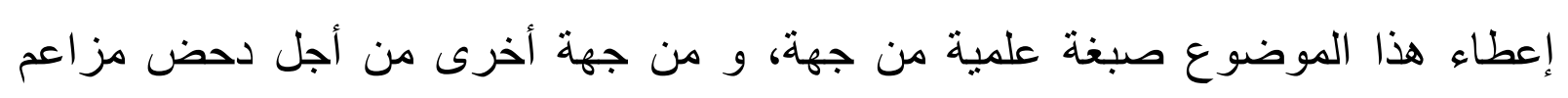

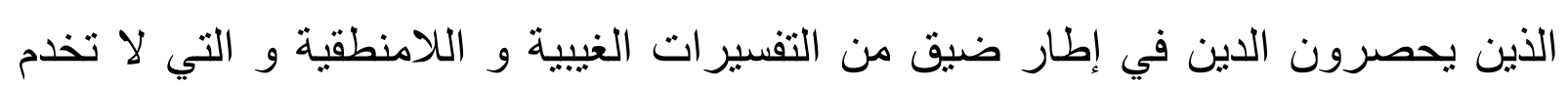

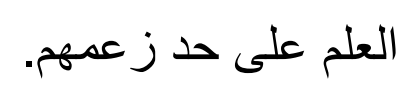


<smiles>[3H]CCCI</smiles> 


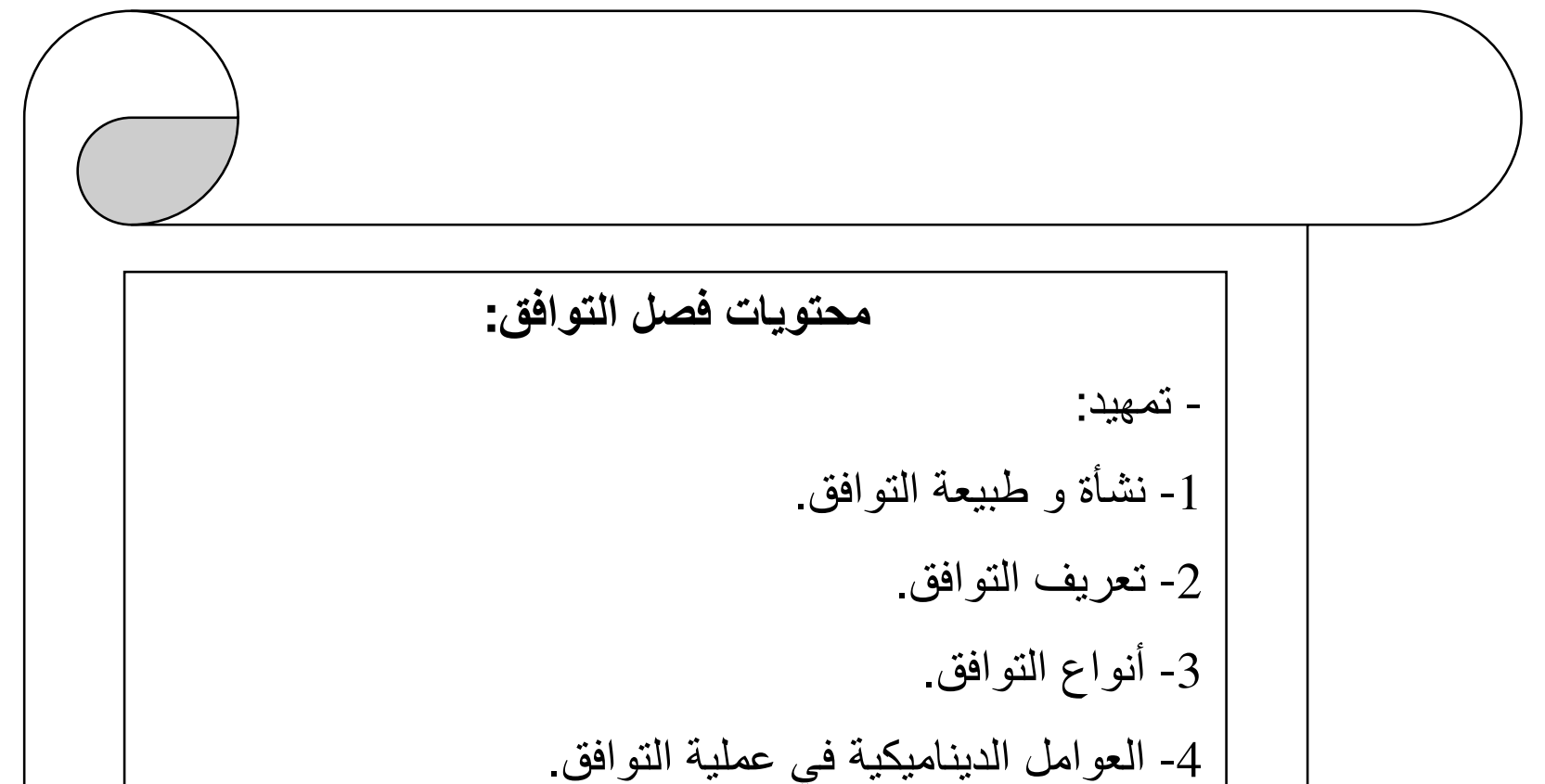




\section{تمهيد:}

يعد التو افق غاية الإنسان يسعى باستمرار إلى تحقيقها، ذلك أن حياة الإنسان و ديمومتها و نجاحه فيها يعتمد على قدر معين من التوافق، و لأن سوء التو افق أو عدم التكيف يسببان الكثير من المشاكل للفرد غير المتو افق و غير المتكيف. 
التو افق من أكثر المفاهيم شيو عا في علم النفس، ذلك أنه تقييم سلوك الإنسان و علم النفس هو علم سلوك الإنسان و تو افقه. و يستخدم التوافق بمعان مختلفة، كالتكيف في مجال العلوم البيولوجية، و التوافق في مجال الصحة النفسية و العقلية, إن التعدد في معاني هذا المفهوم يرجع إلى تباين رؤية البعض له، و كثرة استخدامه في كثير من ميادين الفكر الإنساني. و مصطلح التكيف (adaptation) مشتق أصلا من نظرية "تشارلز داروين" عن التطور مئري التي ظهرت في القرن ال19 (محمد السيد الهابط، بدون سنة، 29). و لقد استعار علماء النفس هذا المفهوم البيولوجي و أعاد تسميته بالتوافق (Adjustement النبات) إز اء البيئة الفيزيقية التي يعيشون فيها (وفيق مختار، 2001، 19)، و هو يشير إلى تلك العمليات و التغيرات التي تطر أ على الكائن الحي تجعله أكثر قدرة على المحافظة على لعى حياته أو بقاء جنسه. و قد تكون هذه العمليات إما على المستوى البيولوجي (كتعديل الكائن الحي لشكله)، أو على المستوى الفيسيولوجي (كالتغيير في كيمياء الجسم)، أو على المستوى العصبي الحسي (كملاعمة الإحساس ليتحمل المنبه الذي يتعرض له طويلا)، كما أن الاستجابة التي يتكيف بها الفرد مع ظروفه تسمى: السلوك التكيفي ،( د. عبد المنعم حنفي، 2003، ص ص 395. $(396$

أما التو افق فهو أشمل و أوسع دلالة من مصطلح التكيف ، و هو مفهوم خاص بالإنسان في سعيه لتنظيم حياته و حل صر اعاته و مواجهة مشكلاته وصولا إلى ما يسمى ب: الصحة النفسية (أ. د. محمد محمد، 2004 ، 14). و عليه فالتوافق مفهوم إنساني، و هو يشير بشكل عام إلى نوع من المواءمة أو الملاعمة بين النفس و متطلبات الموقف، فيكون موقف الإنسان أكثر من مجرد تكييف النفس لمتغيرات البيئة، إذ قد يغير الإنسان في البيئة لتكون متو افقة معه (عبد السلام الدويبي، 
فالتوافق هو تعديل الكائن بحيث ينلاءم مع البيئة و هو ما أسماه (يونغ) "مغايره" أو يلجأ الكائن إلى إحداث تعديل في البيئة و هو ما أسماه (يونغائن (accomodation)

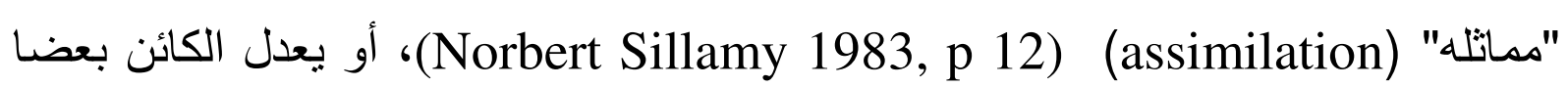
منه و بعضا من البيئة لإعادة التو افق و التوازن. و البيئة هنا تشمل كل المؤثرات و الإمكانات و القوى المحيطة بالفرد و التي يمكنها أن تؤثر على جهوده للحصول على الاستقر ار النفسي و البدني. و لهذه البيئة أوجه ثلاث -كما أوردة ذلك (د. جنان الرحو): البيئة الطبيعية، البيئة

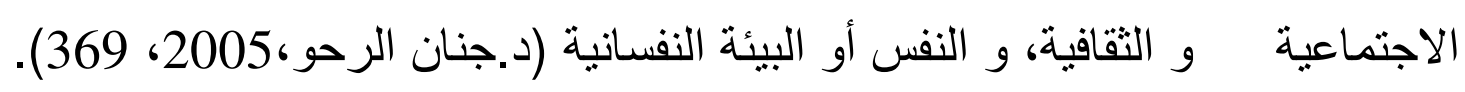
و يضيف (أ.د المهدي بن عبود) إلى هذه الأنو اع ما يلي:

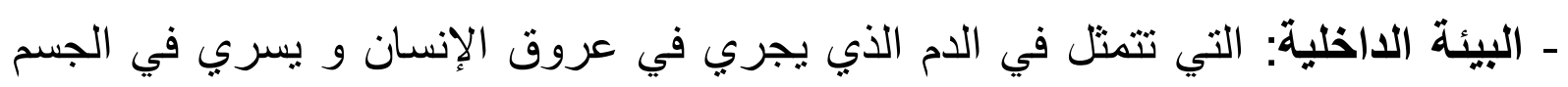
كله. ـ البيئة الخلقية: و تعبر عن الجو المعنوي الصالح بالفضائل، أو الفاسد بالرذائل و تأثيره على النفس. (نستطيع إدراج هذا النوع في البيئة الاجتماعية).

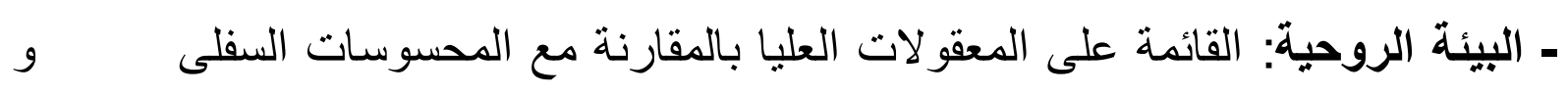

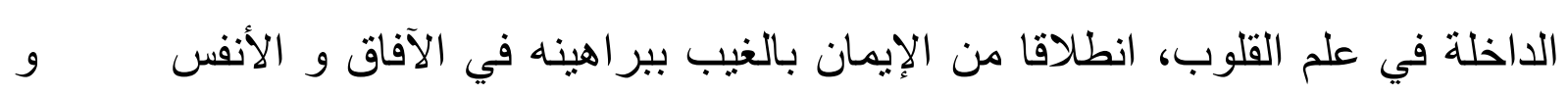

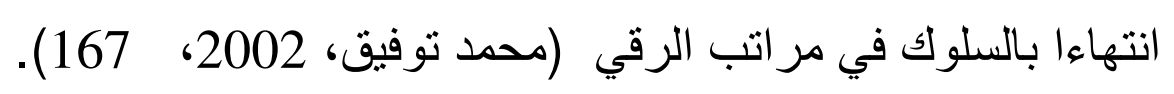

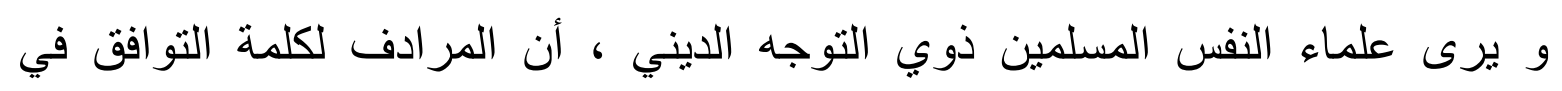
الإسلام هو الطاعة. أما سوء التوافق "Maladjustement" فهو فثل الإنسان في تحقيق إنجازاته و إثباع

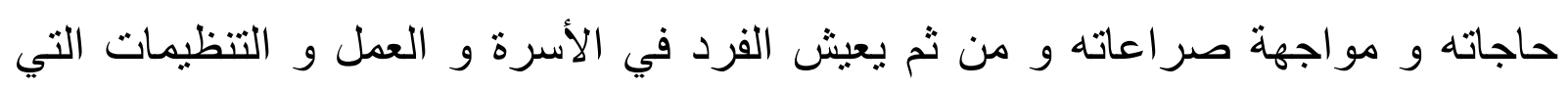

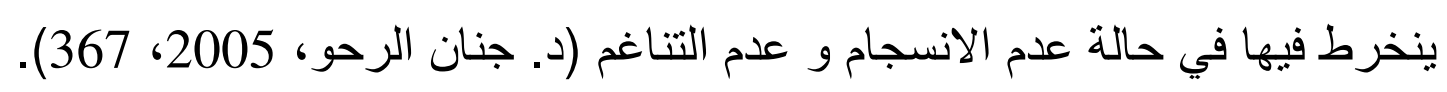

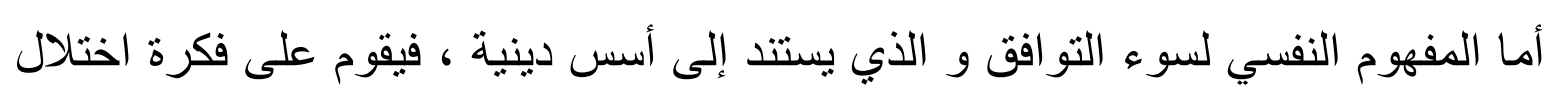

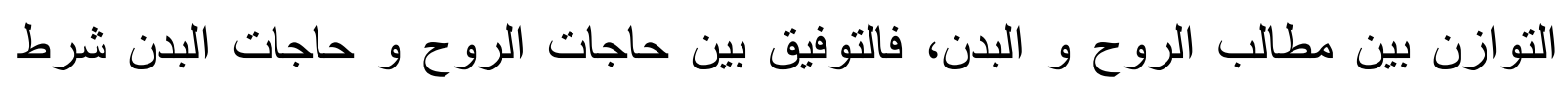

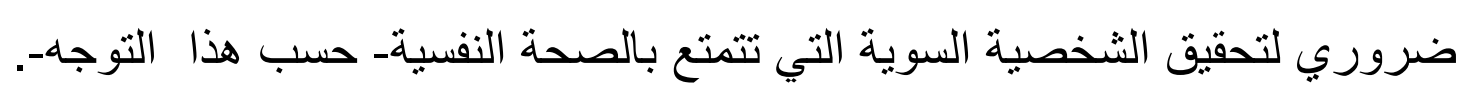

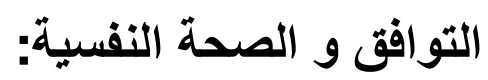


لابد من توضيح اللبس القائم بين مصطلحي التوافق و الصحة النفسية، حيث بلاحظ أن كثير من الباحثين يوحدون بين الصحة النفسية و حسن التو افق، و يرون أن دراسة الصحة

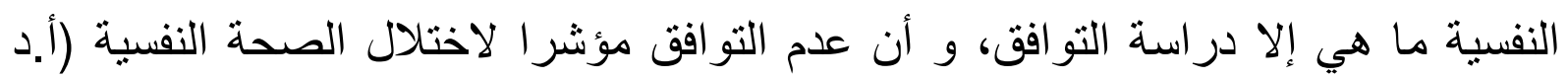
صبرة علي و أثرف شريت 2004، 127). و يرى باحثون آخرون أن السلوك التو افقي ليس هو الصحة النفسية بل هو أحد مظاهرها و السلوك التو افقي دليل تو افر ها. و هذا الارتباط الوثيق بين التوافق و الصحة النفسية يبين أن العلاقة بينهما متداخلة و و متثابكة (محمد مياسا، 1997، 25). فالتداخل كبير بين هذين المصطلحين.

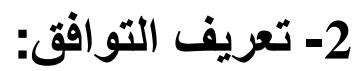

تتضمن الحباة القيام بعطليات تو افقية بصفة مستمرة، و بشكل دائم، و حالة التوافق هي لافي حالة نسبية و مؤقتة، و على العموم يمكن أن نميز بين 4 مر احل لعملية التو افق: التحريض، السعي إلى الحل، بلوغ الهذف، و تخفيض التوتر، و لا تخرج هذه النظرة عن كونها عدا

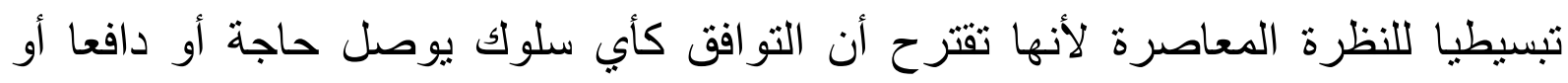
تحريضا إلى نهايته و بالتالي يعيد حالة التو ازن للكائن (د. ميخائيل أسعد، 1996 216).

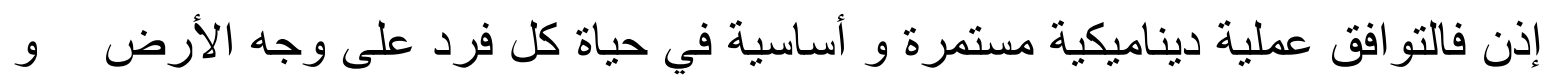
قد اهتم عدد من العلماء بتطوير تعريفات مختلفة للتو افق، تسلط الضوء على هذا المصطلح

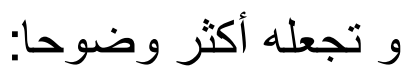

حيث يعرفه معجم المصطلحات التربوية بأنه: "عملية تعديل السلوك ليوائم موقفا متغيرا أو جديدا في محيط الفرد المادي و الاجتماعي، و بستدل على هذا التواؤم في انعدام أعراض التوتر، و القدرة على الاحتفاظ بعلاقات شخصية طية" (جرجس وحنا الله 1998، ص ص ص 15 16-16).

لكن عملية التو افق لا تقتصر على التغيير و التعديل في سلوك الفرد فقط، بل تتشل البيئة أيضا بالتغيير و التعديل، و هو ما ذهب إليه (د. حامد زهران) في تعريفه للتوافق حيث أنشار إلى أن التوافق هو: "عملية ديناميكية مستمرة تتناول السلوك و البيئة الطبيعية و 
الاجتماعية بالتغيير و التعديل، حتى يحدث توازنا بين الفرد و البيئة" (حسين حشمت و مصطفى باهي 2006، 47). و ينوقف تأثز و تأثير الفرد على البيئة على أمرين: أ- قابليته للتأثر و قدرته على التأثير.

ب- الإمكانيات المتاحة في البيئة للتأثر و التأثير (أ.د سهير كامل أحمد، 1999، 29). و يربط (د. أحمد عزت راجح) بين التوافق و القدرة على العيش، و حسبه فإن: "التوافق الحسن هو قدرة الفرد على أن يعيش في زحمة الحياة عيشة راضية منتجة في حدود قدر اته و استعداداته" (عبد السلام الدويبي، 2003، 139). أما (محمود الزيادي) فيوضح أن المقصود بالتوافق هو: "القدرة على إقامة علاقات اجتماعية مع الآخرين مثمرة و مدتعة، تتسم بقدرة الفرد على الحب و العطاء هذا من ناحية، و من ناحية أخرى القرة على العمل المنتج الفعال الذي يجعل من الفرد شخصا نافعا في محيطه الاجتماعي، فالتو افق مفهوم شامل يرمز إلى حالة معينة من النضج يصل إليها الفرد" (حسين حشمت و مصطفى باهي، 2006، 44). لكن بالر غم من أن التو افق يعني تكوين علاقة أكثر نفعاو فائدة في بيئة الفرد، إلا أن هذا لا يعني بالضرورة حصول الفرد على مكانة اجتماعية ثابتة أو رضا أو هدوء عقلي فكونك

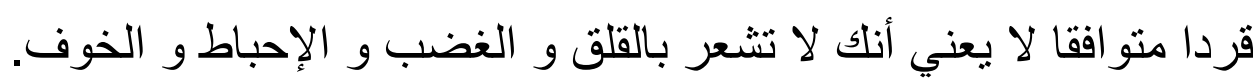
فالتوافق هو: "القدرة على انتقاء أساليب فعالة و ملائمة لمقابلة متطلبات البيئة،مع الاحتفاظ باتجاه صحي نحو الظروف" (مرجع سابق، 2006، 45). و يرى (أيدلبيرج Eidelberg) التوافق بأنه: "تكامل الحاجات الغريزية مع شروط و و منطلبات العالم الخارجي و مقتضيات الأنا الأعلى، و تللك مهمة تضطلع به الأنا عن طريق التعلم و اختيار الو اقع" (حسين حشمت و مصطفى باهي، 2006، 47). و التو افق بالمعنى الطبيعي يحدث دون إر ادة منا، كما أنه مستقل عن سعينا الثعوري في أغلب الحالات (قماري محمد، 1990 34). و قد طور (د. صالح مرحاب) من خلال استعر اضه لجملة من تعريفات التو افق تعريفا أنشار فيه إلى أن: "التو افق يتضمن تقبل الذات من جهة، و تقبل الآخرين من جهة أخرى، و مول 
إن تقبل الذات هو أساس عملية التوافق الثخصي، و أن تقبل الآخرين هو أساس عملية

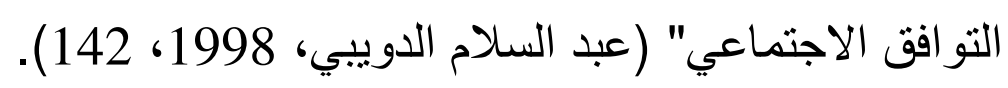
إذن فعمليات النو افق الإنسانية تسعى لـقابلة متطلبين هامين: منطلب اجتماعي: يتعلق بالتعامل مع الآخرين و ينشأ بسبب المعيثة الجمابلة الجماعية. منطلبات داخلية: ناشئة عن التكوين الطبيعي للفرد، و لها مطالب عضوية خاصة، مثل:

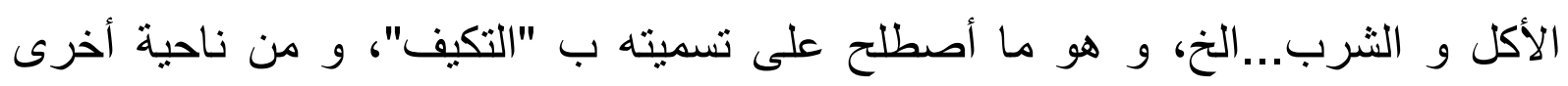
للإنسان حاجات اجتماعية معينة، مثل: الحاجة إلى التحصيل، و الحاجة إلى تقدير الآخرين

$$
\text { و غير ذلك (أ.د محمد محمد، 2004، 22). }
$$

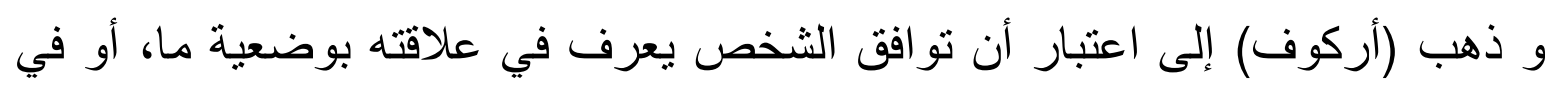
حالة ما فيقال التوافق الاجتماعي عند النظر إلى الفرد في سلوكه و علاقاته و أدواره في

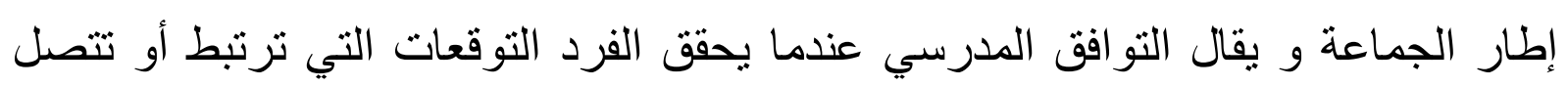
بمخرجات العملية التعليمية، أو النجاح في التحصيل العلمي (عبد السلام الدويبي 1998

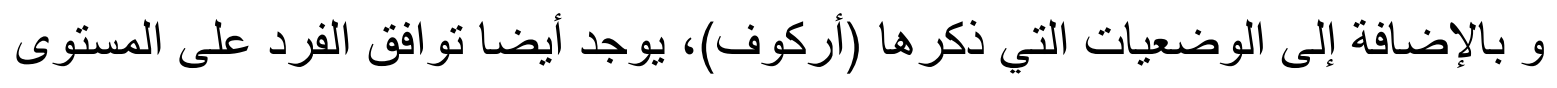

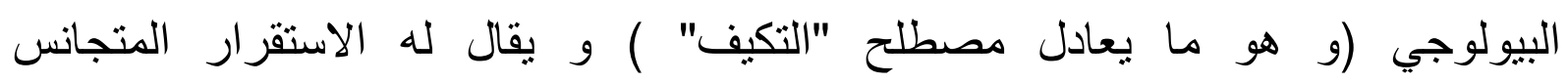
"Homeostasis" و هو ثبات البيئة الداخلية للفرد، و يتحقق له بوسائل التو افق البيولوجية لهادية

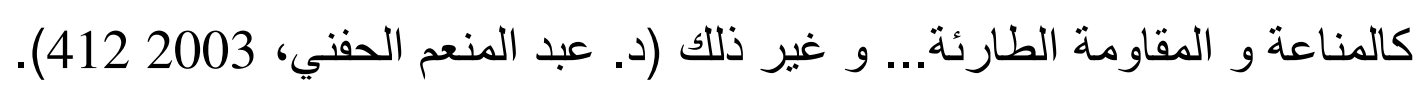
كنلك التو افق على المستوى العقلي، الديني، المهني، الانفعالي...الخ، أي الوضعيات التئي التئي

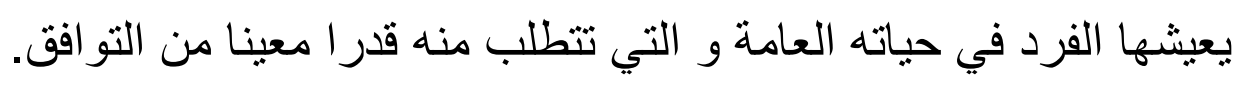

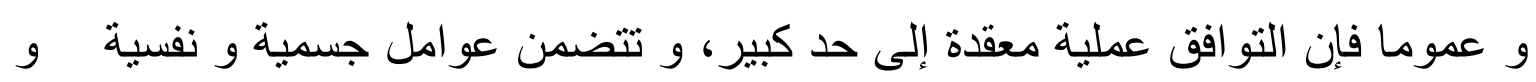
اجتماعية كثيرة تسعى أساسا إلى تحقيق سعادة الفرد و بقائه.

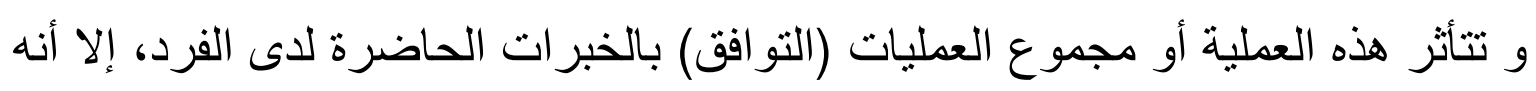

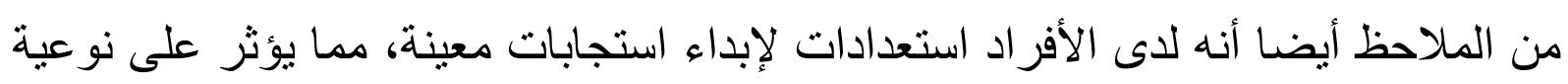

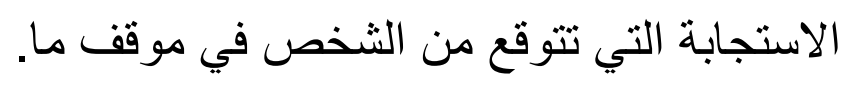


و قد قام كل من (د. حشدت و د. باهي، 2006) بتصنيف تعريفات التوافق إلى ثلاث

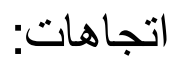

الاتجاه الأول: يرى أن التو افق يتحقق بإنثباع دو افع الفرد.

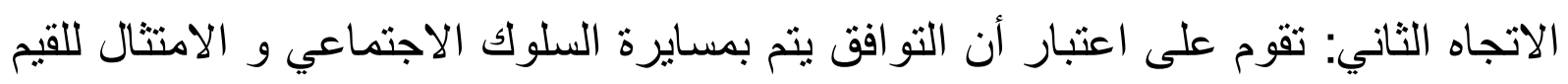

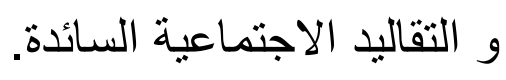
أما الاتجاه الثالث: فهو اتجاه بربط ما بين الاتجاهين السابقين، حيث يرى أن الثوافق لا لا

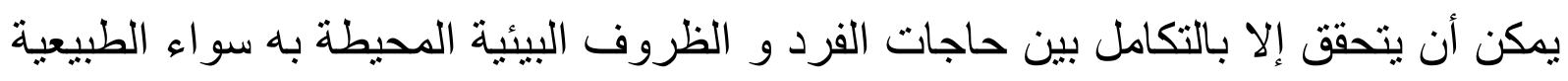

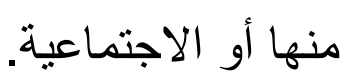
و الهدف من هذا التصنيف، هو الوقوف على نواحي القصور في هذه التعريفات و و

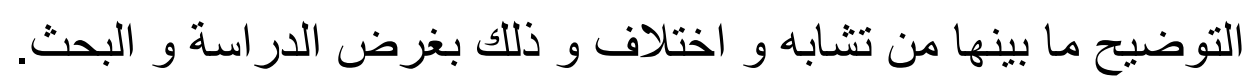

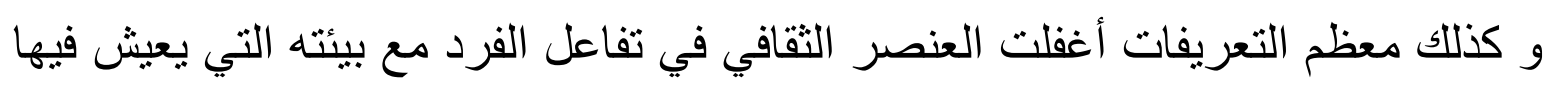
و في سعيه لتحقيق نو افقه ( حسين حشت و مصطفى باهي، 2006، ص ص صن 48-49).

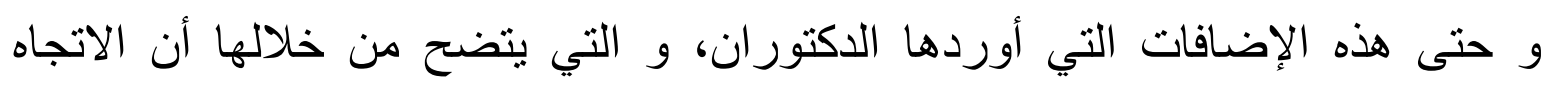

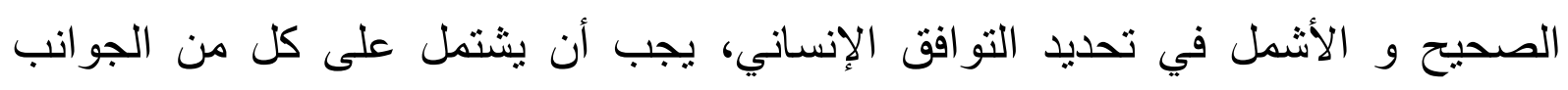

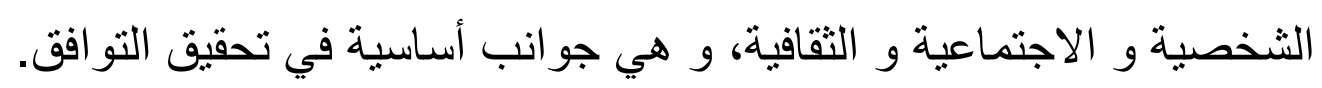

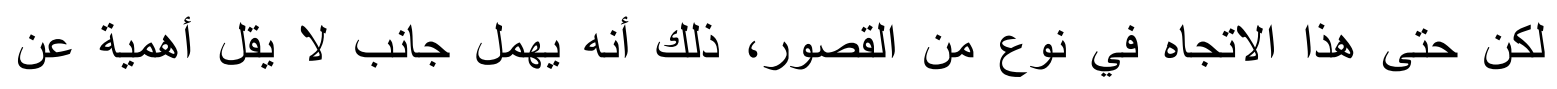

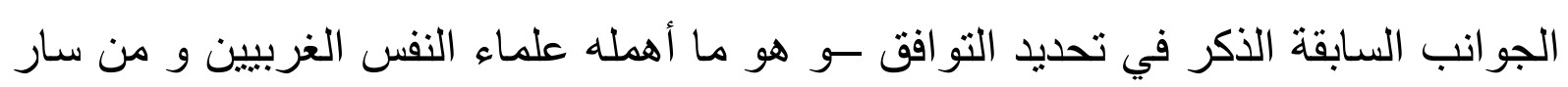

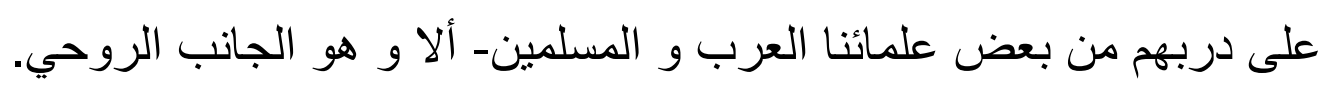

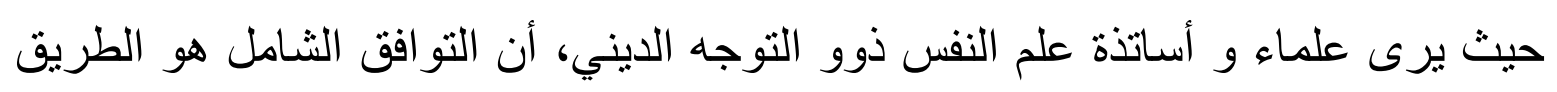

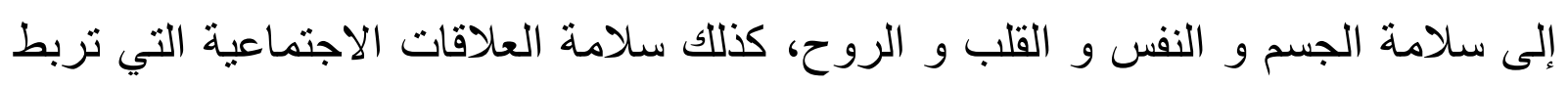
الفرد بالآخرين، و يتحقق ذلك بالتزام الفرد بالأخلاق الفاضلة و المعاملات السمحة في

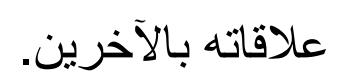
و عموما، فإنه مهما اختلفت تعاريف التو افق في اتجاهاتها فإنها تتكامل لتعطينا شرحا شاملا للتو افق، هذا الأخير الذي يحدث من خلال كل اتجاهات السلوك بالفرد الواحد.

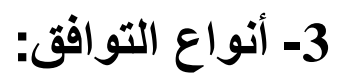


يشير (د. صلاح مرحاب) إلى وجود بعدين أساسيين للتوافق النفسي هما: التوافق

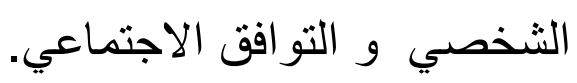

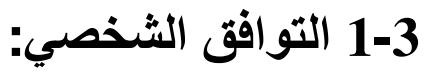

يتعلق بالتنظيم النفسي الذاتي، أي تنظيم العلاقات الداخلية الذاتية التي على أساسها يتحقق

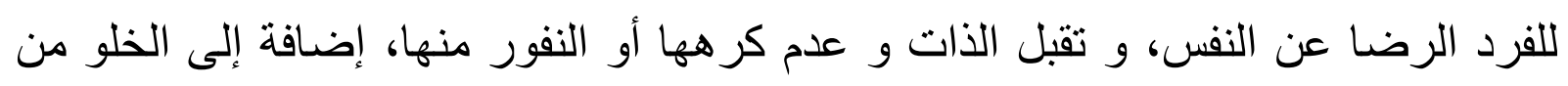

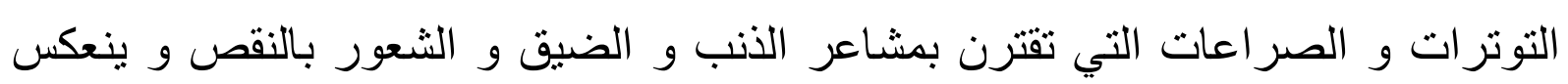

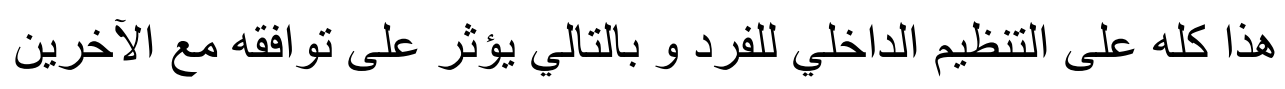

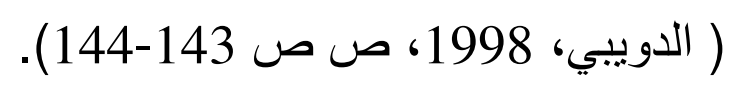

و يندرج تحت هذا النوع أبعاد أخرى كالتوافق العقلي و النوافق الترفيهي...الخ (أ.د.

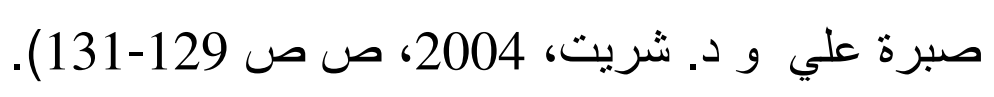

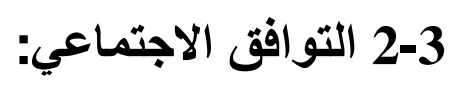

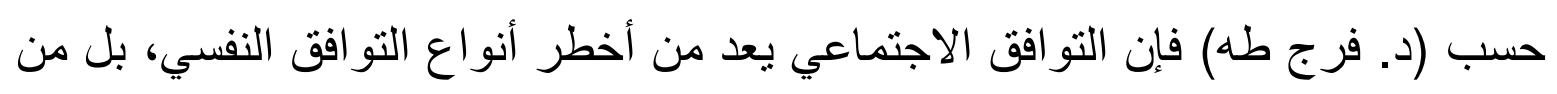

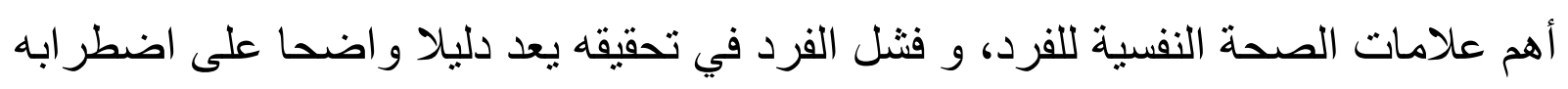
النفسي (د. فرج طه، 2003، 278).

و التو افق الاجتماعي هو تو افق الفرد مع بيئته المادية و الاجتماعية.

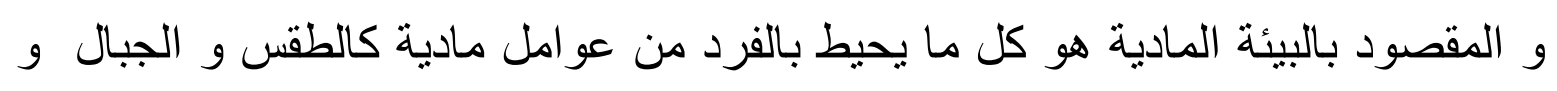
البحار و الأنهار و الأبنية و وسائل المواصلات و الأجهزة و و الآلات.

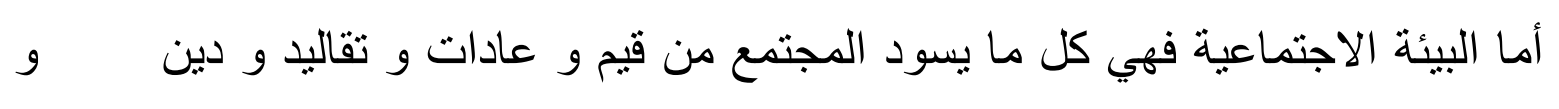

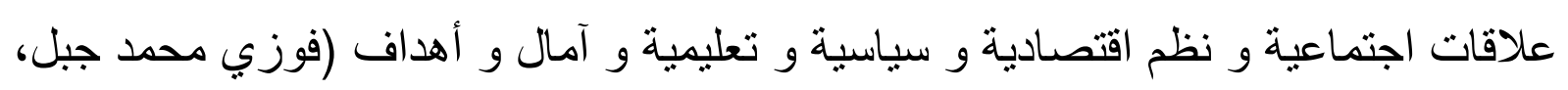

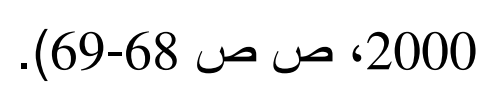

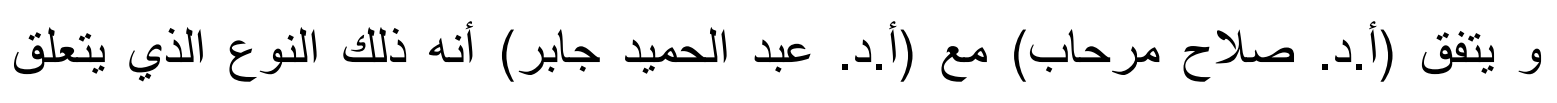
بطبيعة العلاقات مع الناس، و هو يتضمن: الاتزان الاجتماعي و الالتزام بأخلاقيات 
المجتمع و المعايير الاجتماعية، و قواعد الضبط و التغير الاجتماعي، بالإضافة إلى سهولة التفاعل و الاختلاط الاجتماعي...الخ.

و يندرج تحت هذا النوع أبعاد أخرى مثل: التوافق الأسري، الدراسي، المهني الاقتصادي الديني...الخ (أ.د. صبرة علي و د. شريت، 2004، ص ص التع 129-132).

4- العوامل الديناميكية في عملية التوافق: - حسب (ريثارد لازراس Richard .L، 1969) فإن العوامل التي تعوق تحقيق التو افق السوي تتلخص في ثلاثة عوامل هي: الإحباط " frustration " و الصراع " conflict"

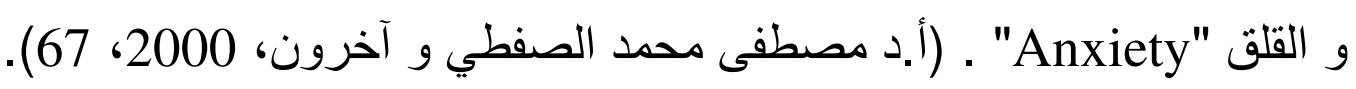

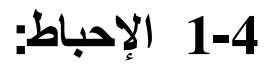
للإحباط مفهومان، الأول: أنه حالة وقتية من الثعور بالخيبة و الانزعاج بسبب عدم إثباع الدافع و الثناني: أنه حالة إيقاف الدافع و سد الدنافذ أمامه. (د. جنان الرحو، 2005 .(378

\section{1-1-4 تقسيم الإحباط: - 1-4}

إن هذا التقسيم يساعد على فهم طبيعة هذه العملية النفسية بصورة أوضح، و هو ينقسم

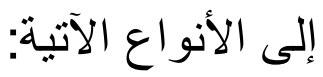

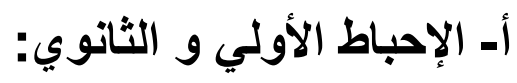

فرق (روزنزميخ) بين نوعي الإحباط الأولي و الثانوي، فاعتبر أن الإحباط الأولي يتضمن مجرد الثعور بعدم الارتباح نتيجة لرغبة في إنباع حاجة ما، مثلا: شعور الإنسان

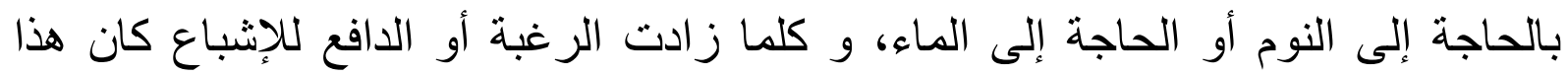

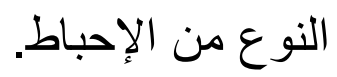
أما الإحباط الثانوي فيقصد به إدراك الفرد لوجود عائق خاص، يحول دون إنثباع حاجة

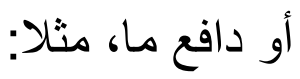


في حالة الثخص الذي يشعر بالحاجة إلى النوم و يفاجئ بوجود عائق معين يحول دون ذهابه إلى الفراش (كحظور زوار إلى المنزل في المساء دون مو عد مسبق) فإن ذلك يعتبر إحباطا ثانويا (أ.د. نبيه إسماعيل، 2001، ص صن صن رئ 174-175).

\section{ب- الإحباط السلبي و الإيجابي:}

قسم (روزنزميخ) المواقف الإحباطية إلى مواقف سلبية و أخرى إيجابية، حيث اعتبر أن الإحباط السلبي (passive)، يقصد به ما يحدث من عوائق في سبيل التقدم نحو هدف معين، دون أن يصحب هذا العائق أي نوع من التهديد، و مثال ذلك: شخص يركب سيارته ليتنزه بها في يوم جميل مشرق و فجأة تتعطل السيارة. ـ أما العو امل الإحباطية الإيجابية فهي تتضمن إدراك الخطر أو التهديد بجانب وجود عائق يحول دون إثنباع الدو افع، و مثال ذلك: رغبة الثاب في إنثباع الدافع الجنسي و ليس لديه الإمكانات التي تحقق الإشباع المشروع، و إذا أقبل على إثباعه بطرق غير مشروعة حرمها الله تعالى كان التهديد بعذاب الضمير (مرجع سابق، 2001، 175). ج- الإحباطات الخارجية و الاخلية (environmental personal.F): يشير (كولمان) إلى أن هناك نوعين من الإحباط: الخارجي External و الداخلي

:Eternal

- الإحباط الخارجي: Environmental. F: و يرجع هذا النوع من الإحباط إلى العقبات البيئية: طبيعة كانت أم اجتماعية، تعوق إرضاء حاجات الفرد و رغباته و آماله، فالقحطو الفقر و الكوارث الطبيعية كالز لازل و و و العو اصف و كذلك الحروب، تعتبر أمثلة خارجية مثيرة للإحباط، أو مصادر للتهديد في البيئة الطبيعية التي يحيا فيها الإنسان، و قد تتمثل العقبات الاجتماعية في التنظيمات المختلفة كضوابط السلوك و في العقاب الذي يلحق من يخالفها، و العقاب بالنسبة للفرد في هذه الحالة يعتبر من العوامل المثيرة للإحباط. كل هذه الظروف تمثل مصادر للضغوط النفسية و التنازمات عند الكثير منا، و مما يجدر ذكره في هذا الصدد أن العقبات الخارجية ليست في ذاتها مصادر للإحباط و الضيق عند 
جميع الناس، بل يتوقف تأثير ها على وقوعها و صداها في النفوس المختلفة، فالبؤس في

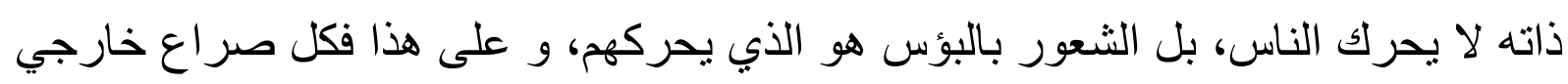
لا يكون له أثر ضار إلى حين ينقلب إلى صر اع داخلي نفسي (د. مجدي عبد الله، 1998،

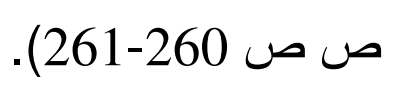

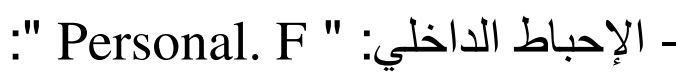

و يرجع هذا النوع من الإحباط أو التأزم النفسي إلى المحددات الثخصية، نفسية كانت أم جسمية أم عقلية، و تأخذ مظاهر النقص العضوي (شذوذ في شكل الجسم)، القدرة غير القار الفير الكافية (انخفاض الذكاء العام)، نقص الجاذبية الاجتماعية للثخص لـأ..الخ، ضروب منتاينة

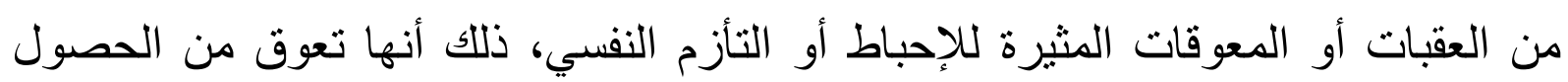

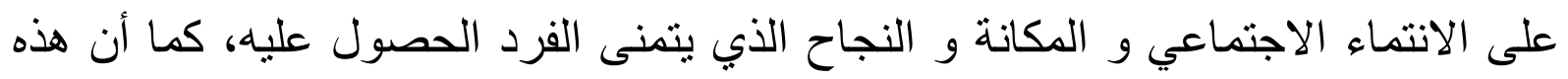

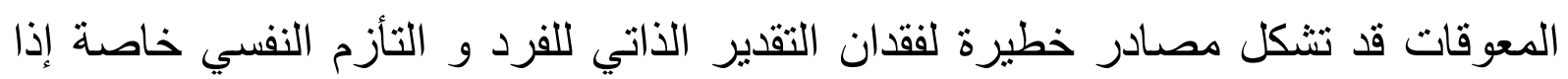
كان الإحباط ناشئا عن تعارض بين دوافع الفرد المختلفة و الضوابط الو اقعية و الأخلاقية

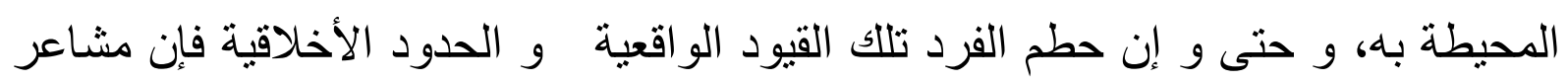
الذنب و الثعور بالتأزم الذاتي هي التي تتبع هذا السلوك في العادة. أيضا قد تعتبر الظروف البيولوجية كالتعب و المرض من العوامل المثيرة للإحباط

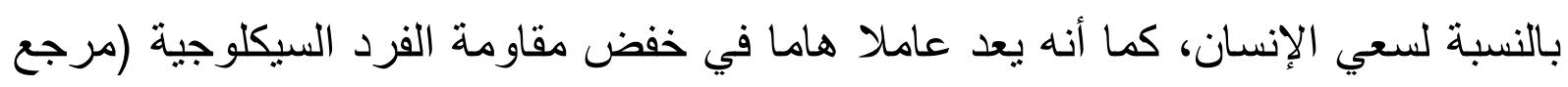

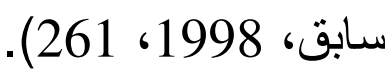

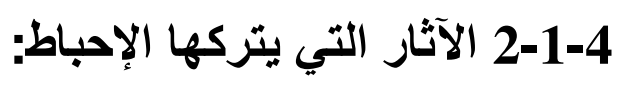

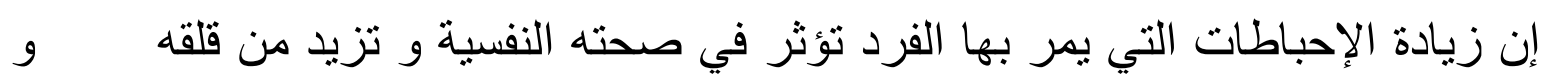

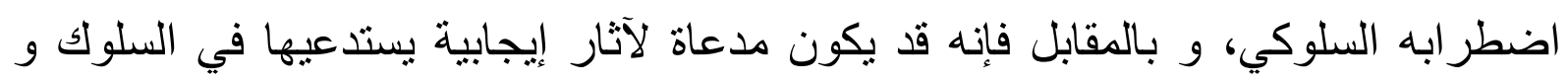

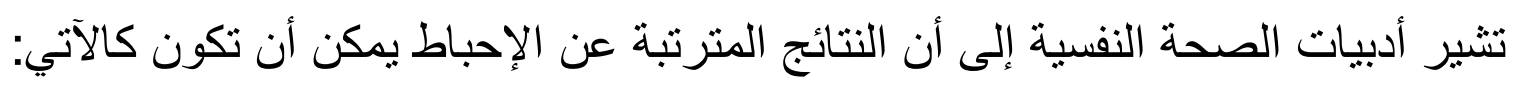

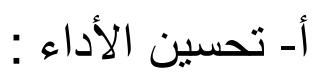

و يحدث خاصة في المو اقف التي يكون فيها الإحباط ضعيفا، فوجود عائق في سبيل

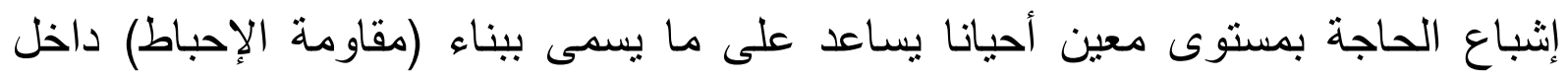
الفرد، و هذه المقاومة تؤدي إلى ما يلي: 


\section{- زيادة في المجهود.}

- زيادة في المرونة و التتويع في الوسائل المستخدمة في الوصول إلى الهدف. - استبدال و تغيير الهدف إذا لم يستطع الوصول إليه بالوسائل التي يمتلكها. و هذه الأخيرة تدخل ضمن أساليب التوافق المباشرة (د. عبد الحميد شاذلي، 1999، 93).

$$
\text { ب- العدوان (السلوك العدو اني): }
$$

رغم أن السلوك العدواني بتطلب الكثير من التشخيص، إلا أنه من الملاحظ أن ظهوره مرتبط و في حالات عديدة مع المواقف الإحباطية خاصة عندما يكون الإحباط شديدا، إن التفسير المحتمل للسلوك العدواني الذي يعقب الإحباط، هو أن الفرد بعد حالة الإحباط تعتريه حالة من الخيبة نولد لديه غضبا شديدا يليه السلوك العدائي، هذا الأخير الذي بوجهه الفرد نحو البيئة المحيطة به المادية أو الاجتماعية، أو يرتد العدوان على الفرد نفسه و هذا ما يتسبب له في العديد من المشاكل التي تسرع ظهور الاضطر ابات النفسية لديه.

$$
\text { ج- النكوص أو الارتداد: }
$$

و قد يحدث النكوص كاستجابة مباشرة للإحباط، و هو حيلة دفاعية لا شعورية يعود بها الفرد إلى أساليب و طرق كانت في الماضي فاعلة في إثباع الحاجات و مواجهة المشكلات، مثلا: حينما يواجه الكبار إحباطاتهم بالبكاء، هذه الاستجابة التي كانت وسيلة فعالة في الطفولة لأن تسرع الأم و تلبي حاجيات الطفل. د- التبلد:

و هو حالة من الذهول و اللامبالاة و تناقص العدوان تماما، حيث لا تبد و على وجه الثخص المتبلد أبي من الملامح الانفعالية التي تعبر عن حالة الإحباط التي يعيشها و. و يحدث في حالات المرض و الإرهاق و الانتظار الطويل و اليأس من الأمل. هـ التخيل (أحلام اليقظة): حيث يهرب الفرد الذي أحبط تحقيق غاياته إلى عالم الخيال ليجد فيه مبنغاه، و قد تبدو أحلام اليقظة للوهلة الأولى مقبولة إذا كانت تحت التحكم الثعوري الواعي المعتدل، أما إذا تعدى ذللك فإنها ستكون ضمن الإطار المرضي (د. جنان الرحو، 2005، ص ص 387- 


\section{:" Conflict " 2-4 الصراع}

هو حالة نفسية مؤلمة نشأ نتيجة تعارض دافعين أو أكثر لا يمكن إثباعها في وقت واحد،

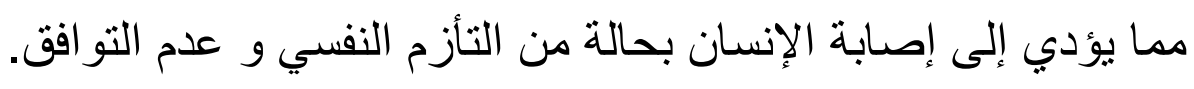
و يحدث الصراع نتيجة تعارض رغبات الفرد و معايير المجتمع التي تقع حائلا دون التهان

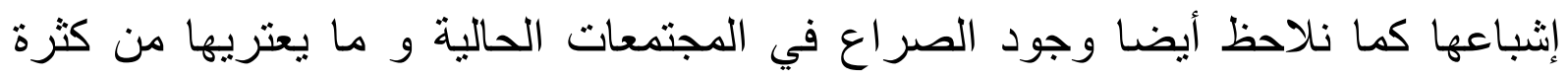

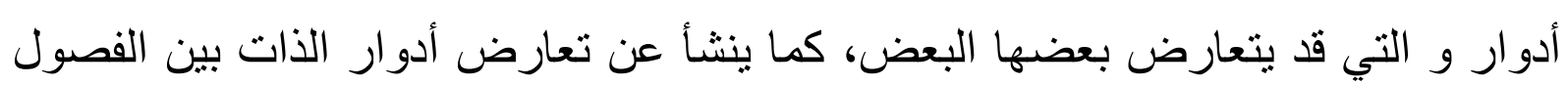

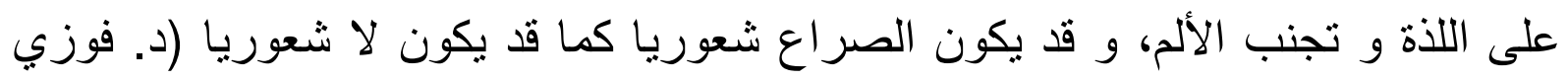
جبل، 2000، 23).

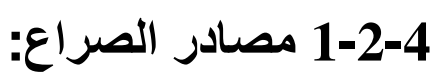
للصراع مصادر قد تكون خارجية كعقبة مادية أو اجتماعية أو جسمية تعوق إرضاء الفرد لدو افعها و تحقيق مطامحه. أو تكون هذه الدصادر داخلية ذاتية ترجع لدو افع الفرد التي تريد أن تثبع و يكون منها

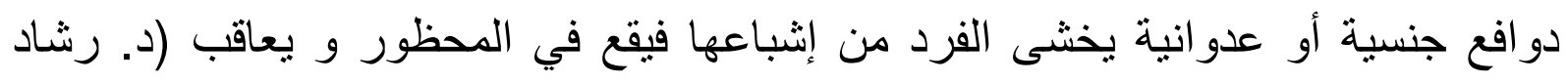
دمنهوري و د. عباس عوض، 2003، 378 378). 2-2-4 أنواع الصراع: 2-2 قسم (ليفين) الصر اع إلى ثلاثة أنواع هي: أ- صر اع إقدام - إقدام (Approach- A conflict): في هذا النوع يو اجه الفرد موقفين متعادلين من حيث الصفات التي تجذبه نحو كل منهما،

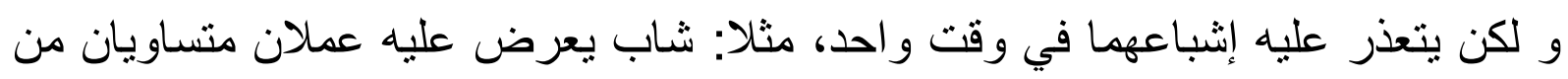

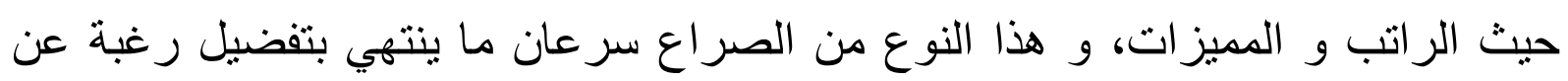

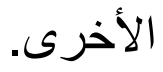

ب- صراع إقدام -إحجام (Approach - Avoidance.C): 
و ينشأ هذا الصراع نتيجة وجود رغبتين متعارضتين إحداهما موجبة و الأخرى سالبة

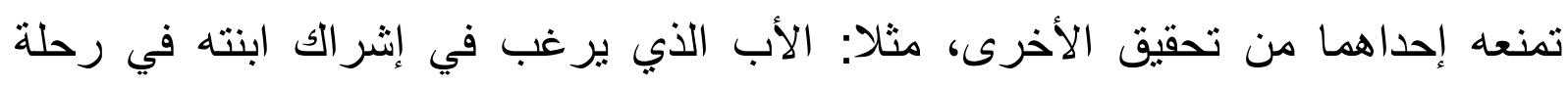

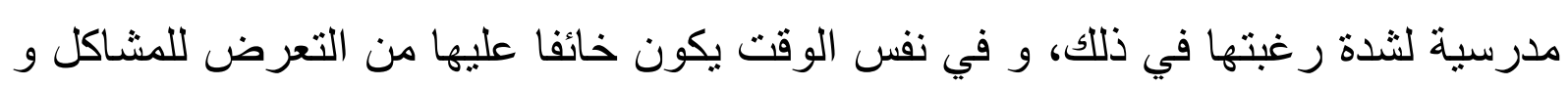

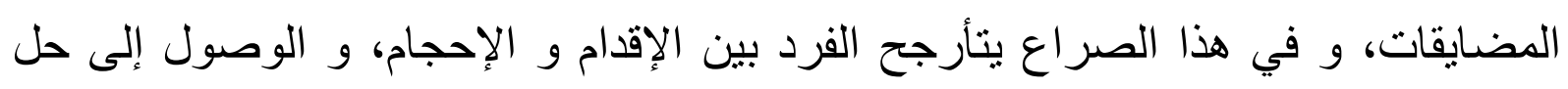

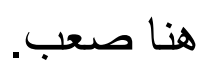

ج- صراع إحجام - إحجام (Avoidance .a.C):

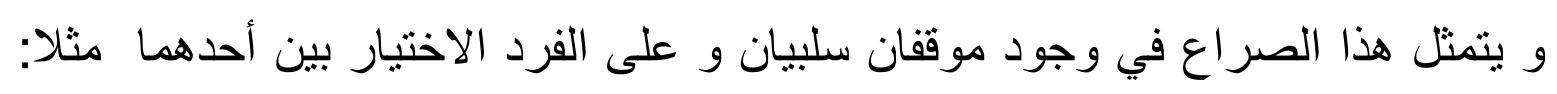

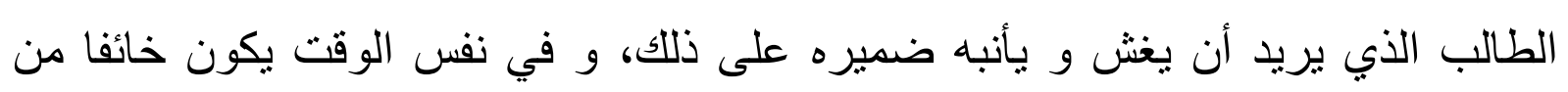

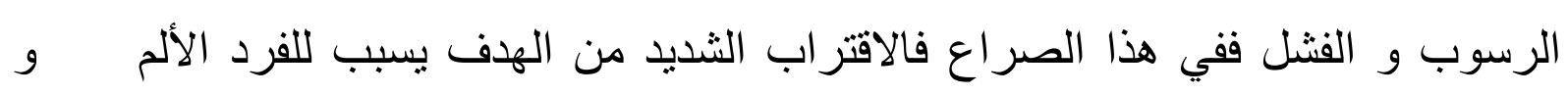

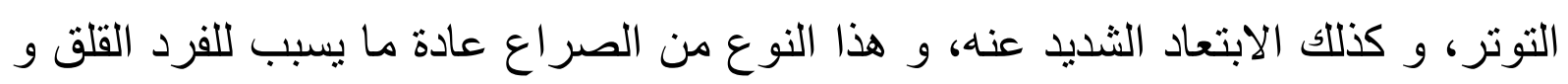

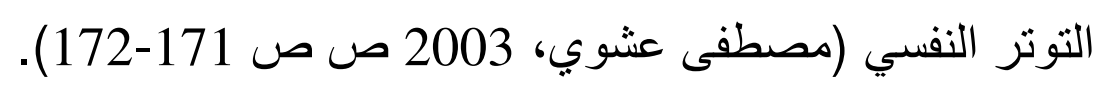

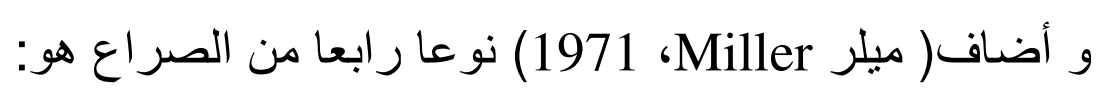
د- صر اع إقدام - إحجام مزدوج:

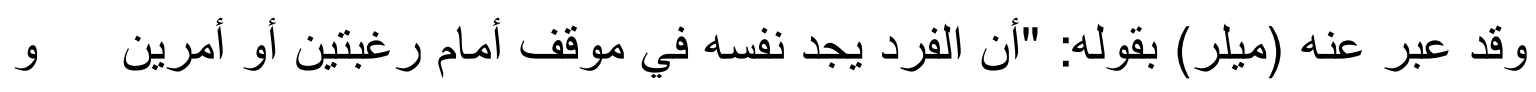

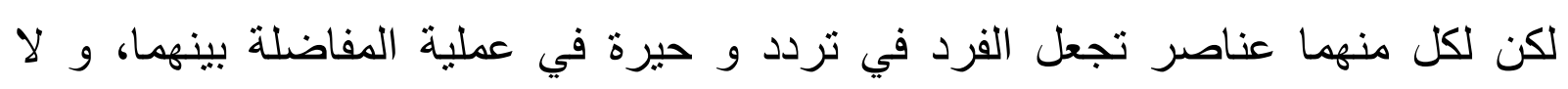

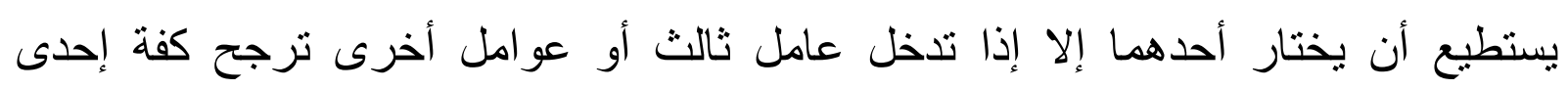

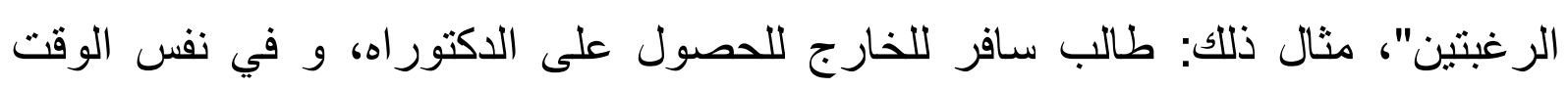

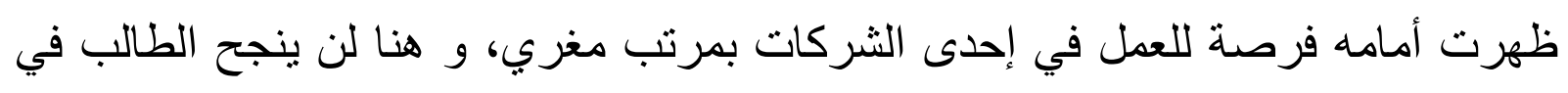
اختبار أحدا الأمرين إلا إذا قارن مزايا كل منهما و بالتالي يرجح كفة أحد الخيارين الأكثر

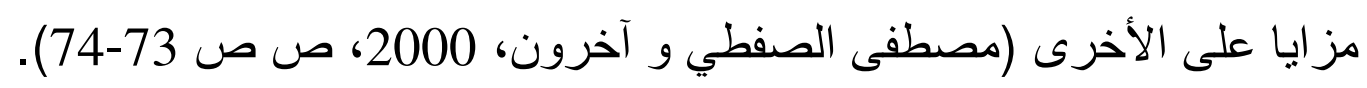

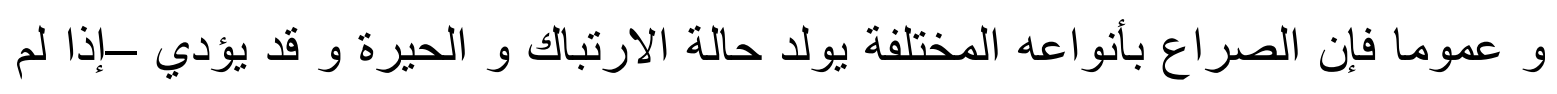

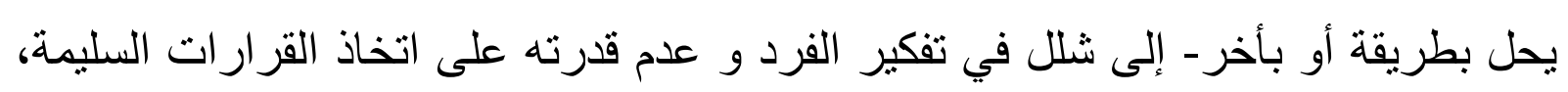
و بالتالي تؤثر في نو افقه و تحول دون تحقيق صحته النفسية. 
و يجب الإشارة إلى أنه هناك علاقة أكيدة بين الصراع و الإحباط، فالإحباط -كما ذكرنا سابقا- وجود عقبة تحول دون إثباع دافع واحد، أما الصراع فهو التعارض بين إثباع دافعين قد يكون أحد دوافع الإحباط واحد منهما (فوزي جبل، 2000، ص ص 87-88).

\section{(Anxietily) (القلق (1)-4} يعرف (نجاتي، 1983): القلق بأنه: "حالة من الخوف الغامض الثديد الذي يتملك الإنسان

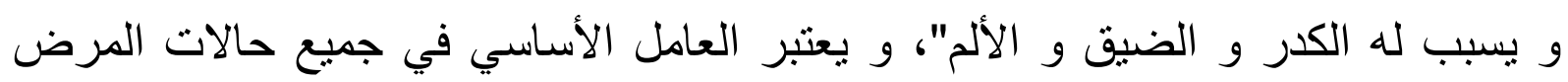
النفسي (د. أشرف شريت و د. محمد حلاوة، 2003، 141).

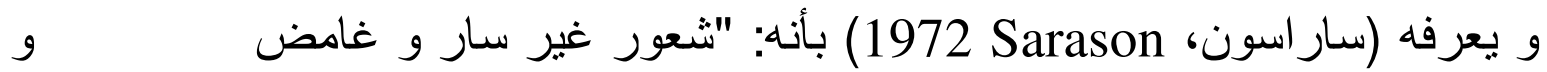
مصحوب بالخوف و توقع الثر، و الثخص الذي يعاني من القلق الحاد تظهر عليه مجموعة من الأعراض العضوية كزيادة ضربات القلب، ضيق التنفس، الإسهال...الخ (مصطفى الصفطي و آخرون، 2000، 75). و يقسم القلق حسب فرويد تبعا لمصدره أو طبقا لتصرفات الأنا مع العناصر الثلاثة التالية (العالم الخارجي، ليبيدو الأنا، قوة الأنا الأعلى) إلى ما يلي: 1-3-4 القلق الموضوعي أو الواقعي: و هو يحدث إزاء خطر خارجي يشكل تهديدا واقعيا للثخص ( جان لابلانش و جاك بونتاليس 1997، 412)، و بالإضافة إلى ذلك التهديد الفعلي فإن ذكريات الأنا للخبرات السابقة تجعلها تستجيب بالقلق لكل خطر مستقبل، و مثال ذلك: استجابة البحار الذي لديه معرفة بسحابة داكنة تلوح في الأفق (بالقلق) لمعرفته المسبقة بأن وصولها سوف يتبعه زوبعة، و مثل هذا القلق يجعل الفرد يأخذ حيطته و حذره من الخطر الذي يهدده، فإما يهرب أو يدافع عن نفسه (د. محمد السيد عبد الرحمن، 2001 91). 
يرتبط هذا القلق عادة بأحداث الطفولة المؤلمة التي تكون ناجمة إما عن التعرض لسوء المعاملة أو القسوة في العقاب أو غير ذلك من الأسباب التي تؤدي إلى ظهور هذا النوع من بن

إن التهديد الموجود في القلق العصابي عادة ما يظهر في موضوع اختيار غريزي للهو، فيخاف الثخص من أثياء تصييه أو وقائع تحل به فلا يستطيع التحكم فيها. 3-3-4 - 3 القلق الخلقي: يحدث بسبب رغبات و أفعال تتجاوز مستويات الفرد عن الصواب و الخطأ و يناقثها الأنا الأعلى في الخفاء، مما ينشأ عنها الإحساس بالخجل أو الذنب، أو بعبارة أخرى يحدث القلق الخلقي عندما تتجاوز رغبات الفرد أو أفعاله مستوى حكمه الخلقي بالصواب أو الخطأ بأل الخاء فيعاقب الأنا الأعلى الأناو ينشأ عن ذلك الإحساس بالخجل و الذنب (عذاب الضمير). و قد يتداخل القلق العصابي مع القلق الخلقي فالفرق يكمن أساسا في درجة الضبط الذي يصدر عن الأنا، و كثير ا ما يكون الفرد في القلق الخلقي عقلانيا و قادر ا على التفكير في

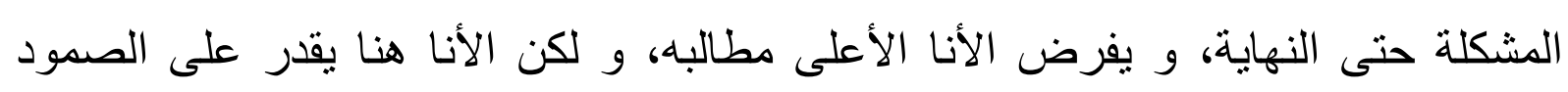

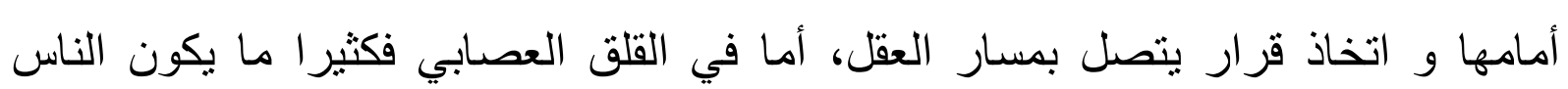
يائسين بل أحيانا في فزع، و لا يستطيعون معه التفكير بوضوح (مرجع سابق 2001، ص صل ص (92-91). (19). (19)

و قد يؤدي القلق في بعض الحالات غاية هامة منمثلة في إعطاء إثنارة تحذيرية للأنا بهذف تجنيب الشخص خطر ما. و يعد القلق المصاحب للثدائد و الإحباط هو أصل معظم الآليات الدفاعية، هذه الأخيرة التي تعد وسائل وقائية ـإذا تم استعمالها في حدود المعقول- تنقذ الفرد من حالة الإحباط و تختزل بذلك حدة التوتر و تحقق الراحة النفسية الوقتية.

5- الآليات النفسية الدفاعية (الحيل الافاعية): هذه الحيل تعد شكلا من أشكال التوافق غير المباثرة، و يمكن تصنيف صور التوافق

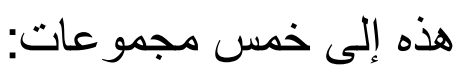


أ- التو افق باستخدام أساليب إعتدائية مثل: العدوان، الإسقاط. ب- التو افق باستخدام أساليب دفاعية مثل: التبرير، التقصص و التعويض الزائد.

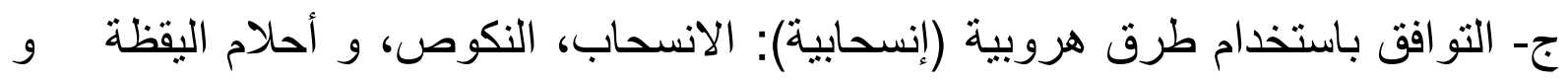

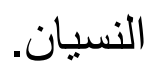

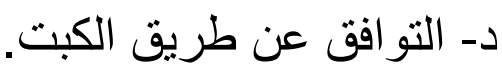
هـ- التو افق عن طريق المرض و الأوجاع البدنية. و تهدف هذه الحيل الدفاعية إلى ما يلي:

ـ الوصول إلى نوع من النوازن بين الدو افع أو الحاجات الدستحيل تحقيقها أو غير المقبولة اجتماعياو بين الدو افع المضادة من معايير أخلاقية و تقاليد...

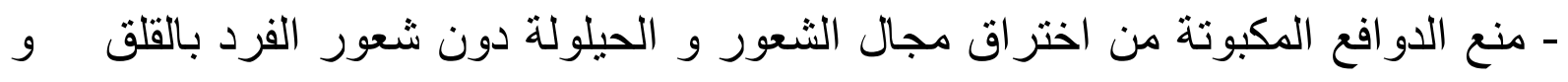

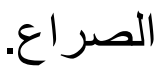
- تحقيق التوازن العاطفي و الثبات الانفعالي و الثُعور بالأمن.

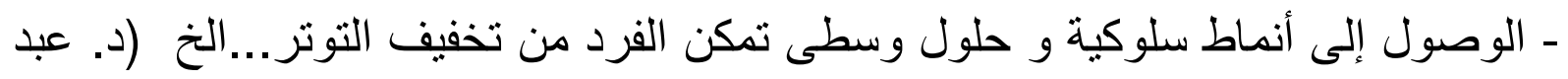

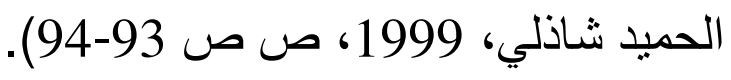
إلا أن الإسراف في استخدام هذه الآليات قد يؤدي إلى: - إعاقة النمو النفسي للفرد و ذلك بحجر ها على طاقات الفرد النفسية و تعطبلها، فإذا نجحت هذه الحيل و صارت ذات أثر فعال في خفض القلق و التوتر و استمرت في سيطرتها و استبدادها على (الأنا) فإنها تنقص من مرونة الفرد في التو افق.

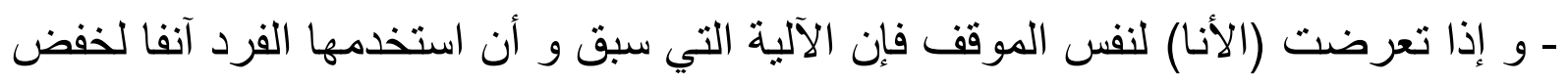

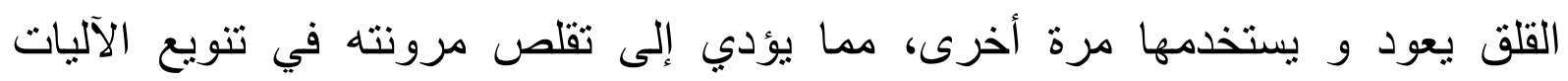

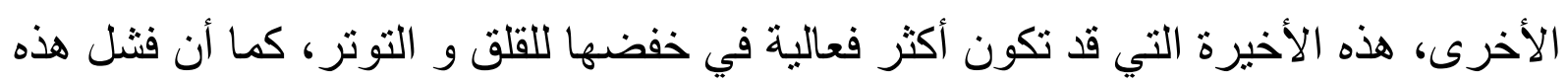
الآليات في خفض التوتر يؤدي إلى وقوع الفرد في عو ائق الانهيار العصبي. - إن هذه الآليات تستنفذ طاقة هائلة من (الأنا)، إذ أن هذه الآليات لا تستهدف حل الأل الأزمة الأل

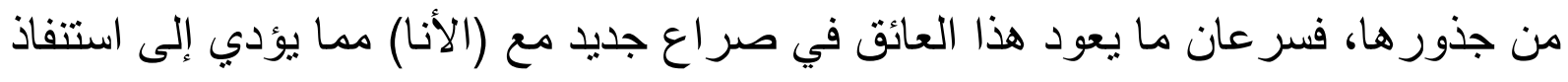

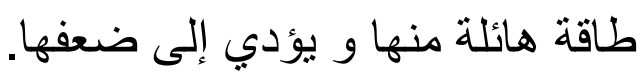


إن هذه الآليات -معظمها- حيل لا شعورية تجعل الفرد طيلة استخدامها يعيش في اللاشعور باستغراق مما يؤدي إلى تفكك الثخصية أحيانا نتيجة الإسراف و الاستغراق في

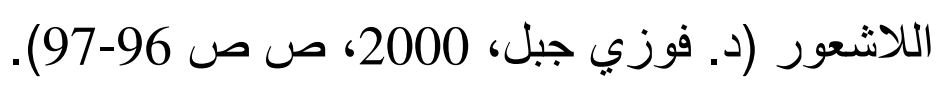

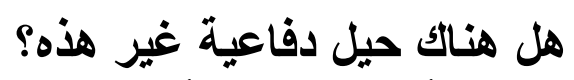
الحقيقة أنه ثبت من الأبحاث التي أجريت في مجال علم النفس، أن الأفراد قد يلجؤون إلى

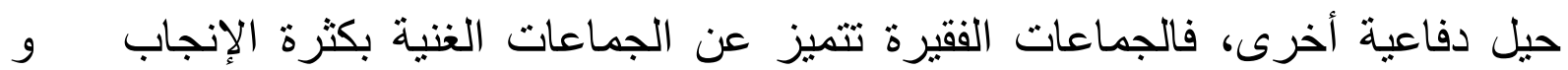
الإسر اف في الجنس ذلك أن الجماعات الغنية يمكن أن تتخلص من الأزمات و من القلق و

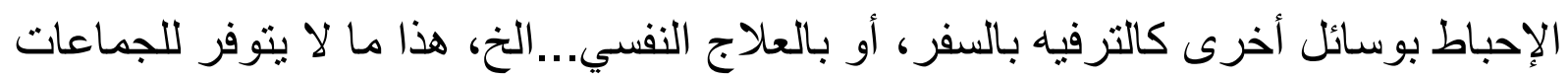

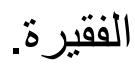
و الفرد المحروم من العطف قد يسرف في الطعام ليتخفف مما يعانيه من قلق و توتر و قد يأخذ الفرد في الإفراط في التنخين أو قضم أظافره أو النوم، كل هذا تخففا من القلق (د. رشاد دمنهوري و د. عباس عوض، 2003، 400). و كل هذه إنما هي حيل دفاعية تو افقية تتم على المستوى اللاشعوري.

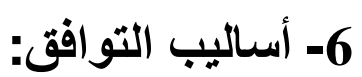
من أجل التكيف لمواقف الحياة، يستخدم الأفراد أساليب تو افقية مختلفة، عندما تجابهه

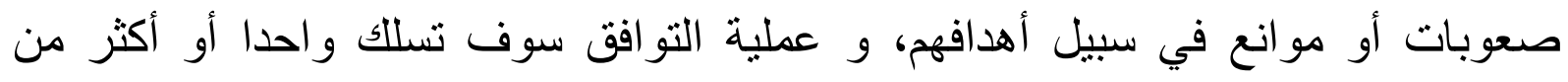

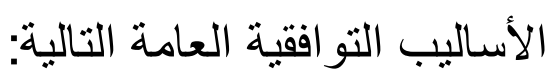

\section{-1-6- المعالجة أو المواجهة المباشرة:}

كأن يشرع الطالب الذي لايه امتحان صعب في الاستذكار، و محاولة فهم الأجزاء المطلوبة منه و حفظها أو مناقثتها مع الآخرين من رفاقه.

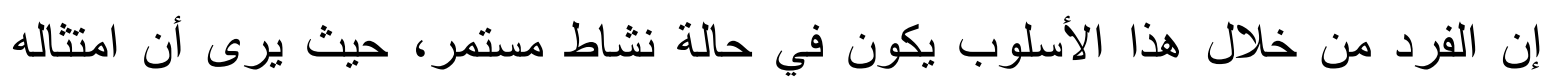

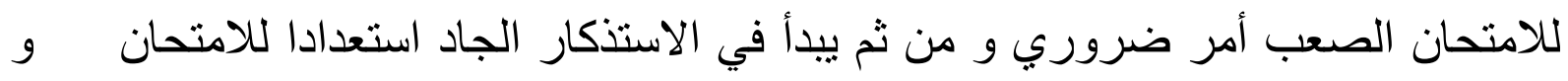


بذلك يتغلب على الصعوبة التي واجهته، و هذا في حد ذاته ينمي قدرته على مواجهة

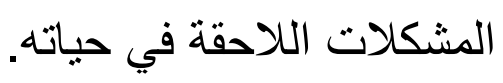

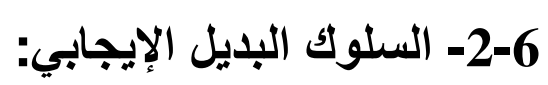

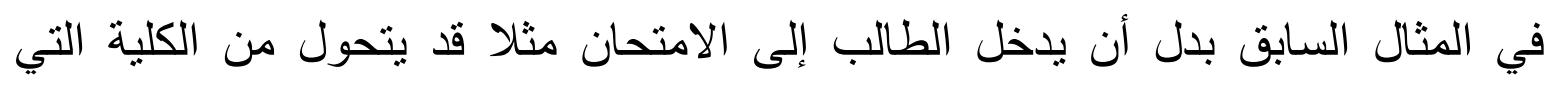

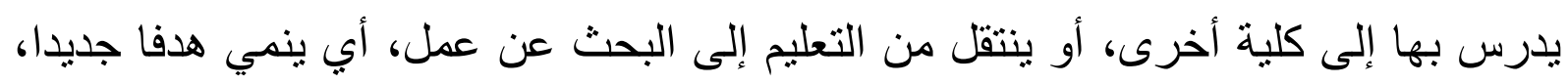
و بالتالي فإن شعوره بأهمية الذات قد ييقى و قد لا ييقى، و يعتمد ذلك على ددى التى ارتباط

هدفه الأصلي بنماذج انفعالية سارة.

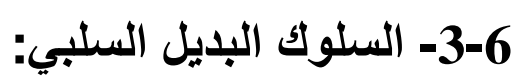
كأن يرتب الطالب لنفسه مكانا في قاعة الامتحان، بجوار طالب مجتهز يساعده أثناء

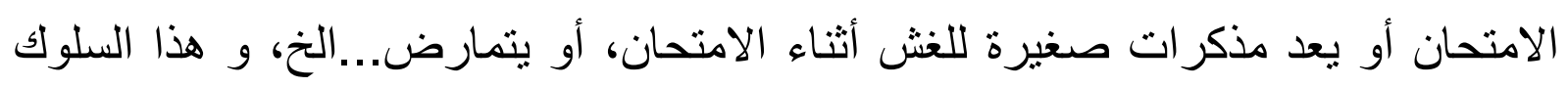

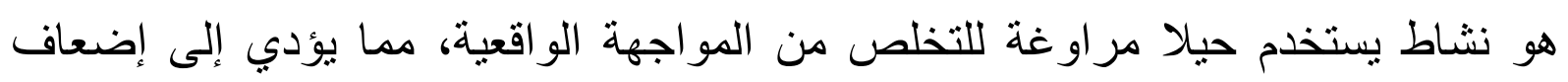

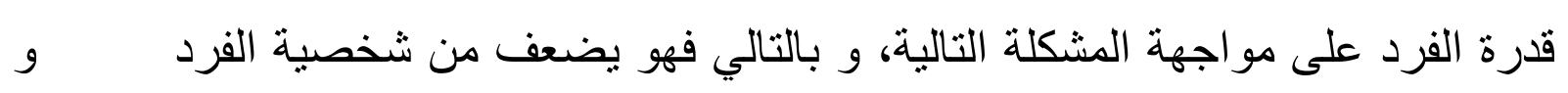
نستمر قدرة الفرد على مواجهة المشكلات في المستقبل بالتتاقص، و يصير أسلوبه غير متكامل، كما أن هذا الأسلوب يقلل الثعور بأهية الذات. 4-6-6 مراحل متقدمة من الأساليب التوافقية الثاذة:

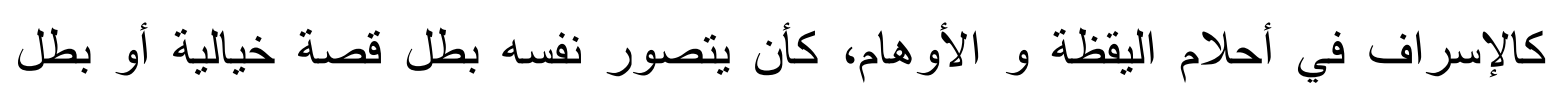

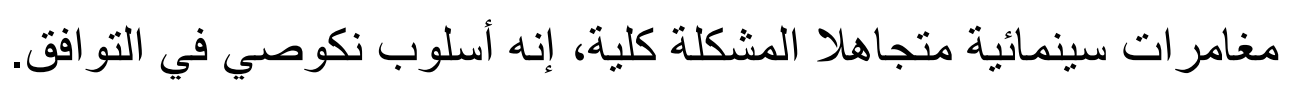

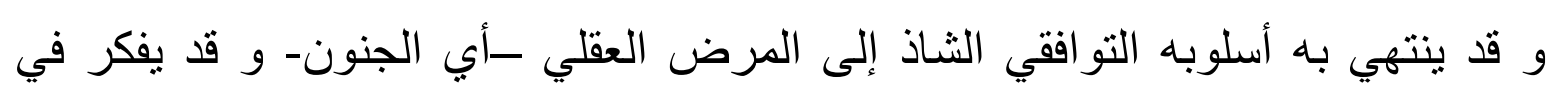

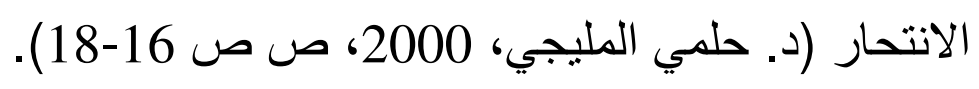

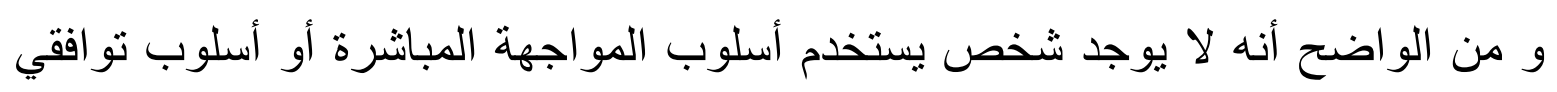
بديل ذكي في كل وقت، فكل شخص يستخدم أسلوب المراوغة و التقهقر في بعض الأحيان،

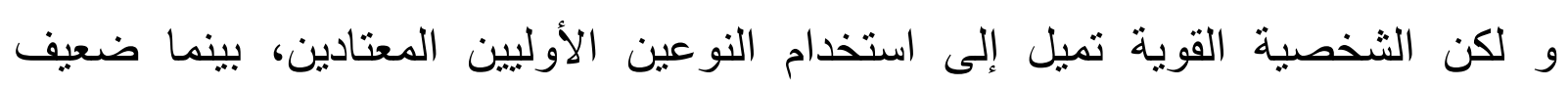

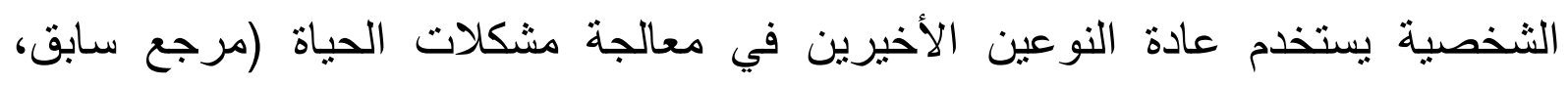
.20، 2000 
و عموما فإنه بناء على العادة التو افقية التي تستقر لدى الفرد فإنه في كل مرة يعالج فيها مشكلة كبيرة أو صغيرة، يسهم فيها في تقوية كفاعته الشخصية أو إضعافها. 7- الاستجابات العصابية و الذهانية كأساليب للتوافق الثاذ: عندما يو اجه الإنسان مشكلة فإنه توجد ثلاث احتمالات للسلوك السوي: (إقدام، إحجام، أو إرجاء الاستجابة) بمعنى الانتظار حتى تتضح عناصر الموقف. و في الحالات الثناث يكون سلوك الفرد مصحوبا بالروية و التفكير، و تغلب جانب العقل على جانب الانفعال، و تثتاسب الاستجابة مع مثير اتها، أما إذا كانت استجابة الفرد مبالغا فيها من حيث الزيادة أو النقصان، و تجاوزت حدود الاعتدال، و لا تتناسب مع درجة الإثارة، أو إذا كانت مصحوبة بشحنة انفعالية حادة، فإن سلوك الفرد يوصف في هذه الحالة بالثذوذ، و ينطبق هذا الثذوذ على الاحتمالات الثلاثة السابقة و بذلك تتحول إلى الأساليب الثناذة التالية:

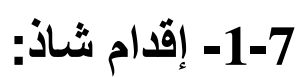
و هو الذي يتخذ شكل الاعتداء و التجني نحو الآخرين و العالم الخارجي، و يكون مصحوبا بانفعال الغضب بصفة خاصة، و يؤدي هذا السلوك إلى الاصطدام بالمجتمع و و القانون لما له من آثار تخريبية و تمرد على السلطة، و يبدو هذا الأسلوب بوضوح في أعر اض "الهوس" بدرجاته المختلفة. 2-7 - - 2-7 إحجام شـاذ: و يتميز هذا الأسلوب من التوافق الثـاذ بالنكوص و الانطواء و التقهر ، و الانصراف كلية عن المشكلة تجنبا للفشل، بل و الانسحاب أيضا من العالم الخارجي، و يكون مصحوبا عادة بانفعال الخوف و خاصة الخوف من الفشل، و يتضح هذا الأسلوب الثشاذ في مرض

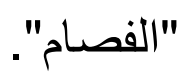
3-7-7 انتظار شاذ: إذا تجاوز الانتظار الحدود المناسبة و أصبح إرجاء الاستجابة مبالغا فيه، فإن سلوك الثخص يتخذ شكل التردد الثاذ، الذي يعني الفثل كلية في تحقيق التوافق، فيتناوب الفرد 
حالات انفعالية متعددة مثل: القلق، اليأس، الغيظ، الخوف، و الغضب، كما يصاب بالتعب و الخور، و يتضح هذا الأسلوب في مرض "القلق و الأفكار الوسواسية".

4-7-7 الاستعطاف الثاذ: و هو أسلوب يتوسط الإقدام الثناذ و الإحجام الثناذ، يهدف إلى حل المشكلة بطريقة رمزية، أو يتصنع عرض مرضي مؤثر بطريقة غالبا لا شعورية حتى تخلصده من مأزق إق حرج لا يقوى على احتماله كما تحدث في نوبات الإغماء الهستيري أو الثلل الهـتيري للذراع أو الساق مثلا، و يرمي الفرد في ذلك إلى لفت الأنظار و جذب اهتمام الآخرين. و يتجلى هذا الأسلوب التو افقي الثاذ في أعر اض "الهستيريا التحويلية". إن الاستجابات التوافقية الثناذة، قد تأخذ أثكال أعراض مرضية، سواء كانت أمراض اض عصابية أي نفسية أو أمر اض عقلية (د. حلمي المليجي، 2000، ص ص 25-26). 8- الاتجاهات الأساسية في تفسير التوافق: يتضح في الدراسات السيكولوجية المختلفة التي تناولت بالدراسة و البحث موضوعات التكيف النفسي و التو افق على أنه هناك مقاربات ( Approches ) متعددة بمكن بها تفسير التوافق و سوء التوافق، على أساس أنه متصل كمي ( Continium ) يحتل الأفراد مو اضع مختلفة عليه تمثل تو افقهم أو عدم تو افقهم، و من أهم هذه المقاربات ما يلي: 1-8 - المقاربة الفيسيولوجية: تعتمد هذه المقاربة على أنه (الصحة الجسمية) تعني التوافق التام بين الوظائف الجسمية المختلفة مع القدرة على مواجهة الصعوبات العادية المحيطة بالإنسان، مع الإحساس الإيجابي بالنشاطو القوة و الحيوية، و يقصد بالتو افق في ضوء هذا التفسير، أن تكون هذه

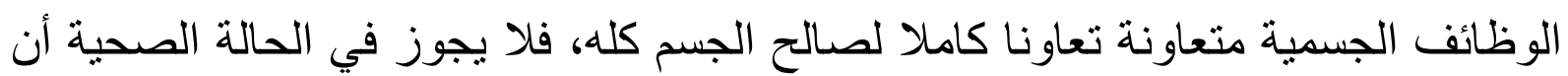
يقوم عضو من الجسم بنشاط أكبر أو أقل مما يتطلبه الجسم كله، و إلا نشأت حالة مرضية أو عدم نو افق، تختلف في شدتها و مدة بقائها باختلاف نوعها و ظروفها، فإذا زاد أو قل هُ هُ نشاط غدة في الفرد و ما يتطلبه الجسم كله كوحدة أدى ذلك إلى حالة مرضية أو سوء توافق (عدم تكيف) ( مجدي عبد الله، 2003، ص ص 253-254). 
و تعتمد هذه المقاربة على أن الصحة النفسية تعني التو افق التام أو التكامل بين الوظائف

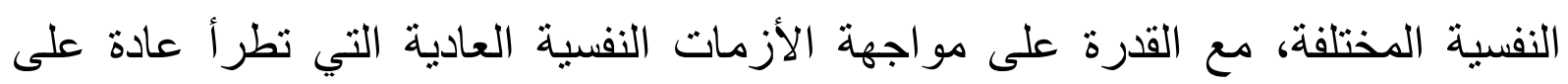
الإنسان مع الإحساس الإيجابي بالسعادة و الكفاية.

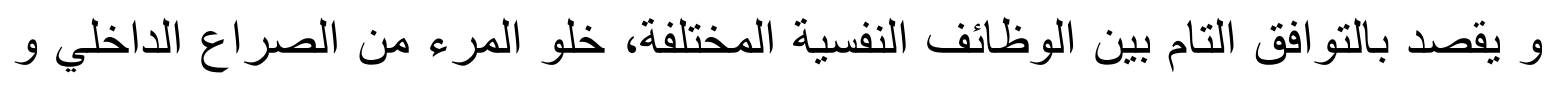
توفر الاتزان و التوافق بين الفرد و بيئته، و كذلك بين الوظائف النفسية لدى الفرد. و وظيفة الحياة النفسية لمختلف عناصر ها هي تكيف الفرد لظروف البيئة الاجتماعية و ولئونئ المادية و غايتها تحقيق حاجات الإنسان، و هي تتحقق عادة بالتفاعل مع البيئة و هذه البيئة متغيرة. و هذا التغير يثير مشكلات يقابلها الإنسان في مجال التفكير و الانفعال و مختلف أنواع السلوك و لكن التغيرات التي تحدث قد تككن شديدة لدرجة تتجاوز الحد الذي يقوى عليه الفرد لمقاومته و التكيف له و هنا تتشأ الحالات المرضية، و لهذا لابد من تعاون الوظائف النفسية المختلفة، و لابد من تقويتها لمقاومة التغير ات العادية. أما عن القطب الآخر للتوافق في ضوء التفسير النفسي و هو قطب عدم التوافق، فإنه يمكن تفسيره على أساس أن عدم التوافق يرجع إلى الإحباط و الصراع سواء أكان هذاء

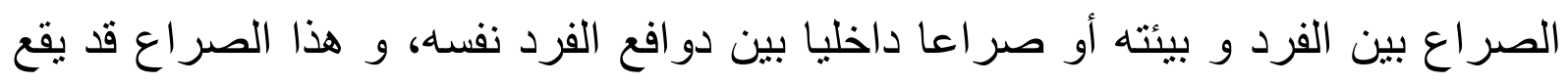
عائقا في سبيل وصول الفرد إلى الكفاية و السعادة و أيضا للمجتمع الذي يعيش في كنفه (مرجع سابق، 2003، 254).

\section{3-8 - المقاربة الثقافية الاجتماعية:}

وجد أن هنالك علاقة بين الثقافة و أنماط التو افق، فلقد ثبت أن هناك اختلافا في الاتجاه نحو الخمور بين اليابانيين و الأمريكيين، كذلك وجدت فروق في الأعر اض الإكلنيكية بين الأمريكيين و الإيطاليين و بين الأمريكيين و الايرلنديين (د. مدحت عبد اللطيف، 1990

و يعتمد هذا المدخل على أن الشخصية المتكاملة، هي الثخصية التي لا يظهر عليها تتاقض أو صراع أو عدم اتساق، و يجب الإشارة إلى أن التكامل بالنسبة للشخصية يعتبر مسألة درجة لا يمكن أن يتحقق في الو اقع بصورة كاملة. 
و عندما نتعرض لدراسة التوافق في ضوء هذا المدخل، فيجب أن نشير إلى أن تعقد المجتمع الحديث يؤدي إلى تقليل فرص تكامل الثخصية، و إلى ظهور احتمالات كبيرة لتفككها، و الدليل على ذلك الزيادة المطردة في نسبة من يقعون فريسة الأمر اض النفسية و العقلية و العصبية في المجتمع الحديث الذي يتغير باستمرار و بسرعة و في كثير من الأحيان. و إذا كان منطلق هذا المدخل أن السوي هو المتوافق مع المجتمع، أي من استطاع أن يجاري قيم المجتمع و معاييره و أهدافه، فإن لهذا المدخل أكثر من عيب لا يمكن إغفاله أو هو

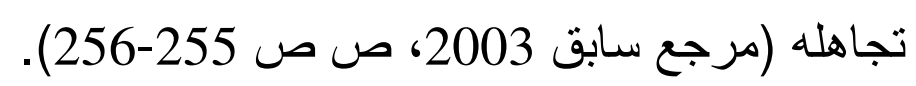
و بما أن الإنسان هو محصلة بين القوى الثثلاث: الفيزيولوجية (البيولوجية)، و النفسية و الاجتماعية، فإن النظرة المتكاملة في دراسة التوافق، و التي تشمل هذه الوجوه الثناثة إنما تشكل نظرة متكاملة الأطر اف لموضوع التو افق. 4-8 ما يحمل على المقاربات السابقة التي وضعها علماء النفس الغربيين سو حتى بعض الثرقيين- إغفالها للجانب الروحي في تحديدو تفسير التوافق و سوء التو افق، و هذا ما أدى إلى قصور واضح في فهمه للشخصية الإنسانية، و في معرفتهم للعو امل المحددة للشخصية

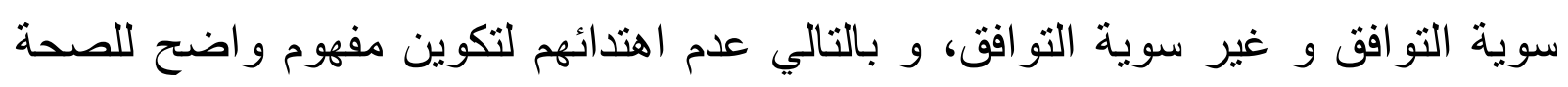
النفسية، فنحن لا نستطيع أن نفهم الإنسان فهما صحيحا إذا قصر اهتمامنا في دراسة شخصيته و نوافقه على الجوانب البيولوجية و النفسية و الاجتماعية و الثقافية و أهملنا

$$
\text { الجانب الروحي (د. محمد نجاتي، 1993، ص ص ص لو 276-277). }
$$

و لذلك اجتهد بعض علماء النفس المسلمين في وضع نماذج للتوافق و الصحة النفسية أعطوا للجانب الروحي فيها اهتماما مركزيا ذلك أنهم يعتبرون أن السلوك الذي يحقق التوافق السوي للفرد هو السلوك الإسلامي، فالإسلام هو دين الفطرة و السلوك المنبثق عنه لهن

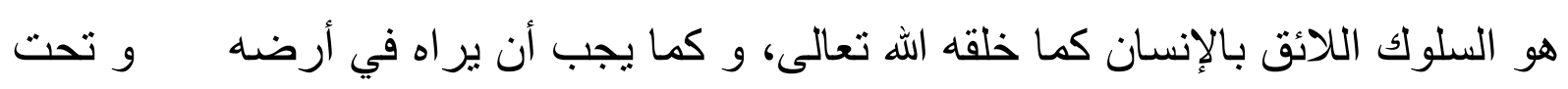
سمائه، و عندما يوافق السلوك الإنساني تعاليم الإسلام فذلك هو الطريق إلى تحقيق التوافق النفسي و الصحة النفسية. 


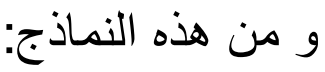

أولا/ نموذج د. محمد عثمان نجاتى: من هـ

يقترح (د. محمد نجاتي) المؤشرات الآتية للتو افق النفسي و الصحة النفسية:

أ- من حيث علاقة الإنسان بربه:

الإيمان بالله تعالى و الإيمان بملائكته و كتبه و رسله و اليوم الآخر و القدر خيره و و

شرهم

ب- من حيث علاقة الفرد بنفسه:

يعرف إمكاناته و تكون طموحاته على قدرها، يسعى دائما إلى تحقيق كماله الإنساني

على حسب قدر اته، يثبع دو افعه بالحلال و باعتدال، و يضبط منها ما لا يتفق مع تعاليم

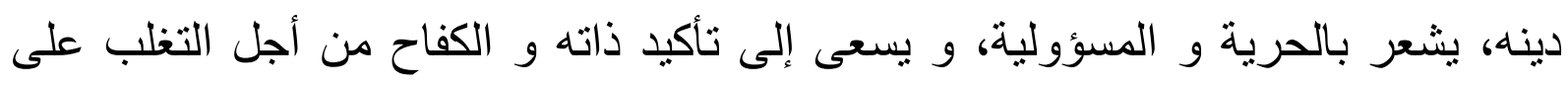
ضغوط الحياة، يحافظ على صحته و بلنه.

ج- من حيث علاقة الفرد بالناس:

علاقة طيبة ملؤها المحبة و المؤالفة و المعاملة بالحسنى، و يؤدي لكل و احد حقه و و

يقيم علاقاته على هذا الأساس، يثعر بمسؤوليته الاجتماعية كاملة. د- من حيث علاقة الفرد بالكون:

يعرف منزلته في الكون، و أن الله تعالى كرمه على سائر مخلوقاته فجعله خليفته في 9 الأرض عليه عمارتها، و تطبيق منهج الله تعالى فيها، يرى فيها الإبداع و الإتقان يشعر معها بالحب و الأنس.

\section{ثنانيا/ نموذج د. محمد عودة محمد:}

و يختار (د. محمد) المؤشرات التالية للسلوك التو افقي في المجتمع الإسلامي:

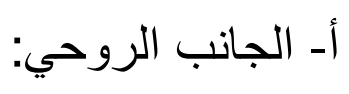

الإيمان بالله، أداء العبادات، إثباع الحاجات بالحلال.

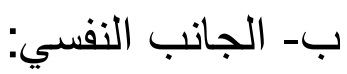

قبول الذات، سلامة الصدر من الحقد و الحسد....

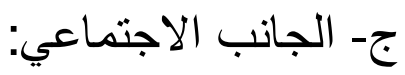


حب الو الدين، حب الزوجة، حب الأولاد، البعد عما يؤذب الناس.

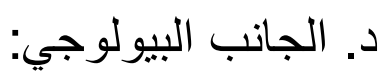

سلامة الجسم من الأمر اض بالابتعاد عن ما يسبب ذلك (محمد توفيق، 2002، ص ص

و لابد من الإشارة إلى أنه من الأفضل أن نبحث إلى جانب المؤشرات الإجرائية عن مصطلحات إسلامية جامعة تستوعب ما ذكر و ما لم يذكر في تلك المؤشرات، و لعل إلى مصطلحي العبادة و الرضا بمفهومهما الإسلامي الصحيح أقدر المصطلحات الإسلامية على لئ تقريب السلوك السوي و التوافق النفسي، ف "العبادة" تصف السلوك الداخلي (العقيدة)، و الخارجي (الأعمال من عبادات و أخلاق و معاملات) الموسوم بالسواء في الإسلام، و

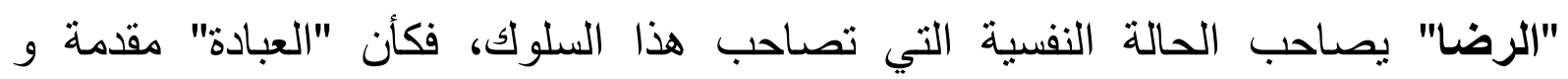
"الرضا" نتيجة (مرجع سابق، 2002، 348). و إلى جانب اجتهادات علماء النفس المسلمين، فقد كان لبعض علماء النفس الغربيين ذوي التوجه الديني، دور أيضا في إعطاء العامل الديني (الروحي) أهمية كبيرة و مركزية في تحقيق التو افق و الصحة النفسية. فكان من أوائل من نادى بذلك الفيلسوف و عالم النفس الأمريكي (William James)

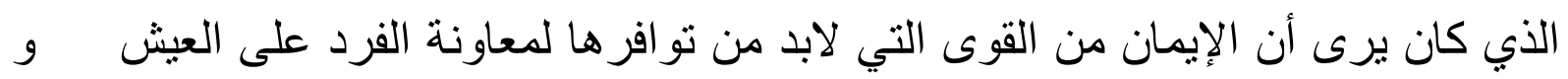
التوافق، و فقدها نذير بالعجز عن تحقيق ذلك.

كذلك المحلل النفسي (Carl Yung)، الذي بين أن معظم مرضاه النفسيين الذين تجاوزوا ـال 35 سنة- كان سبب معاناتهم و مرضهم افتقار هم إلى وجهة نظر دينية في الحياة (ناهد الخر اثي 2003 139).

إذن، فالإيمان باله قوة خارقة تمد الإنسان المتدين بطاقة روحية تعينه على تحمل مشاق الحياة و تجنبه القلق الذي يعاني منه الكثير من الناس في العصر الحديث و تساعده على تحقيق التوافق السوي و الصحة النفسية و بالتالي السعادة التي ينشدها كل إنسان على وجها

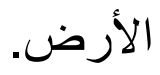


يعد التو افق حاجة و دافع إنساني هام تؤثر فيه عدة عوامل و يتم بعدة أساليب و طرق و آليات و هو عامل أساسي في استمر ار حياة الإنسان و نجاحه فيها.

\section{خلاصة الفصل: - (1)}

تناولت الباحثة في هذا الفصل موضوع التوافق، حيث تطرقت بداية إلى ننأة و طبيعة التوافق و الفرق بينه و بين مصطلح "التكيف"، كما تطرقت إلى أنواع البيئة التي يتعامل

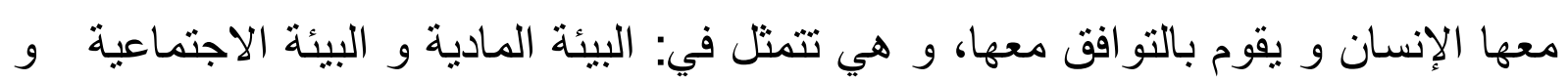
البيئة النفسانية (النفس)، كما أضافت الباحثة لهذه الأنواع: البيئة الروحية. ثم تتاولت الباحثة العلاقة بين مصطلحي (التوافق) و (الصحة النفسية)، حيث توصلت الباحثة من خلال طرح بعض وجهات النظر التي تدور حول ذللك، إلى أنه يوجد تداخل كبير بين هذين المصطلحين، و أنه من الصعب التفريق بينهما. ثم قامت الباحثة بعرض مجمو عة من تعاريف التوافق، حيث لاحظت من خلال ذلك أنه يوجد ثناث اتجاهات لهذه التعاريف: - التعاريف التي تركز على الجانب النفسي في التوافق. ـ التعاريف التي تركز على الجانب الاجتماعي في التوافق. 
ـ التعاريف التي تولي أهمية لكلا الجانبين النفسي و الاجتماعي في عملية التو افق. ثم تتاولت الباحثة أنواع التوافق، و التي تتمثل في نوعين: التوافق الثخصي و التوافق الاجتماعي. ثم تطرقت الباحثة إلى العوامل الديناميكية في عملية التوافق، و التي تتلخص في ثلاثة عو امل أساسية و هي: الإحباط، الصراع، القلق. ثم تناولت الباحثة الآليات الدفاعية، هذه الأخيرة التي تساعد الإنسان على تحقيق قدر معين من التو افق المؤقت. ثم تناولت الباحثة الأساليب التوافقية، حيث تبين لها من خلال هذا العنصر أنه توجد أساليب توافقية سوية و أخرى غير سوية (شاذة) أو مرضية. ثم تطرقت الباحثة إلى الاتجاهات الأساسية في تفسير التوافق، و التي تتلخص في: المقاربة الفيزيولوجية، المقاربة النفسية، المقاربة الاجتماعية و الثقافية، و أخيرا المقاربة الدينية (الروحية). و في الأخير، و بعد أن تم عرض آراء بعض علماء النفس الغربيين (أمثال ويليام جيمس و كارل يونغ) حول أهمية الدين في عملية التوافق، نوصلت الباحثة إلى نتيجة مفادها أن للدين دور مهم في مساعدة الإنسان على تحقيق التو افق مع نفسه و مع الآخرين. 


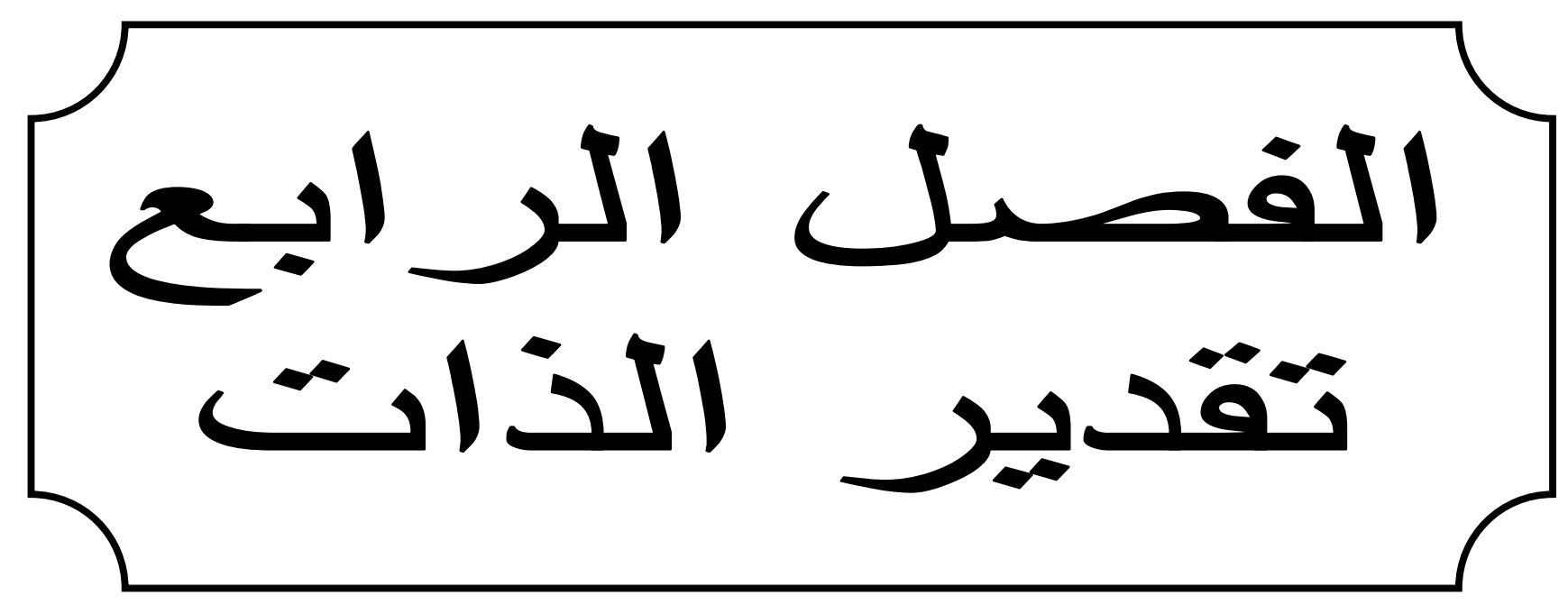




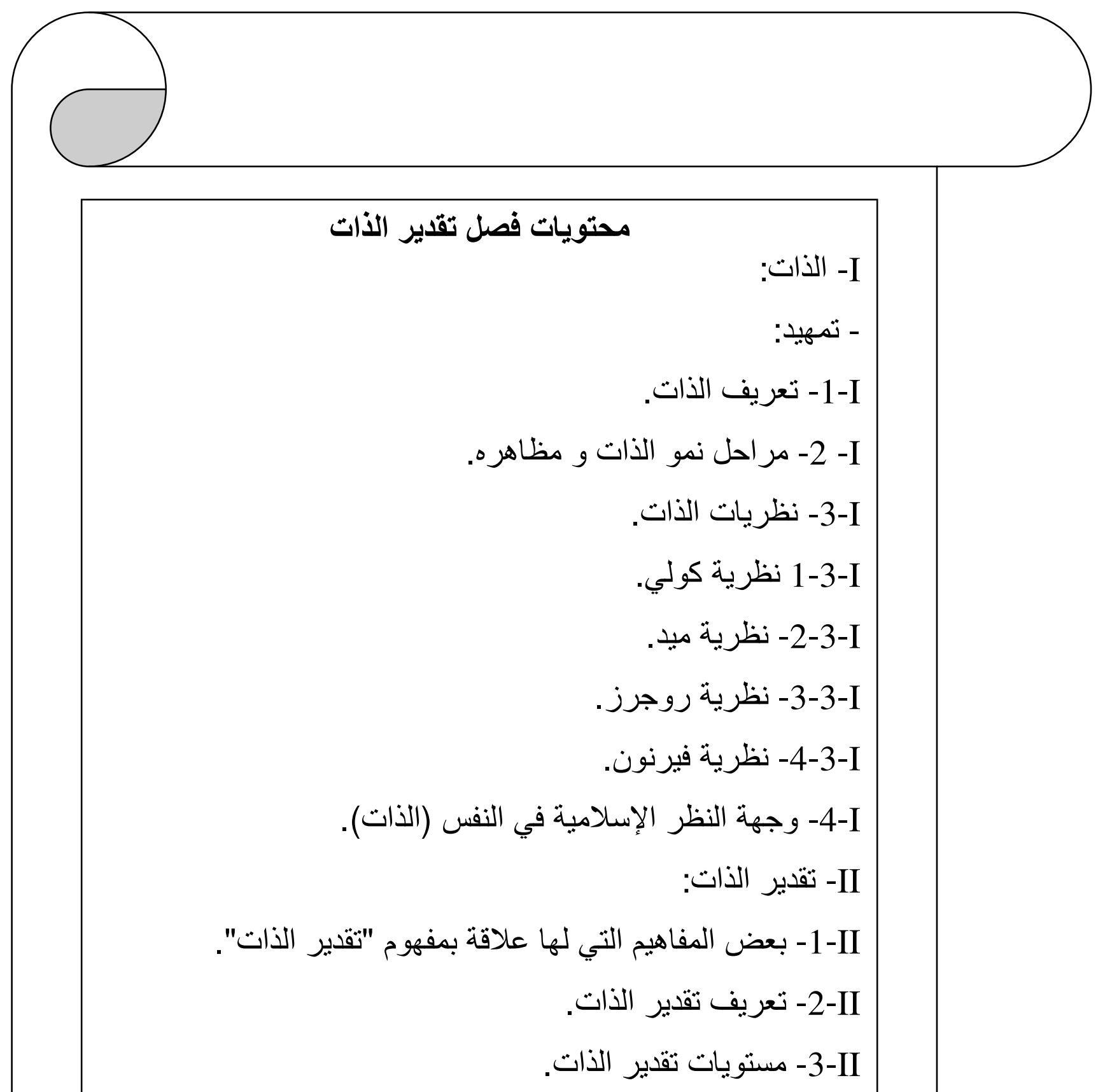


فصل تقدير الذات.

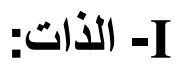

تمهيد:

إن أي لغة في العالم سسواء القديمة منها أو الحديثة- و في مختلف الثقافات و الحضارات، لا نظلو من ألفاظ: مثل "أنا"، "و لي"، "و خاصني"، و التي تثثير كلها

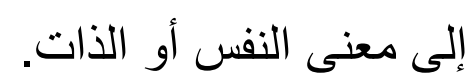

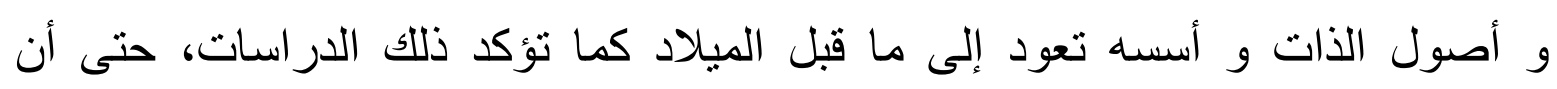

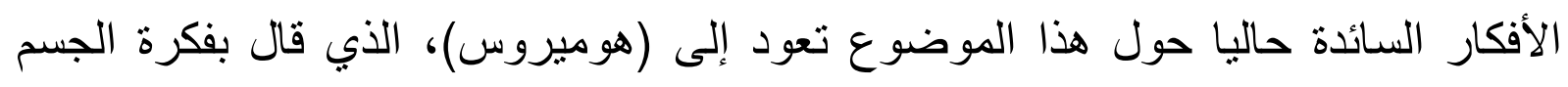

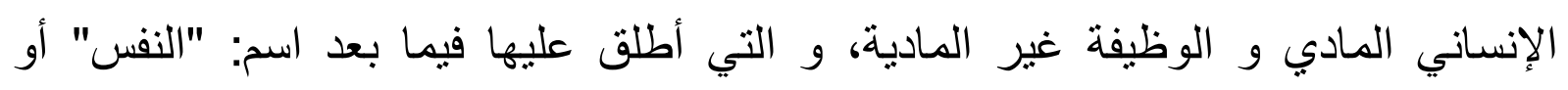
"الروح" (Soul, Spirit, Psych).

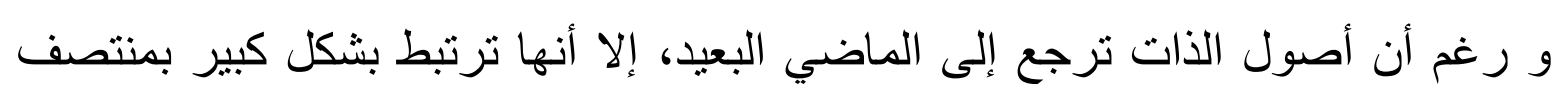
القرن ال 20 و خاصة بمجال علم النفس الإكلينيكي و مجال الإدر الك الاجتماعي. 
كما كان للعلماء و المفكرين العرب و المسلمين قبل هذا، إسهامات كبيرة في هذا الموضوع، فقد اهتموا أيضا بدراسة "النفس" أو "الذات" كابن سينا في القرن العاثر و أبو

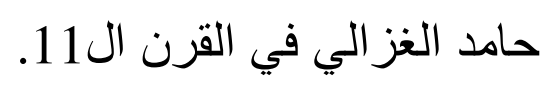
كما أن الدين -خاصة الدين الإسلامي- قد أعطى ل "النفس" أو "الروح" محلا و اسعا من العناية و الاهتمام، و يظهر ذلك جليا في آيات القرآن الكريم (الذي يعد مرجع عظيم للتشريع الإسلامي و إلى جانبه السنة النبوية الثريفة)، حيث ورد هذا المفهوم لأكثر من مرة في القرآن الكريم، قال الله تعالى: "و لا أقسم بالنفس اللوامة" [القيامة:02]. و قال تعالى: "يا أيتها النفس المطئنة، ارجعي إلى ربك راضية مرضية" [الفجر:27]. و أيضا في قوله نعالى: "و نفس و ما سواها، فألهمها فجور هاو تقو اها" [الثمس:7-7]. كما ورد هذا المفهوم أيضا في بعض أحاديث النبي صلى الله عليه و سلم مثل: "أعدى عدوك نفسك التي بين جنبيك" [حديث شريف]. و الذات قد نرادف النفس "psych" كما في قولنا الثيء ذاته، أي نفسه، كما يعتبر ها "yung" (الذات) معادلة للنفس أو الثخصية. و الذات بالنسبة للأشياء هي الحقيقة وراء كل الظواهر، و بالنسبة للشخصية هي كل الثخصية و هي يقصد بها كل ما يخص و يتعلق بالثخص من: جسده، و سماته و قدر اته و ممتلكاته و أسرته و أصدقائه، و أعدائه و مهنته....الخ. و يوحد بعض الباحثين بين مفهومي "النفس" (الذات) و "الروح" (soul) أمثال "جون لوك" و "جورج بيريكلي" و "هيوم " و "توماس" و "براون" و "جيمس ميل" و "كانت"...الخ. و يشير (محمد جلوب فرحان) إلى أن مفهوم الروح (soul) أدخله سقر اط (سنة 470 أو 469 ق.م) حين أدرك المعنى العميق للعبارة المنقوشة على معبد دلفي "إعرف نفسك بنفسك" (د. قحطان الظاهر ، 2004، 15). و في العقائد الدينية -خاصة العقبدة الإسلامية- فإن النفس هي الروح و هي تنتمي إلى عالم الغيب لذلك فإن كنهها خارج علوم و معارف البشر، قال الله تعالى: "و يسألونك عن الروح، قل الروح من أمري ربي، و ما أوتيتم من العلم إلا قليلا" [الإسر اء: 85]. 
فالنفس هي الروح من حيث الطبيعة و الجو هر لكن الاختلاف يكون في الخصائص فإذا دخلت الروح في الجسم فإنه تصير نفسا و تصبح لها أحكام أرضية بحكم ارتباطها بالبدن و خصائص روحية بحكم أصلها الروحي (محمد عمر سالم، الإنسانية و أمر اضها بين الطب و البدن، مجلة النفس المطمئنة، العدد 71، يوليو 2002)، و النفس بهذا المعنى تحمل سمات كل من الجسم و الروح و صفات الجسم و خصائصد الأساسية تشكل جزءا من سلوك ولك الإنسان (فالطول، القصر ، البدانة، أو النحافة...) تؤثر بشكل أو بآخر على شخصية الإنسان

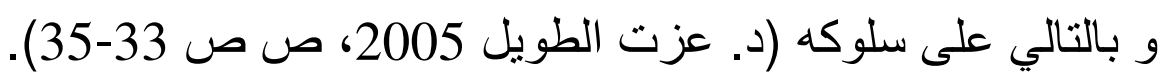
و يمثل "الذات" (النفس) مجموع الخبرات و الاتجاهات التي تدور حول الثخص و التي تأتي تدريجيا إلى الوجود و هي قابلة للتعديل نتيجة تغير الخبرة و تنمو نتيجة للنضج و التعلم، فالذات كما أصبح معروفا ليست فطرية، فالإنسان يولد بدونها وهي تنمو تدريجيا على التفاعل الاجتماعي مع الآخرين (د. إبر اهيم أحمد أبو زيد، 1987، 98). و فكرة الثخص عن ذاته هي التي تحدد نوعية شخصيته، كما تحدد سلوكه و تصرفه إزاء المو اقف و الأفراد و كيفية إدر اكه لتلك المواقف و هؤلاء الأفراد، و ذلك أن المواقف و الأحداث الخارجية يتوقف معناها بالنسبة للثخص على الصورة التي يدرك بها نفسه ففكرة الثخص عن نفسه هي الأساس الذي تقوم عليه الثخصية، أي أن الذات هي الأساس لهاس الذي تقوم عليه شخصية الفرد و سلوكه (د. زينب محمود شقير، 2002، 71). و يرى (وليام جيمس, James) أن الإنسان يمتلك من الذوات يقدر عدد الأشخاص الذين يعرفونه فعنده ذات لو الديه و أخرى لأصدقائه و ثالثة لزملائه في الدراسة أو العمل و رابعة لربه....الخ. و هذا ما ذهب إليه (Mead) الذي يرى أن للإنسان عدد من الذوات يكون بعده الأدوار

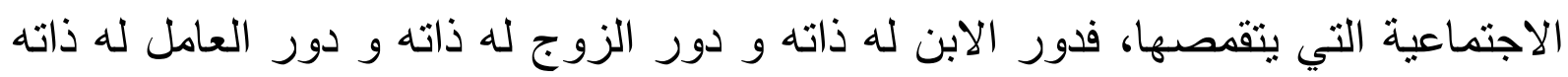
أيضا....الخ. ـ الفرق بين مفهومي "الأنا" و "الذات": يعرف (فرويد) الأنا (ego) بأنها: "الجزء المنظم من الهو الذي تغير نتيجة اصطدامه بالواقع و هو منطقة الثعور و الإدرالك التي تعمل على تحقيق توازن الثخصية و المبدأ 
الأساسي الذي يوجه الأنا هو مبدأ الواقع، حيث يعمل الأنا على التوفيق بين الحاجات

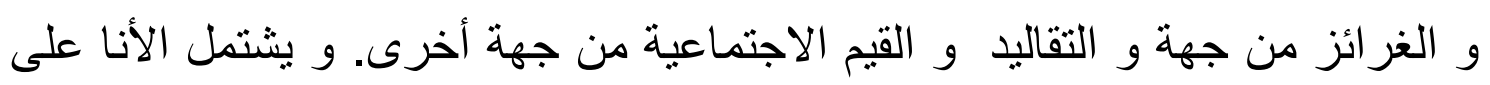

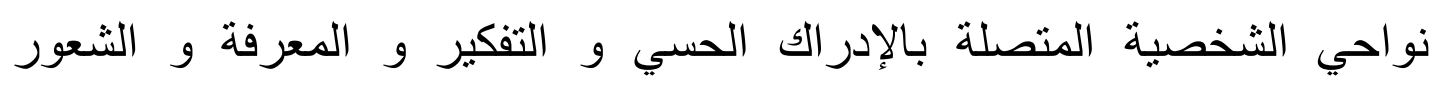

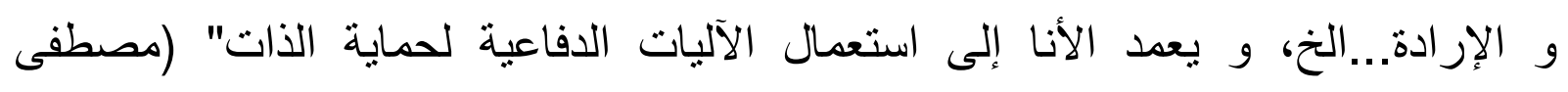

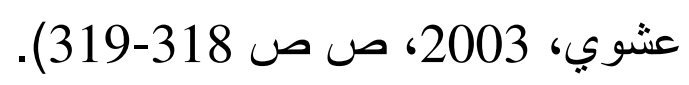
و حسب هذا التعريف فالأنا تمثل فاعل أو عملية. و يحتفظ بعض الباحثين و المفكرين بتعبير الذات (self)، ليثير بذلك إلى نسق الأفكار و القيم التي يكونها الثخص عن ذاته، (و هي تختلف بهذا المعنى عن المعنى التقليدي السابق ذكرهو الذي يتعلق بالأنا كفاعل و محرك للسلوك). و بينما الأنا هو طاقة الفرد للأداء، فإن مفهوم الذات يحدده أداءه الفعلي أي الأنا يعتبر كفاعل و الذات كموضوع. (د. حلمي المليجي، 2001، 202). و قد تعددت وجهات النظر و تباينت بين الباحثين و العلماء حول تحديد و استعمال مفهومي "الأنا" و "الذات". حي يوجد فريق من العلماء يستعمل الأنا كفاعل أو كعلية مرة و كموضوع مرة أخرى

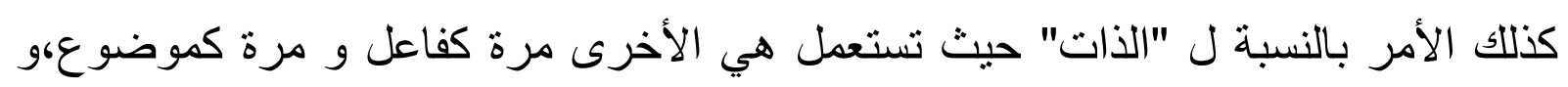
من هؤ لاء العلماء نجد كوفكا (Kofka)، كذللك آلبورت (Allport) الذي وحد بين مفهومي "الذات" و "الأنا" و ما يتعلق بهما في مفهوم و احد أسماه البروبريوم أو (proprium) الذات الممتدة المميزة الموحدة و هي تشمل جميع مناحي الثخصية. كذلك نجد كل من (Cherif \& Centril \& Catell) و غير هم. و فريق آخر من العلماء و الباحثين من يستعملون الواحد مكان الآخر، حيث يعتبرون الذات كفاعل و الأنا كموضوع. بينما نجد أن (فرويد) قد أسقط من اعتباره "الذات" بالكلية و أكد على "الأنا" الذي يعتبره

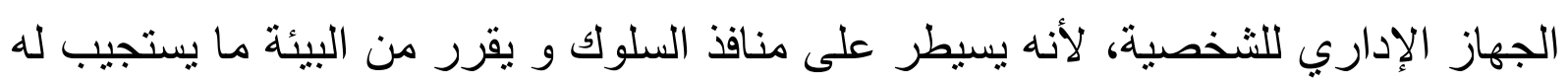

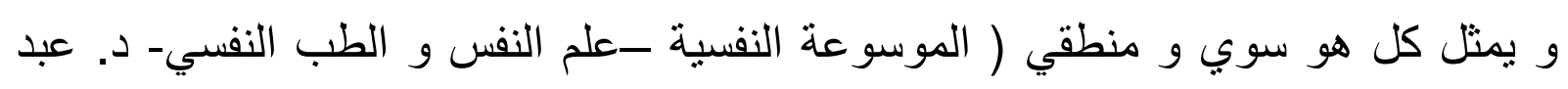
المنعم الحفني، 2003، 477). 
و في مقابل هذا نجد أن فريق آخر من الباحثين أمثال: وليام جيمس و روجرز

$$
\text { و غير هم أكدوا على الذات أكثر. }
$$

و نتيجة لهذا الخلط الذي حصل حول استعمال مفهومي "الأنا" و "الذات"، فإن هناك مجموعة أخرى من العلماء ميزت بوضوح بين مفهومي "الذات" و "الأنا"، و ذلك من خلال التمييز بين مظهرين مختلفين للذات:

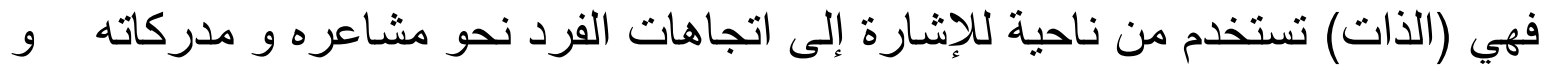
تقييماته لذاته كموضوع "self as object" و هذا المعنى هو ما يقابل مصطلح "الذات". و من ناحية أخرى تستخدم "الذات" للإشارة إلى ارتباطها بمجموعة من العمليات

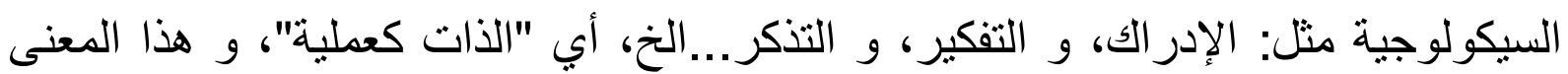

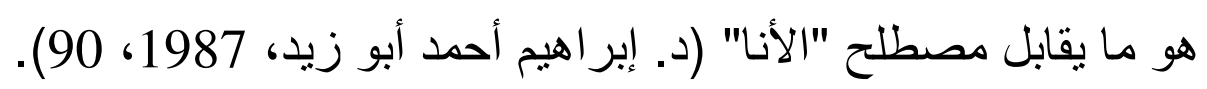
1-I - I تعريف الذات: النفس الإنسانية هي ذلك الكل المركب من الجسد و الروح و الذي نطلق عليه بلغة علم

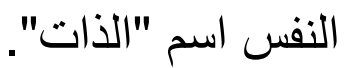
و قد اجتهد كثير من العلماء و الباحثين سواء العرب و المسلمين أو الغربيين في دراسة

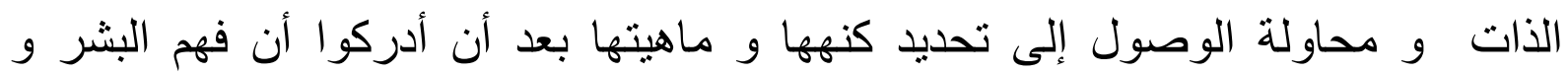

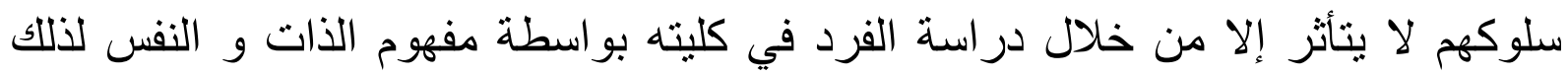
جاءت تعريفاتهم عديدة و متشعبة نذكر منها:

يعرف ابن سينا (في القرن 10م) الذات بأنها: "الصورة المعرفية للنفس البشرية". أما أبو حامد الغزالي فيرى أن للنفس أصناف خمسة و هي: النفس الملهمة، النفس اللوامة، النفس البصيرة، النفس المطئنة و النفس الأمارة بالسوء. و حسبه فإن الأربعة الأولى منها حميدة و الخامسة غير حميدة. أما من الناحية الدينية -خاصة في الإسلام-، فتعرف النفس (الذات) بمعاني عديدة أهمها معنبان: n المعنى الأول: براد به المعنى الجامع لقوة الغضب و الثهوة في الإنسان، و هذا الاستعمال هو الغالب على أهل التصوف، لأنهم بريدون بالنفس: الأصل الجامع للصفات 
المذمومة من الإنسان، فيقولون: لابد من مجاهدة النفس و كسرها، و ذلك مصداقا لقول النبي (صلى الله عليه و سلم): "أعدى عدوك نفسك التي بين جنبيك".

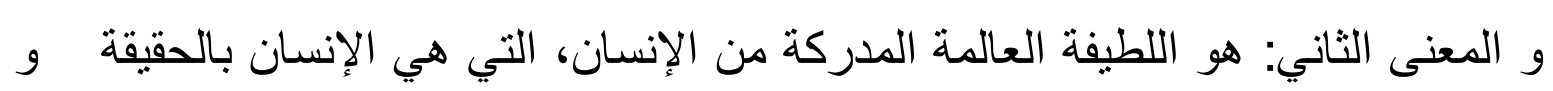

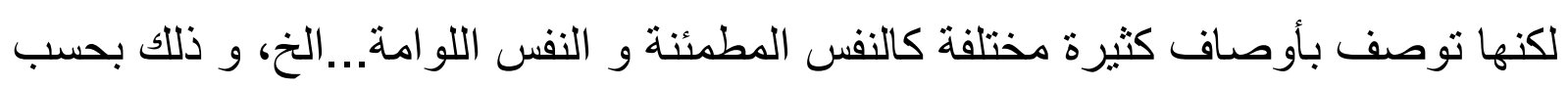

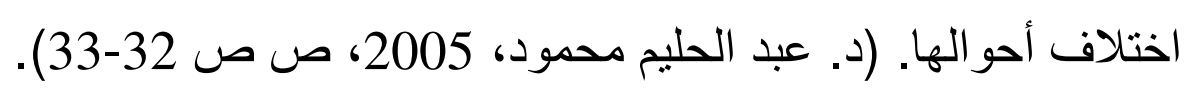
و يلاحظ أن هذا التعريف يقترب من مفهوم الذات عند علماء النفس.

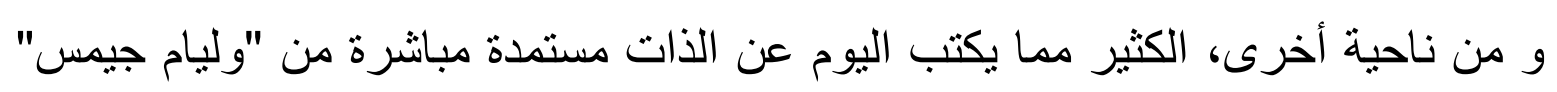
(1910) هذا الأخير الذي يعتبر نقطة التحول من الأساليب القديمة إلى الأساليب الحديثة في در اسة الذات. و قد حدد أسلوبين لدراسة الذات، الذات كفاعل و التي تشمل على مجمو عة من النشاطات النفسية كالتفكير و التذكر و الإدر اك...الخ، و سماها ب"الذات العارفة"، و التي يرى أننا لا نستطيع أن نفهم بواسطتها السلوك. أما الذات كموضوع و التي أسماها (جيمس) "الذات التجريبية" فهي تتضمن: الذات المادية، الذات الاجتماعية، الذات الروحية، بالإضافة إلى الذات الممتدة(Reflected self) التي تشمل كل ما يتقاسمه الفرد مع الآخرين كالعائلة و المجتمع...الخ. و يعرف (James) الذات على أنها: "كل ما يمكن تسميته "خاصته"، فالذات ضمن الآن الأشياء الأخرى، نسق للأفكار و الاتجاهات و القيم و الأحكام، فهي البيئة الذاتية الكلية للشخص". (د. إبر اهيم أحمد أبو زيد، 1987، 192، 92). و قد ميز (لاند هولم، Land holem: 1940) بين "الذات الذاتية" و "الذات الموضوعية"، فالأولى تمثل النظرة إلى الذات من خلال الذات، أي الرموز التي يدركها الفرد بنفسه أي ما يعتقده الثخص اتجاه نفسه، أما الثانية "الذات الموضوعية" فتنتمثل في لثي النظرة إلى الذات من خلال ما ينظر الآخرون إليه، أب مجموعة الرموز التي يكونها لهاه الثخص من خلال ما ير اه الآخرون فيه (والاس د.لابين و بيرت جرين، 1981، 12). و يرى (هيلكارد، Hilgard، 1947) الذي وصف الذات أمام الجمعية النفسية الأمريكية أنها صورة الإنسان عن نفسه، و أنه لا يمكن الاستغناء عنها لفهم ميكانيزمات دفاع الأنا 
الفرويدية يرى أن أحسن طريقة لفهم طبيعة الذات أو صورة الأنا، هو الوسائل الإسقاطية أو

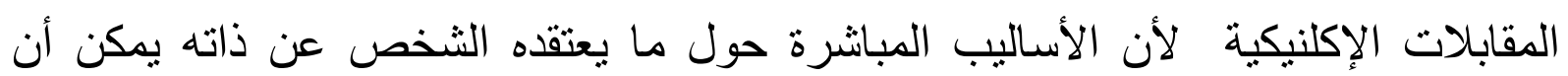

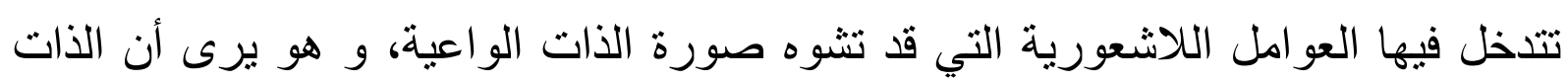

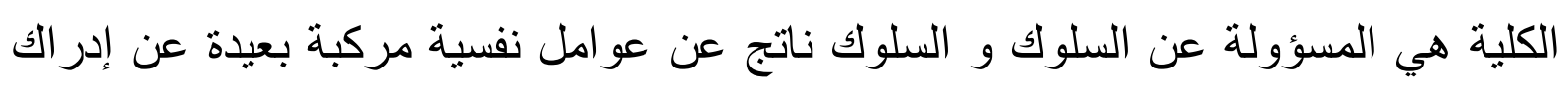
الثخص، و هو ليس نتاج الذات و حدها(مرجع سابق 2004، ص ص صل 23-24). و يرى (ساربين، Sarbin: الثخص عن مختلف نواحي وجوده، من جسمه (الذات البدنية) و أعضاء الحس للديه (الذات الحسية، و سلوكه الاجتماعي (الذات الاجتماعية)".

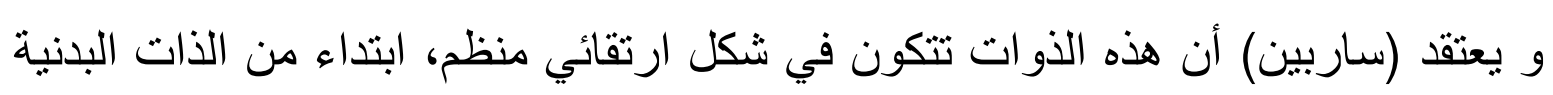

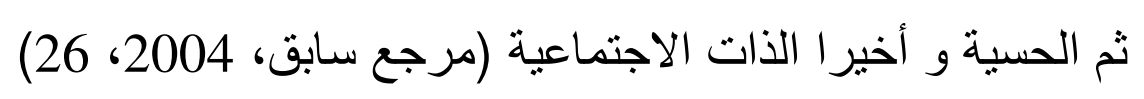

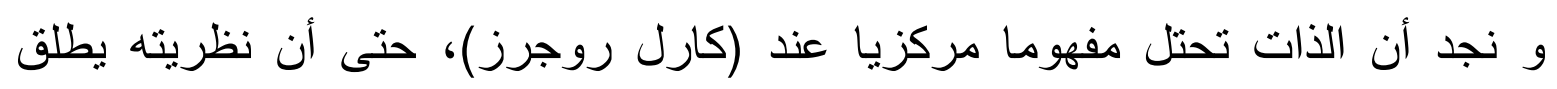

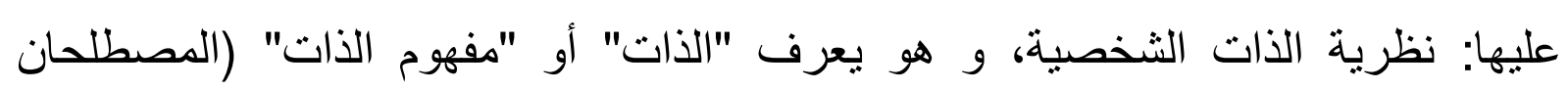

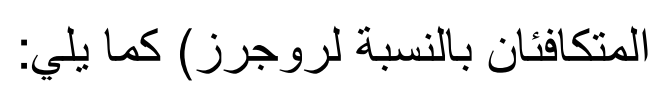

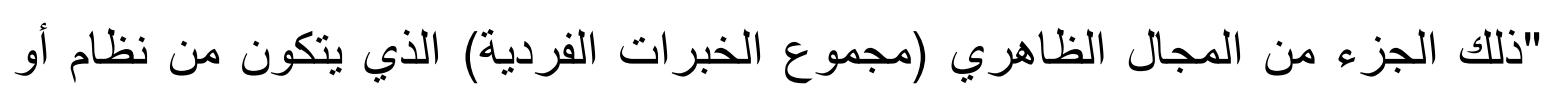
نسق من الإدر اكات و القيم المتعلقة بالذات أو بخصائص الأنا و الآخرين أو بالفرد كصدر الفرد للخبرة و السلوك (د. زينب محمود شقير، 202، 71).

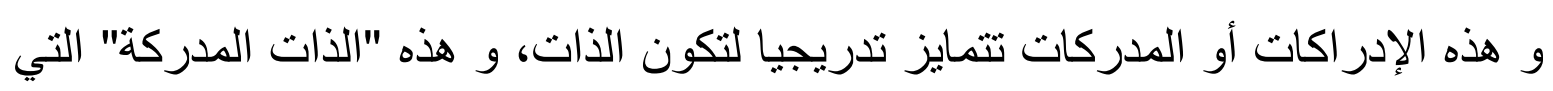
تعادل "مفهوم الذات" تؤثر في الإدر الك و السلوك. و يتفق كل من (سوليفان و كولي و ميد) على أن الذات تنتظم من التفاعل الاجتماعي. و يرى (سوليفان، Sullivan: 1953) أن نظام الذات يتكون من خلال النواهي الني

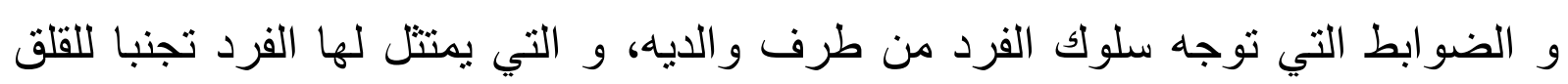

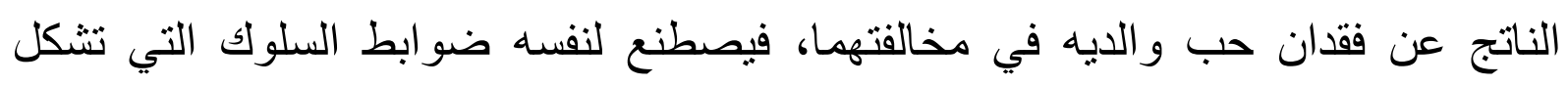
"نظام الذات" و يسلك وفقا للقيم الاجتماعية (د. قحطان الظاهر، 2004، 26 26). 
و يجب التتويه أن (سوليفان) يختلف مع (كولي) و (ميد) في كونه يولي اهتماما أكبر

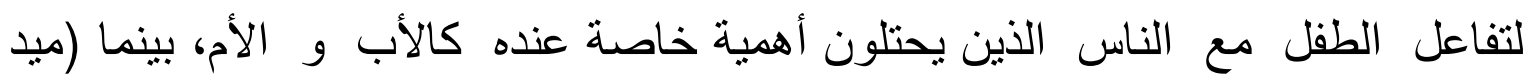
و كولي) يرون ضرورة التفاعل مع المجتمع ككل.

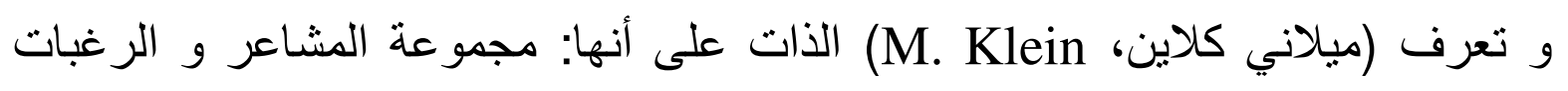

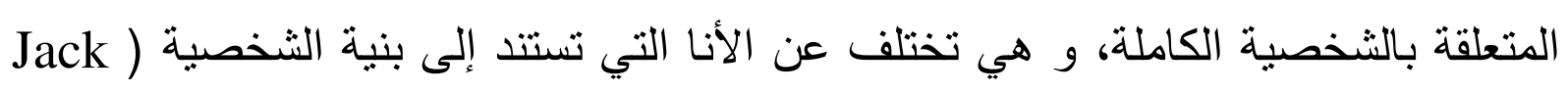
. Postel بالإضافة إلى هذا: يعرف (أحمد عزت راجح، 1985) الذات على أنها: "الصورة التي يشكلها الفرد عن

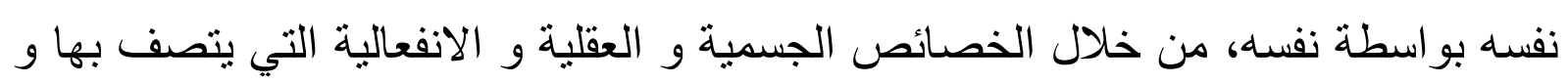
من خلال القيم و المعايير الاجتماعية التي ينتمي إليها.

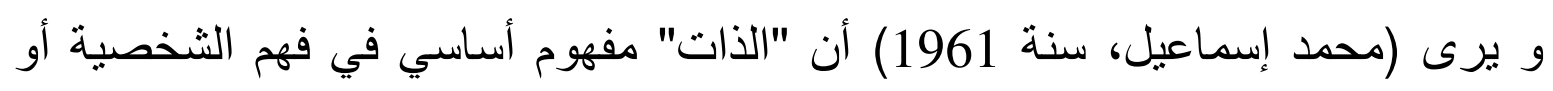

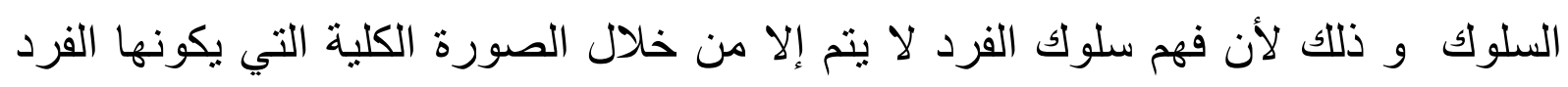
عن نفسه. كما يقرر أن مفهوم الذات قد يكون شعوريا كما قد يكون لا شعوريا.

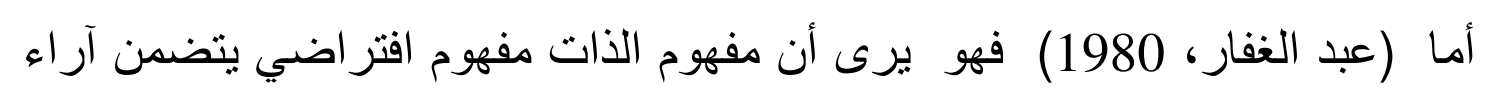

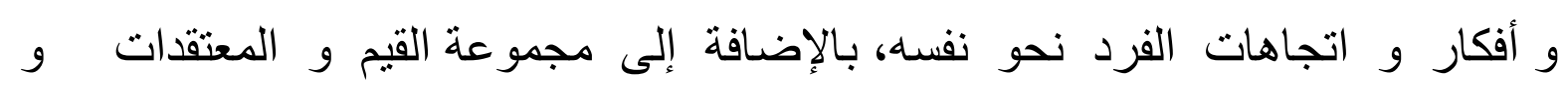

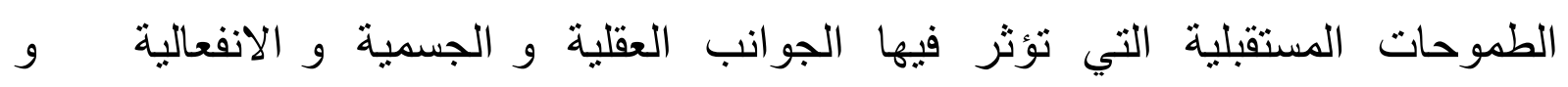

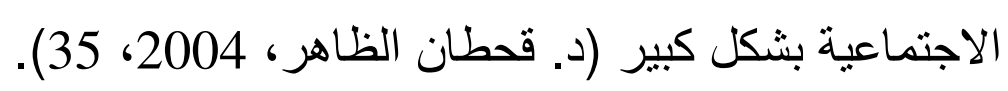

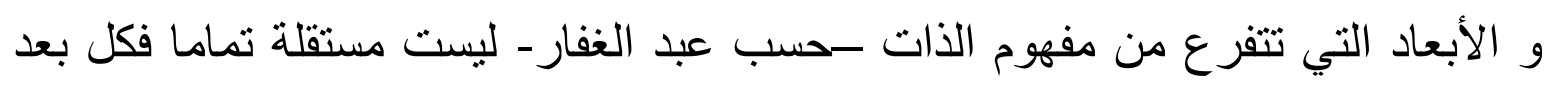
يؤثر و يتأثر بالآخر فمثلا: مفهوم الذات الجسمي يؤثر على منى مفهوم الذات الاجتماعي ....و هكذا. من خلال التعريفات السابقة يمكن أن نستخلص ما يلي: 1) تعتبر الذات كموضوع أكثر منها عملية (فاعل)، و يتضح ذللك من خلال ما أنشار إليه جيمس بالإضافة إلى هيلكارد و روجرز ، و هناك تعبيرات استعملت في نظرية الذات مثل:

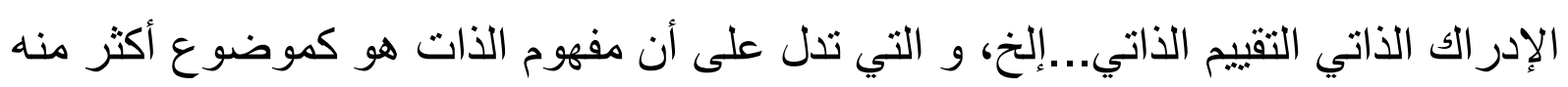


2) الذات أساس بناءو تنظيم الثخصية، كما أنها مسؤولة عن تحديد سلوك الفرد و

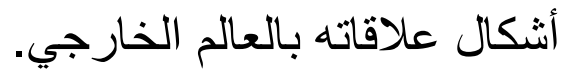

3) يتفق معظم الباحثين على أن مفهوم الذات مكتسب و ليس وراثي. 4) تتمو الذات و تنتظم من خلال الخبرات الإدراكية التي يكتسبها الفرد، و من خلال التفاعل الاجتماعي خاصة مع الأثخاص المقربين كالأب و الأم، و كذلك من خلال الحاجات و القيم و المعايير و الاتجاهات...الخ. 5) بما أن القيم و المعايير و الاتجاهات هي عوامل غير ثابتة و قابلة للتغيير، و باعتبار أنها تؤثر في تكوين الذات، إذا فمهوم الذات عند الفرد غير ثابت أيضا و قابل للتغيير خاصة في المر احل العمرية الأولى. 6) يدرك مفهوم الذات من خلال رؤية الفرد لنفسه، و رؤية الآخرين له كما يدركها هو . 7) قد يكون مفهوم الذات شعوريا كما قد يكون لا شعوريا. 8) تتكون الذات من عدة أبعاد و مستويات مثل: الذات الاجتماعية و الذات الجسمية...الخ و هذه الأبعاد و المستويات هي غير مستقلة بشكل مطلق، بل تتأثر كل منها بالأخرى. 9) تختلف طرق معرفة طبيعة الذات التي وضعها الباحثون، فبينما يرى بعضهم أمثال

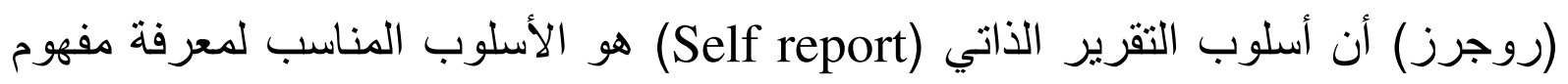
الذات (أي من خلال ما يعتقده الفرد حول نفسه)، نجد أن البعض الآخر أمثال (هيلكارد)

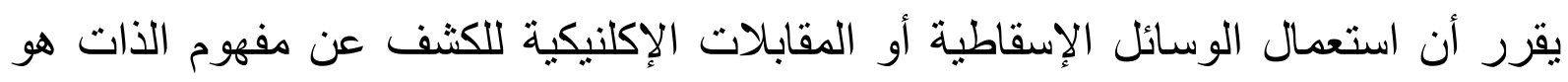
الأنسب.

10) البعض من العلماء يفسرون مفهوم الذات في ضوء الاتجاه الاجتماعي أمثال ميد (1934) و إسماعيل (1961)، بينما البعض الآخر يتبنون التحليل النفسي في تفسير الذات

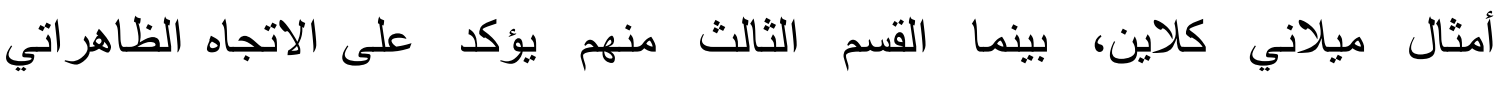
(phenomenology) في تفسيره مفهوم الذات كل من الاتجاه الاجتماعي و الاتجاه الظاهراتي أمثال راجح .(1985) 
2-I

لقد صاغ عدد من العلماء و الباحثين ممن اهتموا بدراسة موضوع الذات المراحل المميزة لنمو الذات كمفهوم مكتسب ينمو و يتطور، و من هؤلاء العلماء و الباحثين البارزين في هذا المجال "بياجيه Piaget" و " آلبورت Allport "، هذا الأخير الذي استخدم مصطلح "البروبريوم" (proprium) ليقابله بمصطلح الذات. و على العموم يمكن تلخيص المراحل التي يمر بها تكوين الذات عند الفرد ابتداءا من الطفولة المبكرة كما يلي:

1-2-I المرحلة الأولى من حياة الطفل يسميها "بياجيه" باسم "المرحلة الحسية الحركية"، حيث في هذه المرحلة يستقبل الطفل المنبهات من العالم الخارجي، مثل: صوت الأم، ضغوط على سطح الجلد...الخ، و يستجيب لهذه المنبهات دون أن تكون هناك ذات وسيطة بين هذه المنبهات و ردود الأفعال الحسية الحركية التي يبديها الطفل، و يدخل كل ذلك حسب "بياجيه" ضمن مجموع كلي غير منمايز من الذات و العالم الخارجي. أما بالنسبة لآلبورت فالبروبريوم في هذه المرحلة (0-3 سنوات)، تأخذ المظاهر التالية: المظهر الأول: الذات الجسمية "The bodely self": التي هي أول ما ينمو من البروبريوم.

المظهر الثاني: الهوية الذاتية " The self identity ". المظهر الثالث: اعتبار (احترام) الذات ( The self esteem ) (د. عبد العلي الجسماني

2-2-I

في هذه المرحلة حسب بياجيه تصبح الذات الجسمية أكثر تحديدا و وضوحا عند الطفل، لكن الطفل سر عان ما يفقد هويته، كما يظهر في لعبه التقصص لبعض الثخصيات كالثرطي و الفارس...الخ، و هو ما يعرف باللعب الإيهامي. 
و يظهر أيضا في هذه المرحلة "مركزية الذات' عند الطفل، حيث يكون جل تفكيره مستتدا على ذاته، فهو يعتقد أن الله موجود ليحفظه و يحميه، و أن القمر يتبعه أينما ذهب...الخ، و لكن هذا التمركز حول الذات ليس مؤسسا عن إدراك بالذات أو ينعلق بها حقا، بل هو يعود إلى طبيعة الثخصية لتفكير الطفل في هذه المرحلة. و بالنسبة لآلبورت، فبالإضافة إلى المظاهر السابقة تتميز هذه المرحلة بالمظهرين الآتيين: - n

" The self extension " المظهر الرابع: امتداد الذات المظهر الخامس: صورة الذات " self image " (مرجع سابق، 2000، 38) 3-2-I مع دخول الطفل المدرسة بزداد إحساسه بهويته و بصورة ذاته و بقدرته على امتداد

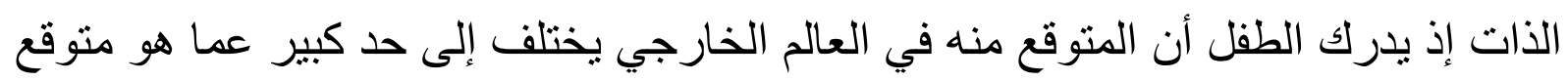
منه داخل المنزل، فيحاول أن يندمج في عالم الواقع و ما يفرضه عليه، كما يقل لعبه الإيهامي و يزداد إحساسه بذاته الواقعية و يظهر ذللك في ارتباطه بالمعايير الخلقية و أحكام اللعب...، و يكون راضيا عن نفسه إذا كان منكيفا. و تتميز هذه الفترة (حسب بياجيه دائما) بالمزيد من الرغبة في المعرفة و حب حبن الاستطلاع و كثرة الأسئلة و الاستفسارات، فهي فترة نمو عقلي. (د. سعد رياض، 2005

و تمثل هذه المرحلة عند آلبورت المظهر الساد من مظاهر نمو الذات و هو: الذات منطقية عاقلة أو الذات المفكرة " The self as rational coper " (د. عبد العلي

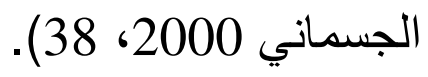

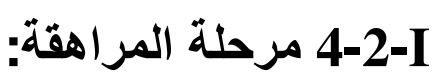
في هذه المرحلة يبحث المراهق من جديد عن ذاته، فهو قد أحس بها في طفولته المبكرة، و لكنه فقدها في الأسرة و الثلة و في الو لاء لهما، فتصبح مشكلة المر اهق البحث من جديد 
و صورة المراهق عن ذاته تتوقف على الآخرين و مدى تقبلهم أو نبذهم له. و ثورة المر اهق و تمرده على السلطة لها علاقة هامة ببحثه عن هويته و ذاته، فهي تمثل المحاولة الأخيرة لتحقيق استقلاله الذاتي.

و قد يلجأ المر اهق إلى أساليب تكثف عن قلقه و بحثه عن شيء لم يصل إليه بعد مثل: ارتدائه لبعض الألبسة أو تصفيف شعره بصورة تشبه الممثلين أو الرياضيين ...الخ (

$$
\text { فالمر اهق في هذه الحالة يكون يبحث عن ذاته و لم يجدها بعد). }
$$

ثم أخير ا تتحد الذات و تتبلور في نمط أدائها و تصبح ذات أداء محدد تعبر عن طبيعة الثخص و يطلق عليها: شخصية الفرد. (د. سعد رياض، 2005، 52). و هذه المرحلة تقابل المظهر السابع عند آلبورت و هو: الذات محددة بسمات و صفات مميزة تسمى: الثخصية، أو ما أسماه آلبورت أيضا: التطلع الأنسب " The propriat striving ": أي التطلع إلى المستقبل و العمل على تحقيق أهداف مهمة يضعها الفرد ليعزز بها كيانه الثخصي. و قد وضع آلبورت عدة معايير ينظر في ضوئها إلى النمو السوي الناضج للثخصية و و

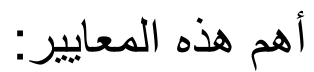
ـ امتداد الإحساس بالذات. ـ العلاقات و الصلات الوطيدة مع الآخرين.

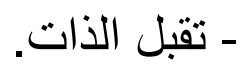
- الإدر الك العقلاني للواقع. ـ النظرة الموضو عية للذات. - فلسفة مقبولة إز اءو واقع الحياة ككل (د.عبد العلي الجسماني، 2000، 39). 3-I

لقد تحدث الباحثون عن أكثر من نوع من الذات مثل: الذات الحقيقية و الذات المثالية و الذات الاجتماعية و الذات العامة...الخ. و قد وضع في هذا الموضوع (موضوع الذات) عدة نظريات، لعل من أهمها نذكر ما 
يعد (كولي) من أو ائل علماء النفس الاجتماعيين الذين كان لهم دور كبير و إسهام فعال

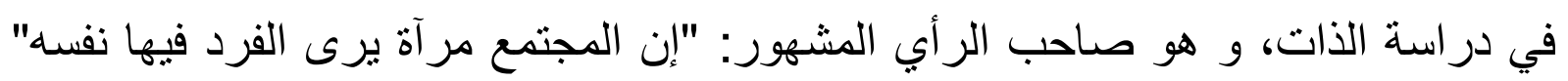

و من هنا جاء مفهوم "الذات المنعكسة" أو كما يسميها " The looking glass self و يرى (كولي) أن الذات المنعكة تشمل على ثلاث عناصر ، تتمثل في: أو لا: تخيلنا فيما نبدو عليه في نظر الآخرين. ثانيا: تخيلنا لحكم الآخرين على هذا المظهر.

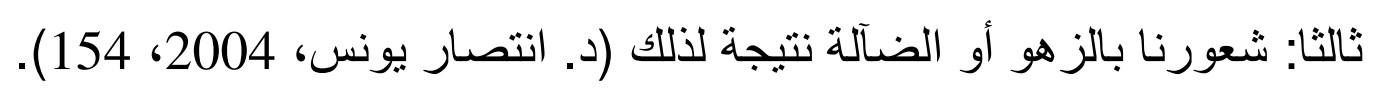

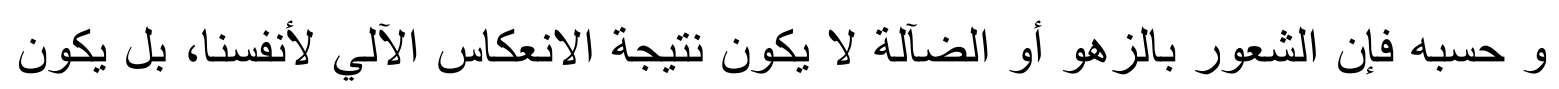
نتيجة الانعكاس على الغير (أي إدر الك الفرد للطريقة التي يراه بها الآخرون).

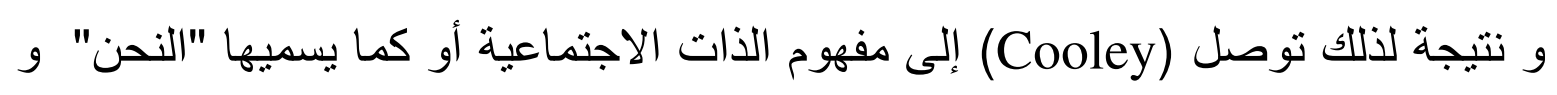
برى أن الثعور ب "النحن" بعتمد على ما يلي:

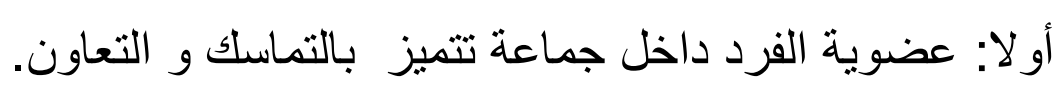

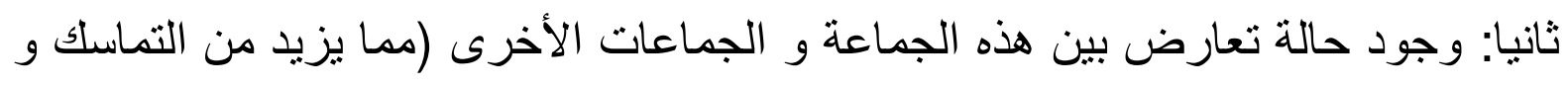

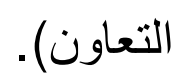
ثالثا: الثعور بما بشبه الملكية المتبادلة بين الذات و الذوات الأخرى.

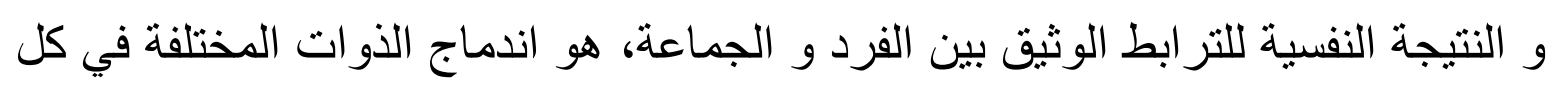

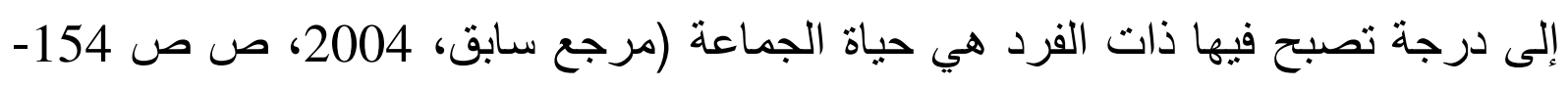

و يجب أن ننوه أنه ليس كل ما يجمع بين الجماعة الأولية (التي يعبر بها كولي عن

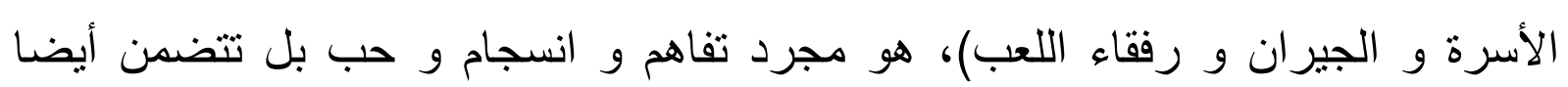

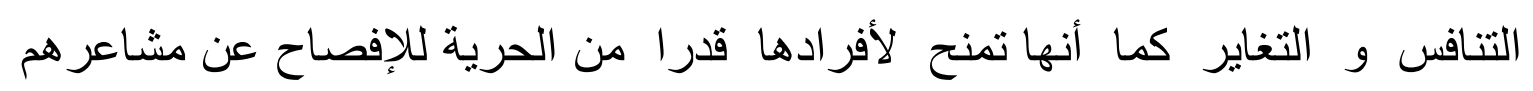

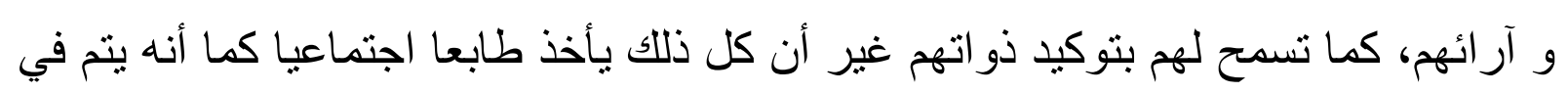
إطار الروح المشتركة للجماعة. 
فمثنا: يكون للفرد طموحات معينة، لكن الغاية الأساسية من هذه الطموحات هو الوصول إلى مكانة معينة عند الغير.

أو مثنا: الطالب في الفريق الرياضي المدرسي، قد يتخالف مع زملائه و يتعارض معهم، لكن يضع فوز فريق مدرسته فوق كل الاعنبار ات.

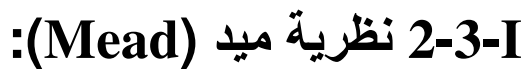

لقد نوسع (ميد) في شرح مفهوم مر آة الذات الذي بدأه (كولي)، و حسبه فالفرد يستجيب بالطريقة التي يتوقع إدر اكها من طرف الآخرين. و قد أورد (Mead) نوعين من الذات، فالأولى سماها "الذات المفردة" و تمثل الذات الحرة غير الممتثلة للقو اعد الاجتماعية و التقافية المكتسبة من طرف الفرد. و تمثل هذان النوعان المتفاعلان من الذات حسب (Mead) كدو افع للسلوك الإنساني. 3-3-I نظرية روجرز (Rogers) إن مفهوم الذات عند (روجرز) هو مفهوم مركزي في نظريته، حتى أن نظريته سميت ب "نظرية الذات الثخصية". و كما سبق و أن أثنارت إليه الباحثة من قبل، فإن (روجرز) يعادل في نظريته بين مصطلحي "الذات" و "مفهوم الذات"، و هو ما تبناه بعض الباحثين فيما بعد. و يعتبر (روجرز) الذات جزء من المجال الظاهري الذي يحدد السلوك كله، و هي تتكون من المدركات الثعورية و القيم المتعلقة ب "أنا"، و يستجيب الكائن ـككل منظمللمجال الظاهري من أجل إثباع حاجاته، و يمكن أن يكون المجال الظاهري شعوريا أو غير شعوري.

و يرى (روجرز) أن مفهوم الذات كمفهوم يتطور من تفاعل الكائن الحي مع البيئة و الكائن الحي لا يستجيب للبيئة الموضوعية، و لكن للبيئة كما يفهها أو يدركها هو و تحدد الحقيقة الذاتية أكثر من الموضوعية الكيفية التي يتصرف بها الفرد (د. مصطفى فهمي، بدون سنة،ص ص 98-99). و الكائن الحي يسلك بطرق تنسق مع مفهومه لذاته، و الخبرات غير المنسقة مع مفهومه لذاته يدركها الفرد كعوامل مهددة قد تؤدي به إلى الإصـابة بالاضطراب الانفعالي لذلك 
تتشكل دفاعات لإنكار هذه الخبرات على الثعور، فقد يشعر الكائن بالتهديد من الأفكار و الخبر ات غير المقبولة و الاحساسات الناتجة من نزعاته الذاتية الممنوعة أو المحرمة لذلك لكئل يعمد إلى استعمال آليات دفاعية قد تؤدي وظيفة نافعة في بعض الأحيان و في أحيان

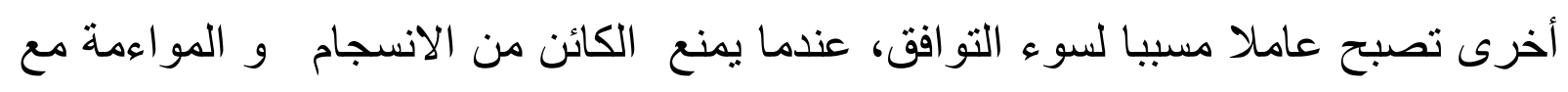
الواقع. (سونيا هانت و جينيفر هلتن، 1988، ص ص ص أب 342-343).

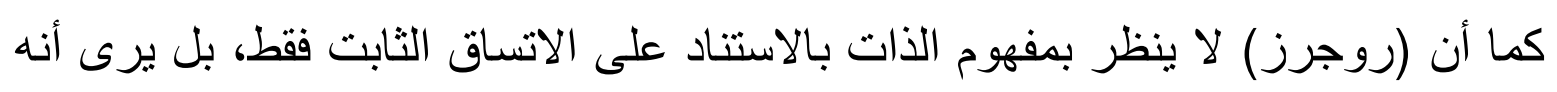
مفهوم قابل للتغيير عن طريق النضج و التعلم، و ذلك في ضوء تنظيم و إعادة تنظيم

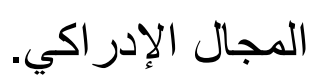

و وضع (روجرز) نظامين بعتقد أنهما أساسيان في بناء الشخصية، و هما: (مفهوم الذات) و (الكائن الحي)، و قد يتداخل هذان النظامان في تداخل أو انسجام فيكون التو افق أو سوء التو افق. و كلما تطور الوعي بالذات كلما نمت الحاجة إلى الاعتبار الإيجابي لأن هذا الاعتبار لا

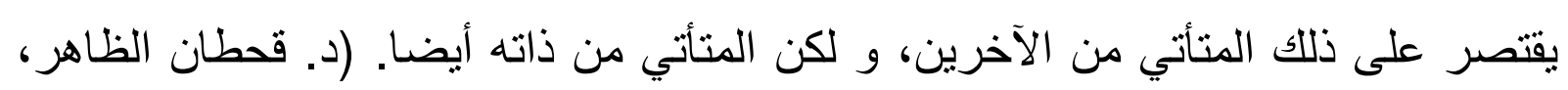

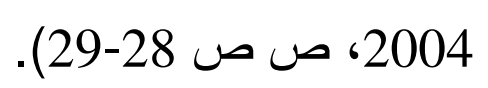
و وجود اعتبار الذات لاى الفرد يعني أنه ينال أثنياء مثل: الحب، التعاطف، الرعاية و و القبول من الآخرين. و تنشأ شروط الاعتبار الذاتي من خلال ما يلقنه الآباء ويتعلمه الأطفال من أنهم سوف الته

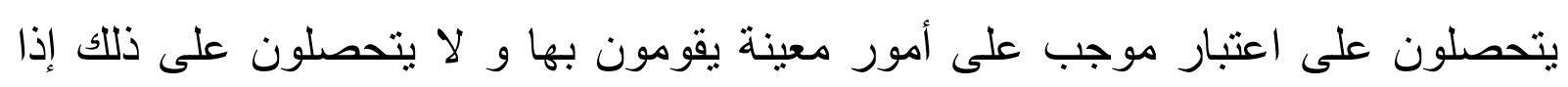
قامو ا بأمور معينة أخرى. (محمد محروس الثناوي، بلون سنة، 279).

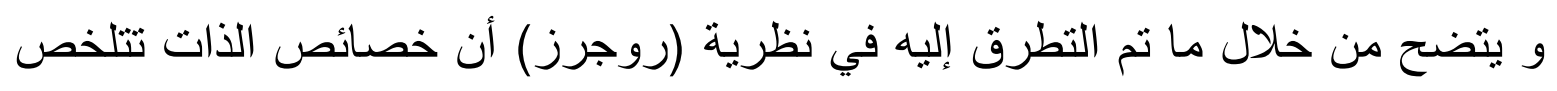
فيما يلي: ـ أنها تنمو من تفاعل الكائن مع البيئة. ـ أنها قد تمثل قيم الآخرين و تدركها بطريقة مشوهة. - يسلك الكائن بأساليب تتسق مع الذات. ـ الخبرات التي لا تتسق مع الذات تدرك على أنها تهديدات. 
- قد تتغير الذات نتيجة للنضج و التعلم. (د. زينب محمود شقير، 2002،ص ص

أما عن المفاهيم الرئيسية التي تؤكدها نظرية (روجرز) فيمكن إيجاز ها فيما يلي: 1) مفهوم الكائن العضوي (Organism): الذي هو الفرد ككل.

المجال الظاهري (phenomenal): الذي تمثل مجموع الخبرات الفردية، و الخبرة

هي حسب (روجرز) كل مسلوكه يجري بداخل بيئة الكائن الحي في أي لحظة. مفهوم الذات: التي و هي ذللك الجزء من المجال الظاهري الذي يتكون من نشكيلة من الإدر اكات و القيم المتعلقة بالذات أو بالأنا أو بالفرد كمصدر للخبرة و السلوك، و التي تحدد شخصية المميز له (مرجع سابق، 2002، 72). الميل إلى تحقيق الذات: هو الميل الفطري الموجود عند جميع البشر نحو حفظ و تعظيم أنفسهم.

الحاجة إلى الاعتبار الذاتي: هي الحاجة إلى الحصول على أثياء مثل: الدفء و المشاركة الوجدانية و العناية و الاحتر ام و القبول من الناس الذين لديهم علاقة بحياة الثخص. شروط الاستحقاق: هي الشروط التي تسمح للشخص أن ينال خبرة الاعتبار الإيجابي $(6$ (د.حلمي المليجي، 2001، 161).

\section{4-3-I نظرية فيرنون (Vernon):}

و لعل من أهم التطور ات الحديثة في نظرية الذات، ما قدمه فيرنون " Vernon "، حيث قسم (فيرنون) الذات إلى مستويات تتمنل فيما يلي: 1) المستوى الأعلى: و يتكون من عدد الذوات الاجتماعية العامة التي يعرضها الفرد للمعارف و الغرباء و الأخصائيين النفسانيين. 2) الذات الثعورية الخاصة: كما يدركها الفرد عادة و يعبر عنها لفظيا، و كما يشعر بها و و هذه يكثفها الفرد عادة لأصدقائه الحميمبين فقط. 
3) الذات البصيرة: التي تتحقق عندما يوضع الفرد في موقف تحليلي شامل، مثل ما يحدث في عملية العلاج النفسي الممركز حول العميل أو التوجيه النفسي. 4) الذات العميقة أو الذات المكبوتة: و عادة ما نتوصل إلى صورتها عن طريق العلاج التحليلي النفسي أو التحليل النفسي. و يلاحظ أن هذه المستويات التي جاء بها (Vernon) تتدرج من الأعلى إلى الأسفل وفق ما تتضمنه من مكونات شعورية أو غر شعورية. و قد أضاف (حامد زهران) إلى هذه المستويات مستوى آخر هو: مفهوم الذات الخاص: و يقصد به المستوى المطور من ذات الفرد الذي يفصح أثناءه الفرد عن أخطائه و ما يخجل منه. و يعتقد (حامد زهران) أن هذا المسنوى يقع في منطقة ما بين "الثعور" و "اللاشعور" (عبد الرحمن سليمان، 1996، ص ص ص 98-99).

4-I تعرف النفس - كما تم التطرق إليه آنفا- على أنها اللطيفة العالمة المدركة من الإنسان التي هي الإنسان بالحقيقة، و هي تساهم كثير ا في تحديد سلوك الإنسان و نوع علاقته بنفسه و ربه و الآخرين و هي توصف بأوصاف مختلفة و ذلك بحسب تأثنير ها على الإنسان و السلوك الناتج عن هذا التأثير فهي إما توجهه إلى الخير فيسلك سلوكا حسنا و إما توجهه إلى الضلال فيسلك سلوكا منحرفا. إن أنواع النفس الإسلامية كما تعامل معها الإسلام، و كما وردت في آيات القرآن الكريم ثلاثة هي: النفس الأمارة بالسوء، النفس اللوامة، النفس المطمئنة، و يضيف بعض الإنها المجتهدين نو عا رابعا أسموه "النفس الملهمة". أـ النفس الأمارة بالسوء: هي التي تميل إلى الطبيعة البدنية، و تأمر باللذات و الثهوات الحسية و تجذب القلب إلى الجهة السفلية فهي مأوى الثر و منبع الأخلاق الذميمة و الأفعال السيئة، و هي أدنى النفوس و أبعدها عن طاعة الله تعالى، لذلك فهي مستحقة لعقابه، و قد ورد ذكرها في قوله تعالى: "و ما أبرىئ نفسي إن النفس لأمارة بالسوء" [يوسف: 53]. 
النفس اللوامة هي التي تنورت بنور القلب تنورا قدر ما تتبهت به عن سنة الغفلة فتبقظت

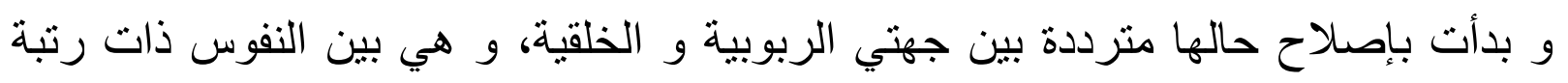
عالية لكنها أقل من رتبة النفس المطينّة، و هي النفس التي أقسم بها الله تعالى بمكانتها

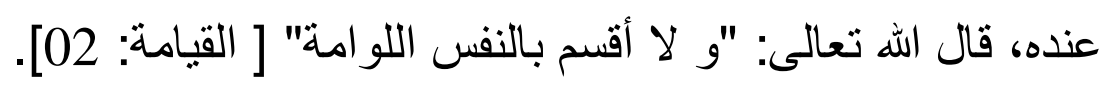

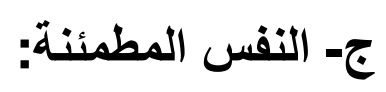

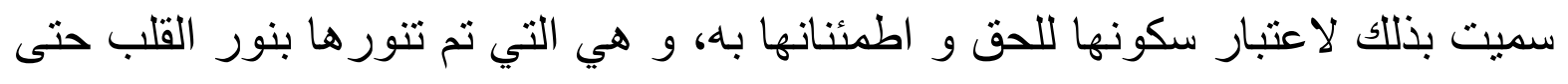

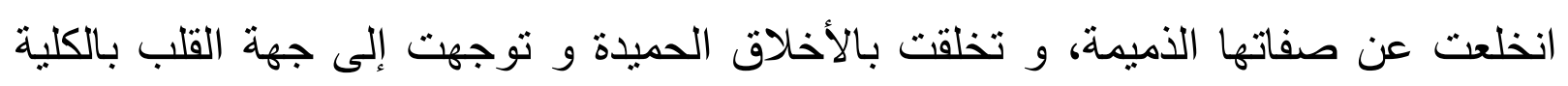

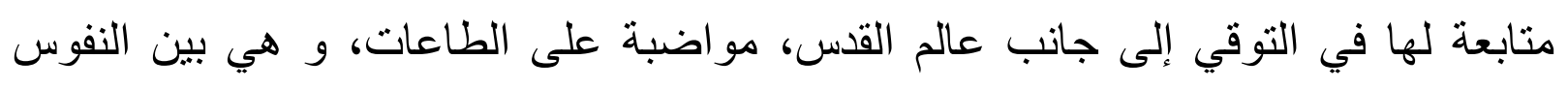

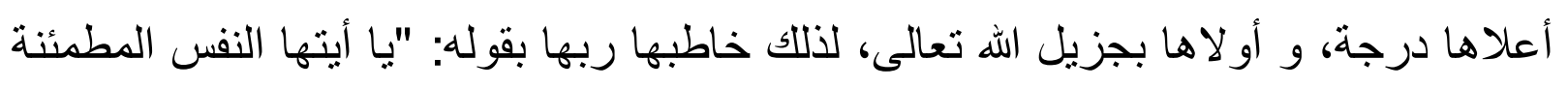

$$
\text { ارجعي إلى ربك راضية مرضية" [الفجر: 27-28]. }
$$

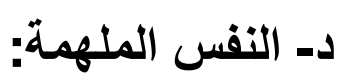

تسمى بذلك لاعتبار ما يلهمها الله تعالى القادر من الخير، فكل ما تفعله من الخير هو بالإلهام الإلهي و كل ما تفعله من الثر هو بالاقتضاء منها بمثابة الأمر لها بالفعل، فكأنها لهاريا

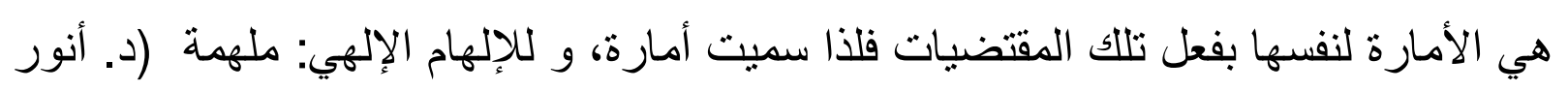

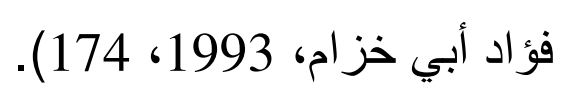

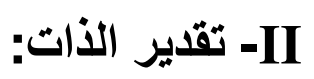

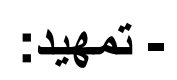
مع نمو الفرد تتدرج الحاجات النفسية تصاعديا، فالحاجات الفيسيولوجية هامة في مرحلة الحضانة بصفة خاصة، و الحاجة إلى الأمن تعتبر حاجة أساسية في الطفولة المبكرة

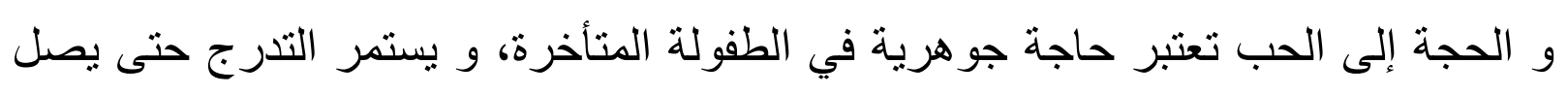
إلى الحاجة إلى تحقيق الذات وهي تعتبر من حاجات الرشند.

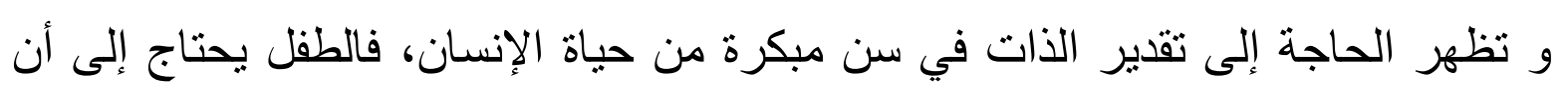

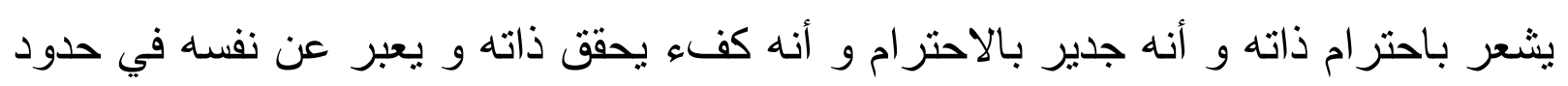

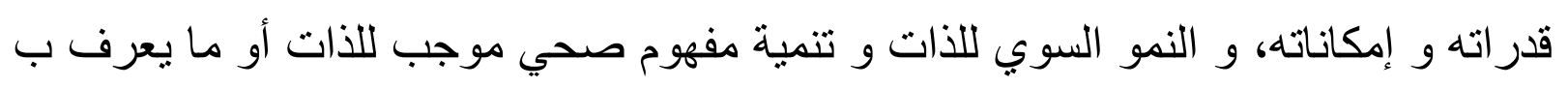


"التقدير الإيجابي للأات"، يحتاج إلى إثباع هذه الحاجة الأساسية (حامد زهران، 1988ص

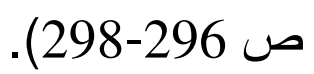

و حسب (ماكدوجال، Mcdougall) فإن تكامل الثخصية ينطلب ما يلي:

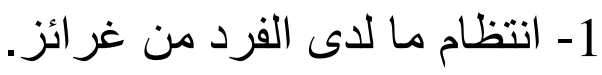
2- انتظام هذه العو اطف في بناء كامل في وحدة تتوجها عاطفة تقدير الذات، و هي العاطفة التي تدور فكرة المرء عن نفسه، و التي تأخذ الذات كموضوع لها و التي تحدد درجة تكاملها الثبات النهائي لطبع الفرد و أخلاقه. و قد بين (ماكدوجال) أن شكل هذه العاطفة (عاطفة تقدير الذات) و وجودها، يعتمد بشكل

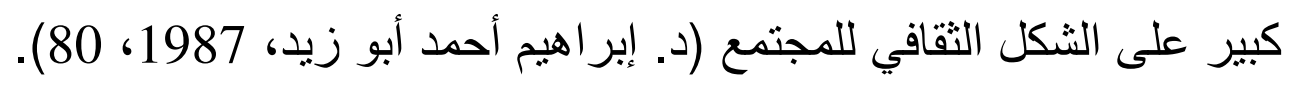
و يستعمل هذا المصطلح بعدة تسميات مثل: احترام الذات، اعتبار الذات، تقويم الذات. و ينمو تقدير الذات و ينطور خلال عملية عقلية تتمثل في تقييم الفرد لنفسه و من خلال

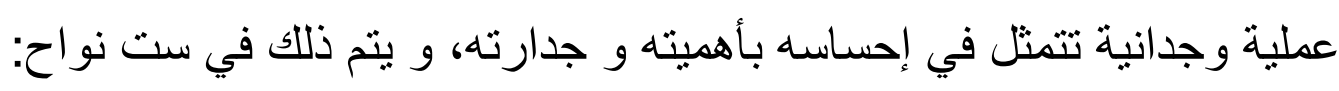
ـ المواهب الطبيعية الموروثة، مثل: الذكاء، و المظهر، و القدرات الطبيعية. ـ - م- الفضائل الأخلاقية و الاستقامة.

- الإنجاز ات و النجاحات في الحياة، مثل: المهارات، الممنلكات، الإنجاز ات. - الثعور بالأهلية أن يكون محبوبا.

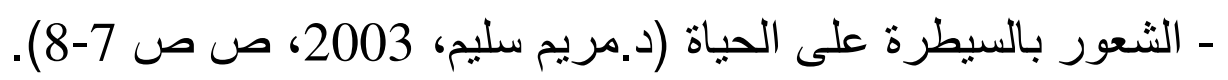

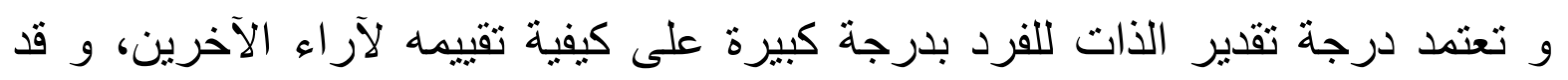

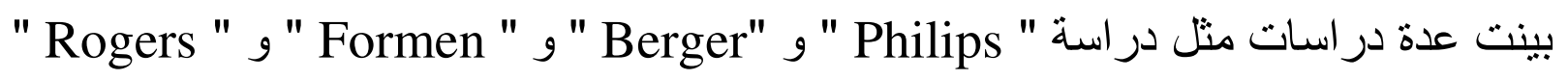
و آخرون، إلى أن تقدير الذات يرتبط إيجابيا بدرجة الاعتبار التي يصفها الفرد للآخرين و و تتمثل هذه العلاقة عادة في شكل ارتباط بين درجة تقبل الذات و درجة تقبل الآخرين

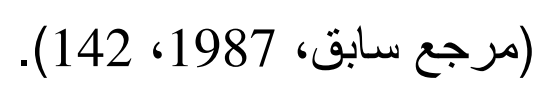

كما تثير الكثير من الدراسات إلى أن الذكور أكثر تقدير الذواتهم من الإناث، كما أن الذكور يعبرون عن قدر اتهم بشكل توكيدي و بثقة أكبر من الإناث. 
كما تلعب الثقافة دورا كبير ا في الفروق بين الجنسين من حيث الفرص التي تعطى لكل منهما و يبدو أن تقدير الذات المتعلق بالتحصيل أعلى منه عند الذكور مقارنة عند الإناث و و إن موضوع العلاقات يرتبط بالإناث أكثر منه عند الذكور. و تشير الدراسات إلى أن الذكور يأخذون امتياز ات ( Prestige ) من خلال الرياضة و و العلاقات و الذكاء، بينما الإناث يأخذون الامتياز ات من خلال المظهر و الجوانب الاجتماعية و التحصيل في المدرسة (د. منذر عبد الحميد الضامن، 2005، 193). و حالة تقدير الذات هي حالة شعورية كما قد تكون لاشعورية. و حسب " Rogers " فإنه على الرغم من أن تقدير الذات (سواء كان سلبيا أم إيجابيا) هو مستقر و ثابت نسبيا لغالبية الناس إلا أنه ينخفض و يرتفع تبعا للظروف التي يعيشها الفرد (مرجع سابق 2005، ص صد ص 195-190). و يكون تقدير الذات منخفضا إذا نظر الثخص لنفسه نظرة نقص أو عند ضعف ثقته في قدرته على القيام بأعماله اليومية، و يكون مرتفعا عندما تكون ثقة الشخص بنفسه كاملة، و يعد الثخص نفسه قادر ا على المنافسة و يكون تقييمه لذاته قويا (مايك كرسب 1422هـ،

1-II 1-1-II

يرى بعض الباحثين أنه إذا كان مفهوم الذات يعني "نحن"، فان تقدير الذات يعني كيف نشعر بأنفسنا، و بمعنى آخر فإن تقدير الذات هو الجانب التقييمي لمفهوم الذات (د. منذر عبد الحميد الضامن، 2005، 91). و يعارض البعض الآخر وجهة النظر هذه، حيث يرون أن "مفهوم الذات" أيضا يشتمل على تقييم أو تقويم الذات، لذلك فهم يعادلون بين مصطلحي "مفهوم الذات" و "تقدير الذات" و يرون عدم ضرورة الفصل بين المفهومين. 
إلا أن فريق آخر من الباحثين و العلماء يستعملون مصطلح "تقدير الذات" للإشارة فقط

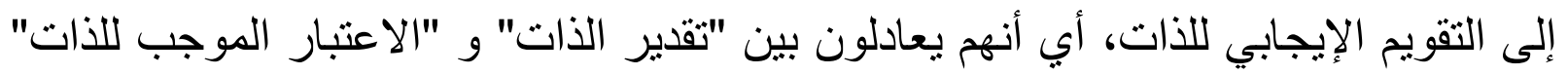
و و "الثقة في النفس" ...الخ. الإئ. 2-1-II

يعرف توكيد الذات على أنه: " التعبير المناسب _عدا القلق- نحو الآخرين عن المشاعر السلبية و الإيجابية و المواقفو القدرة على المبادأة و الاستمرار في التفاعلات الاجتماعية" (د. ظريف شوقي فرج، 1998، ص ص 52-53).

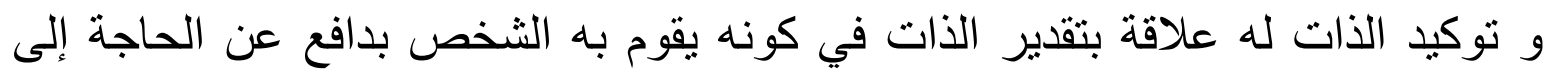

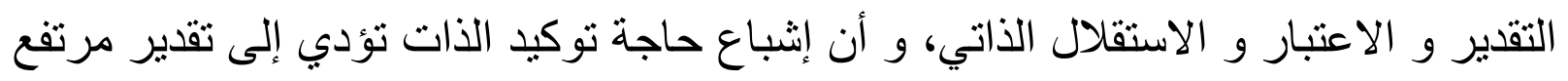
للأات و العكس صحيح. 3-1-II

عندما يحكم الفرد على نفسه و يقيمها فهو يمنحها صفة من الصفات بدرجة معينة و بالنسبة لمعيار معين يشتقه الفرد من المعايير الاجتماعية، و مستويات السلوك التي

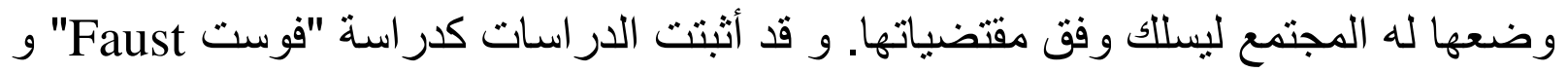

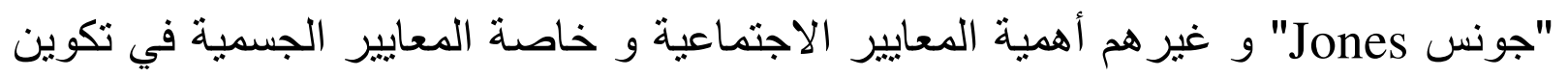

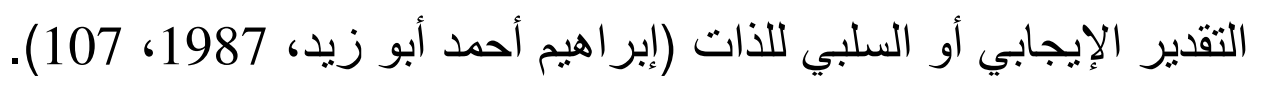

4-1-II

من المعلوم أن المعايير الثقافية و الاجتماعية تساهم بشكل كبير في تكوين و تقدير الذات لدى الفرد، لكن ذلك لا يتم إلا بتدخل العمليات الإدراكية، فتقدير الذات يعتمد بشكل كبير على الطريقة الني يدرك بها الفرد هذه المعايير. 5-1-II أوضحت نتائج العديد من الدراسات مثل دراسة ( Coombs، 1969) و غيره أن التفاعل

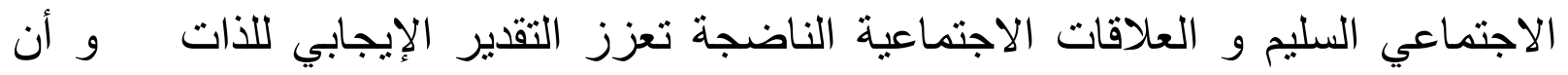

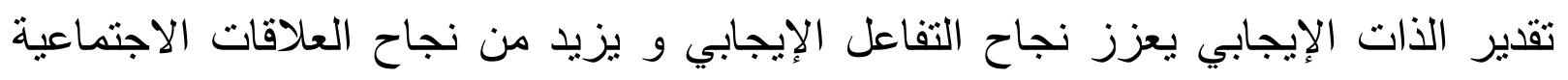

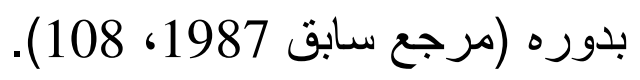




\section{6-1-II}

إن مستوى طموح الثخص يعتبر جزءا هاما من صورة ذاته، لأنه يمثل الفرد ليس فقط بما هو كائن عليه، و لكن بما يود أن يكون أيضا، و لذلك كان مستوى طموح الفرد يتحدد في الأغلب بكمية تقدير الذات التي يحتاج للحفاظ عليها. و قد سلم عدد من السيكلوجيين بأن السلوك في مستوى الطموح التجريبي هو وظيفة

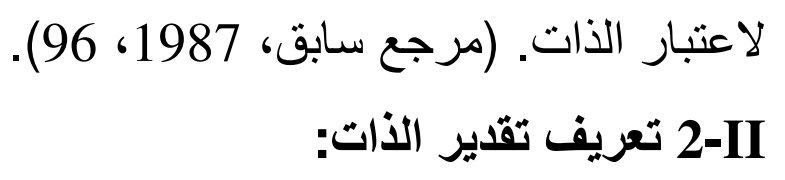

يعد تقدير الذات طبع في الثخص، و هو يقصد به:" الطريقة التي ينظر بها الإنسان إلى نفسه و يقيمها بهاو تنعكس على سلوكياته و تصرفاته، كما أنه نظام التقة الداخلي للثخص". و قد حظي هذا المفهوم -تقدير الذات- بعدة تعريفات من طرف بعض الباحثين و و العلماء، نذكر منها:

حسب (ماهر محمد عامر) فإن مصطلح تقدير الذات يدل على "مدى تقبل الثخص لنفسه بما فيها من إيجابيات و سلبيات، و مدى تقديره لخصائصها العامة، حيث بتضمن تقويما شاملا لكل جو انبها الثخصية و الاجتماعية و التربويةو المهنية، و كلما انخفض تقديره لذاته كان أقل تقبلا لذاته و أقل احتر اما لها". (ماهر محمد عامر، مفهوم الذات في الأسرة مجلة النفس المطمئنة، العدد 65، يناير 2001). و تعرف (ممدوحة سلامة، 1988) تقدير الذات بأنه: "تقويم الفرد العام لذاته فيما يتعلق

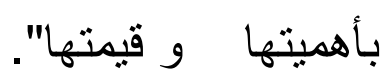
و يشير التقدير الإيجابي -حسبها- إلى مدى قبول الفرد لذاته و إعجابه بها على ما هي عليه و إدر اكه لذاته على أنه شخص ذو قيمة جدير باحترام الآخرين، أما التقدير السلبي للذات فيثير إلى عدم قبول الفرد لنفسه و تقليله من شأنها و شعوره بالنقص عند مقارنته لنفسه بالآخرين (د. حسين فايد، 2004، 241). و تعرفه (د. زينب محمود شقير) على أنه: "التقويم الذي يضعه الفرد لنفسه لكل من الصفات الحسنة و الصفات السيئة لديه في حياته" (د. زينب محمود شقير، تقدير الذات و العلاقات الاجتماعية المتبادلة و الثعور بالوحدة لدى عينتين من تلميذات المرحلة الإعدادية 
في كل من مصر و المملكة العربية السعودية، مجلة العلوم الاجتماعية، المجلد 21، العدد الأول و الثاني، ربيع صيف 1993). أما قاموس "ويبشر" فيعرفه على أنه: "ثقة الثخص بنفسه و رضاه عنها" (كوني فلادينو .) 13 2002 و يعرفه (إنجلش و إنجلش، English \& English) بأنه: "تقويم صريح للنقاط الحسنة و

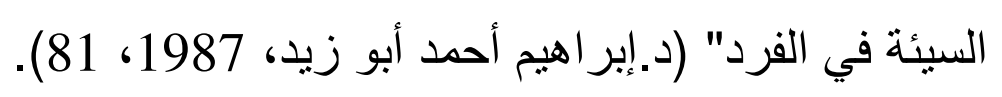
أما (سميث Smith، 1981) فيرى أن تقدير الذات هو: "الحكم على صلاحية الفرد من

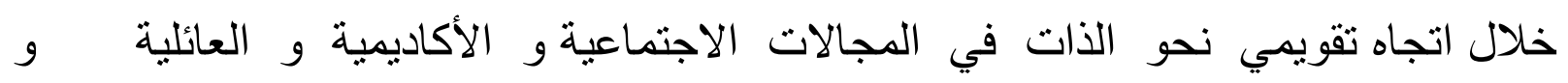

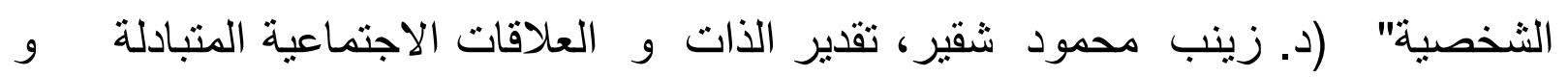
الشعور بالوحدة لدى لدى عينتين من تلميذات المرحلة الإعدادية في كل من مصر و و المملكة العربية السعودية، مجلة العلوم الاجتماعية ، المجلد 21 العدد الأول و الثاني ربيع صيف 1993). و يعتبر (كارل و رجرز: 1961) أنه محور الثخصية السليمة، فالأشخاص الذين يحبون أنفسهم لديهم مشاعر إيجابية نحو الآخرين و نحو أنفسهم بشكل عام، كما أن الأشخاص الذين يقدرون أنفسه تقدير ا منخفضا، لا يشعرون بالأمن في علاقاتهم مع الآخرين و يشعرون الآن

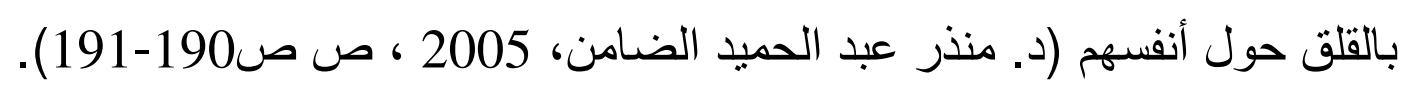
و يمكن أن نستخلص مما سبق ما يلي: بأي

يتضمن تقدير الذات التقويم الثامل للجوانب المختلفة من الثخصية (الاجتماعية

$$
\text { و الأكاديمية و العائلية و الثخصية...الخ). }
$$

- يتضمن تقدير الذات الحكم على أهمية الذات و قيمتهاو مدى صلاحيتها. - يتضمن تقدير الذات تقويم للصفات الحسنة و السيئة في الثخصية. - يكافئ مفهوم "تقدير الذات" عند بعض الباحثين ثقة الثخص في النفس و الرضا عنها. - يتضمن تقدير الذات نوعان: تقدير الذات الإيجابي و تقدير الذات السلبي. - يشمل تقدير الذات الإيجابي: رضا الفرد عن نفسه و ثقته فيها و إعجابه بها و الإحساس بقيمتها...الخ، كما أنه يشمل احتر ام الفرد للآخرين. 
أما تقدير الذات السلبي فيشتمل على: عدم قبول الثخص لنفسه و عدم احتر امه لها و التقليل من شأنهاو الشعور بالنقص...الخ. 3-II

إن تقدير الذات هو كعملية و كثيء يبحث عنه الناس و يكافحون من أجل إحرازه المحافظة عليه، فالأشخاص يطورون تمثيلات و أفكار عن الذات لها قوة دفاعية هائلة و إن إن إن هذه الأفكار من القوة بحيث تصبح أحيانا أكثر أهمية من الحياة ذاتها، فمثلا الناس الذين ينتحرون بعد خبرة جلبت لهم العار، إنهم يفضلون الموت على أن يعيشو ا مع احتقار أنفسهم و تصغيرها، كذلك في فقدان الثهية و لخدمة الأفكار عن الذات و تقييمها تصل إلى درجة الكمال الجسمي، تقوم بعض الفتيات الثابات غالبا بتجويع أنفسهن إلى درجة الموت (كارول. س دويك، 2006، 339)، فتقدير الشخص لذاته له أهمية كبيرة جدا في علاقته بنفسه و علاقته بالآخرين و علاقته بالحياة أيضا. و يقسم تقدير الذات إلى مستويين:

$$
\text { - تقدير الذات الإيجابي. }
$$

1-3-II

يثير التقدير الإيجابي للذات إلى مدى قبول الفرد لذاته و إعجابه بها على ما هي عليه و إدر اكه لذاته على أنه شخص ذو قيمة جدير باحتر ام و تقدير الآخرين (د. حسين فايد 2004،

و هو يتضمن أيضا احترام الفرد لمهار اته و قدراته و تتولد لديه قدرة فيما ينجزه من أعمال و لا يضعف أمام التحديات، كما يؤدي تقدير الذات المرتفع إلى الإحساس بالأمن الداخلي و بالر احة بحيث ينعكس ذللك في موقف إيجابي و اثق (مايك كرسب، 1422 هـ 17). و قد وجد كوبر سميث (Cooper Smith) في بحثه عن تقدير الذات، أن الأشخاص ذووا

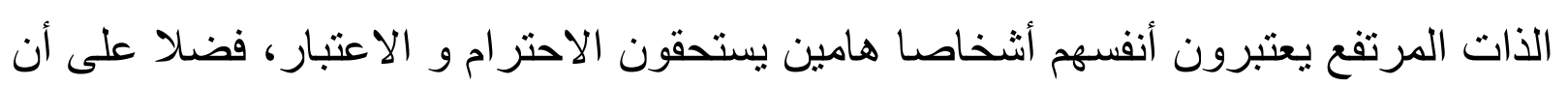

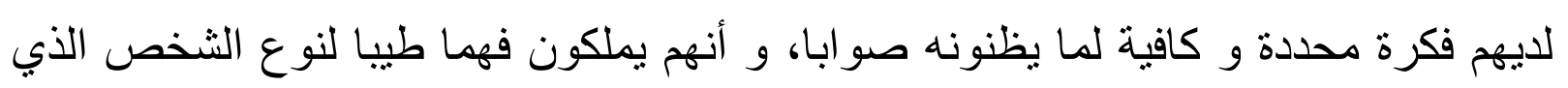


يكونونه كما أنهم بستمتعون بالتحدي و لا يضطربون عند الثدائد (إبراهيم أحمد أبو زيد، 1987، ص ص صن 82-81). و قد وضعت (د. مريم سليم) مجموعة من الخصائص التي تمكن أن ينم بها تحديد

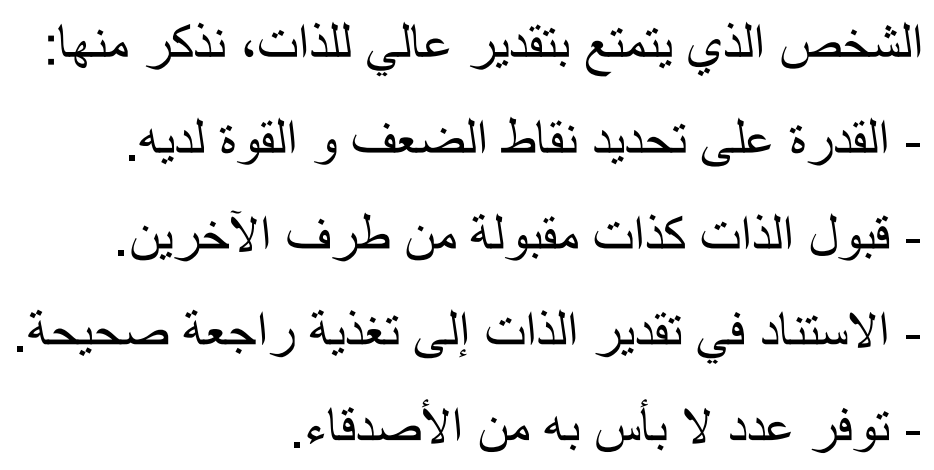
- القدرة على الانسجام مع الآخرين في مختلف المجالات و الميادين (العمل، الددرسة

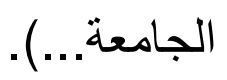
ـ الاستجابة للتحدي و القيام بمحاو لات جديدة. - عدم الثعور بالتهديد عند حدوث تغير ات أو ظهور مو اقف جديدة طارئة.

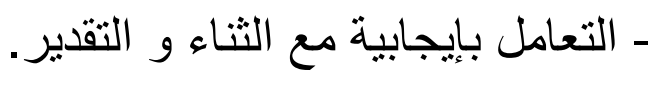
- تحديد الأهداف بدقة و موضو عية. ـ الثعور بالرضا عن الإنجازات الراجع إلى تحمل المسؤولية إزاء النتائج. ـ التعبير عن الآراءو وجهات النظر بصراحة و دون الخوف من رد فعل الآخرين.

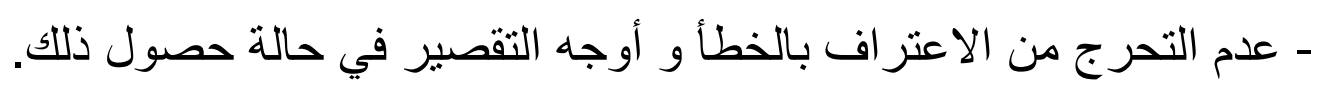
و غير ذلك من الخصائص التي يتميز بها الثخص ذو التقدير العالي للأات. 2-3-II يشير تقدير الذات السلبي إلى عدم قبول الفرد لنفسه و التقليل من شأنها و شعوره بالنقص

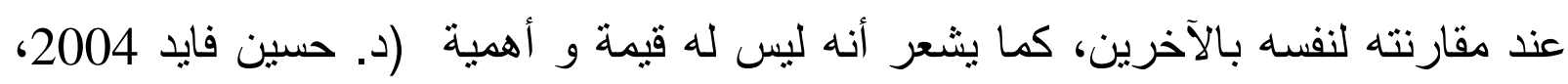
241) و لا يشعر بالأمن في علاقته بالآخرين كما يشعر بالقلق حول نفسه.

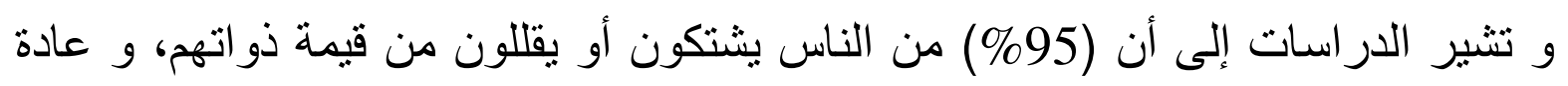

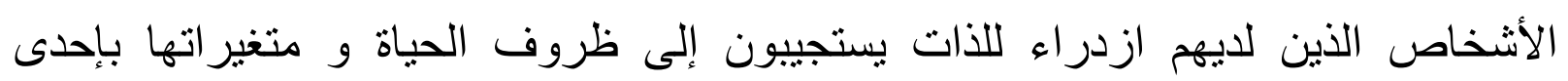
الطريقتين: 
- إما بالثعور بالنقص اتجاه أنفسهح.

- أو بالثعور بالغضب و الرغبة في الثأر من العالم (مبارك بقنة 2007/05/13). و قد وجد "كوبر سميث" (في بحثه دائما حول تقديرات الذات) أن الأشخاص ذووا التقدير

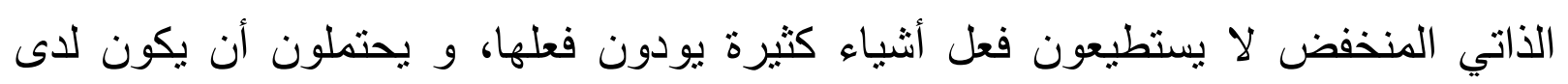
الآخرين أحسن مما لايهم، هذا فضلا على أنهم لا يستطيعون التحكم فيما يحدث لهم

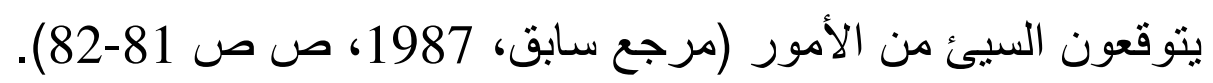
كما وضعت (د. مريم سليم) مجمو عة من الخصائص أيضا التي يمكن أن نحدد من خلاله الأشخاص ذووا التقدير المنخفض للذات و هي: تركيز الاهتمام في المحافظة على المشاعر الداخلية على الذات أي تفضيل ما يسمى "الفثل بشرف" بدل السعي و بذل الجهد في الوصول إلى النجاح.

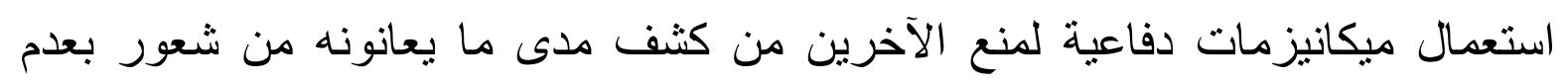
الأمن و القصور، و هي باختصار: التمرد، المقاومة، الثنك، إلقاء اللوم على عاتق الآخرين في حالة الفشل أو الخطأ الإستقواء على الآخرين أو تهديدهم، الانسحاب، الخجل، تعاطي المسكرات...الخ. و عادة ما يكون لتقدير الذات المنخفض عدة نتائج تنعكس على الفرد الذي يعاني منه نذكر منها: القلق، التونز، الثعور بالوحدة، الاحتمال المتز ايد للاكتئاب، إفساد العمل أو تدني التحصيل الأكاديمي، المشاكل في العلاقات و الصدقات، عادات سيئة كالتدخين...الخ. باتل و هؤلاء الأشخاص الذين يعانون من تقدير و اطي للذات، سو اء كانوا راشدين أو مر اهقين أو أطفالا فإنهم ير غبون في كل من: الحب و القبول و التقدير الإيجابي و الاحتر ام من قبل الآخرين، لذلك لابد من تزويدهم ب:

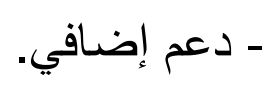

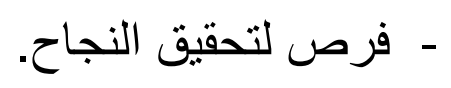
- تغذية راجعة.

- مشاعر تدل على أن هنالك من يهتم بهم (د. مريم سليم، 2003، ص ص 18-19). 


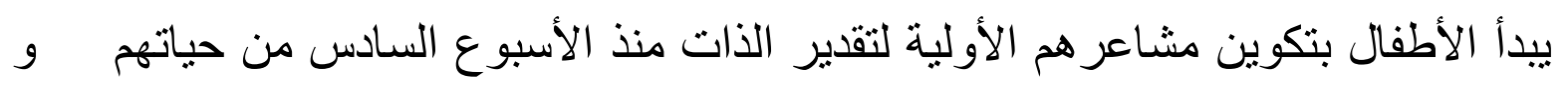
ذللك بالاستتاد إلى الكيفية التي بستجيب بها العالم من حولهم.

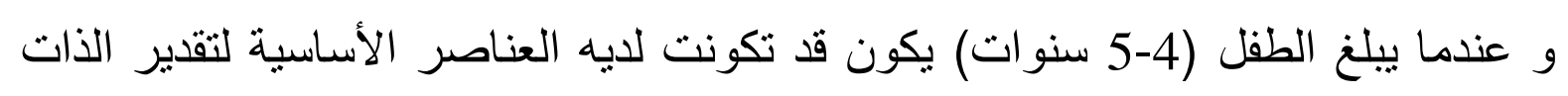

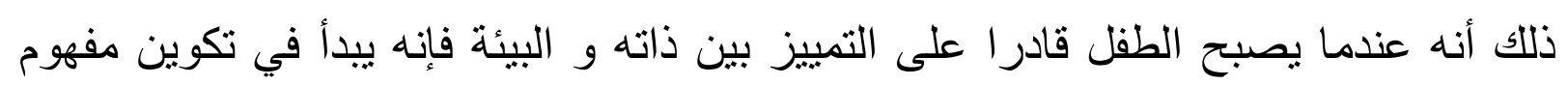

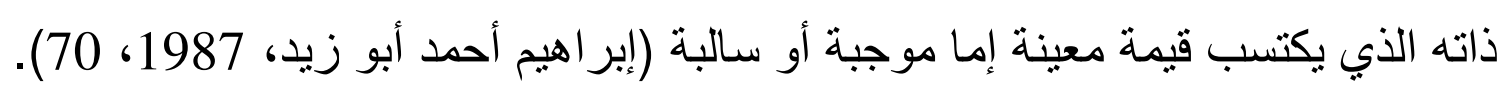

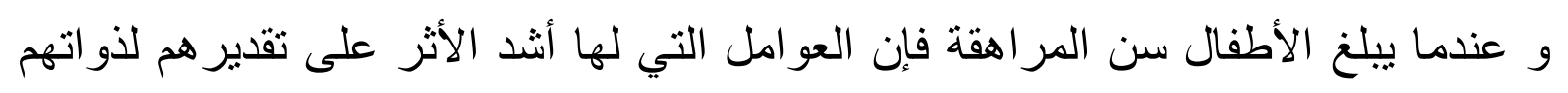
تبدأ بالتحول من إرضاء الكبار إلى كسب قبول الاطنال سن الأقران (الرفاق). كما يكرس المر اهقون وقتا كبير ا من الاهتمام ب: الهاه المظهر الخارجي، مو اكبة أخبار عالم المر اهقة الخاص بهم، التنفيس عن مشاعر هم. و يصبح الوضع الاجتماعي للمر اهق بين أقر انه مهما بالنسبة إليه.

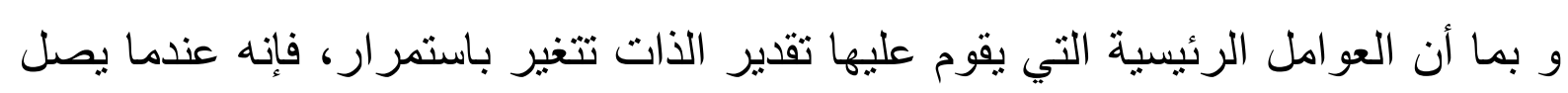
المر اهق إلى مرحلة الثانوية فإن القلق بشأن:

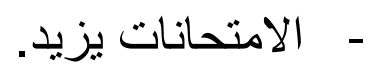

- تقل - ت أهية الثعبية الاجتماعية. - تعطى أهمية أقل لتقييم الفرد لقدر اته. و مع بداية مرحلة الرشد تعطى الأهمية لكل من: النجاح، الإنجاز ، و الدخل.

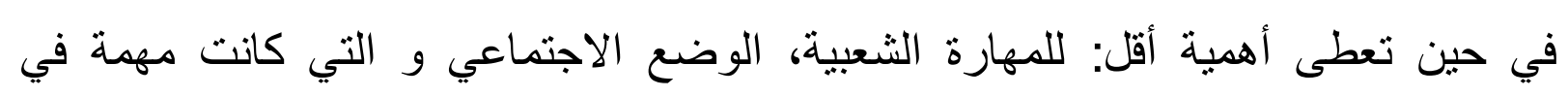

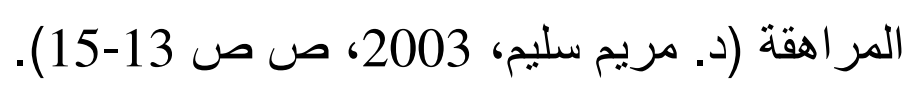
و كل هذه العوامل و الاهتمامات التي تخص الأشخاص - و التي سبق التطرق إليها-

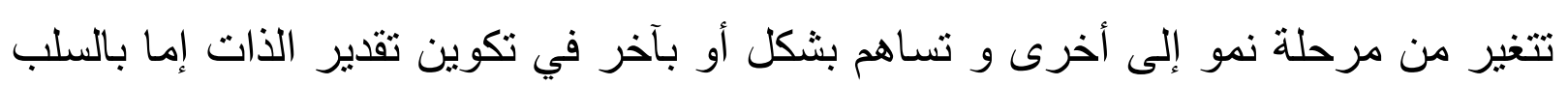

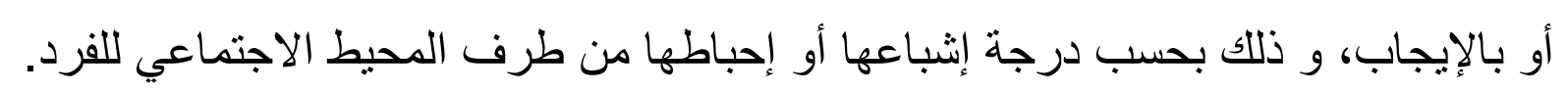

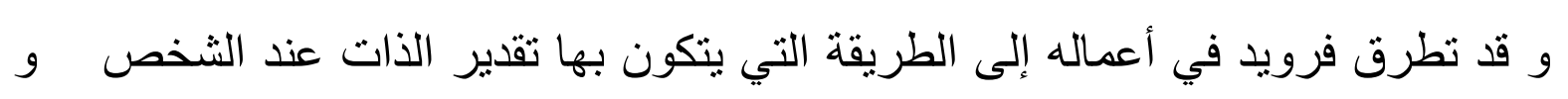
هو يرى أن تقدير الذات يتكون من خلال ما يلي:

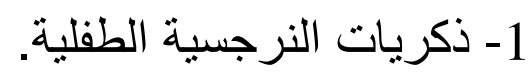


2- التوكيد على أثياء معينة أو نفيها عن طريق التجربة.

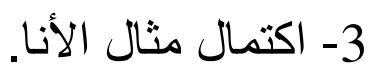

4- و أخيرا الإثباعات الليبيدية الني مصدر ها الموضوع. فبالنسبة للعنصر الأول و الثاني لهما علاقة بالتخلي المطلق عن النرجسية، و تجنب الأفعال التي تستدعي عدم رضا الو الدين (حيث يدرك الطفل عن طريق التجربة الأفعال التي التي تثير استحسان الو الدين فيقوم بها، و الأفعال التي تثير سخطهم فيتجنبها، و بساهم ذلك في

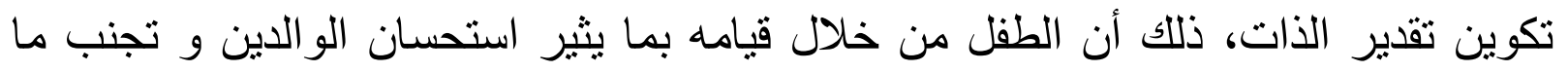

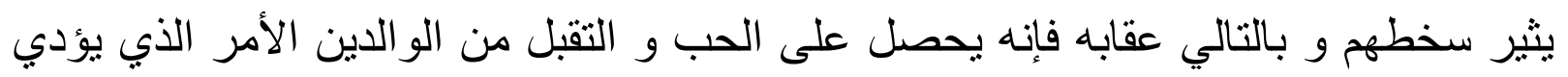

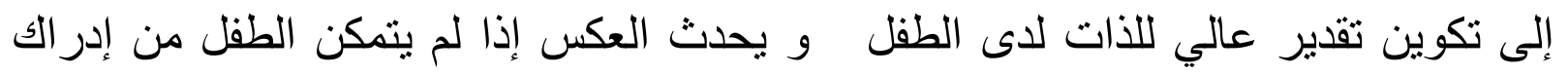
ذلك أو لم يهتم بإنباعه). أما بالنسبة للعنصر الثالث: فالصور الوالدية تقوم بدور رئيسي في تكوين تقدير الذات انطلاقا من مثال الأنا الو الدي الذي يسهم في تنكيل تقدير الذات بثكل كبير.

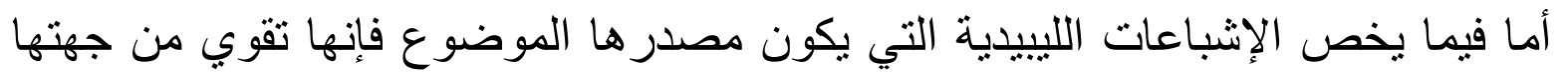

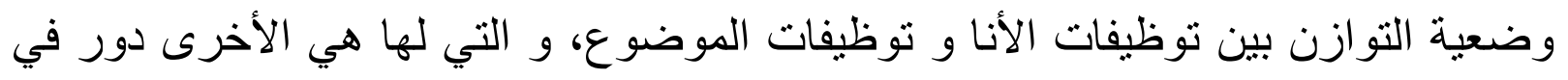

تكوين تقدير الذات (Gérard Poussin et Isabelle Say, 1990, p p 203-204). أما (Rogers) فيلخص -من خلال نظريته في الذات - الكيفية التي ينم بها تكوين تقدير

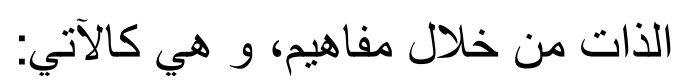
1- الحاجة إلى الاعتبار الإيجابي من الآخرين: و هي حاجة عامة ترنقي بظهور الوعي

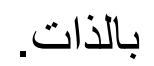
2- الحاجة إلى اعتبار الذات: و يكتسبها الفرد نتيجة لخبرات الذات بإثباع أو إحباط حاجتها إلى الاعتبار الذاتي، و تعمل الحاجة إلى اعتبار الذات مستقلة عن العلاقات مع الآخرين.

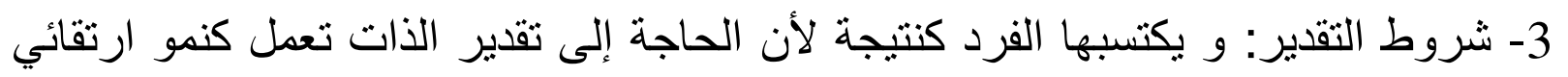
و هذه الثروط هي ما يساعد الفرد على تجنب بعض خبرات الذات و السعي وراء بعضها الآخر بناءا على استحقاقها أو عدم استحقاقها لاعتبار الذات (د. إبراهيم أحمد أبو زيد،

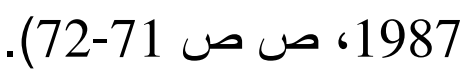


و يمكن أن نستخلص من كل ما سبق ما يلي: ينكون تقدير الذات الذي يحمل عادة قيمة معينة (إما موجبة أو سالبة) تبعا لما يلي: ـ الكيفية التي يستجيب بها الأفر اد الدهمين في حياتتا. - درجة النجاح التي نحققها في اجتياز كل مرحلة من مراحل النمو (د. مريم سليم، 2003

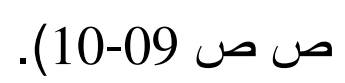

- مدى القدرة على التميز أو الفنشل بالمقارنة مع الآخرين، مثلا: القدرة على فعل أثنياء أحسن من الآخرين، أو الفثل في عمل أثنياء يحسنها معظم الآخرين.

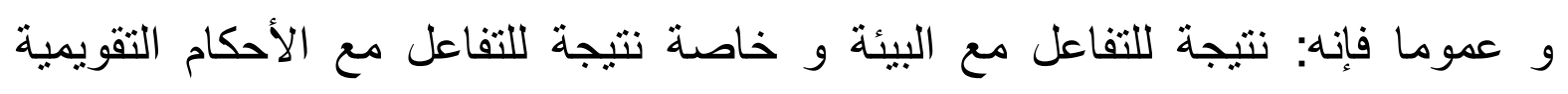

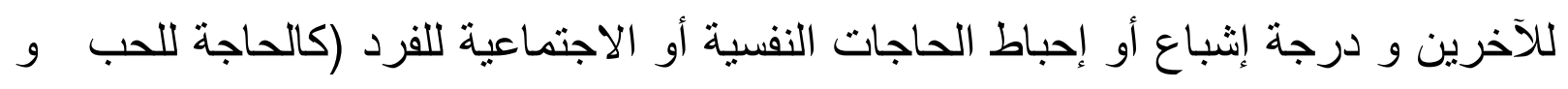

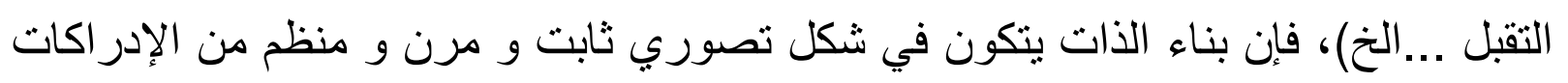

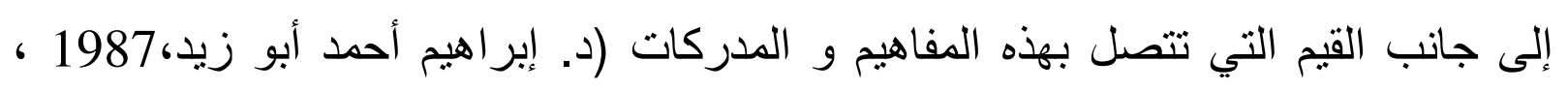
. (70

\section{5-II}

إن ظهور الكلام عند الطفل دليل على أنه بحاجة إلى الاستقلالية، و يمر تقديره لذاته بقدرة الو الدين على الاعثراف به كفرد مختلف له رأيه و كلمته.

و في حدود السنتين تكون المرحلة الأولى التي يعي فيها الفرد بقوته الثخصية. و بين (3-4 سنوات) ينسع عالم خيال الطفل، تظهر الدخاوف و إستراتيجيات الإغو اء...

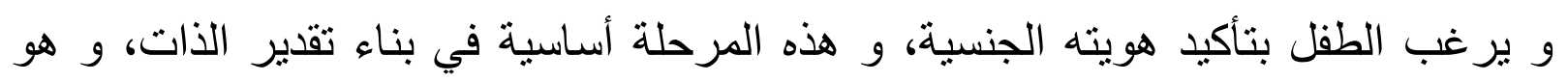

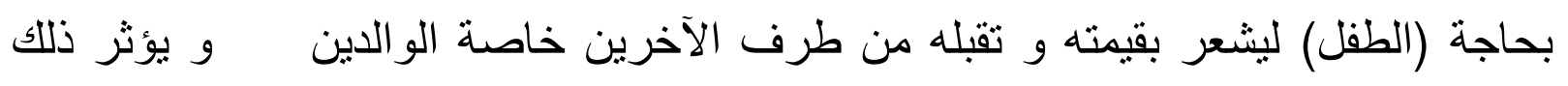

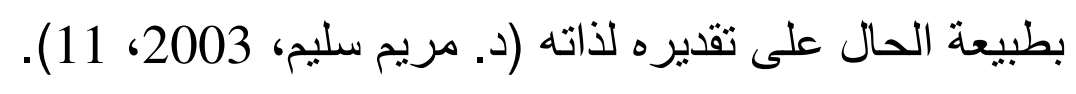

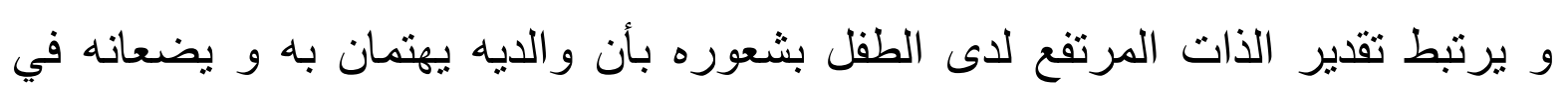

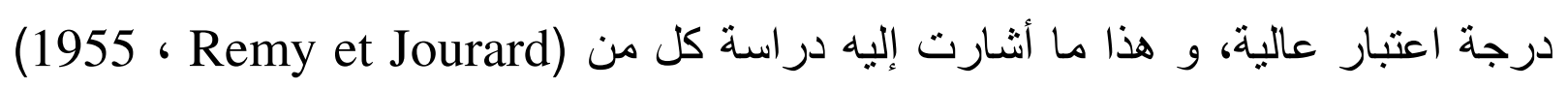

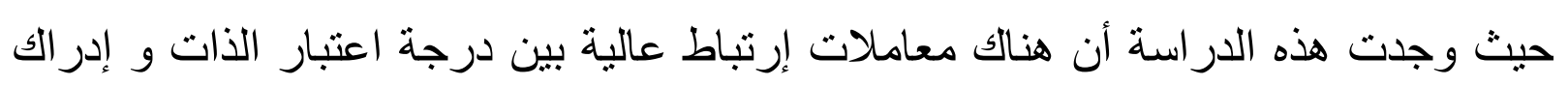

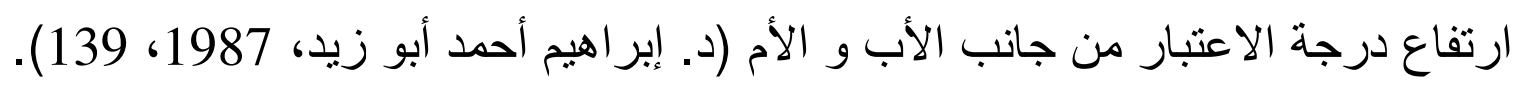


و بدخول الطفل إلى المدرسة (7-8 سنوات) تظهر عند الطفل البنيات العقلية التي تمكنه من التفكير و إصدار أحكام عملية، و هو يستطيع التعاون مع الرفاق و لديه رغبة في تعلم أشياء جديدة و تؤثر ضغوط الو الدين و المدرسة من أجل إتقان المهارات على تقدير الذات في هذه المرحلة. و لعل المر اهقة هي المرحلة الحرجة لتكوين و بناء تقدير الذات، فالتقدير ات الجسدية و و النفسية تشعر المراهق بالحاجة إلى الاستقلال و الابتعاد عن الكبار من أجل تأكيد الهوية الذاتية، و بالرغم من ذلك فيبقى بحاجة إلى مؤازرتهم و اعتر افهم بقيمته و تتميتهم شعوره بالاعتز از بذاته (د. مريم سليم 2003، ص ص ص بر 11-12). و عموما تشير الدراسات إلى أن تقدير الذات يصبح أكثر سلبية ما قبل المراهقة و أثناء مرحلة المراهقة المبكرة (12-13 سنة)، و يصل أدناه في حدود (13 سنة)، و يميل إلى الاستقرار خلال المر اهقة المتوسطة، و يبدو عليه التحسن خلال المراهقة المتأخرة و بداية

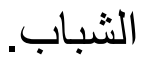
و هذا يعني أن الثعور الإيجابي نحو الذات ـعموما- يحدث في الطفولة و المر اهقة

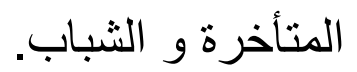

\section{أما عن الأسباب فهي كما أوضحتها الدر اسات كما يلي:} بالنسبة لانخفاض تقدير الذات في المراهقة المبكرة فيرجع إلى تأثير الأقران و الثعور بالعزلة و تحديات المدرسة و التغيرات الفيزيولوجية و الجسمية و النفسية التي تحدث في إي المر اهقة. - مقاه

أما عن سبب ارتفاع تقدير الذات في المراهقة المتأخرة و بداية الثباب فيرجع إلى المهارات الاجتماعية التي يكون قد اكتسبها الفرد، كذلك الخبرات التي مرجعها الرضا عن النفس كل ذلك يساهم في ارتفاع تقدير الذات (د. منذر عبد الحميد الضامن، $2005 \quad 193$ 
لقد استأثرت النفس (الذات) في الإسلام -كما سبق و أن أشرنا لذلك من قبل- بقسط وافر

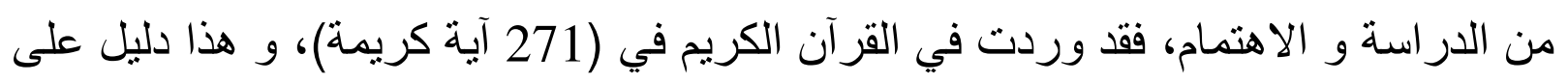
تقدير الدين الإسلامي للنفس الإنسانية من جهة، و للجانب النفسي من سلوك الإنسان و المجالات التي تظهر فيها الحياة النفسية من جهة أخرى، و كذلك على قيمة الخبرة النفسية الإنية

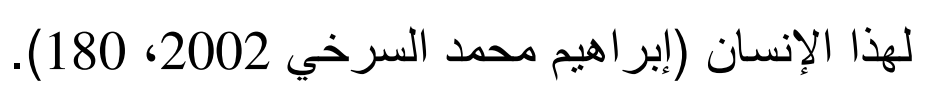

و لم يوجد مصطلح علم النفس إلا و يوجد ما يقابله (يعادله أو يحتويه) في الدين

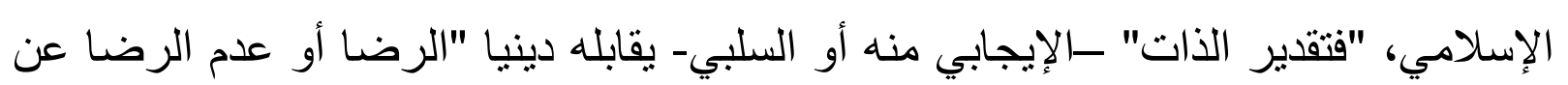

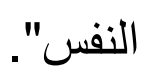

و يشير "الرضا عن النفس" إلى "رضا الفرد عن نفسه و تقبلها بما تثمله من قدرات و

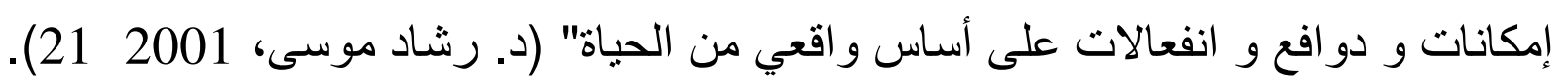

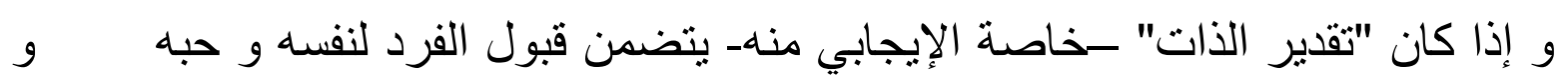
احترامه لها و يتعلق كل ذلك و بشكل كبير بمدى القبول الاجتماعي للفرد، فإن المصطلح

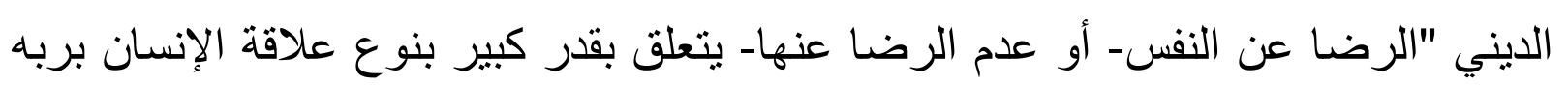

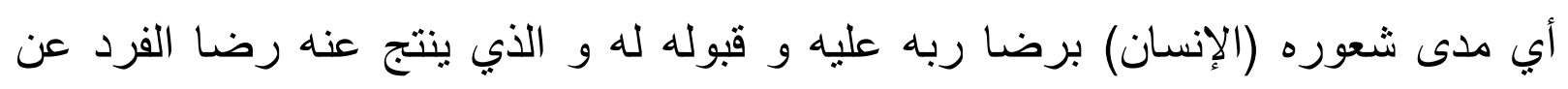
نفسه، كما يتعلق أيضا بالرضا بقضاء الله تعالى و قدره و الرضا عن الكون هذا بجانب التبان الرضا عن النفس بما تملكه من قدرات و إمكانات...الخ.

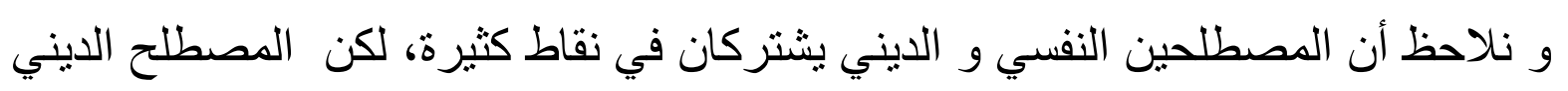

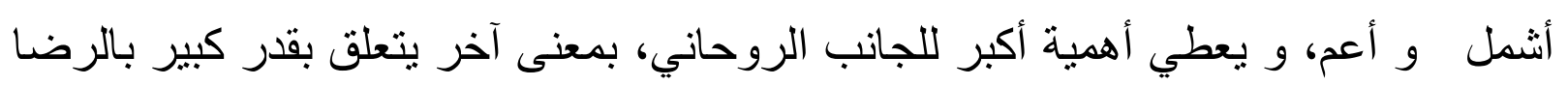

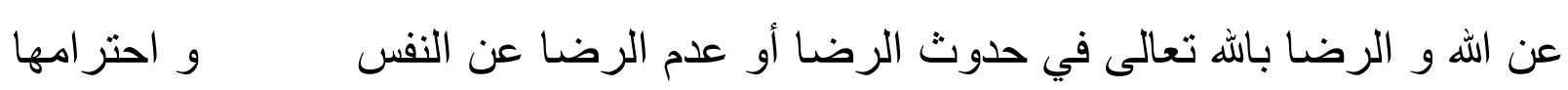

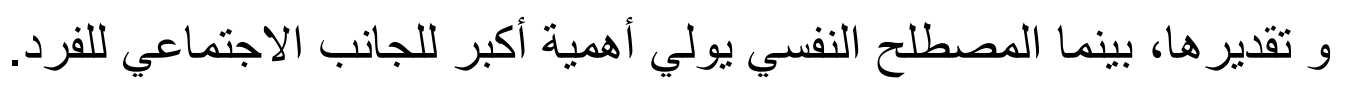

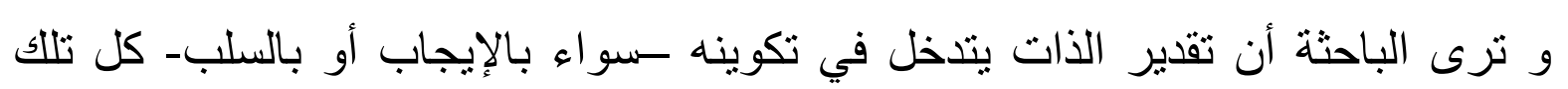

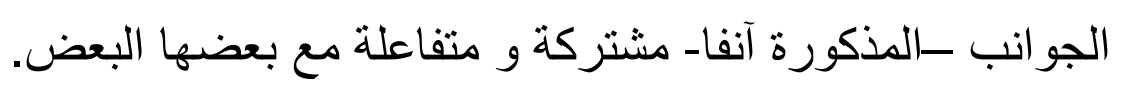

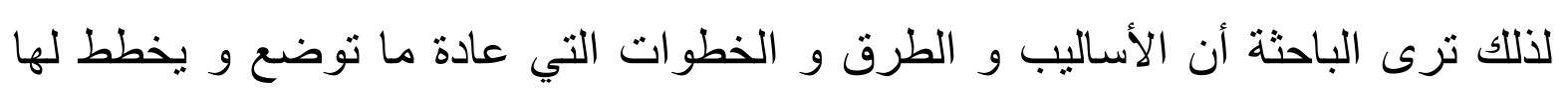

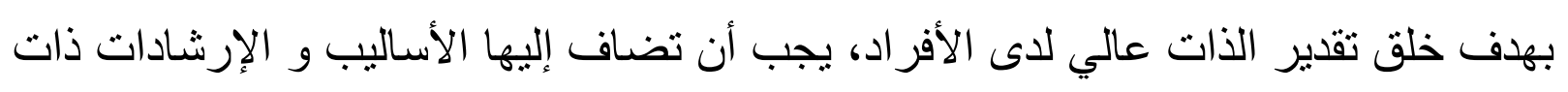

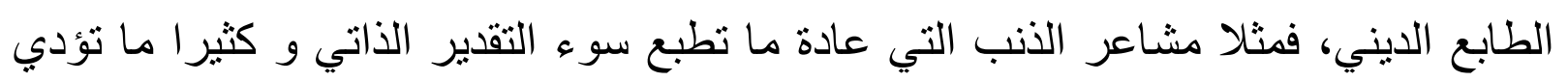


إليه، تجد لها حلولا فعالة في الدين، هذا طبعا دون التقليل من أهية أساليب العلاج و الإرشاد النفسي الأخرى في هذا المجال.

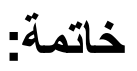

و ختاما فإن الوصول إلى تقدير ذات عالي و الحفاظ عليه هذه الأيام و في هذا العالم الذي يزداد تعقيدا ليس بالأمر الهين و ذلك لكثرة التجارب السيئة، و الانتقادات الموجهة التي لئي

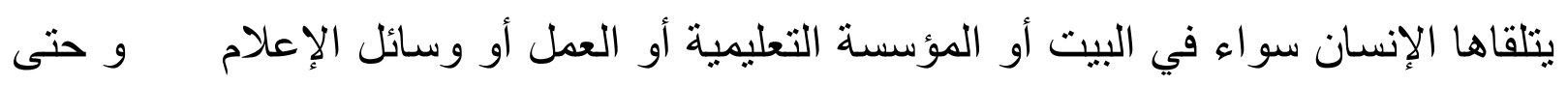

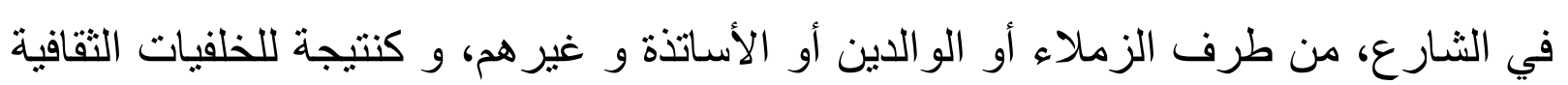

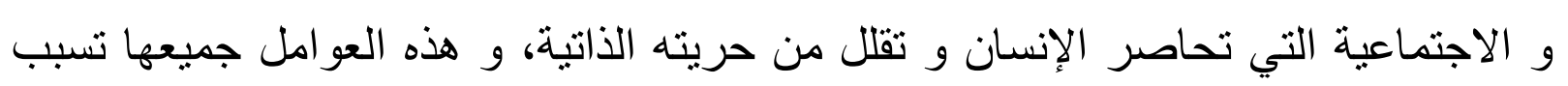
الخوف للإنسان و تجعله ينظر إلى ذاته نظرة نقص و احتقار و إذا ما تمت تقوية هذه الشاعر بنماذج سلبية من عدم الثقة فإنها تصبح عادة متأصلة و راسخة عند الفرد.

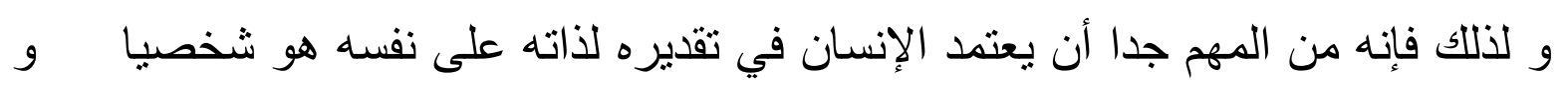
لا يجعل تقديره لذاته تابعا للآخرين و لا متعلقا بهم و بآر ائهم فيه.

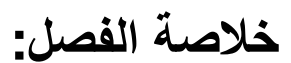

تناولت الباحثة في هذا الفصل موضوع تقدير الذات، حيث ارتأت أن تتعرض في البداية

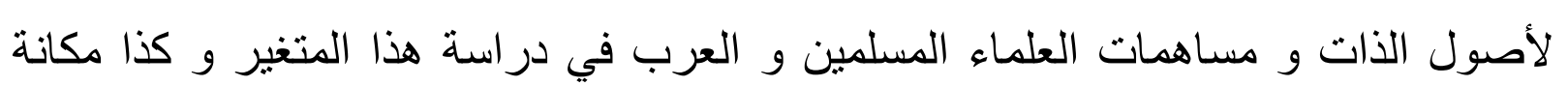
الذات (النفس) العظيمة في الدين الإسلامي.

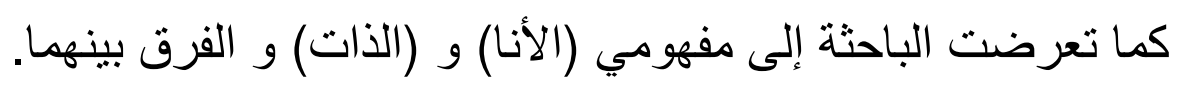


ثم قامت الباحثة بطرح مجموعة من التعاريف التي تتاولت مفهوم الذات، و ذلك لعدد من الباحثين و علماء النفس المسلمين و الغربيين و توصلت من خلال ذللك على مجموعة من

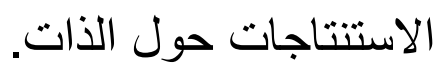
ثم تطرقت إلى مر احل نمو الذات و مظاهره عند الإنسان، و ذلك من خلال المراحل التي

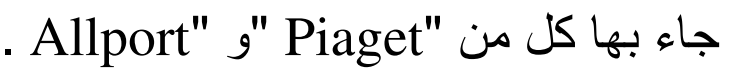
ثم تطرقت الباحثة إلى النظريات التي عالجت موضوع الذات، منها نظرية (كولي) و. و نظرية (روجرز) و نظرية (فيرنون)...الخ، حيث اتضح من خلال هذه النظريات إلى أنه يوجد عدة أنواع من الذوات، كالذات المادية و الذات الاجتماعية...الخ، هذا إلى جانب استنتاجات و ملاحظات أخرى. ثم تتاولت الباحثة وجهة النظر الإسلامية في الذات، حيث ترى وجهة النظر هذه أن للذات أو النفس أربعة أنواع، هي: النفس الأمارة بالسوء، النفس اللوامة، النفس المطمئنة النفس

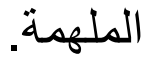
ثم انتقلت الباحثة إلى متغير تقدير الذات، حيث ارتأت إدراج بعض المفاهيم التي لها علافة بهذا المتغير مثل: مفهوم الذات، توكيد الذات...الخ.

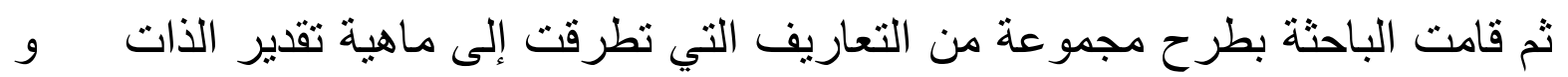
قد خرجت الباحثة من هذه التعاريف بمجموعة من الاستنتاجات. ثم تعرضت الباحثة إلى مستويات تقدير الذات و التي تتمثل في: تقدير الذات الإيجابي و تقدير الذات السلبي.

ثم تناولت الباحثة كيفية تكوين تقدير الذات عند الإنسان إبتداءا من الطفولة المبكرة و و إلى غاية المرحلة التي يتحدد فيها الثكل النهائي لتقدير الذات عند الفرد بشكل ثابت نسبيا. و أخير ا قامت الباحثة بعرض وجهة النظر الإسلامية في تقدير الذات، حيث بينت أن تقدير الذات يعادل إسلاميا مصطلح الرضا أو عدم الرضـا عن النفس. 

منهج و إجراءات الدراسة:

تتلخص إجراءات الدراسة في العناصر الآتية:

1- 1 - منهج الاراسة:

يعد اختبار منهج المستخدم في الدراسة من الخطوات الهامة و الأساسية في كل دراسة جادة، و يتم ذلك وفقا لعدة اعتبار ات منها:

طبيعة الموضوع المر اد دراسته، و نوعية الدراسة و الهدف منها.

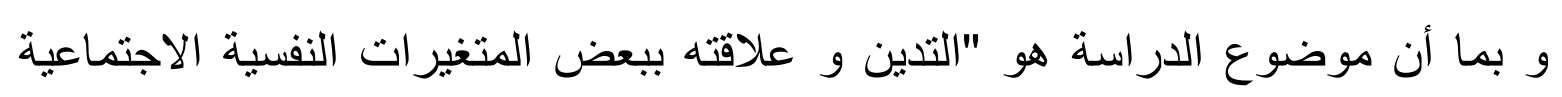

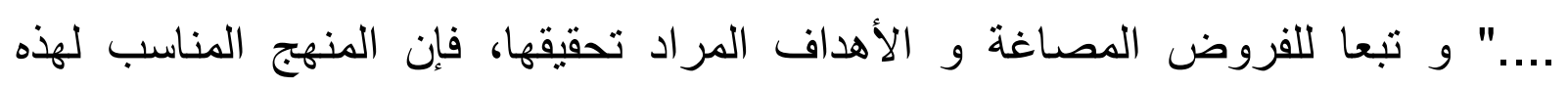


الدراسة هو النهج الوصفي الذي يقوم أساسا بوصف ما هو كائن و تفسيره دون إحداث أي

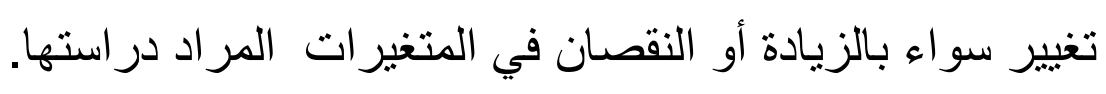

$$
\text { 2- 20 - مكان إجراء الدراسة: }
$$

ينحصر إجراء هذه الدراسة على مستوى ولايني سطيف و قسنطينة، و ذلك تماثيا مع العاء

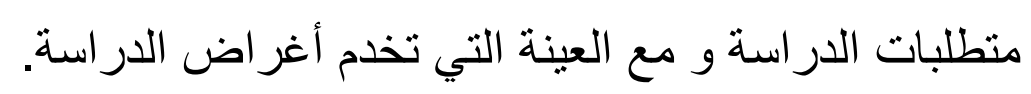

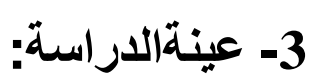

تثمل عينة الدراسة 204 طالبا و طالبة من طلاب الجامعة.

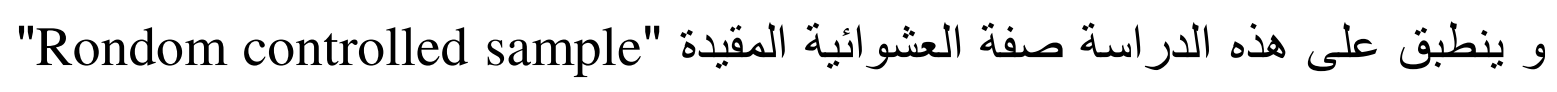

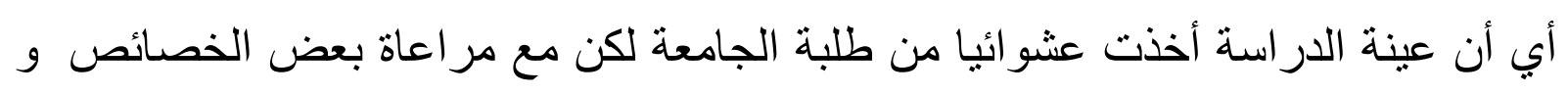

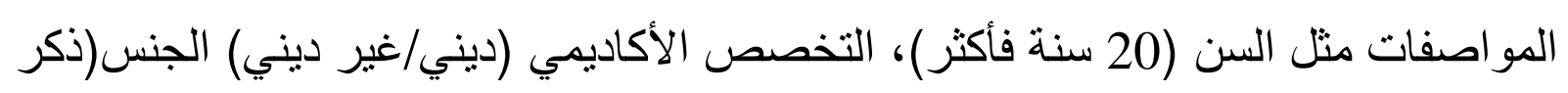
/ أنثى).

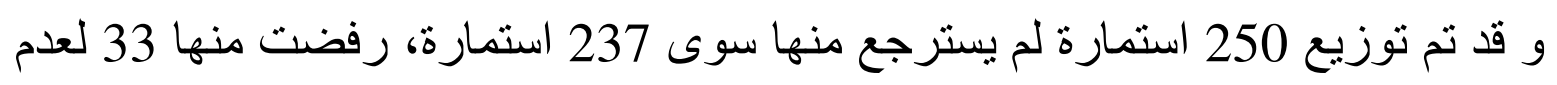
تطبيق التعليمات أو استيفاء الثروط المطلوبة، و بذلك أصبح العدد النهائي لأفراد عينة الدراسة هو: 204 فردا.

\section{1-3- - - مواصفات العينة:}

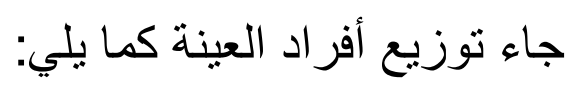

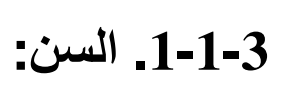

أخذت العينة من طلبة الجامعة الذنن تتجاوز أعمار هم (20 سنة) بمنوسط عمري يقدر ب

(22,33 سنة) ، و معظمهم يدرسون بالسنو ات النهائية (السنة الثالثة أو الر ابعة). و وقع اختيار الباحثة على هذه المرحلة الدراسية و العمرية الأسباب التالية:

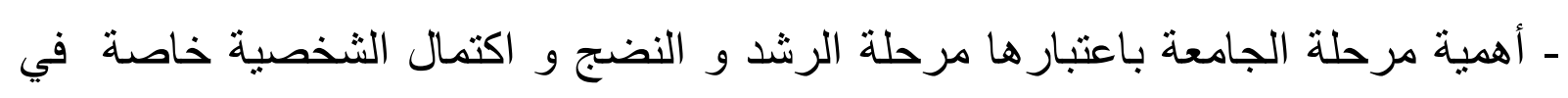
المر احل النهائية منها. ـ أهمية فئة الثباب في المجتمع باعتبار ها موردا بشريا و طاقويا هاما تتوقق عليها نهوض المجتمعات و تطور هاو ازدهار ها. 
- الأفراد في هذه المرحلة العمرية (20 سنة فأكثر) يكونون أكثر استقرارا في توجهاتهم الدينية و خصائصهم النفسية (منها التوافق الاجماعي و تقدير الذات).

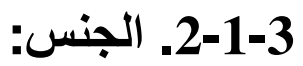
شملت عينة الدراسة أفراد من الجنسين (الذكور / الإناث)، و ذلك لمعرفة إذا كان هناك فروق في متغيرات الدراسة (التنين، التو افق الاجماعي، تقدير الذات) حسب متغير الجنس. و الجدول التالي يوضح نوزيع أفراد العينة حسب متغير الجنس: جدول (1): (1)

عدد الذكور و الإناث و النسبة المئوية لكل منهما في العينة الكلية.

\begin{tabular}{|c|c|c|}
\hline النسبة المئوية \% & العدد & الجنس - الجس \\
\hline$\% 47,06$ & 96 & ذكور \\
\hline$\% 52,94$ & 108 & إناث \\
\hline$\% 100$ & 204 & ل لمجموع \\
\hline
\end{tabular}

3-1-3 - - - 2-3 السنة الدراسية:

معظم أفراد عينة الدراسة هم من طلاب السنوات النهائية (الثالثة و الرابعة) و ذلك للأسباب التي تم التطرق إليها في العنصر السابق.

\section{4-1-3 - التخصص الأكاديمي:}

تثمل عينة الدراسة طلبة تخصصهم الدراسي (ديني)، و طلبة آخرين تخصصهم الدراسي (غير ديني) أو عام، و ذلك تمانشيا مع ما تتطلبه هذه الدراسة.

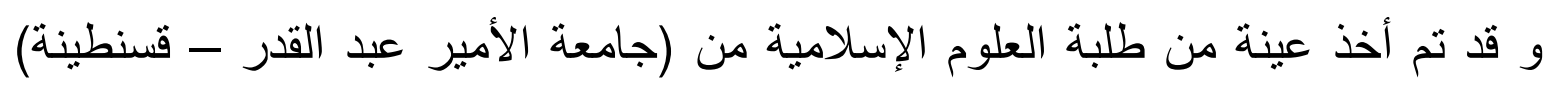

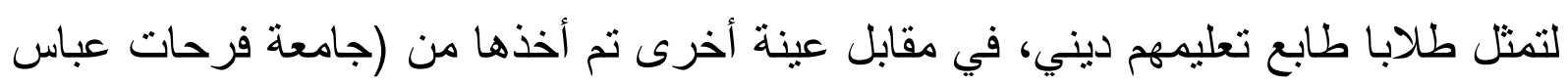
سطيف) لتمثل طلابا طابع تعليمهم غير ديني (عام). 
و تشمل عينة طلاب التعليم غير الديني أفرادا من تخصصات مختلفة، و تتمثل هذه التخصصات في (علم النفس، الطب،الحقوق، لغة إنجليزية، اللغة العربية و آدابها، اللغة الفرنسية، علم الاجتماع بيولوجيا، كيمياء حيوية) و ذلك بنسب مختلفة. و الجدول التالي يمثل عدد أفر اد العينة في كل تخصص دراسي (ديني / غير ديني) و و النسب المئوية لكل منهما:

جدول (2)

عدد أفراد العينة حسب التخصص الدراسي (ديني / غير ديني) و النسبة المئوية لكل منهما

\begin{tabular}{|c|c|c|}
\hline النسبة المئوية \% & العدد & التخصص \\
\hline$\% 48,04$ & 98 & ديني \\
\hline$\% 51,96$ & 106 & غير ديني (عام) \\
\hline$\% 100$ & 204 & المجموع \\
\hline
\end{tabular}

4- أدوات القياس: يرتبط اختيار الأداة أو إعدادها ارتباطا وثثقا بأهداف الدراسة، و تعتبر هذه الخطوة جد مهمة، إذ أن نتائج الدراسة و صدقها يعتمد بدرجة كبيرة على مدى مناسبة و صلاحية هذه الأدوات و مدى ثباتها و صدقها في قياس الخاصية موضع الدر اسة. 1-4. الاستبيان (استبيان التدين الإسلامي): يعرف التدين (الإسلامي) إجرائيا بأنه: " ما يقوم به الفرد من ممارسات دينية تنبع من إيمان عميق بالله تعالى، تتمثل في العبادات و المعاملات و الأخلاق، و ذللك في محاولة إرضاء خالقه و تحسين علاقاته بالآخرين و تمثلك بالأخلاق الحميدة التي يدعو إليها الدين

$$
\text { الإسلامي" (د. رشاد موسى، 1999، 678). }
$$

و قد قامت الباحثة بتصميم استبيان مستوى التدين الإسلامي، و الذي يهدف إلى قياس مستوى التدين لاى أفر اد عينة الدر اسة المتمتلين في طلبة الجامعة. 
اعتمدت الباحثة في تصميم الاستبيان على الدراسة الاستطلاعية، هذه الأخيرة التي تعد تقنية تستخدم كتمهيد للار اسة و ذلك من خلال جمع بيانات عن الدر اسة الهدف منها: إن الهدف من إجراء الدراسة الاستطلاعية في هذه الدراسة هو التعرف على مختلف الجوانب و الأبعاد المكونة لمتغير "التدين"، و مختلف الصفات و السمات و الخصائص التي يمكن بها تحديد الأشخاص المتدينين تدينا مرتفعا، و هذا ما سوف يساعد الباحثة على 9 بناء خلفية للاستبيان الذي تعده بهدف قياس مستوى التدين لدى أفراد عينة الدراسة مدى تطابقه ثقافيا مع هذه العينة. و لقد اعتمدت الباحثة في در استها الاستطلاعية على ما يلي:

1- الاستمارة:

لقد اعتمدت الباحثة في در استها الاستطلاعية على الاستمارة التي كانت على شكل سؤ ال مفتوح موجه إلى أفراد العينة الاستطلاعية، و ذللك لإعطاء حرية أكبر للمبحوثين كي يدلو الو بمعلومات واسعة قد تكون مفيدة في بناء الاستبيان المتعلق بقياس مسنوى التدين الإسلامي. و كان السؤال على الثكل التالي: - ما هي أهم أبعاد و جو انب التدين؟ - ما هي الصفات و الخصائص و السلوكيات التي يتميز بها الثخص المتدين عن غيره في

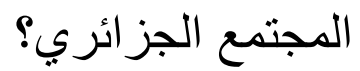
و قد شملت عينة الدر اسة ما يلي: - 7 أئعة مساجد بو لاية سطيف. - 2 دكاترة في الثريعة الإسلامية. - و بعض طلاب الماجيستير في العلوم الإسلامية. و قد تم توزيع هذه الاستمارات و الحصول على الاستجابات خلال أثنهر (جويلية أوت، سبتمبر من عام 2006). 
2- الإطلاع على التراث الثقافي و النفس-ديني و الدراسات السابقة، و كذلك الدفاهيم النظرية للندين و أبعاده المختلفة، و ذلك بهدف الإلمام بمختلف الجوانب و الأبعاد الدكونة

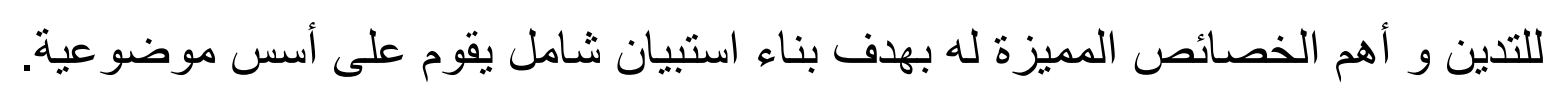

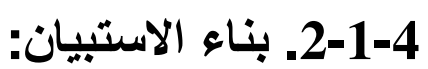
بعد تحليل نتائج الدراسة الاستطلاعية بمختلف مصادرها، تم التوصل إلى الدحاور

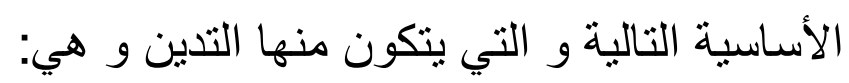

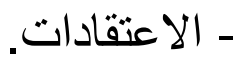
ـ ـ العبادات. كما تم الحصول على أهم السمات و الخصائص التي تندرج تحت كل محور من الححاور

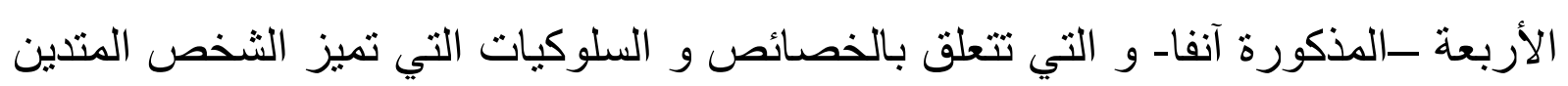

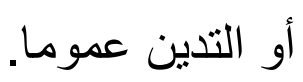
و قد قامت الباحثة بتحوير الإجابات و المعلومات التي تم الحصول عليها من خلال الدراسة الاستطلاعية في شكل بنود "Items"، حيث أن الاستبيان في معظمه هو إعادة تركيب و بسط لإجابات العينة الاستطلاعية من خلال البحث الاستطلاعي الذي أجرته

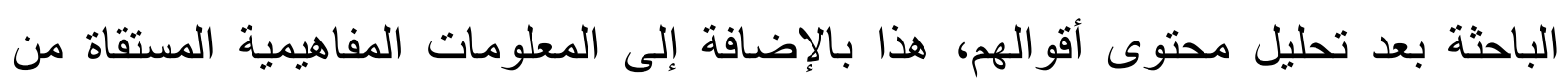
الكتب و المصادر العلمية و التي أخذت منها الباحثة ما يخدم الاستييان.

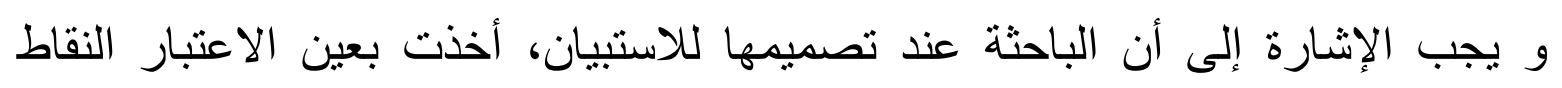

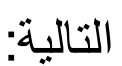
- اكثقت الباحثة بإدر اج المو اضيع الدينية التي يشترك فيها كل من الجنسين (الذكور و و

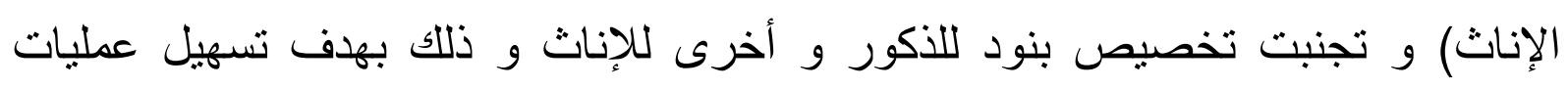
المعالجة و التحليل و التقييم ، بالإضافة إلى نوفر كم لا بأس به من السمات و الخصائص التي يشترك فيها كلا الجنسين و التي تكفي لتغطية الخاصية محل القياس. 
ـ تجنبت الباحثة إدراج المواضيع و القيم الدينية غير السائدة في المجتمع الجزائري. حيث من المعروف وجود اختلافات بين المسلمين في بعض الفروع (و ليس في الأصول طبعا). تقنين المقياس: بعد أن تم تحديد أبعاد (محاور) المقياس الأربعة ـالتي تم ذكرها سابقا- تم صياغة العبارات ( البنود) التي تتدرج تحت كل بعد، ثم تم عرض الاستبيان على 8 محكمين من أساتذة علم النفس و دكاترة و مختصين في القياس النفسي للتعرف على مدى ملاءمة العبارات لقياس مستوى التدين (إن كانت تقيسه فعلا أم لا ؟ و مدى ملاءمة الصياغة

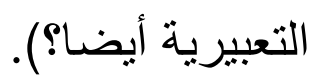
و قد وافق المحكمون على محاور الاستبيان أولا، كما تم حذف بعض العبار ات من كل بعد ثانيا و تم أيضا إعادة صياغة بعض الفقرات، كما نصح بعض المحكمين الباحثة بزيادة عدد من البنود حتى يصبح الاستبيان أكثر شمولية، و هو ما دفع الباحثة إلى إضافة 8 بنود تتوزع على المحاور الأربعة المكونة للاستبيان. ليصبح الاستبيان في شكله النهائي يحتوي على 48 بندا موزعة على ثلاثة محاور و هي: الاعتقادات، العبادات، الأخلاق و المعاملات. 3-1-4. وصف الاستبيان: يتكون الاسنبيان في صورته النهائية من 48 بندا تتوزع على 3 محاور كما يبينها

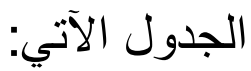

جدول (3)

توزيع البنود على محاور الاستبيان

\begin{tabular}{|c|c|}
\hline عدد البنود & اسم المحور \\
\hline 13 بندا & الاعتقادات \\
\hline 12 بندا & العبادات \\
\hline 23 بندا & الأخلاق و المعاملات \\
\hline
\end{tabular}


و يجب الإشارة إلى أن الباحثة قامت بدمج كل من محوري (الأخلاق) و (المعاملات) في محور واحد، و ذللك لكثرة التداخل بين عبار ات كل منهما و صعوبة التفريق بينهما و و در عا للوقوع في الخلط. و قد تمت صياغة 99 عبارة للاستبيان في البداية، و بعد المراحل التي مر بها الاستبيان - - و التي تم ذكر ها آنفا- و التي خضع فيها هذا الأخير لعدة مر اجعات تقييمات و تصحيحات من طرف أساتذة و دكاترة و مختصين في القياس النفسي بالاستعانة ببعض الأساتذة الذين يجمعون بين التخصص النفسي و الديني، أصبح عدد عبارات الاستبيان 48 عبارة موز عة على ثناثة محاور. أما عن شكل الاستبيان الذي تم توزيعه على أفراد عينة البحث موضوع الدراسة، فقد قامت الباحثة بخلط عبار ات الاستبيان، و جاء الترتيب بوضع سؤال من محور الاعتقادات و سؤال من محور العبادات و سؤالين من محور الأخلاق و المعاملات، و هكذا دواليك. 4-1-4. تقديم الاستبيان: يطلب من أفر اد العينة أن يقوموا بالإجابة على عبار ات المقياس بإعطاء تقدير و اضح و

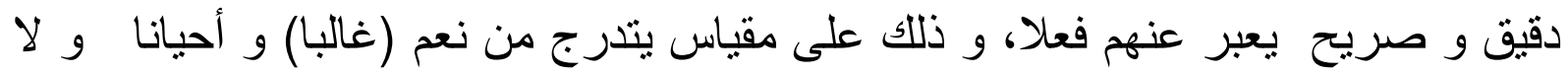
(مطلقا) و موضوع أمام هذه التقدير ات ثلاثة درجات هي:(3، 2، 1) على الترتيب و ذلك عندما يتعلق الأمر بالعبار ات الإيجابية (التي سوف تنطرق إليها الباحثة لاحقا) بينما تكون التقدير ات الثناث في اتجاه عكسي(1، 2،3) عندما يتعلق الأمر بالعبار ات السالبة. 5-1-4. تصحيح الاستبيان: يشتمل الاستبيان على 48 بندا تقيس مستوى التدين الإسلامي، و تتوزع على ثلاثة محاور و تتر اوح الدرجة الكلية للاستبيان بين (1 - 144 درجة)، و تشير الدرجة المرتفعة إلى مستوى مرتفع من التدين، بينما تثير الدرجة المنخفضة إلى مستوى منخفض من التدين (تدين منخفض)، أي أنه كلما زادت درجة المفحوص على هذا الاستبيان كلما زاد مستوى 
و يتكون المقياس من فقرات موجبة و أخرى سالبة، و الجدول التالي يبين أرقام الفقرات الموجبة و أرقام الفقر ات السالبة و طريقة تصحيحها:

\section{جدول (4)}

يمثل أرقام الفقرات الموجبة و السالبة و طريقة التصحيح الخاص بها

\begin{tabular}{|c|c|c|}
\hline طريقة التصحيح & أرقام الفقرات & \\
\hline 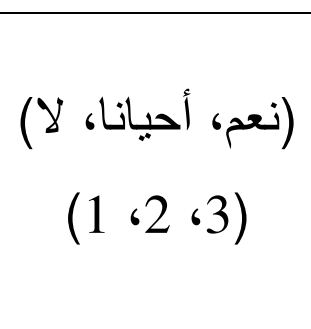 & 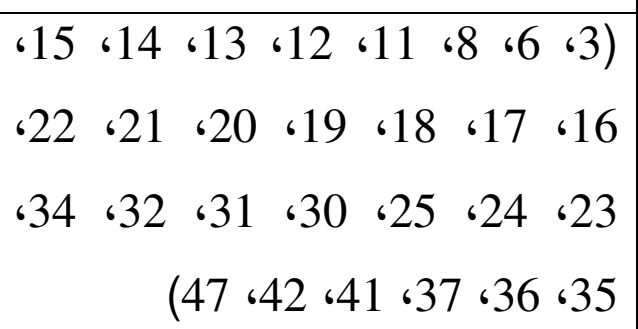 & الفقر ات الموجبة \\
\hline 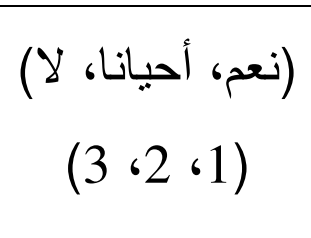 & 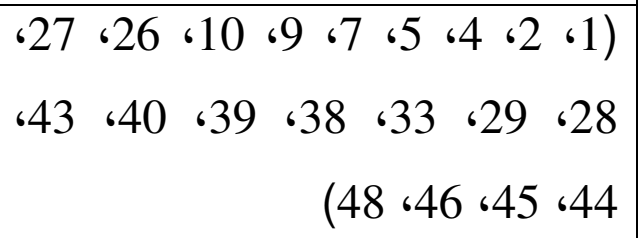 & الفقر ات السالبة \\
\hline
\end{tabular}

\section{6-1-4 الدراسة الاستطلاعية:}

تم تطبيق الاستبيان على عينة أولية بلغ عددها (15 طالباو طالبة) و ذلك بغية التعرف

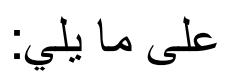
- تحديد صعوبات اللغة. - تحديد صعوبات فهم العبار ات من حيث استيعاب المعاني. و قد تم التوصل إلى ما يلي: 
- فمن ناحية اللغة لم يظهر أي نوع من الصعوبات، و ذلك راجع إلى المستوى التعليمي العالي لأفر اد العينة (المستوى الجامعي). ـ أما بالنسبة لفهم معاني العبارات فقد لاحظت الباحثة وجود صعوبة في فهم معاني بعض لإل البنود و ذلك من طرف عدد كبير من الطلبة مثل عبارة: "أتأمل في ملكوت السماو ات و الأرض بنية العبادة" و هو ما دفع الباحثة إلى حذفه نهائيا،

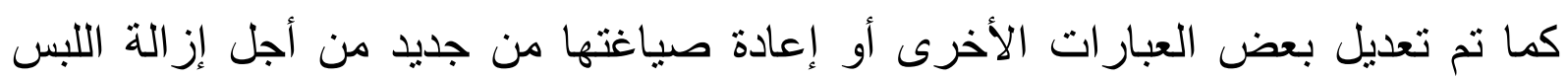
القائم و توضيح المعنى أكثر.

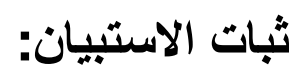
ثم حساب ثبات الاستبيان بطريقة إعادة الاختبار بفاصل زمني قدره أسبوعين بين الإجر اءين على عينة مكونة من 28 طالبا و طالبة من طلاب الجامعة، و قد بلغ معامل الارتباط بين الإجر اءين 0,62. بالإضافة إلى ذلك نم حساب ثبات الاستبيان بطريقة (ألفا كرونباخ) على عينة مكونة من 30 طالبا و طالبة من طلاب الجامعة، فوصل معامل الثبات إلى $0,98$.

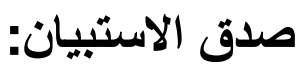
تم تقدير صدق الاستيبان بطريقتين هما:

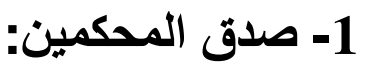
تم عرض المقياس على مجموعة من المحكمين بلغ عددهم (8) من المختصين في علم النفس و علوم التربية، و أجمعو ا على مناسبة عبارات الاستنبان إلا أن بعضهم رأى تبسيط عبار ات الاستبيان أو إعادة صياغة بعضها لتنتاسب مع عينة الدراسة الحالية دون الإخلال

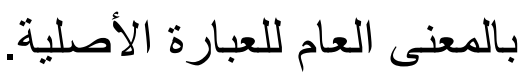

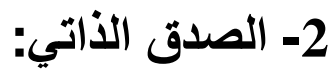
تم تقدير صدق الاستبيان أيضا بطريقة "الصدق الذاتي" و التي تقوم على القاعدة التالية:

$$
\text { الصدق = }
$$

و قد وصلت درجة الصدق إلى: 0,98. و منه: الاستبيان يتمتع بصدق و ثبات جيدين. 
يعرف التو افق الاجتماعي بأنه: " قدرة الفرد على المشاركة الاجتماعية الفعالة شعوره بالمسؤولية الاجتماعية و امتثاله لقيم المجتمع الذي يعيش فيه، و قدرته على تحقيق الانتماء و الولاء للجماعة من حوله، و القدرة على إقامة علاقات طيبة إيجابية مع أفراد المجتمع بما يحرص على حقوق الآخرين في جو من الثقة و الاحترام المتبادل معهم، و شعوره بالرضا و السعادة في كل ذلك (د. زينب محمود شقير، 2003، 06). 1-2-4. خطوات بناء المقياس:

المقياس هو من إعداد (د. زينب محمود شقير)، حيث قامت الدكتورة بالإطلاع على العديد من التراث الثقافي و الدراسات السابقة و كذلك المفاهيم النظرية للتو افق النفسي و و أبعاده المتعددة، كما تم الاطلاع على بعض مقاييس التوافق النفسي مثل مقياس كاليفورنيا للشخصية و مقاييس التوافق لعدة باحثين أمثال:عبد الوهاب كامل و وليد القفاص و غير هما، و هذه المقاييس أجريت على فئة العادين من الناس، إلى أن تم التوصل إلى الأبعاد الأساسية للتوافق النفسي و التي ترى فيها المؤلفة على أنها تجمع أهم جوانب حياة الفرد

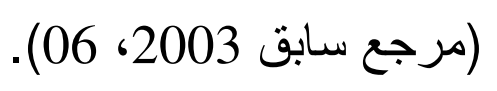

و بما أن موضوع دراستتا ينصب اهتمامه حول التوافق الاجتماعي، فقد اكتقت الباحثة بأخذ هذا البعد و ما يتعلق به من فقرات من المقياس الكلي (التوافق النفسي) وحده منفردا باعتباره الجزء المطلوب و الذي يخدم البحث موضوع الدر اسة، لذلك فإن كل ما سيتم ذكره سوف يدور حول هذا البعد (التوافق الاجتماعي) فقط. 2-2-4 وصف المقياس: يتكون هذا المقياس من 20 بندا، و قد تم التوصل إلى 30 فقرة (موقفا) في البداية انتهت إلى 20 فقرة فقط و ذلك بعد الانتهاء من تقنين المقياس. 3-2-4. تقديم المقياس: يطلب من المفحوص أن يتعرف على كل موقف أو عبارة من عبار ات المقياس بدقة ثم يحاول أن يجيب عليها و ذلك بإعطاء تقدير واضح و صريح و ينطبق مع طريقته المعتادة في التصرف و الثعور الصادر منه اتجاه كل موقف، و ذلك على مقياس يتدرج من موافق 
(نعم) و محايد (أحيانا)، و معارض (لا)، و يقابل هذه النقديرات درجات ثلاثة هي:( 2،

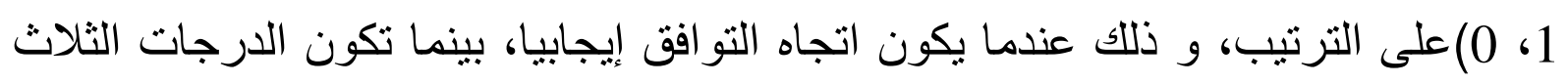

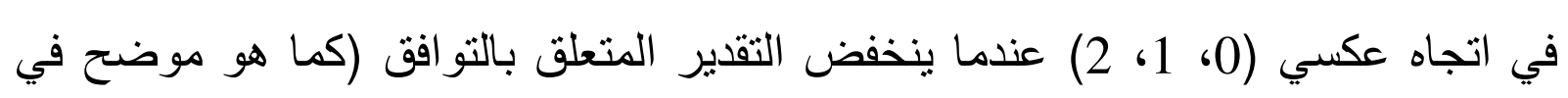

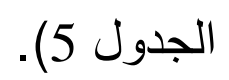

\section{4-2-4. تصحيح المقياس:}

يضم المقياس (20) فقرة تقيس التوافق الاجتماعي، و تنزراوح الدرجة الكلية بين (0 -

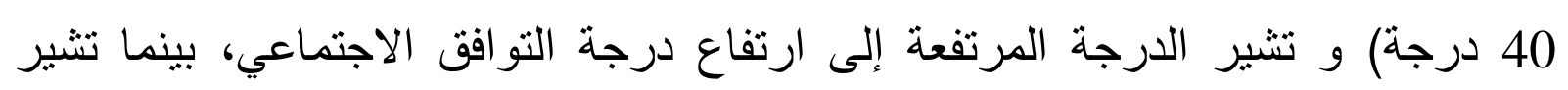
الدرجة المنذفضة إلى انخفاض درجة التو افق الاجتماعي. هذا و يفيد المقياس في جميع الأعمار الزمنية من الجنسين ابتداء من نهاية مرحلة الفيأيا

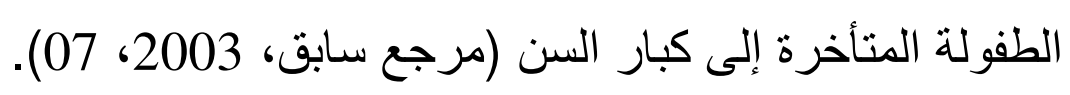

جذول (5)

يمثل الفقرات الموجبة و العالبة في مقياس التوافق الاجتماعي و اتجاه تصحيحها

\begin{tabular}{|c|c|c|c|}
\hline مستويات التوافق & الدرجة الكلية & اتجاه التصحيح & أرقام الفقرات \\
\hline 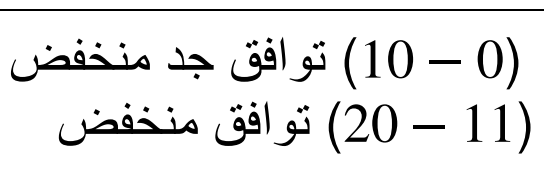 & \multirow{2}{*}{ (40) } & (2 - 1 - صفر) & 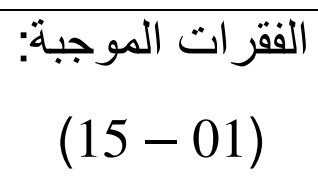 \\
\hline (31) - 30 - 30 ) تو افق متوسط مرتفع & & (صفر - 1 - 2) & $\begin{array}{c}\text { الفقرات السالبة: } \\
\text { (20 - } 16 \text { (20) }\end{array}$ \\
\hline
\end{tabular}

\section{2-2-4. تقتين المقياس (الخصائص السيكومترية):}

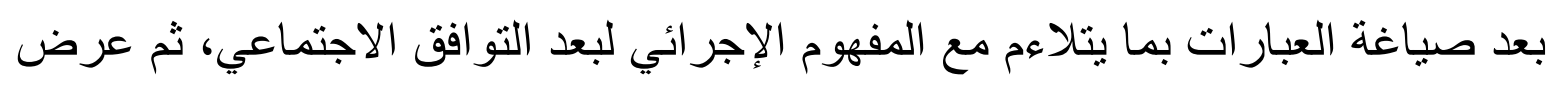

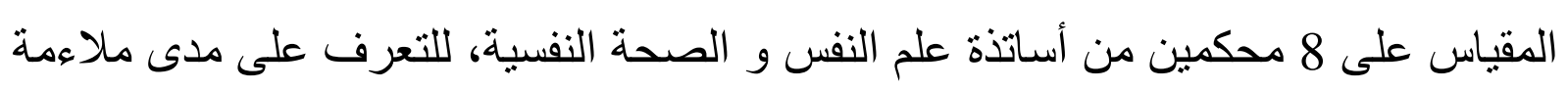

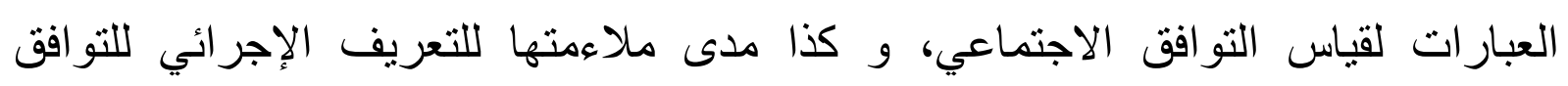

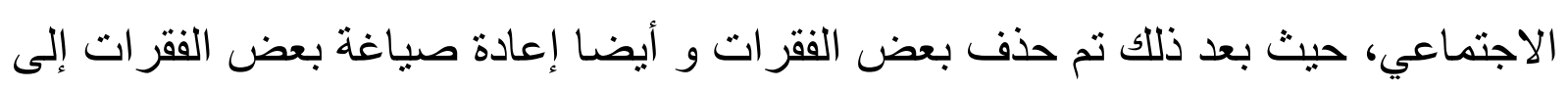
أن أصبحت فقرات المقياس كما هي موضحة في الملحق. 
و بعد ذلك تم تطبيق المقياس على عينة (عينة التقتين) بلغ عددها (400) فردا من الذكور

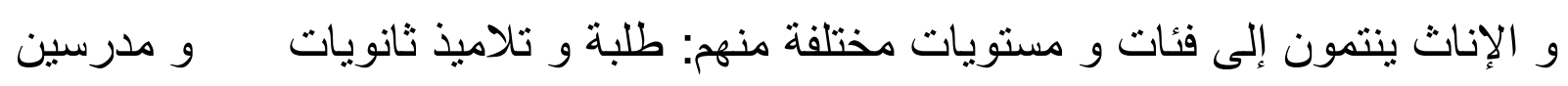

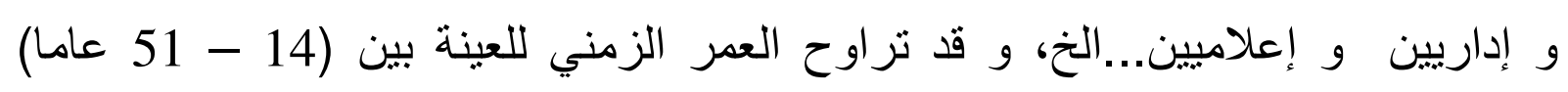

$$
\begin{aligned}
& \text { (مرجع سابق، } 2003 \text { ص ص: 9-10). } \\
& \text { أولا: صدق المقياس: }
\end{aligned}
$$

تم قياس صدق المقياس بعدة طرق مختلفة تتمثل في: صدق التكوين، صدق التميز صدق

$$
\text { المحك (الصدق التجريبي). }
$$

و قد أظهرت هذه الطرق صدق جيد على كل النطاق، أب أن الدقياس يتمتع بصدق جيد.

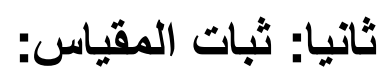

تم حساب ثبات المقياس أيضا بعدة طرق و تتثثل هذه الطرق في: طريقة إعادة التطبيق:

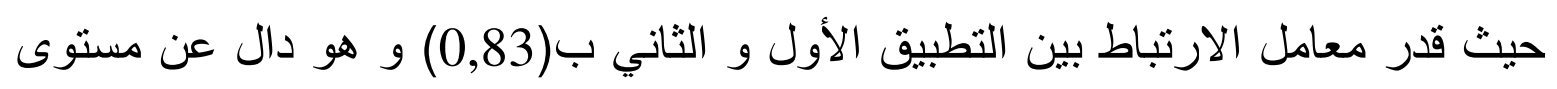

طريقة التجزئة النصفية: حيث قدر معامل الثبات ب (0,78) و هو دال عند مستوى

طريقة معامل ألفاكرونباخ: و قد قدر معامل الثبات ب (0,59) و هو دال أبضا عن

$$
\begin{aligned}
& \text { مستوى }(0,01) . \\
& \text { أي أن المقياس يمتاز بثبات جيد. } \\
& \text { 3-4. مقياس تقدير الذات: }
\end{aligned}
$$

يعرف تقدير الذات بأنه: "تقييم يضعه الفرد لنفسه و بنفسه و يعمل على المحافظة عليه.

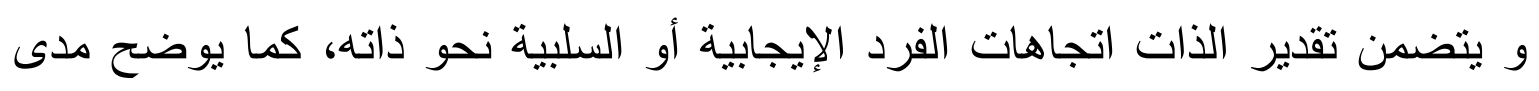

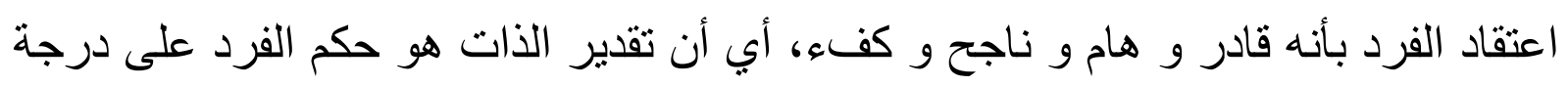

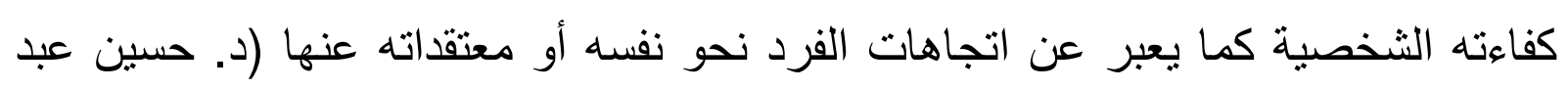
العزيز الدريني و آخرون بدون سنة، 3). 
استخدمت طرق و أساليب متعددة لقياس تقدير الذات منها:

التمييز السيمانتيكي الذي وضعه أوسجود و آخرون.

أيضا طريقة الملاحظة في تقدير الذات التي وضعها (سافن و جاكويش سنة 1981). و أخير أساليب التقدير الذاتي (Self report) في قياس تقدير الذات، و يمثل هذا مقياس روزنبرج، ويقوم هذا الأسلوب على أن يقدر الثخص ذاته بوضع علامة على مقياس متدرج أمام كل عبارة من عبار ات مقياس تقدير الذات. و لقد رأى واضعو الاختبار الحالي أن الطريقة المناسبة لتقدير الذات في البيئة العربية هي استخدام طريقة التقدير الذاتي لما تتمتع به من مميزات، فقد أشار (جرجين) إلى أن أن طريقة التقدير الذاتي توفر معلومات نافعة و دقيقة، كما أنها أكثر ملاعمة لقياس العلاقة بين تقدير الذات و بعض المجالات النفسية و الاجتماعية الأخرى، بل و تتفوق في هذا عن غير ها من الطرق (مرجع سابق بدون سنة، 4). خطوات إعداد المقياس: أولا:

لوضع وحدات المقياس أستعرض واضعو الاختبار عددا من الدراسات و المقاييس

$$
\text { 1 أهمها: }
$$

3- مقياس المظاهر السلوكية المستخدمة في تقدير الذات. 4- بعض الكتابات في علم النفس الإنساني. 5- بعض الكتابات في علم النفس المرضي.

$$
\text { 7- 7- مقياس كوبر سميث (1978). }
$$

8- دراسة عن تقدير الذات و مفهوم الذات و أهداف الحياة و الاتجاهات المرتبطة بالدور الخاص بالجنس لاى طلبة الجامعة. 
9- دراسة عن سمات الثخصية الإبتكارية من وجهة نظر علم النفس الإنساني، و قد أدى هذا إلى وضع 57 وحدة تدور حول تقدير الذات.

ثانيا:

صممت صورة أولية للمقياس.

ثالثا:

طبقت الصورة المبئية على مجموعة من طلبة و طالبات كلية التربية بجامعة قطر و و كان وجه الإفادة من هذه التجربة المبدئية هو التعرف على بعض الصعوبات التي قد يعاني منها المستجيبون و تعديل صياغة بعض الوحدات التي قد يصعب فهمها. بناءا على ذلك عدلت الصورة المبدئية للمقياس و بعض العبار ات لكي تكون أكثر مناسبة لطلبة و طالبات الجامعة. أعيدت تجربة المقياس بعد التعديل، و كان الغرض من هذه التجربة استخدام النتائج في حساب الخصائص السيكومترية. رابعا: تقديم المقياس: يمكن تطبيق هذا المقياس فرديا كما يمكن تطبيقه جماعيا.

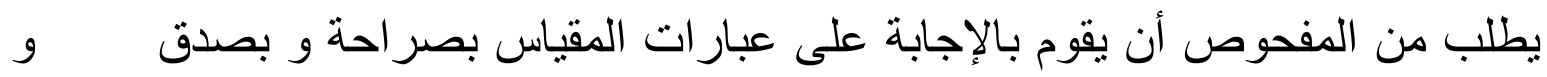
ذلك على مقياس يتدرج من نعم (غالبا)، و أحيانا، لا (أبدا)، و موضوع أمام التقديرات التالية: (3، 2، 1) على الترتيب، و ذلك عندما يكون اتجاه تقدير الذات إيجابيا (تقدير ذات إيجابي) بينما تكون التقديرات الثناثة في اتجاه عكسي (1، 2، 3) عندما ينخفض تقدير

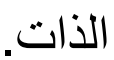

خامسا: تصحيح المقياس يحتوي المقياس على 30 عبارة تقيس تقدير الذات و منها عبار ات موجبة و أخرى سالبة. و الجدول التالي يبين أرقام العبار ات الموجبة و العبار ات السالبة و اتجاه تصحيحها: جدول(6) 
أرقام العبار ات الموجبة و السالبة و اتجاه تصحيحها

\begin{tabular}{|c|c|}
\hline اتجاه تصحيحها & أرقام العبارات \\
\hline 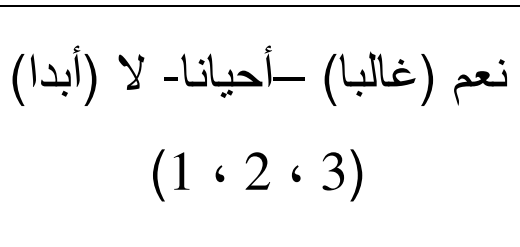 & 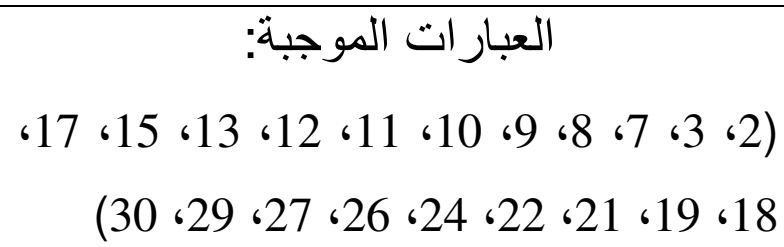 \\
\hline 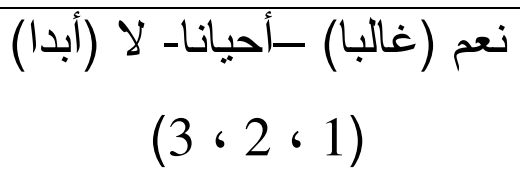 & 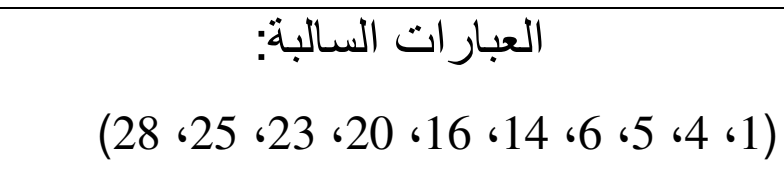 \\
\hline
\end{tabular}

\section{سادسا: الخصائص السيكومترية:}

لتحديد الخصائص السيكومنرية للمقياس أتبع ما يلي:

$$
\text { 1- تحليل الوحدات: }
$$

اقتضى تحليل الوحدات وجود محك معين يستخدم في تقسيم الأفراد إلى قسمين، و قد أستخدم واضعو الاختبار لهذا الغرض المحك الذي وضعه و اتكنس (1978). و باستخدام مؤشر تقدير الذات لدى كل أفراد أمكن قسمة العينة ذكورا و إناثا باستخدام المنوسط إلى قسمين: أعلى من المتوسطو عددها 62 و أدنى من المتوسطو عدن عددها 60. و بحساب الفروق بين المجمو عتين على كل وحدة أمكن التوصل إلى 30 وحدة مميزة و تم استبعاد وحدة واحدة لأنها لا تتفق مع النظام التعليمي المتبع في الجامعة و هي "أرى أنني عضو هام في عملي".

\section{2- 2 حساب ثبات الاختيار:}

استخدمت طريقة التجزئة النصفية و كان الثبات قبل التصحيح هو 61 و بعد التصحيح بمعادلة سبيرمان بر اون 0,76 و (ن = 122) و هون الانب معامل ثبات مرتفع و دال. 3- حساب صدق الاختبار:

إن القدرة التمييزية للاختبار دليلا على صدقها مما يزيد من الصدق العام للاختبار. و نظرا لعدم وجود اختبارات أخرى يمكن استخدامها كمكات للحكم على صدق الاختبار لذلك أستخدم الصدق التكويني Construct كمؤشر لصدق الاختبار. 
و توصل الباحثنون من خلال ذلك أن الاختبار يتمتع بدرجة عالية من الصدق. المعايير:

تكونت عينة حساب المعايير من 70 طالبا و74 طالبة من المنتظمين في جامعة قطر بكلية التربية، و قد تميزت العينة بالخصائص الآتية: - جميع أفر ادها حاصلون على الثانوية العامة. - منوسط السن بالنسبة للبنين 19,3 و بالنسبة للبنات 18,7.

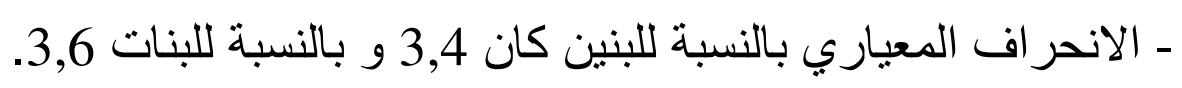

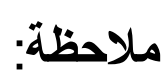

لم تقم الباحثة بحساب صدق و ثبات مقياسي (التوافق الاجتماعي و تقدير الذات) للبيئة الجزائرية ذلك أن الباحثة لاحظت عدم وجود أي صعوبات لاى العينة أثناء التطبيق

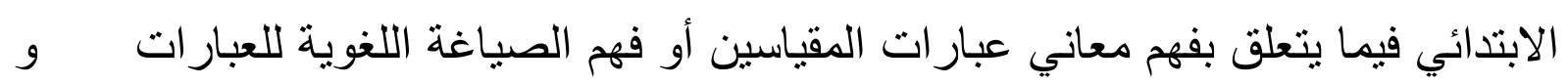
ذلك راجع للمستوى التعليمي العالي لأفراد العينة (المستوى الجامعي). كما يتفق معظم الباحثين و أساتذة علم النفس على صلاحية المقياسين لجميع البيئات العربية و منها البيئة الجزائرية.

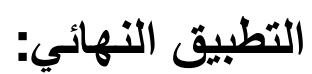

تم التطبيق النهائي خلال شهري (أفريل و مابي من سنة 2007) على عينة يقدر عددها

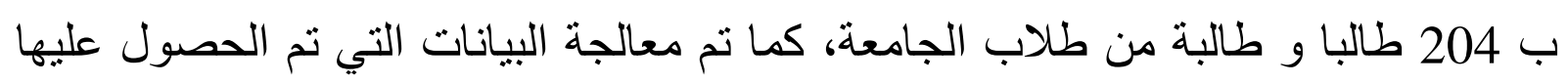
بالأساليب الإحصائية المناسبة لها. 



\section{نتائج الدراسة و مناقشتها:}

تتطرق الباحثة في هذا الفصل إلى عرض نتائج الدراسة و تحليلها، محاولة الإجابة عن تساؤلات الدراسة و منه تأكيد الفروض أو نفيها، مع التطرق للأساليب الإحصائية التي نم استخدامها لمعالجة البيانات المتحصل عليها. و بعد ذلك يتم التطرق إلى تفسير النتائج التي تم التوصل إليها، و ذللك في ضوء كل من لئن 9 الإطار النظري للبحث سموضوع الدراسة- إلى جانب نتائج الدراسات السابقة

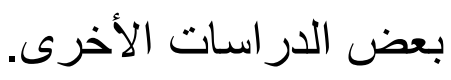

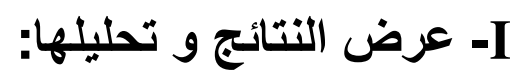


كانت تساؤلات الدراسة التي تم طرحها من طرف الباحثة، كما يلي: التساؤل الرئيسي للاراسة:

- ما طبيعة العلاقة بين كل من التدين و بعض المتغيرات النفسية الاجتماعية (التوافق الاجتماعي، تقدير الذات) عند طلبة الجامعة ؟

\section{التساؤلات الفرعية:}

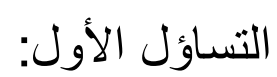

- ما طبيعة العلاقة بين كل من التدين و التوافق الاجتماعي عند طلبة الجامعة؟ التساؤل الثاني:

ـ ما طبيعة العلاقة بين كل من التدين و تقدير الذات عند طلبة الجامعة؟ التساؤل الثالث: - هل يوجد فروق ذات دلالة إحصائية في مستوى التدين حسب نوع التخصص الدراسي

$$
\begin{aligned}
& \text { (ديني / غير ديني)؟ } \\
& \text { التساؤل الر ابع: }
\end{aligned}
$$

- هل يوجد فروق ذات دلالة إحصائية في مستوى التدين حسب متغير الجنس (ذكور / إناث)

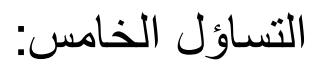

- هل يوجد فروق ذات دلالة إحصائية في مستوى التوافق الاجتماعي حسب متغير الجنس التس

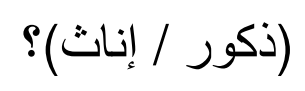

التساؤل السادس:

- هل يوجد فروق ذات دلالة إحصائية في مستوى تقدير الذات حسب متغير الجنس (ذكور / إناث)

للإجابة عن هذه التساؤلات استخدمت الباحثة جملة من الأساليب الإحصائية بهدف معالجة البيانات المتحصل عليها في الدر اسة الميدانية، و هي تتلخص في الجدول التالي: 
جدول (7)

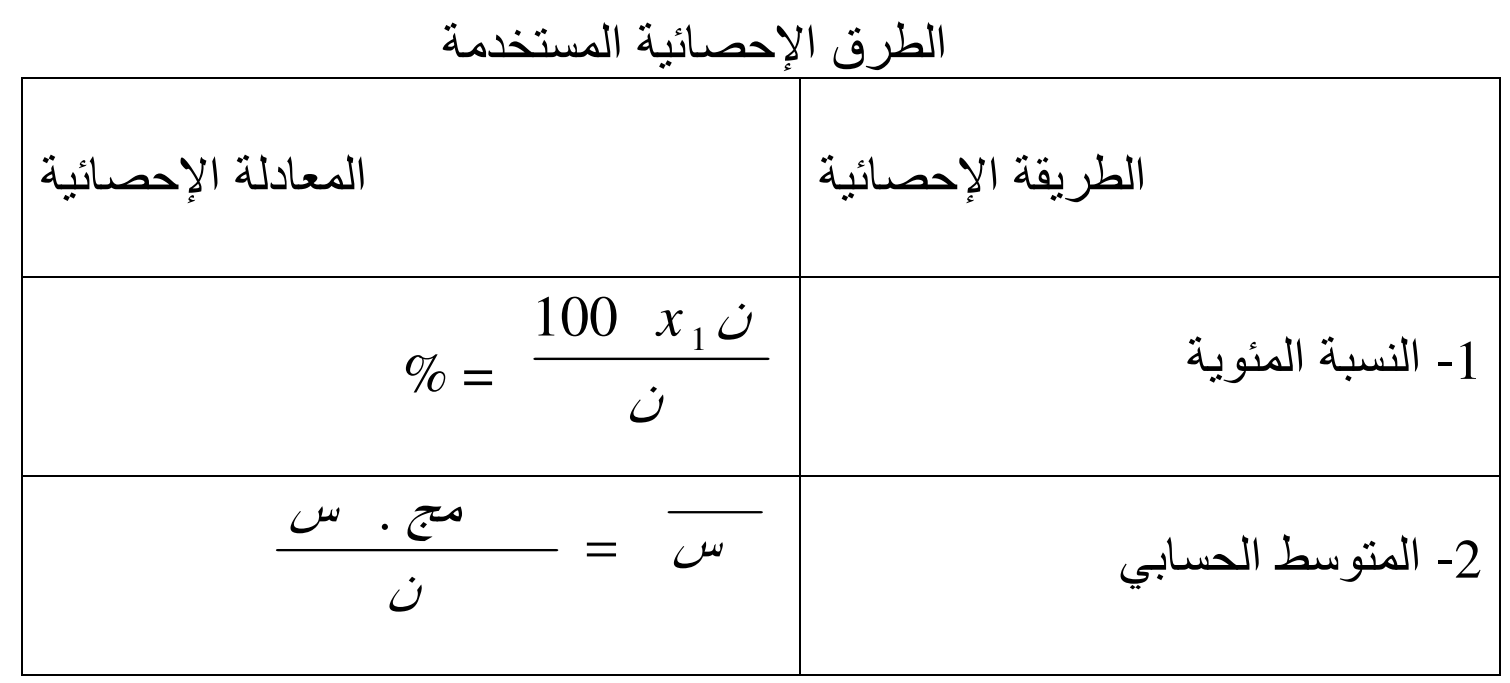




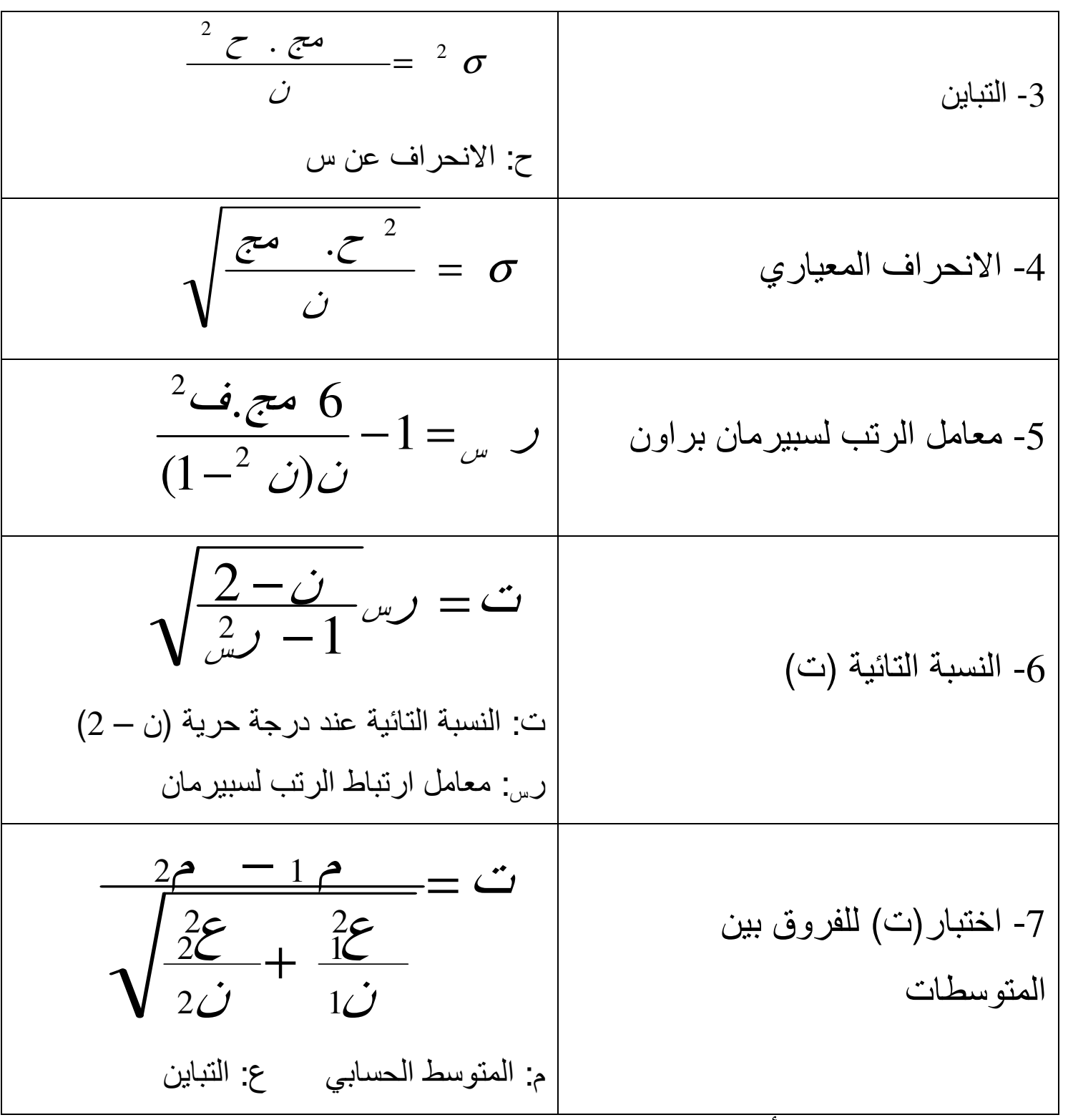

و يجب الإشارة إلى أنه سوف يتم الإجابة عن التساؤل الرئيسي للار اسة من خلال الإجابة عن التساؤ لات الفر عية: 1- 1 - عرض نتائج التساؤل الأول: العلاقة بين التدين و التوافق الاجتماعي:

للتعرف على نوع و طبيعة العلاقة بين كل من التدين و التو افق الاجتماعي، استخدمت الباحثة معامل الرتب لسبيرمان براون، ذلك أن كل من (التدين و التوافق الاجتماعي) هي متغير ات رتبية كما أنه أكثر الأساليب الإحصائية ملاءمة لدر اسة هذه العلاقة. 
و نظر الأن عينة الدراسة هي أكبر من 10، فإن الباحثة لجأت إلى اختبار دلالة معامل

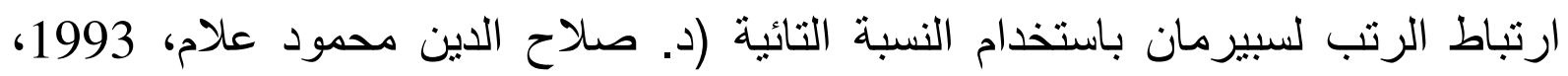

و يلخص الجدول التالي النتائج التي نم التوصل إليها:

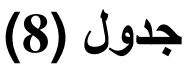

الارتباط بين كل من التدين و التو افق الاجتماعي

\begin{tabular}{|c|c|c|c|c|c|c|c|}
\hline الإحصائية & قيمة & $\begin{array}{c}\text { المعياري } \\
\text { الإنحراف } \\
\text { (ס) }\end{array}$ & المستوسطي & المئوية & (ن) & الجنس & المتغيرات \\
\hline \multirow{6}{*}{ مستوى (إحصائية عند } & \multirow{6}{*}{7,35} & \multirow{3}{*}{16,05} & \multirow{3}{*}{125,23} & $\% 47,06$ & 96 & الذكور & \multirow{3}{*}{ التدين } \\
\hline & & & & $\% 52,94$ & 108 & الإناث & \\
\hline & & & & $\% 100$ & 204 & المجموع & \\
\hline & & \multirow{3}{*}{4,10} & \multirow{3}{*}{30,29} & $\% 47,06$ & 96 & الذكور & \multirow{3}{*}{ الاجتماعي } \\
\hline & & & & $\% 52,94$ & 108 & الإناث & \\
\hline & & & & $\% 100$ & 204 & المجموع & \\
\hline
\end{tabular}

من خلال النتائج التي تم عرضها في الجدول (8)، يتضح أن هناك علاقة ارتباطية موجبة بين كل من التدين و التو افق الاجتماعي. و قد وصلت قيمة هذا الارتباط الموجب إلى (7,35)، و هي دالة عند مستوى دلالة (0,05) أي بنسبة ثقة تقدر ب (95\%). 2- 2 - عرض نتائج التساؤل الثناني: العلاقة بين التدين و تقدير الذات:

بهذف الكثف عن طبيعة العلاقة بين كل من التدين و تقدير الذات، استخدمت الباحثة أيضا معامل ارتباط الرتب لسبيرمان براون، كما نم اختبار دلالة معامل ارتباط الرتب لسبيرمان باستخدام النسبة التائية، نظر العدد أفر اد العينة الذي يتجاوز العشرة. 
جدول (9)

الارتباط بين التدين و تقدير الذات.

\begin{tabular}{|c|c|c|c|c|c|c|c|}
\hline الإحصائية & قيمة & الانحراف & الحسابي & المئوية & (ن) & الجنس & المتغيرات \\
\hline \multirow{6}{*}{ إحصائية عند لهالة } & \multirow{6}{*}{4,21} & \multirow{3}{*}{16,05} & \multirow{3}{*}{125,23} & $\% 47,06$ & 96 & الذكور & \multirow{3}{*}{ التدين } \\
\hline & & & & $\% 52,94$ & 108 & الإناث & \\
\hline & & & & $\% 100$ & 204 & الدجموع & \\
\hline & & \multirow{3}{*}{7,46} & \multirow{3}{*}{72,80} & $\% 47,06$ & 96 & الذكور & \multirow{3}{*}{ تقدير } \\
\hline & & & & $\% 52,94$ & 108 & الإناث & \\
\hline & & & & $\% 100$ & 204 & الدجموع & \\
\hline
\end{tabular}

من خلال النتائج التي عرضها في جدول (9)، ينتين أن هناك علاقة ارتباطية موجبة بين

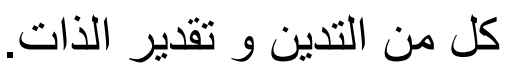
و قد وصلت قيمة هذا الارتباط الموجب إلى (4,21)، و هي قيمة ارتباط مرتفعة و و دالة عند مستوى دلالة (0,05)، أي بنسبة ثقة تقدر ب (95 \%). 3- 3رض نتائج التساؤل الثالث: الفروق في مستوى التدين حسب نوع التخصص الدراسي (ديني / غير ديني).

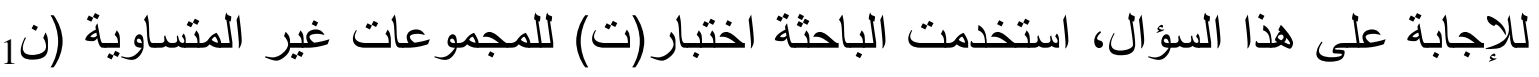

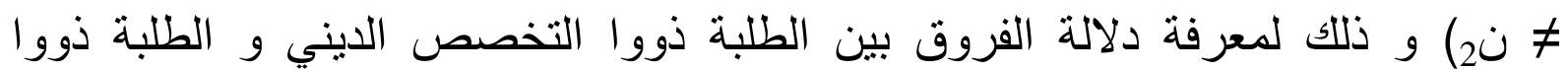
التخصص غير الديني في مستوى التندين، و أيضا لتحديد اتجاه الفروق. و الجدول التالي يوضح النتائج التي تم التوصل إليها: 


\section{جدول (10)}

الفروق في مستوى التدين حسب نوع التخصص الاراسي (ديني / غير ديني)

\begin{tabular}{|c|c|c|c|c|c|c|c|}
\hline الإحصائية & قيمة & الانحراف & الحسابي & المئوية & العداد & الجنس & المتغيرات \\
\hline \multirow{6}{*}{ إحصائية عند دلالة } & \multirow{6}{*}{3,82} & \multirow{3}{*}{6,93} & \multirow{3}{*}{130,33} & $\% 44,90$ & 44 & الذكور & \multirow{3}{*}{ التخصص } \\
\hline & & & & $\% 55,10$ & 54 & الإناث & \\
\hline & & & & $\% 100$ & 98 & المجموع & \\
\hline & & \multirow{3}{*}{5,81} & \multirow{3}{*}{120,51} & $\% 49,06$ & 52 & الذكور & \multirow{2}{*}{ التخصص } \\
\hline & & & & $\% 50,94$ & 54 & الإناث & \\
\hline & & & & $\% 100$ & 106 & المجموع & غير الديني \\
\hline
\end{tabular}

من خلال النتائج الموضحة في الجدول (10)، يتضح ما يلي:

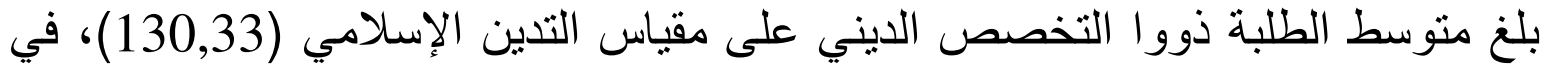
حين بلغ متوسط الطلبة ذووا التخصص غير الديني (120,51)، بفرق قدره $(9,82)$ و هو

$$
\text { فرق كبير، و بحساب قيمة (ت) وجد أنها تساوي (3,82). }
$$

و بالكثف في جدول الدلالة الإحصائية لاختبار (ت) بدرجة حرية (ن - 2)، تبين أن أن النائ قيمة (ت) التي تم التوصل لها دلالة إحصائية عند مستوى دلالة (0,05)، أي بنسبة ثقة التة

و هذا يدل على وجود فروق بين طلبة التخصص الديني و التخصص غير الديني في مستوى التدين لصالح طلبة التخصص الديني، بمعنى أن مستوى التدين لاى طلبة التخصص الديني أعلى منه لاى طلبة التخصص غير الديني. و منه نرفض الفرض الصفري (H))، بمعنى أنه توجد فروق.

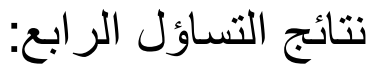


الفروق في مستوى التنين حسب متغير الجنس (ذكور / إناث):

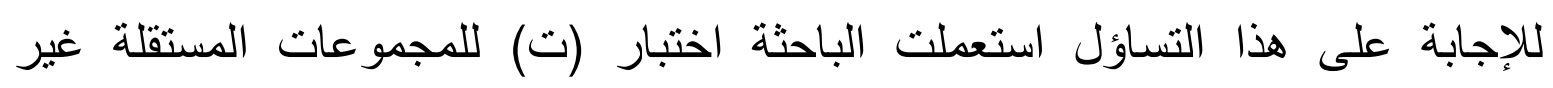

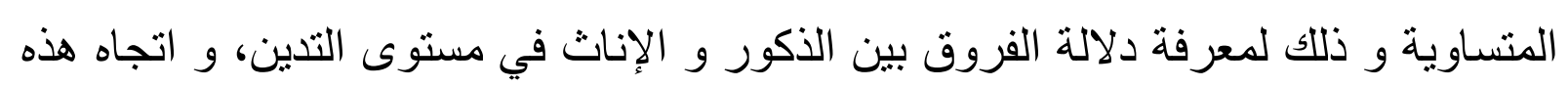

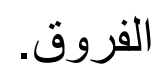
و الجدول التالي يوضح النتائج التي تم التوصل إليها حول ذلك:

جدول (11)

الفروق بين الذكور و الإناث في مستوى التندين

\begin{tabular}{|c|c|c|c|c|c|c|}
\hline الدلالة الإحصائية & قيمة & $\begin{array}{c}\text { الانحراف } \\
\text { المعياري } \\
\text { (б) }\end{array}$ & $\begin{array}{c}\text { الحستوسطي } \\
\text { (م) }\end{array}$ & $\begin{array}{l}\text { المئوية } \\
\text { النسب } \\
\text { (\%) }\end{array}$ & العدد & المتغيرات \\
\hline \multirow{2}{*}{ إحصائية عند مستوى لها دلالة } & \multirow{2}{*}{0,05} & 9,37 & 124,51 & $\% 47,06$ & 96 & الذكور \\
\hline & & 8,63 & 125,87 & $\% 52,94$ & 108 & الإناث \\
\hline
\end{tabular}


من خلال النتائج التي تم عرضها في الجدول (11) يتضح ما يلي:

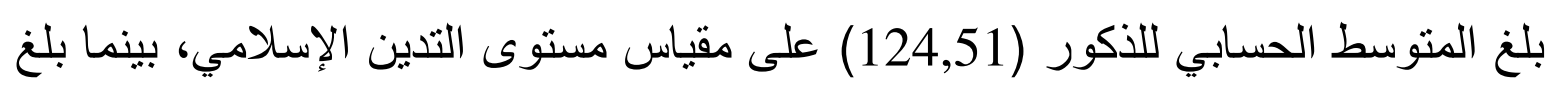

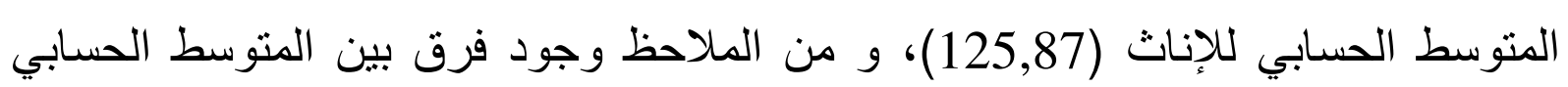

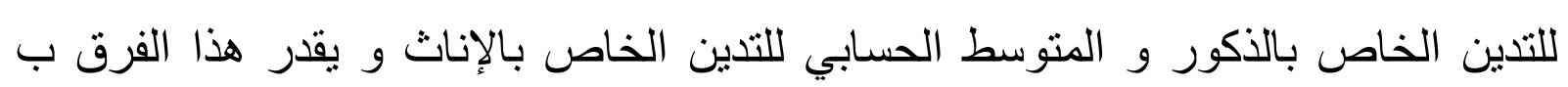
(1,36) فهو فرق بسيطو غير دال إحصائيا.

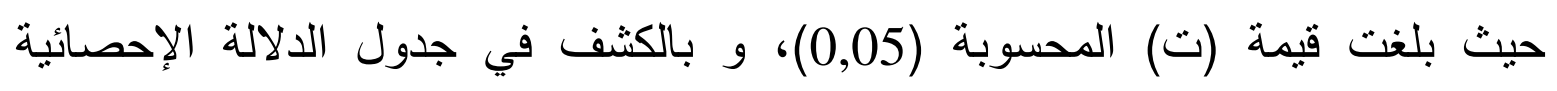
لاختبار (ت) بدرجة حرية (ن - 2)، و يتضح أن قيمة (ت) الني تم التوصل إليها ليس لهاليال دلالة إحصائية عند مستوى دلالة $(0,05)$.

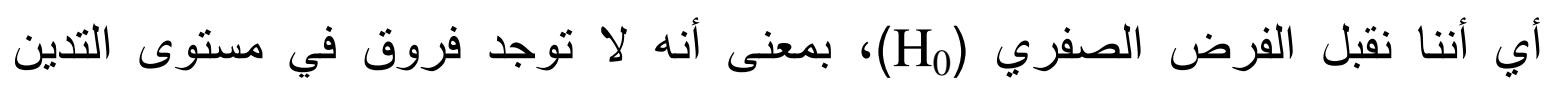
باختلاف الجنس (ذكور / إناث).

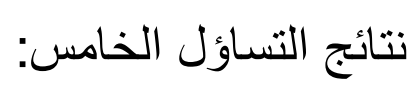

الفروق في التو افق الاجتماعي حسب متغير الجنس (ذكور / إناث).

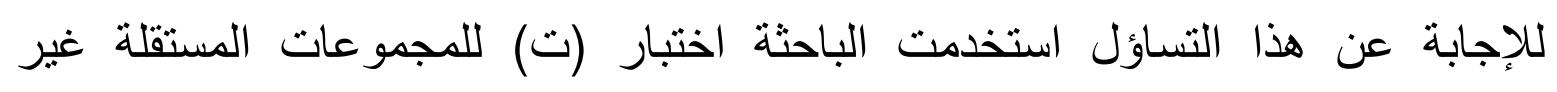

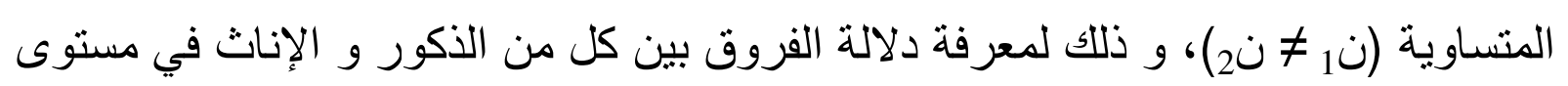
التو افق الاجتماعي و اتجاه هذه الفروق أيضا.

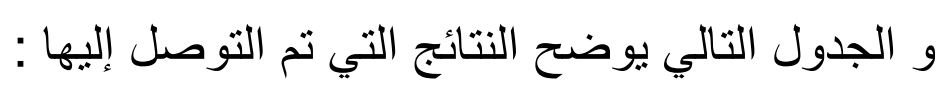

جدول (12)

الفروق بين الذكور و الإناث في التوافق الاجتماعي 


\begin{tabular}{|c|c|c|c|c|c|c|}
\hline الدلالة الإحصائية & قيمة & الانحراف & المتوسط & المئوية & (ن) & المتغير ات \\
\hline لا نوجد فروق ذات دلالة & 0.005 & 4,57 & 30,22 & $\% 47,06$ & 96 & الذكور \\
\hline دلالة $(0,05)$ & & 3,66 & 30,36 & $\% 52,94$ & 108 & الإناث \\
\hline
\end{tabular}

من خلال النتائج التي تم عرضها في الجدول (12)، يتضح ما يلي: بلغ المتوسط الحسابي للذكور في التوافق الاجتماعي (30,22)، بينما بلغ المتوسط

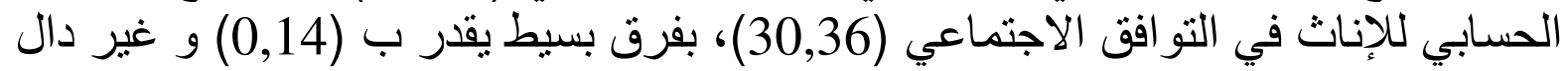
إحصائيا.

$$
\text { و بحساب قيمة (ت) وجد أنها تساوي (0,005). }
$$

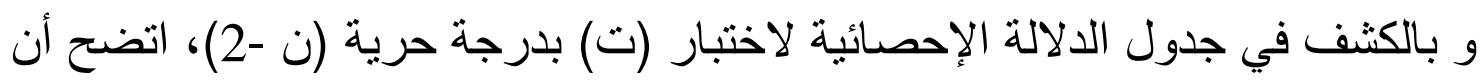

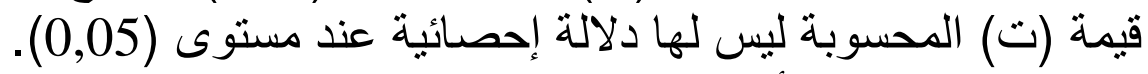

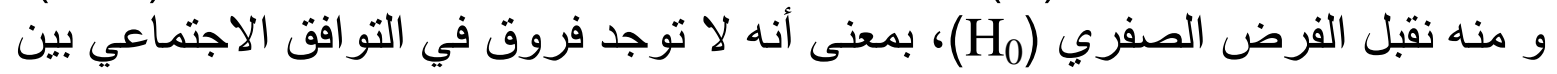

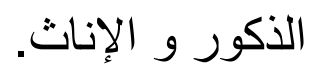
عرض نتائج التساؤل السادس: الفروق في مستوى تقدير الذات حسب متغير الجنس (ذكور / إناث). للإجابة عن هذا التساؤل استخدمت الباحثة أيضا اختبار (ت) للمجموعات المستقلة غير المتساوية (ن1 \# نح)، و ذلك لمعرفة دلالة الفروق بين الذكور و الإناث في متغير تقدير الذات، و أيضا لتحديد اتجاه الفروق. و الجدول التالي يوضح النتائج التي تم التوصل إليها: 
الفروق بين الذكور و الإناث في مستوى تقلير الذات.

\begin{tabular}{|c|c|c|c|c|c|c|}
\hline الالالة الإحصائية & قيمة & الإنحر افعياري & الحتوسط & النسببة & (نعد العد & المتغيرات \\
\hline \multirow{2}{*}{ إحصائية عند مستوى لها دلالة } & \multirow{2}{*}{0,76} & 7,65 & 72,38 & $\% 48,90$ & 89 & الذكور \\
\hline & & 6,08 & 73,22 & $\% 51,10$ & 93 & الإناث \\
\hline
\end{tabular}

من خلال النتائج الموضحة في الجدول (13)، يتضح ما يلي: بلغ منوسط تقدير الذات للذكور (72,38)، بينما بلغ منوسط تقدير الذات للإناث (73,22)، بفرق قدره (0,84) و هو فرق بسيطو غير دال إحصائيا. حيث بلغت قيمة (ت) المحسوبة (0,76) و وجدت الباحثة أنها غير دالة إحصائيا عند مستوى دلالة (0,05). و منه نقبل الفرض الصفري(H) ) ، بمعنى أنه لا نوجد فروق في مستوى تقدير الذات باختلاف الجنس (ذكور / إناث). باقاقشة نتائج الدراسة: أو لا: علاقة التدين بالتو افق الإجتماعي: جاءت العلاقة موجبة بين كل من التدين و التوافق الاجتماعي، و هي دالة إحصائيا عند مستوى دلالة (0,05) و درجة حرية (ن - 2). 
و يعني ذلك أنه كلما زاد تدين الثخص و التزامه بتعاليم الدين بمختلف أبعاده (الاعتقادات العبادات، الأخلاق، و المعاملات)، كلما زاد ذلك من تو افقه الاجتماعي.

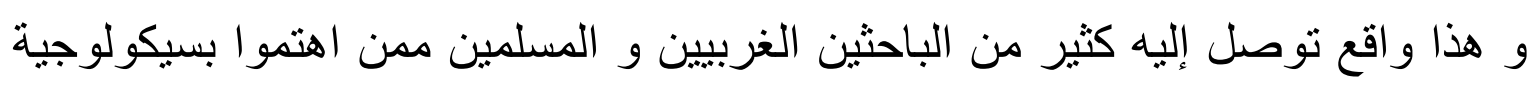
الدين في مجال الصحة النفسية. و من بين الذين أكدوا هذه العلاقة الوثيقة بين التدين و التوافق الاجتماعي، (مركز أبحاث جامعة ديوك و مر اكز أخرى تدعم من قبل منظمات الصحة النفسية) حيث وجدت هذه المر اكز أن التدين له علاقة جيدة في معظم الأحيان بمعايير الصحة النفسية، كما وجد أن من لايهم مستوى تدين عال هم أقل شكوى من صعوبات في الأداء الاجنماعي، أي أنهم لايهم تو افق اجتماعي عكس الأشخاص الأقل تدينا (سعاد مطر الثمري، 2006/02/14). هذا بالإضافة إلى الدراسات التي أجريت على الدين الإسلامي و الملتزمين به، مثل دراسة (عبد الله بن خراز و منصور بن سفر الزهراني، 1412هـ)، كذلك دراسة محمد الثيخ (1980م) و كريمة محمود (1987م)، و التي ذهبت كلها إلى توكيد هذه العلاقة بين كل من التدين و التو افق الاجتماعي. و تعزو الباحثة ذلك (دور الدين الإيجابي في تحقيق التو افق الاجتماعي للفرد) للأسباب الآية: الآتية:

(يجب الإشارة إلى أن هذه الدراسة تنطلق من منظور ديني إسلامي بالدرجة الأولى فضلا على أن عينة الدراسة يدين جميع أفر ادها بالدين الإسلامي الحنيف، لذلك فإن إنى تفسير النتائج التي تم التوصل إليها سوف يتم في ضوء ذللك). إن الدين الإسلامي الحنيف يقوم على أسس و مبادئ الرحمة و الثورى و التآخي و تكافؤ الفرص. و قد اهتم الإسلام كثيرا بتنظيم الجانب الاجتماعي من حياة الفرد في علاقته بالجماعة حيث حض على الإخاء، و يتضح ذلك من خلال قوله "صلى الله عليه و يلم": "المسلم أخو المسلم، لا يظلمه و لا يسلمه و من كان في حاجة أخيه كان اله في حاجته" [حديث شريف]. 
كما يدعو الدين الإسلامي الحنيف لإقامة الحياة الاجتماعية على أساس من المساواة فالناس كلهم سواسية، فلا فرق بين عربي و أعجمي إلا بالتقوى، كما يشجع الإسلام أبناءه على البر و التقوى و التعاون و التضامن. و يدعوا الإسلام إلى التكافل الاجتماعي، كما يتمثل ذلك في الصوم و الزكاة، كما يهتم بتأسيس العلاقات الاجتماعية الإيجابية بين مختلف شر ائح المجتمع. و هذا كله يؤدي في الأخير إلى بناء منظومة اجتماعية متناغمة و منسجمة و التي يسودها روح الوحدة و المشاركة الاجتماعية. إن الالتزام بتعاليم الدين الإسلامي الحنيف و بمقتضياته العقائدية و العملية يحقق التوافق الاجتماعي للأفر اد و ذلك من جانب ما تعرضنا له سابقا من أخلاق و معاملات يلتزم بها المسلم فتحقق له توازنه النفسي من جهة، و من جهة أخرى تسهل تكيفه مع الآخرين و تو افقه معهم، يقول صلى الله عليه و سلم: " إنما بعثت فيكم لأتمم مكارم الأخلاق" [حديث شريف].

و من بين هذه الأخلاق: إفثناء السلام، صلة الرحم، عيادة المريض، تشميت العاطس...الخ، و هذه كلها تقرب الفرد من الآخرين و تشهل تقبلهم له و بالتالي انسجامه الهاه

معهم.

أيضا فالدين الإسلامي يدعو إلى التجمع و الاختلاط بالآخرين و مخالطتهم، يقول الرسول صلى الله عليه و سلم: "المؤمن الذي يخالط الناس و يصبر على أذاهم، خير من المؤمن الذي لا يخالط الناس و لا يصبر على أذاهم" [ حديث شريف]. كما يلاحظ أن الدين الإسلامي غني بالمناسبات الدينية الاجتماعية التي يحرص فيها على له له التقريب بين أبنائه و تحقيق تو افقهم مع بعضهم البعض، و من أمثلة ذلك صلاة الجمعة التي تعد مؤتمر ا إسلاميا و اجتماعيا و علميا، كذلك صلاة الجماعة و صلاة العيدين، و فريضة

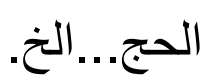

و الملتزم حقيقة بتعاليم الدين يتعود في كل مرة الاختلاط بالآخرين و الاندماج معهم في كل مرة إما في صلاة الجماعة في المسجد أو أثناء أداء فريضة الحج أو غير ذلك. 
كما يدعو الإسلام إلى التخاطب بين أبنائه من خلال حثهم على الأمر بالمعروف النهي عن المنكر....و هذه كلها أمور تسهم في تحقيق التوافق الاجتماعي للأفراد المتدينين أكثر من غير هم.

2- علاقة التدين بتقدير الذات:

من خلال النتائج التي تم التوصل إليها، تبين أن العلاقة بين كل من التدين و تقدير الذات طردية و دالة إحصائيا أي أنه كلما زاد مستوى تدين الفرد كلما أدى ذلك إلى زيادة تقديره

لذاته.

و تتفق هذه النتيجة مع الكثير من الدراسات التي تناولت هذه العلاقة مثل: دراسة هولترز (Hoelters, 1989)، و دراسة فلانيلي (Flannely, 1974)، حيث تشير هذه الدر اسات إلى علاقة ارتباطية موجبة بين كل من التدين و تقدير الذات الإيجابي. و تعزو الباحثة هذه العلاقة إلى ما يلي:

إن تقدير الذات يعتمد بدرجة كبيرة على تقبل الآخرين و تقدير هم، و في الدين الإسلامي من التعاليم و التشريعات ما يسهل على المؤمن أن يكون مقبولا لدى الآخرين و نيل إعجابهم و تقدير هم و ذلك من خلال ما يدعو إليه الدين الإسلامي الحنيف من التحلي بحسن الأخلاق و مكارم الصفات يقول النبي صلى الله عليه و سلم: "إن من خياركم أحاسنكم

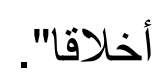

و من هذه الصفات: التواضع، الأمانة، الصدق، الكلام الحسن...الخ. و يعتمد اكتساب هذه الأخلاق بدرجة كبيرة على التنشئة الاجتماعية بمختلف مصادر ها كما أن تقدير الذات يعتمد بدرجة كبيرة على نوع التنشئة الأسرية، كما ذهبت إلى ذلك عدة بلى بله در اسات كدر اسة كوبر سميث و غير هم. كذلك الفرد المتدين يكون راضيا عن نفسه قانعا بما وهبه الله له من قدر ات جسمية نفسية، متقبلا لو اقعه و ما قدر له، شاكر ا في السراء صابر ا في الضر اء، محتسبا عند البلاء

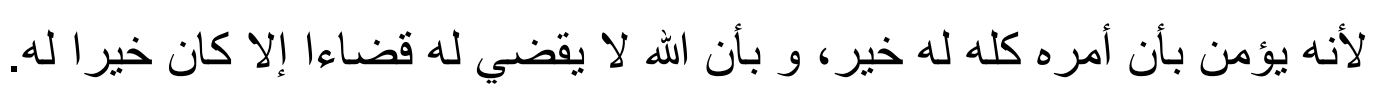


و بالإضافة إلى هذا فالدين الإسلامي الحنيف بشجع أبناءه على الاعتزاز بأنفسهر

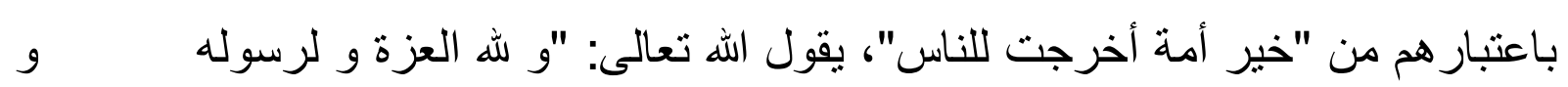

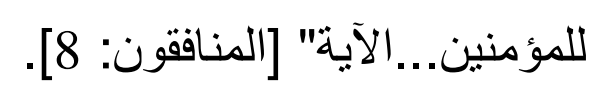

3- الفروق في مستوى التدين حسب نوع التخصص الدارسي (داسيني / غير ديني):

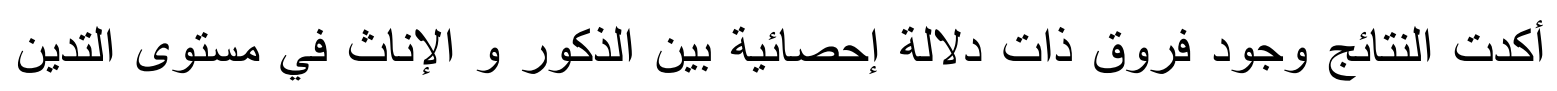
لصالح طلبة التخصص الديني، أي طلبة التخصص الديني أعلى في مسنوى تدينهم من التهن

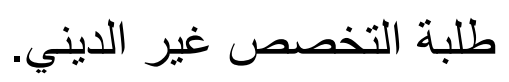

و تتفق على هذه النتيجة عدة دراسات، نذكر منها: دراسة سعيدة أبو سوسو (1991) و دراسة عبد المحسن إبر اهيم حمادة (1992).

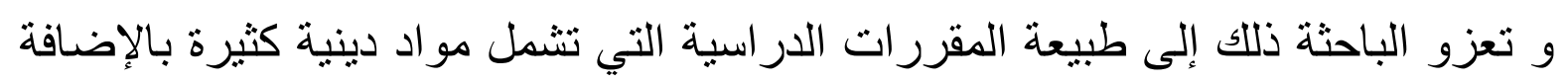

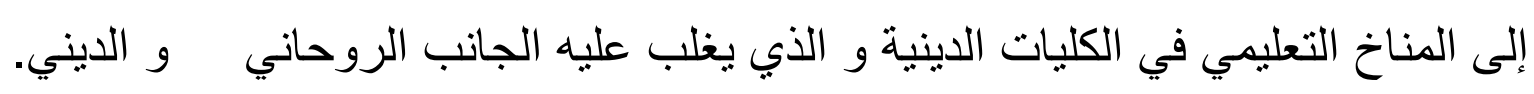
4- الفروق بين الذكور و الإناث في مسنوى التدين: أكدت النتائج عدم وجود فروق ذات دلالة إحصائية بين الذكور و الإناث في مستوى التدين بمعنى أن نوع الجنس لا يؤثر في مستوى التدين لاى الأفراد.

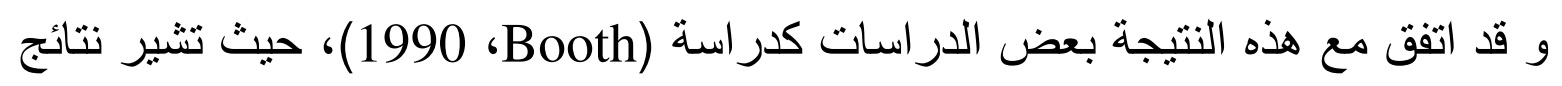
هذه الدراسة أنه لا توجد فروق بين الذكور و الإناث في مستوى التدين.

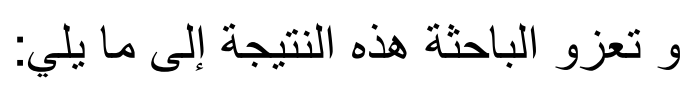

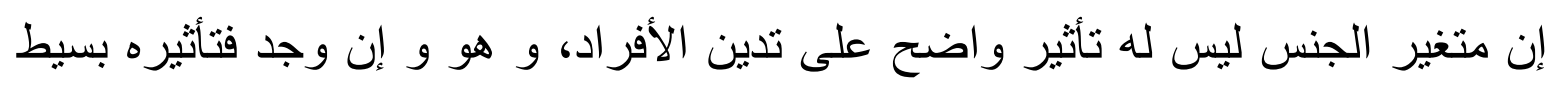

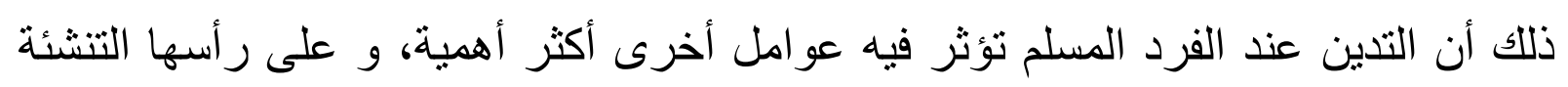

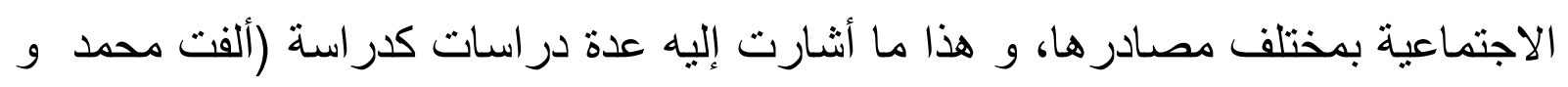


آخرون، 1990) كذلك دراسة (إسماعيل دياب و عبد الرحمن النقبب، 1984)، حيث توصل إلى أهم العوامل التي لها تأثير كبير على تدين الأفراد و هي كما يلي بالترتيب: الأسرة، قراءة الكتب الدينية، ثم الأصدقاء، و المجتمع القريب ثم إمام المسجد ثم وسائل

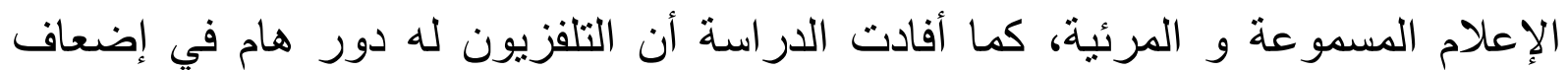

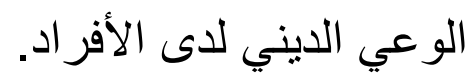
كما توصل الباحثان إلى أنه لا توجد فروق بين الذكور و الإناث في أثر هذه العو امل

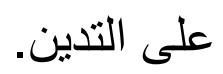
5- الفروق بين الذكور و الإناث في متغير التوافق الإجتماعي:

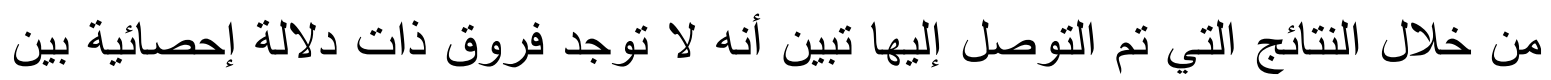
الذكور و الإناث في التو افق الاجتماعي. و ترى الباحثة أن هذه نتيجة منطقية، لعدم وجود فروق بين الذكور و الإناث في متغير

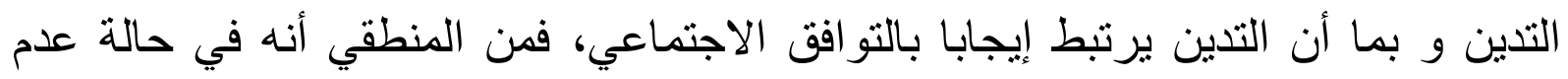
وجود فروق في التنين بين الذكور و الإناث، لا يوجد فروق بينهما في متغير التوافق الاجتماعي. إضافة إلى ذلك، فبالرغم ما كان ينداول حول تفوق الذكور على الإناث في التوافق الاجتماعي، إلا أنه من الملاحظ أن ما كان سائدا من قبل فيما يتعلق بنظرة المجتمع للفتاة و التضييق من مساحة حريتها و تفضيل الذكر عليها، قد تراجع في السنوات الأخيرة خاصة

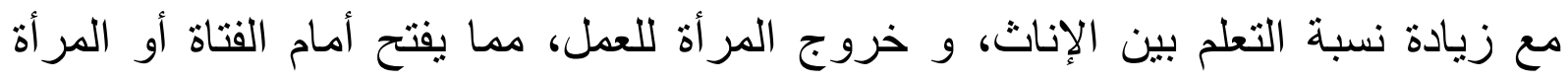
مجالا واسعا من العلاقات الاجتماعية مع الآخرين. 6- الفروق بين الذكور و الإناث في تقدير الذات:

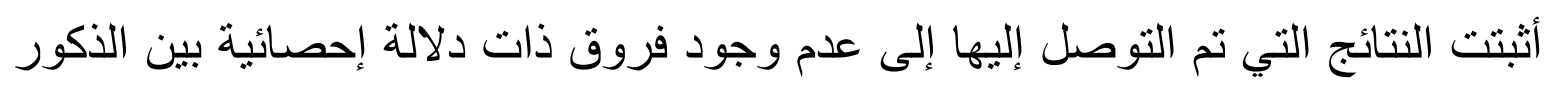
و الإناث في متغير تقدير الذات.

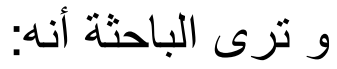


بما أن تقدير الذات له علاقة ارتباطية موجبة بالتدين فإنه بانعدام الفروق (ذات الدلالة الإحصائية) بين الذكور و الإناث في متغير التدين ينتج عن ذلك انعدام الفروق (ذات الدلالة الإحصائية) بينهما في متغير تقدير الذات. كذلك من ناحية أخرى، فإنه بالرغم مما كان شائعا حول أن الذكور أكثر تقدير الذواتهم من الإناث، إلا أن النتيجة التي توصلت إليها الباحثة قد يكون لها علاقة بالمستوى التعليمي بلتي الذي وصلت إليه الفتاة (المستوى الجامعي) مما جعلها أكثر وعيا بقيمة ذاتها و أنها إنسان كامل جدير بالاحتر ام و التقدير كالأكر تماما. كما أن المرحلة الجامعية (و الوسط الجامعي عموما)، يسمح للفتاة بالتحرر من القيود و و و الضغوط التي كانت مفروضة عليها في مر احل سابقة، كإجبارها على التصرف بطريقة معينة....، مما كان يشعر ها بالدونية و احتقار الذات، فتخلصها من تلك القيود قد يساعدها على استرجاع ثقتها في نفسها من جديد، و بالتالي لا يختلف تقدير ها لذاتها عن الذكر. التوصيات و المقترحات:

لقد تبين لنا من خلال هذه الدراسة أن التدين يرتبط إيجابيا مع بعض مؤشرات الصحة النفسية كالتوافق الاجتماعي و تقدير الذات الإيجابي، و على ضوء هذه النتائج التي تم التوصل إليها، فإن الباحثة تعرض مجموعة من التوصيات، كما تقترح أيضا بعض البحوث المستقبلية: 1- التوصيات: - إعداد برامج توجيهية و إرشادية لمختلف المراحل العمرية -خاصة للثباب-، و ذلك

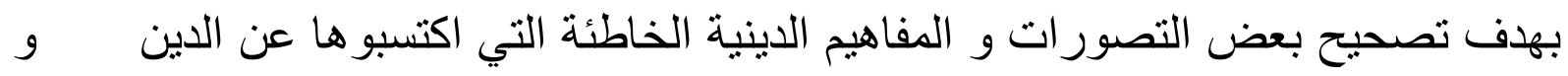
من أجل توعيتهم بأهمية الدين في تحقيق السعادة و الأمن النفسي لهم. ـ العمل على زيادة الوعي الديني، و نرشيح القيم الأصيلة، و إعادة البناء القيمي الإسلامي بناءا يقينيا خاصة لدى طلاب الجامعة، باعتبار هم يمثلون الطبقة المثقفة التي يعول عليها مستقبلا في بناء المجتمعات الإسلامية و النهوض بها لتنافس باقي المجتمعات الأخرى. - تزويد المقرر الدراسي لطلبة علم النفس -خاصة- (باعتبار هم الأكثر تعاملا مع النفس البشرية "مستقبلا")، بمقررات دينية تدرس إلى جانب المقررات الأخرى. 
- العمل على وضع برامج دراسية لتأهيل بعض الأطباء النفسيين دينيا، حتى يدعم ذلك تكوينهم النفسي. - تزويد المستشفيات و مر اكز العلاج المختلفة بمرشدين دينيين، يعملون إلى جانب الأطباء النفسانيين و المختصين في الطب العقلي. - و أخير ا، إعادة تفعيل دور الدين من جديد، ليشمل جميع مناحي الحياة اليومية للأفراد

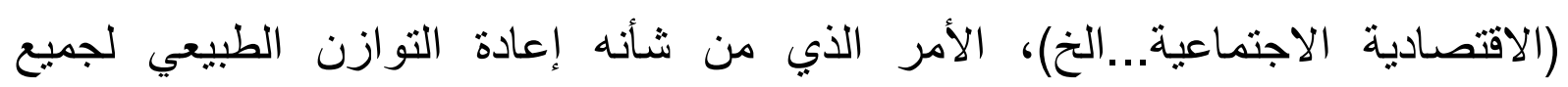
المجالات و لمختلف الميادين.

تقترح الباحثة البحوث النالية: - در اسة متغير التدين مع متغير ات نفسية و اجتماعية أخرى. - در اسة متغير التدين عند باقي الفئات العمرية الأخرى. ـ القيام بدراسة مقارنة بين أصحاب التدين المرتفع و أصحاب التدين المنخفض في بعض المتغير ات النفسية الاجتماعية. - در اسة الفروق في مستوى التدين حسب متغير ات: (مستوى التعليم، المستوى الاقتصـادي و الاجتماعي، السن). - در اسة مقارنة بين الأصحاء و المرضى النفسيين في مستوى التدين. - در اسة علاقة التربية الدينية بنوع سمات الثخصية لاى الأفر اد. - و أخير ا القيام بدراسة تطبيقية علاجية باستخدام الدين (استخدام القرآن الكريم، الأذكار الدعاء ...الخ) في علاج بعض الاضطر ابات و الأمر اض النفسية. 


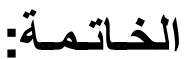

لقد تناولنا في هذه الدراسة موضوع التدين في علاقته ببعض المتغيرات النفسية الاجتماعية كالتوافق الاجتماعي و تقدير الذات و ذللك عند عينة من طلبة الجامعة، حيث

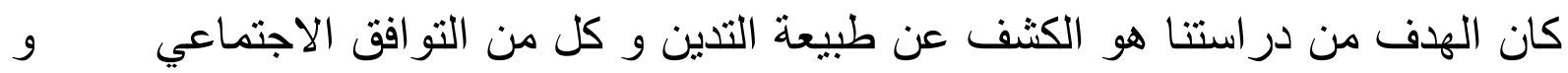
تقدير الذات، و ذلك بعد أن أصبح موضوع التدين يشغل مساحات واسعة من اهتمام أكبر الباحثين و الدفكرين النفسانيين (خاصة في الغرب)، و بعد أن أصبح و بثهادة الكثير من

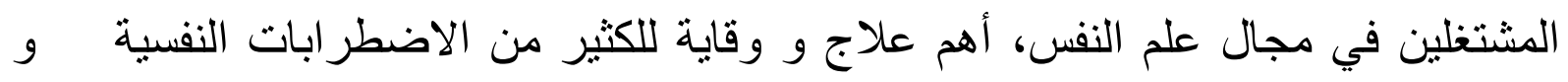
العلل التي يعاني منها إنسان هذا العصر. و جاءت نتائج دراستنا متفقة مع هذه الحقائق، و تتلخص هذه النتائج فيما يلي: 1- يرتبط التندين ارتباطا موجبا مع كل من التو افق الاجتماعي و تقدير الذات المرتفع فالدين

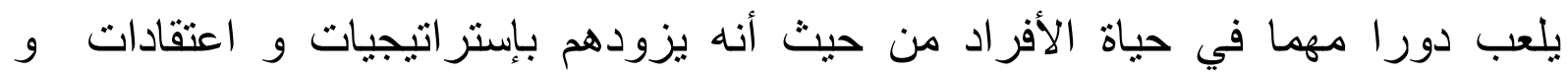

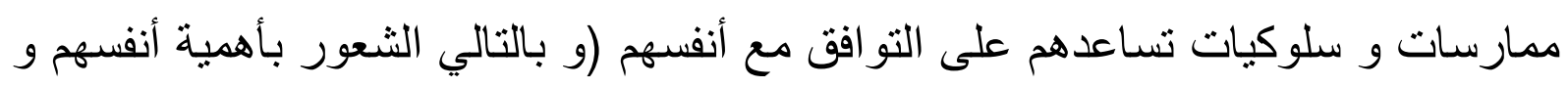
قيمة ذو اتهم)، و مع الآخرين (و بالتالي تحقيق تو افقهم الاجتماعي). 2- يوجد فروق (ذات دلالة إحصائية) في مستوى التنين حسب نوع التخصص الدراسي

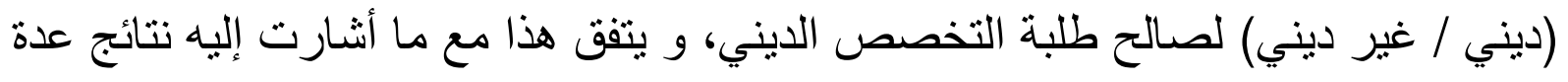


دراسات في أن طلبة التخصص الديني يتفوقون عن غيرهم من طلاب التخصصات الأخرى في مستوى التدين. 3- لا يوجد فروق (ذات دلالة إحصائية) بين الذكور و الإناث في مستوى التدين، ذلك أن مستوى التدين يؤثر فيه عو امل أخرى لا تتعلق بتغير الجنس.

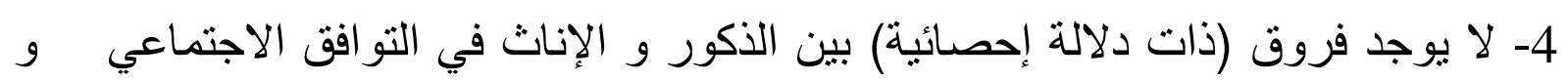
تقدير الذات و ذلك قد يتعلق بالتغيرات الاقتصادية و الاجتماعية التي يشهدها العالم بأسره، و منها المجتمعات الإسلامية.

و ختاما، يمكن القول أن الدين كان و لا يزال و سوف يظل الملاذ العظيم و المنقذ الكبير

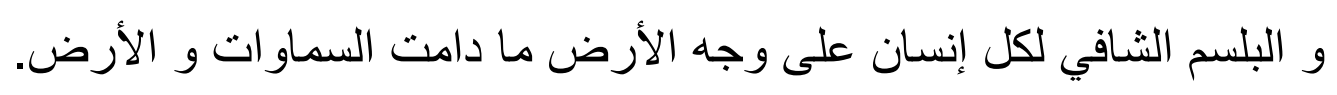

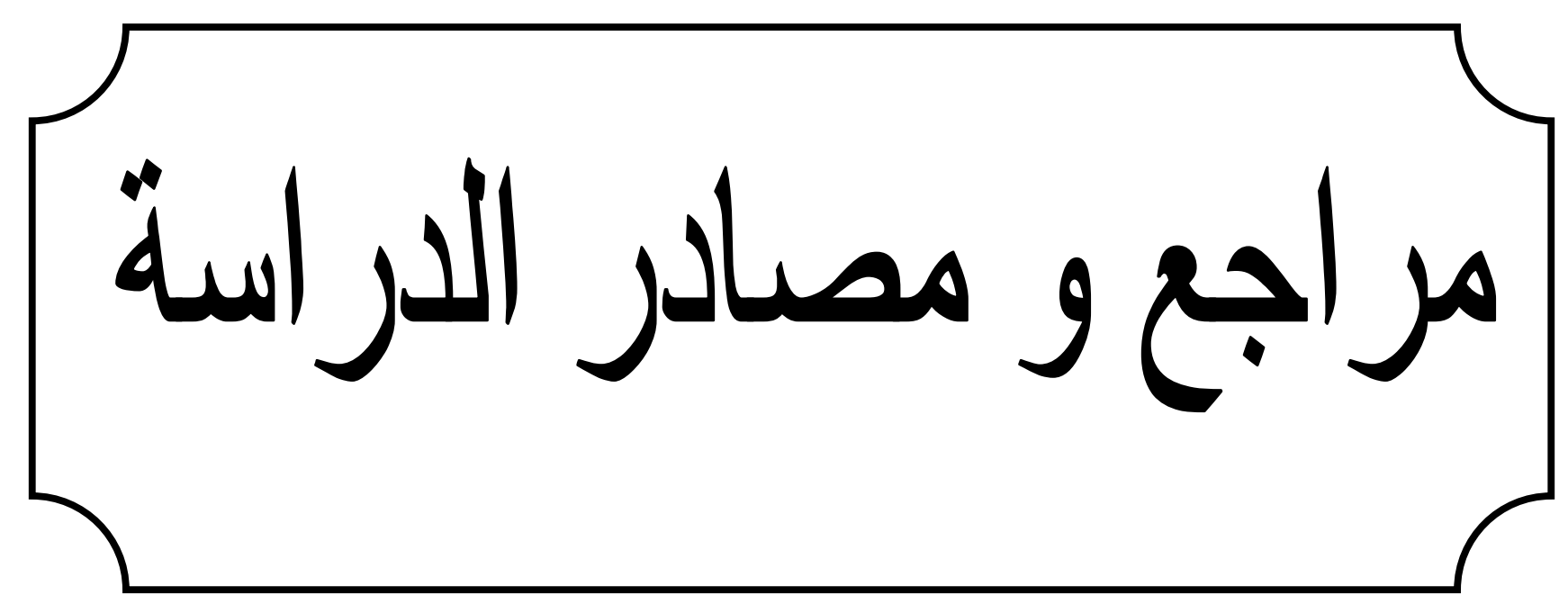




\section{قائمة المراجع و المصادر:}

I - Iائمة المراجع و المصادر العربية:

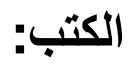

1- د. إبر اهيم أحمد أبو زيد سيكلو جية الذات و التو افق- بدون طبعة-الإسكندرية-دار

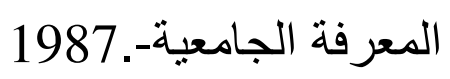

2- د. إبراهيم محمد السرخي -السلوك و بناء الثخصية بين النظريات الغربية و بين

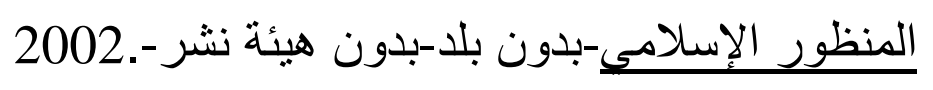

3- إسماعيل علي سعد -الاتصال الإنسانى في الفكر الاجتماعي- الإسكندرية - دار

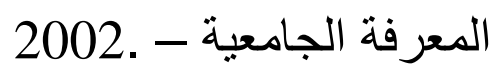

4- د. أثنرف محمد عبد الغني شريف، د. محمد السيد حلاوة- الصحة النفسية بين النظرية و التطبيق- بدون طبعة- الإسكندرية- المكتب الجامعي الحديث-

$$
2003 .
$$

5- إنتصار يونس- السلوك الإنساني -بدون طبعة- بدون بلد- دار المعرفة الجامعية2004.

6- جان بول ويليم -الأديان في علم الاجتماع- (ت،ر) بسمة بدران -بيروت- المؤسسة

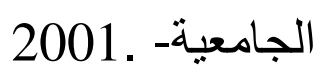


7- جليل وديع شكور -أمر اض المجتمع: الأسباب، الأصناف، التفسير، الوقاية و العلاج-

$$
\text { 1998. - بيروت }
$$

8- د.جنان سعيد الرحو -أساسيات فى علم النفس- بيروت- الدار العربية للعلوم 2005.

9- د. حامد عبد السلام زهران -ـر اسات في الصحة النفسية و الإرشاد النفسي-

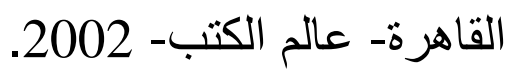

10- د. حامد عبد السلام زهر ان -علم النفس النمو "الطفولة و المراهقة"- الطبعة 1995. الخامسة - القاهرة- عالم الكتب

11- د. حسين أحمد حشت، د. مصطفى حسين باهي -التو افق النفسى و التوازن

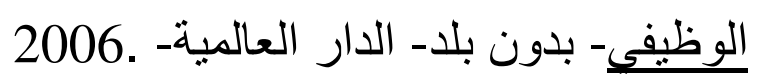

12- د.حسين عبد الحميد أحمد رشوان -الدين و المجتمع، دراسة في علم الاجتماع

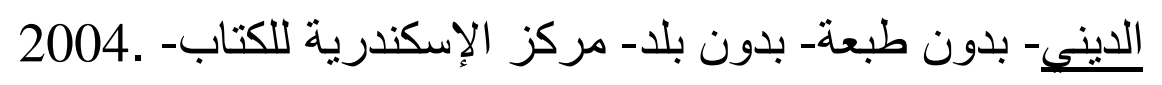

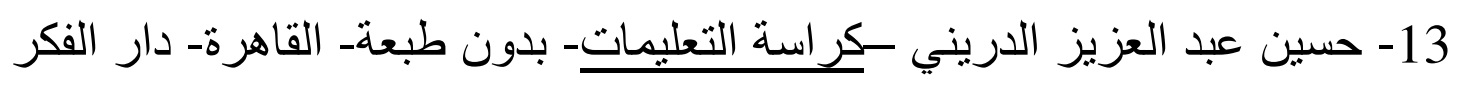

$$
\text { العربي- بدون سنة. }
$$

14- د. حسين فايد -ـراسات في السلوك و الثخصية- القاهرة، الإسكندرية- مؤسسة

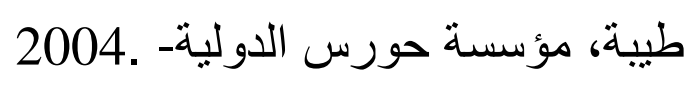

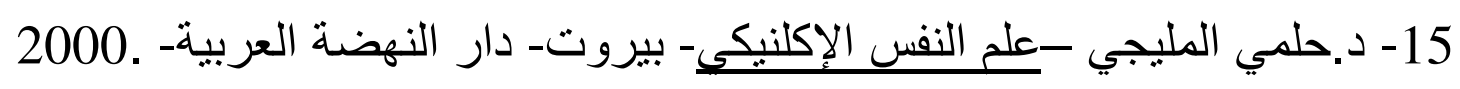

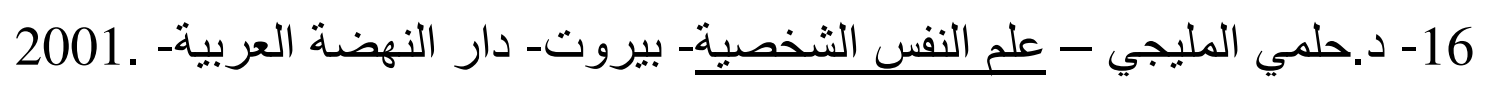
17- دايل كارينجي -ـدع القلق و ابدأ الحياة- بدون طبعة- بيروت- دار و مكتبة

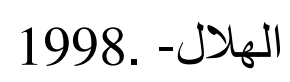

18- رشاد صالح دمنهوري، د. عباس محمود عوض -علع النفس الإجتماعى، نظرياته و

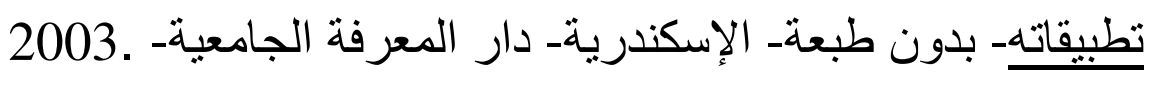

19- د. رشاد علي عبد العزيز موسى -أساليب العلاج النفسى في ضوء القرآن الكريحو

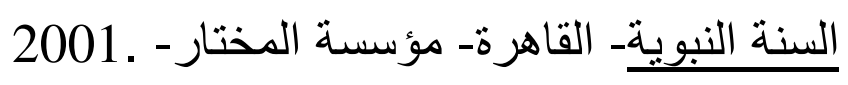


20- د. رشاد علي عبد العزيز موسى -علع النفس الدعوة بين النظرية و التطبيق-

$$
\text { 1999. - الإسكندرية- المكتب العلمي للكمبيونر }
$$

21- د. رشاد علي عبد العزيز موسى و آخرون -علم النفس الديني- بدون طبعة- مصر

$$
\text { الجديدة- } 1996 .
$$

22- د. رمضان محمد القذافي -علع النفس في الإسلام، ج1، علع النفس- بدون بلد -

$$
\text { 1999. مكتب الإعلام و البحوث }
$$

23- د. زينب محمود شقير -الثخصية السوية و المضطربة- الطبعة الثانية- القاهرة-

$$
\text { 2002. مكتبة النهضة المصرية }
$$

24-د. زينب محمود شقير -كر اسة التعليمات -القاهرة- دار الكتاب الحديث- .2003

25- سامي أحمد الموصلي -الإسلام طبيب أمر اض العصر-- دمشق- دار النفائس-

$$
2004 .
$$

26- د. سعد رياض -الثخصية: أنو اعها، أمر اضها، و فن التعامل معها- القاهرة-

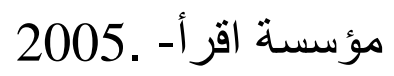

27- د. سعد رياض -مدخل في الاضطر ابات النفسية- المنصورة- دار الكلمة- .2003

28- أ. د. سهير كامل أحمد -الصحة النفسية و التو افق- بدون طبعة- الإسكندرية-

1999. - مركز الإسكندرية للكتاب

29- سونيا هانت، جينيفر هيلتن -نمو شخصية الفرد و الخبرة الاجتماعية- (ت.ر) قيس

1998. النوري- بدون بلد- دار الثؤون الثقافية العامة

30- أ. د. سيد صبحي -الإنسان و صحته النفسية- القاهرة- الدار المصرية اللبنانية-

$$
2003 .
$$

31- د. ظريف شوقي فرج - 1998.

32- أ. د. صبرة محمد علي و أنشرف محمد عبد الغني شريت- الصحة النفسية و 2004. التو افق النفسى_ـبدون طبعة- بدون بلد- دار المعرفة الجامعية-

33- د. صلاح أحمد مرحاب سسيكلوجية التو افق النفسي و مستوى الطموح- الرباط- 


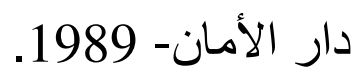

34- د. صلاح الدين محمود علام- الأساليب الإحصائية- الإستدلالية البار امترية و اللابار امترية في تحليل بيانات البحوث النفسية و التربوية- بدون بلد-

$$
\text { 2003. دار الفكر العربي- }
$$

35- د. عبد الحميد محمد شاذلي -الصحة النفسية و سيكلوجية الثخصية- بدون طبعة-

$$
\text { 1999. - الإسكندرية- المكتب العالمي للكمبيوتر }
$$

36- عبد الرحمن سيد سليمان- السو اء في النظريات النفسية و الآيات القر آنية- بلون

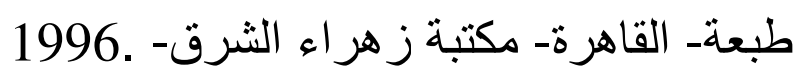

37- أ.د. عبد الرحمن عيسوي -الإسلام و الإنسان المعاصر، در اسة نفسية- بيروت-

$$
\text { 2001. دار الراتب الجامعية }
$$

38- أ. د عبد الرحمن عيسوي- الإسلام و العلاج النفسى الحديث- بدون طبعة-

$$
\text { بيروت- دار النهضة العربية- بدون سنة. }
$$

39- أ. د عبد الرحمن عيسوي- الإيمان و الصحة النفسية- بدون طبعة- الإسكندرية-

$$
\text { 2005. المكتب العربي الحديث- }
$$

40- أ. د عبد الرحمن عيسوي- النمو الروحي و الخلقي- بدون طبعة- بيروت- دار

$$
\text { 1992. - النهضة العربية }
$$

41- عبد السلام الدويبي- التمهيد في علم النفس الاجتماعي- طر ابلس- جامعة الفاتح

$$
\text { 1998. - إدارة المطبو عات و النشر }
$$

42- عبد العزيز جادو - الطريق إلى عالم النور و الحق في ضوء علم النفس الحديث

$$
\text { - بدون طبعة- الإسكندرية- المكتب الجامعي الحديث- } 2000 .
$$

43- عبد العلي الجسماني- القرآن و علم النفس، نداء الفطرة الإيماني- بيروت- الدار

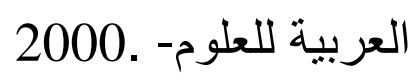

44- د. عبد الفتاح دويدار - سيكلوجية العلاقة بين مفهوم الذات و الاتجاهات- بدون 
1992. طبعة- بيروت- دار النهضة العربية-

45- د. عزت عبد العظيم الطويل- في النفس و القرآن الكريم- الطبعة الثالثة- بدون

$$
\text { 2005. بلد- المكتب الجامعي الحديث }
$$

46- د. علي عبد الحليم محمود- النفس في الإسلام- القاهرة- دار التوزيع و النشر

$$
\text { 2005. الإسلامية }
$$

47- عمر محمد التومي الثينابي- الأسس النفسية و التربوية لرعاية الثباب- بدون

$$
\text { طبعة- بيروت- دار الثقافة- بدون سنة. }
$$

48- د. فوزي محمد جبل- الصحة النفسية و سيكلوجية الشخصية- بدون طبعة-

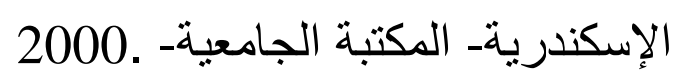

49- قحطان أحمد الظاهر - مفهوم الذات بين النظرية و التطبيق- عمان- دار و ائل-

$$
2004 .
$$

50- كارول دويك- نظريات الذات و دور ها في الو اقعية و الثخصية و النمو - (ت.ر)

2006. أ.د ماهر أبو هلال و آخرون -غزة- دار الكتاب الجامعي

51- كمال إبر اهيم مرسي- السعادة و تنمية الصحية النفسية، ج1، مسؤولية الفرد في

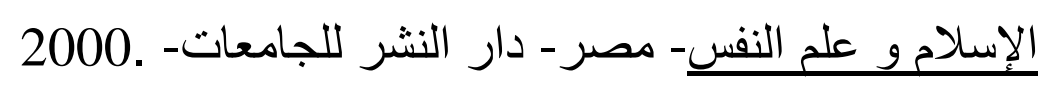

52- كوني فلادينو - تطوير احتر ام الذات- (ت.ر) عادل منصور - الرياض- دار 2002. المعرفة للتنمية البشرية

53- د. لطفي الثربيني- الطب النفسى و مشكلات الحياة- بيروت- دار النهضة

$$
\text { 2003. العربية- (10) }
$$

54- مايك كرسب- انثتا عشرة خطوة للتطوير الذاتي- (ت.ر ) مفيد ناجي عودة-

الرياض- دار المعرفة للتنمية البشرية- دار الناشر الدولي- 1422هـ.

55- مجدي أحمد محمد عبد الله- علم النفس التربوي بين النظريةو التطبيق- بدون

$$
\text { طبعة- بدون بلد- دار المعرفة الجامعية- } 2003 .
$$

56- مجدي أحمد محمد عبد الله- علم النفس العام "در اسة في السلوك الإنسانى و 
جو انبه"- بدون طبعة- بدون بلد- دار المعرفة الجامعية- .1998 57- محمد جاسم محمد- مشكلات الصحة النفسية، أمر اضاو علاجها- عمان- مكتبة 2004. دار الثقافة

58- محمد السيد عبد الرحمن- نظريات النمو "علم النفس المتقدم"- القاهرة- مكتبة زاء

59- محمد السيد الهابط- التكيف و الصحة النفسية- الطبعة الثانية- الإسكندرية- المكتب

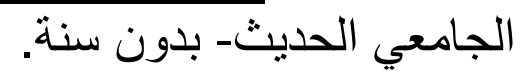

60- د. محمد عبد الله دراز - الدين "بحوث مدهدة لدار اسة تاريخ الأديان"- بدون طبعة-

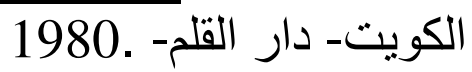

61- د. محمد عثمان نجاتي- الحديث النبوي و ولم النم النفس- الطبعة الثانية- القاهرة1993. بيروت- دار الثرق الندان

62- محمد عثمان نجاتي- القرآن و علم النفس- القاهرة، بيروت- دار الثروق1982.

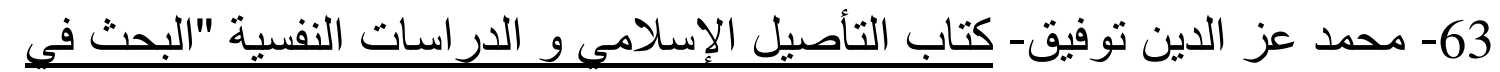

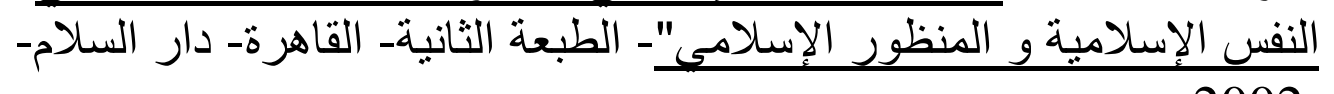
2002.

64- محمد محروس الثناوي- نظريات الإرشاد و العلاج النفسي- بدون طبعة- بدون بلد- دار غريب- بدون سنة النئ.

65- محمد محمد الحداد- كيف نربي أو لادنا، نصائح و تو جيهات إسلامية- القاهرة-

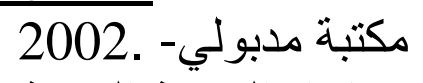

66- محمد مياسا- الصحة النفسية و الأمر اض النفسية و العقلية، وقاية و علاجيا1997. بيروت- دار الجيل

67- د. مريم سليم- تقدير الذات و الثيل- دئة بالنفس "دليل المعلمين"- بيروت- دار النهضة

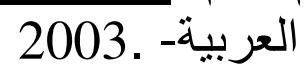

68- د. مريم سليم- كيف ننمى تقدير الذات و الثقة بالنفس و النجاح عند أبنائنا "دليل 2003. الو الدين"- بيروت- دار النهضة العربية

69- مصطفى خليل الثرقاوي- علم الصحة النفسية- بلون طبعة- بيروت- دار النهضة

$$
\text { العربية- بدون سنة. }
$$

70- مصطفى عشوي- مدخل إلى علم النفس المعاصر - الطبعة الثانية- الجزائر - ديوان 2003. المطبو عات الجامعية

71- د. مصطفى فهي- علم النفس الإكلنيكي- بدون طبعة- بدون بلد- مكتبة مصر - 
بدون سنة.

72- مصطفى محمد الصفطي و آخرون- الصحة النفسية و علم النفس الاجتماعي و2000. التربية الصحية- بدون طبعة- بدون بلد- دار المعرفة الجامعية

73- منذر عبد الحميد الضامن- علم النفس النمو، "الطفولة و المر اهقة"- الكويت

$$
\text { 2005. الإمار ات العربية المتحدة- مكتبة الفلاح }
$$

74- ميخائيل أسعد- السيكلوجيا المعاصرة- بيروت- دار الجيل- . 1996

75- ناهد الخر اثي- أثر القر آن الكريم في الأمن النفسي- الطبعة الرابعة- القاهرة

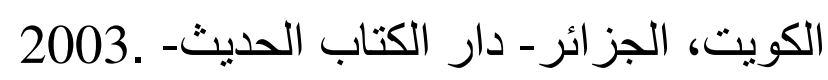

76- د. نبيل محمد توفيق السمالوطي- الإسلام و قضايا علم النفس الحديث- بدون

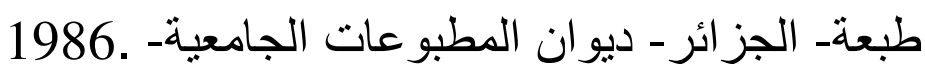

77- د. نبيل محمد نوفيق السمالوطي- الدين و البناء الاجتماعي، جـ- جدة- دار

$$
\text { 1981. - الثروق }
$$

78- نبيه إبر اهيم إسماعيل- عو امل الصحة النفسية السليمة- القاهرة- إيتر اك- 2000.

79- والاس د.لابين، بيرت جرين- مفهوم الذات (أسسه النظرية و التطبيقية)- (ت.ر)

أ.فوزي بهلول- بدون طبعة- بيروت- دار النهضة العربية، .1981

80- وفيق صفوت مختار - أبناؤناو صحتهم النفسية- بدون طبعة- القاهرة- دار العلم

$$
\text { 2001. - 2001 الثقافة }
$$

81- وينفريد هوبز - مدخل إلى سيكلوجية الثخصية- (ت.ر ) د. مصطفى عشوي- بدون طبعة- الجزائر - ديوان المطبو عات الجامعية- 1995.

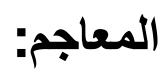

82- د. أنور فؤاد أبي خز ام- معجم المصطلحات الصوفية- بيروت- مكتبة لبنان 1993. - ناشرون

83- د. بودون، ف. بوريكو - المعجم النقدي لعلم الاجتماع- (ت.ر) د. سليم حداد- 
1986. بدون بلد- المؤسسة الجامعية للار اسات

84- جان لابلانش، جاك بونتاليس- معجم مصطلحات التحليل النفسي- (ت.ر ) مصطفى 1997. حجازي- الطبعة الثالثة- بيروت- المؤسسة الجامعية للار اساتئ85- ميشن تكلاجرجس، رمزي كامل حنا الله- معجم المصطلحات التربوية- بلون طبعة- بيروت- مكتبة لبنان ناشرون- 1998.

الموسو عاث: - (اث:

86- موسوعة البحث العلمى و إعداد الرسائل و الأبحاث و المؤلفات- د. عبد الفتاح 1997. - مر اد- بدون طبعة- الإسكندرية- الكرنك للكمبيونر 87- موسو عة الطب النفسىـ المجلد الأولـ- د. عبد المنعم الحفني- الطبعة الرابعة2003. القاهرة- مكتبة مدبولي-

88- الموسو عة العربية العالمية(10)- بدون مؤلف- الرياض- مؤسسة أعمال

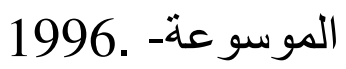

89- موسوعة علم النفس و التحليل النفسي- د. عبد المنعم الحفني- الطبعة الرابعةالقاهرة- مكتبة مدبولي- 1994.

90- الموسو عة النفسية، علم النفس و الطب النفسي- د. عبد المنعم الحفني- الطبعة الثانية- القاهرة- مكتبة مدبولي- 2003.

91- د. إحسان كار افاس- المسار الإنساني التاريخي للطب النفسي في الإسلام- مجلة 1990. الثقافة النفسية- بيروت- دار النهضة العربية- العدد 2- نيسان

92- د. زينب محمود شقير - تقدير الذات و العلاقات الاجتماعية المتبادلة و الشعور بالوحدة لدى عينتين من تلميذات المرحلة الإعدادية في كل من مصر و المملكة العربية السعودية- مجلة العلوم الاجتماعية- المجلد (1،2)الكويت- مجلس النشر العلمي- العدد الأول و الثاني- ربيع صيف .1993 
93- د. صالح فيلالي- الدين و المجتمع (دراسة سوسيولوجية)- مجلة الباحث

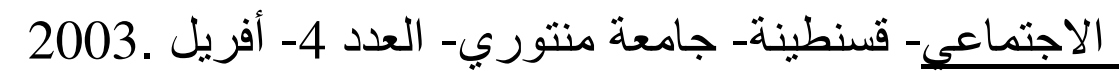
94- أ. د لوكيا الهاثمي- مجلة أبحاث نفسية و تربوية- عين مليلةـ دار الهاى2002. - العدد 00

95- د. الهادي سريط- حقيقة العلاقة بين الفلسفة و الدين في الماضي و الحاضر -

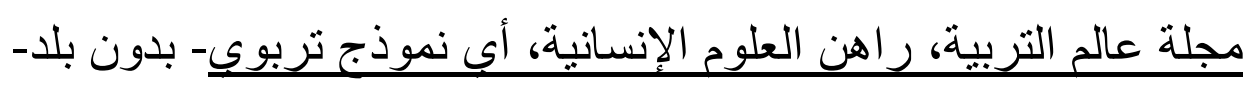
مطبعة النجاح الجديدة- العدد 16- 2005.

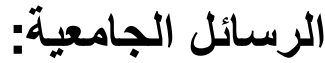

96- زعطوط رمضان- الاتجاه نحو السلوك الصحي و علاقته ببعض المتغيرات النفسية الاجتماعية (الكفاءة الددركة، الدعم الاجتماعي، التندين)عند عينة من مرضى السكري و ضغط الدم بمدينة ورقلة- رسالة ماجيستير غير منشورة- كلية الآداب و العلوم الاجتماعية "قسم علم النفس"- جامعة ورقلة- .2005

97- محمد قماري، التو افق و علاقته بالانبساطو أثر ذلك على التحصيل الدراسي لدى طلاب المرحلة الثانوية- كلية الآداب "قسم علم النفس"- جامعة الإسكندرية. 


\section{قائمة المراجع و المصادر الأجنبية: \\ * Les livres :}

98- Michaelle Man. Macmillan Student en cyclopedia socioliogy.

Twice edition. London.Maccmillan press. 1985.

99- Gérard pousin, Isabelle sayn. Un seul parent dans la famille. Sans édition. Paris. Contrion. 1990.

Les dictionnaires :

100- Jack Postel. dictionnaire de psychiatrie et de psychopathogie climique. sans édition. Paris. Larousse-Borda. 1998.

101- Nicholas Abercrombie et al. dictionnairy of sociology. fourth edition. U.S.A. penguin referance. 2000.

102- Norbert Sillamy. dictionnaire usuel de psychologie. sans édition.

Paris. Bordas. sans année.

-III

103- http ://www. Saaid.net/aldawh/190.htm.

104- http://www. Elazayem.com/B(54).htm.

105- http://www. Jaberna.com/vb/archiv/index.php/t-11649.html. 


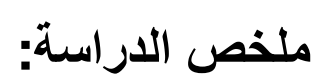

يعد التندين عامل هام في تحقيق الصحة النفسية للأفراد، و في وقايتهم أو علاجهم من الأمر اض النفسية و البدنية، كما يعد البعد عن الدين و من ثم الفراغ الروحي عوامل معجلة

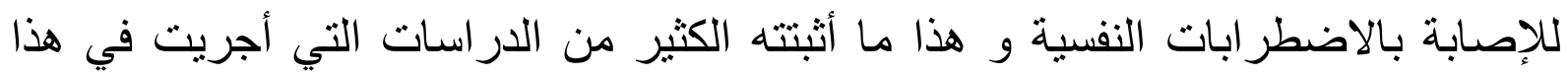

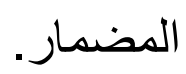
و لا يخفى على أحد اليوم حجم الاضطر ابات و الأمراض النفسية المنتشرة في جميع أرجاء العالم و منها العالم الإسلامي الذي لم بسلم هو الآخر من هذا الداء، فضعف الإيمان

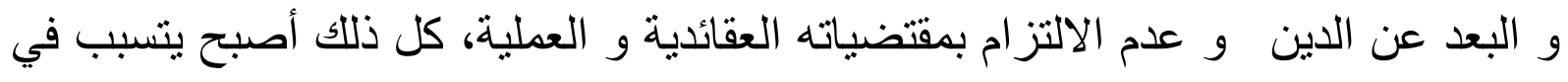
الكثير من المشاكل التي لا حصر لها. 
و يؤكد الكثير من الباحثين و العلماء النفسانيين على أن العودة إلى الدين هو الحل الأمثل للمشاكل التي يتخبط فيها الإنسان المعاصر، فالدين بمنظومته الفكرية المنطقية و العلمية

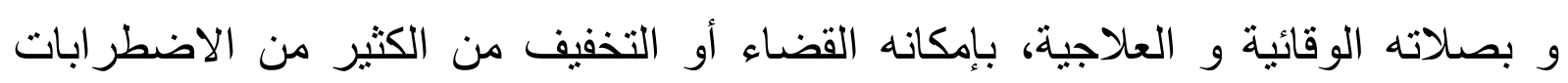
النفسية أو النفسمية التي عجز العلم عن تخفيف الكثير منها فضلا عن القضاء عليها. لذللك فإن هذه الدر اسة تهدف إلى الكثف عن طبيعة العلاقة بين التدين و بعض المتغيرات النفسية الاجتماعية كالتوافق الاجتماعي و تقدير الذات كعوامل أساسية في الصحة النفسية، و ذلك عند عينة من طلبة الجامعة. كما تهدف هذه الدراسة إلى معرفة الفروق بين طلبة التعليم الديني و طلبة التعليم غير الديني في مستوى التدين، كما تهدف إلى الكثف عن الفروق بين الذكور و الإناث في كل من التدين و التوافق الاجتماعي و تقدير الذات. و قد افترضت الباحثة وجود علاقة إرتباطية موجبة بين التدين و كل من التوافق الاجتماعي و تقدير الذات، كما افترضت وجود فروق بين طلبة التعليم الديني و طلبة التعليم غير الديني في مستوى التدين، كما افترضت أيضا وجود فروق بين الذكور الإناث في كل من(التدين، التو افق الاجتماعي و تقدير الذات). أما عن أدوات القياس المستخدمة في هذه الدراسة، فتتمثل فيما يلي: ـ استبيان مستوى التدين من إنشاء الباحثة، حيث تم التأكد من صدقه و ثباته على 58 طالبا و طالبة من طلاب الجامعة. - مقياس التوافق الاجتماعي المأخوذ من مقياس التوافق النفسي من إعداد (أد. زينب محمود شقير). - مقياس تقدير الذات من إعداد (د. حسين عبد العزيز الدريني و آخرون). و قد شملت عينة الدراسة (204) طالبا من طلاب الجامعة، حيث أخذت عينة من طلبة العلوم الإسلامية لتمثل طلابا طبيعة تعليمهم ديني، في المقابل عينة ثانية من طلبة العلوم الأخرى (علم النفس، الطب، لغة عربية و آدابها...الخ) لتمثل طلابا طابع تعليمهم غير دئ 


$$
\begin{aligned}
& \text { و قد تم التطبيق النهائي خلال شهري (أفريل و ماي من سنة 2007)، كما تم معالجة } \\
& \text { البيانات التي تم التحصل عليها بو اسطة الأساليب الإحصائية المناسبة لها. } \\
& \text { و قد بينت النتائج التي تم التوصل إليها على وجود علاقة إرتباطية موجبة بين التدين و و } \\
& \text { كل من التوافق الاجتماعي و تقدير الذات. } \\
& \text { كما دلت النتائج على وجود فروق ذات دلالة إحصائية في مستوى التدين حسب نوع } \\
& \text { التخصص الدراسي (ديني / غير ديني)، لصالح طلبة التخصص الديني. } \\
& \text { كما تبين من خلال النتائج التي تم التوصل إليها أنه لا توجد فروق ذات دلالة إحصائية } \\
& \text { بين الذكور و الإناث في متغير ات التدين و التو افق الاجتماعي و تقدير الذات. }
\end{aligned}
$$

\section{Le résumé d'étude}

Le religionisme se considère un facteur important dans la réalisation de la santé psychique des individus et leurs prévention ou guérisons des maladies psychiques et organiques, l'éloignement de la religion et par la suite le manque de foie, se considèrent comme des facteurs favorisants l'atteinte par des troubles psychiques, ce qui à affirmé la majorité des études faite dans ce domaine.

Comme, il est connu que les troubles et les maladies psychique sont très étendues dans le monde entier, surtout le monde musulman, qui n'est pas épargné de ce phénomène, le manque de foie et l'éloignement de la religion sont devenus une cause de nombreux problèmes.

Plusieurs chercheurs et des psychologues, affirment que le retour à la 
religion est la solution idéale aux problèmes dont souffrent l'être humains de ce siècle, cette religion dans sa constitution idéologique et logique scientifique, et sa prière préventive et curative, peut éliminer ou diminuer la majorité des troubles psychiques ou psychosomatiques, que la science n'a pas pu les résoudre.

C'est pour ça cette étude vise à dépister la nature de la relation entre la religion et quelques variables psychosociologiques comme l'ajustement sociale et l'estime de soi, comme étant des facteurs principaux dans la santé psychique et cela dans une catégorie des étudiants universitaire.

Cette étude à pour but de connaître la différence entre les étudiants des sciences religieuse et les étudiants des sciences non religieuse, en ce qui concerne le niveau du religionisme.

Et elle vise aussi les différences entre les deux sexes «masculin, féminin», en ce qui concerne le religionisme, l'ajustement social, et l'estime de soi.

La chercheuse à supposé l'existence d'une corrélation positive entre le religionisme et l'ajustement social, et l'estime de soi, et comme elle à supposé l'existence des différence entre les étudiants des sciences religieuse et les étudiants des sciences non religieuses dans le religionisme.

Comme elle à supposé aussi l'existence des différentes entre les deux sexes en ce qui concerne le religionisme, l'ajustement, et l'estime de soi.

Pour les moyens de mesure utilisés dans cette étude, sont

Questionnaire de niveau de le religionisme qui s'est constituée par la chercheuse, elle à confirmé sa validité et sa stabilité sur «58 » étudiants universitaires. 
$>$ Test de l'ajustement sociale, pris du test de l'ajustement psychologique qui édité par «P.ZINEB MAHMOUD CHOKIER ».

Test d'estime de soi qui édité par « Dr. HOCINE DERIM et AL ».

Cette étude à été appliquer sur « 204 » étudiants universitaires, une catégorie a été pris des étudiants des sciences religieuses, face à une 2éme catégorie des étudiants des autres filières « psychologie, médecine, etc.... », Qui présente des étudiants des autres sciences «non religieuses».

L'application finale a été faite pendant les mois d'avril et mai de l'an 2007.

Et l'analyse des résultats obtenus par les méthodes statistiques qu'ils lui conviennent.

Les résultats obtenus ont démontré l'existence d'une relation positive entre le religionisme et l'ajustement social et l'estime de soi.

Les résultats obtenus ont démontré aussi l'existence des différences dans les niveaux de le religionisme selon la spécialité « religieuse/non religieuse », le taux des étudiants spécialités religieuses plus élevée.

Toujours, ces résultats obtenus, démontré qu'il n'existe de différences de signification statistique entre les deux sexes «masculin, féminin » dans variable : le religionisme, l'ajustement social, et l'estime de soi. 


\section{$\underline{\text { Abstract about the approach }}$}

The worship factor seems to be vital for the health and the well-being of people. It has its positive effect against psycho -physical diseases. It is noticed that breach and break with religious practise has bad feedback upon those people. Studies proved it as well.

Nowadays, depressions and psychic diseases are widespread even Islamic world is touched by those abnormal depressions. This state is a logical result of the break with religious matter and practise.

Researchers confirmed that return to religion is the best solution to mankind troubles.

No one can deny that religion- with its well-established rules and instructions is strongly recommended and necessary to man soul. Where science fails to 
smooth people sufferings, religion is said to be the suitable treatment opposite Our study deals with the existing relationship between (religion-mania) another psychological changes such : social harmony and self-confidence which are basical factors for healthy mind and soul. This study is applied on a specimen of students.

This study aims, also, at discovering diffrences between « religion matter student » and «non-religion matter students ». also, it takes into account those différences with regards to both sexes around « religion-mania » and self confidence.

The researcher supposes the existence of relationship between « religion practise », « social harmony » and « self-esteem ». obviously, the researcher mentions the différences between « religion matter students » and «non-

religion matter students » concerning the degree of religionism différences between the two sexes are not neglected.

If we refer to instruments used in this study, thr researcher concentrates on the following ones.

Enquiry and questions posed 58 university students, this enquiry is focused on « the degree of religionism».

The social harmony scale as it is taken from the psychological equity which is elaboratd by (dr zineb mahmoud chaquir).

The scale of self-esteem elaborated by (dr abdelaziz - al - darini and others). 
204 student were taken as a obj ect for this study .

A sample of islamic sciences students (whose domain is islamic sciences ) on one hand, on the other hand non-islamic students (psychology, medecine, letters streams... etc).

The final practice was done during the two months (april and may-year 2007), the results were analyzed according to the suitable processing.

The obtained results show the close relationship between « religion mania », social harmony and self-esteem. Those results show also clear countable différences concerning the « degree of religionism » with regard to pedagogical stream (religious/non-religious), religious-tream students defeated others. In addition, it is conclued that there are really no différences between the two sexes with regard to religionism, social harmony and self-esteem.

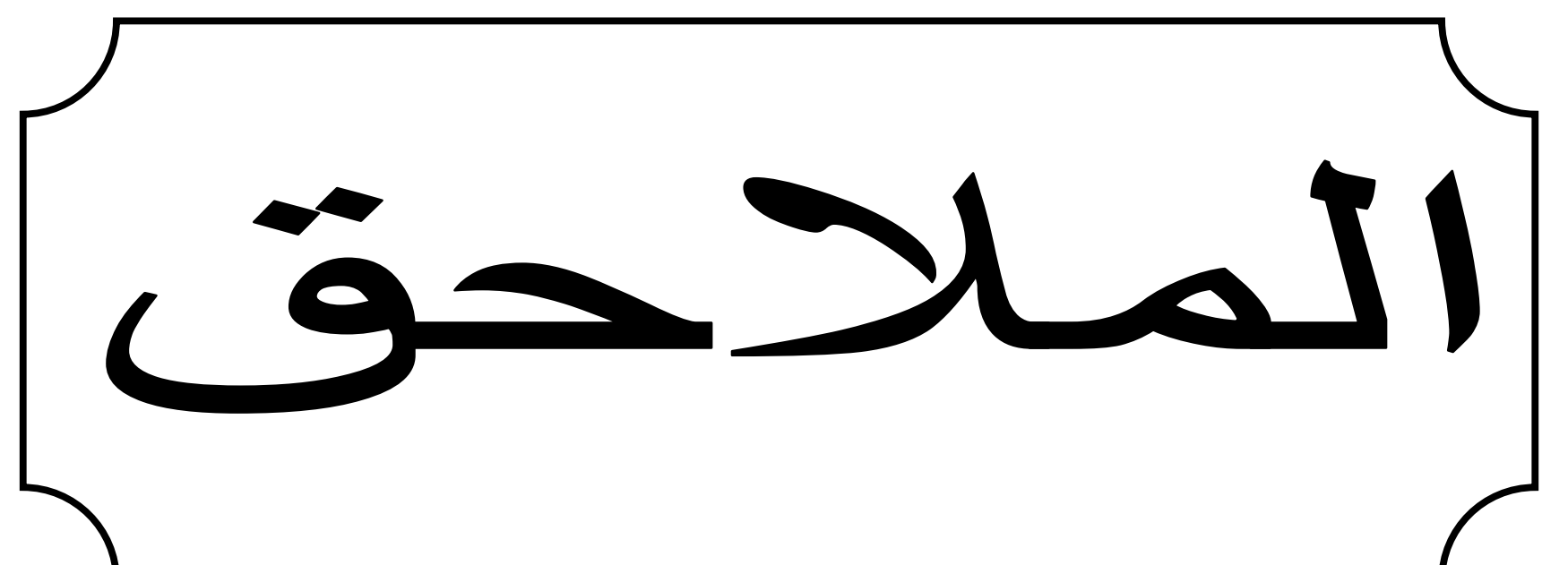


استبيان مستوى التّين الإسلامي

\begin{tabular}{|c|c|c|c|}
\hline \multirow[t]{7}{*}{ نعم غالبا } & أحيانا & لا مطلقا & لمحاور و عدد البنود \\
\hline & & & 1 1الاعتقادات \\
\hline & & & |أجزع و أسخط على قدري إذا حلت بي مصيبة \\
\hline & & & |ؤ أؤمن بقدرة أنشياء معينة (كثنل يد أو ما شابه ذلك) على دفع تأثير العين \\
\hline & & & أترك أنشياء أرغب فيها لأنها تتعارض مع تعاليم الدين \\
\hline & & & يهيني أن يرى الناس عملي الخير \\
\hline & & & |أعتقد في قدرة السحرة و المشعوذين في الإطلاع على الغيب و ما يخبئه \\
\hline & & & |أحب الخير للآخرين منلما أحبه لنفسي \\
\hline
\end{tabular}




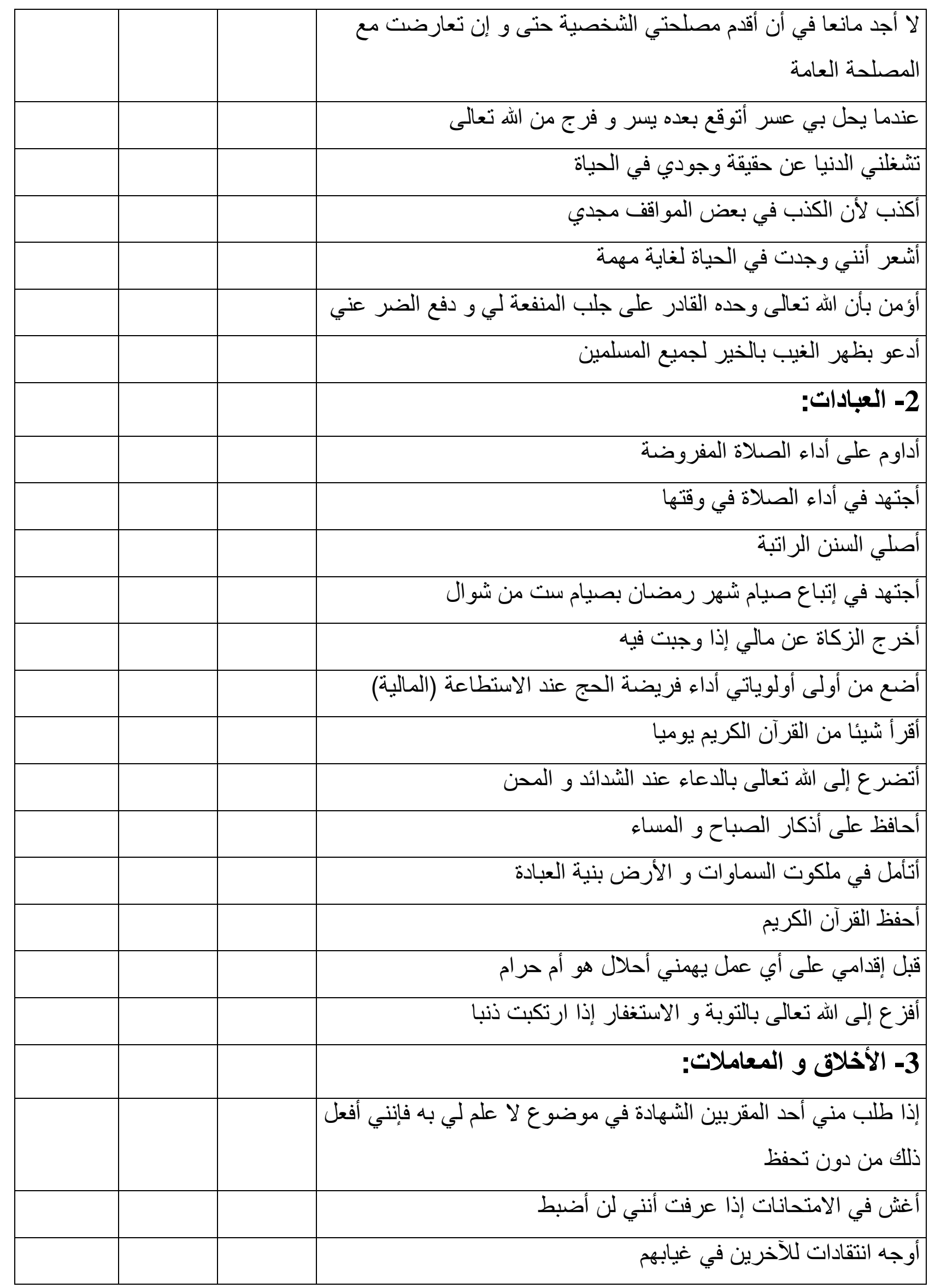




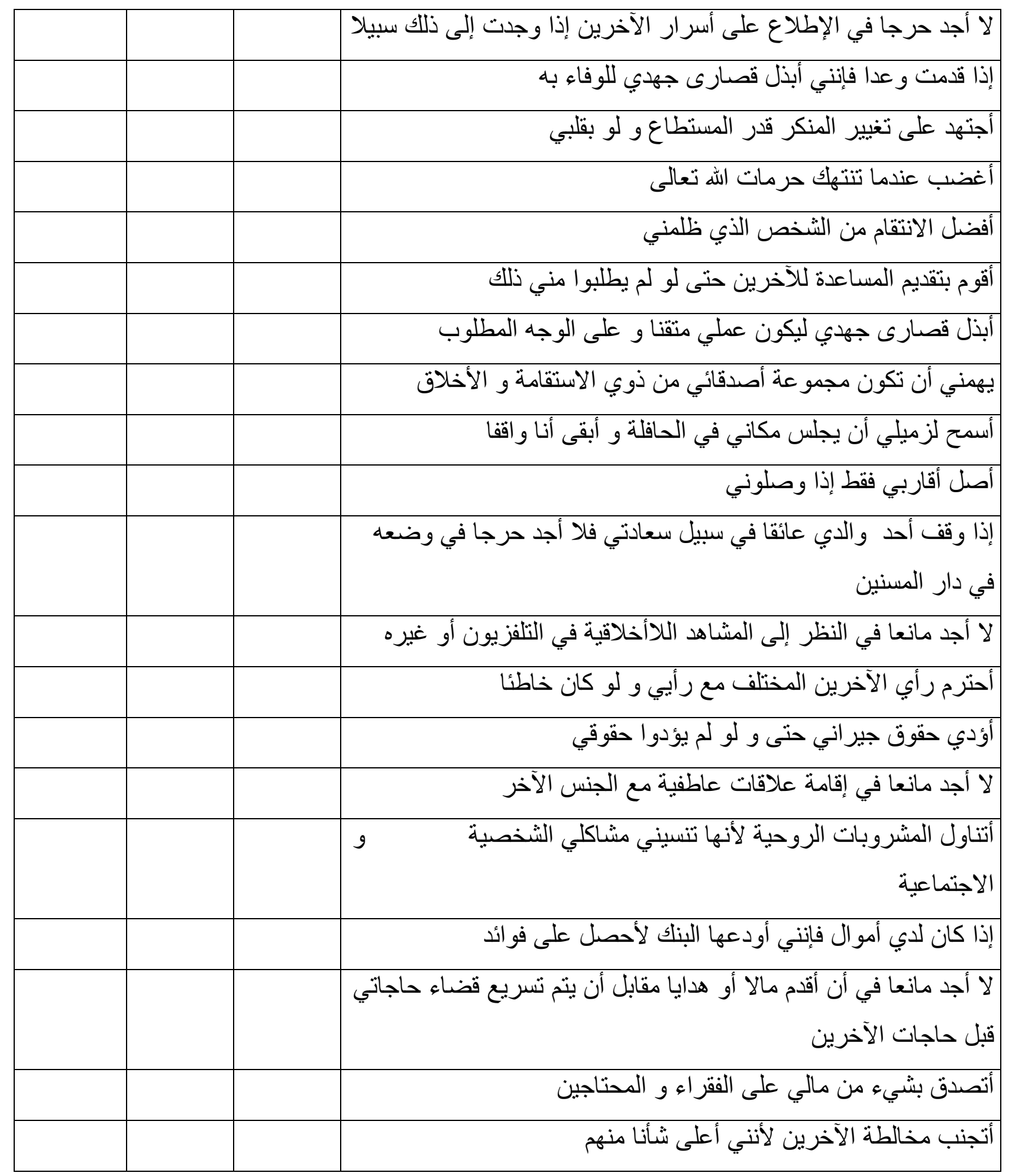




\section{مقياس التوافق الاجتماعي}

\begin{tabular}{|c|c|c|c|}
\hline ل ال لاطبق & أحيانا & نتطبق & العـبــــــــــارة \\
\hline & & & الآخرين ؟حص على المشاركة الإيجابية الاجتماعية و الترويحية مع \\
\hline & & & هل تستمتع بمعرفة الآخرين و الجلوس معهم ؟ \\
\hline & & & هل تشعر بالمسؤولية تجاه تنمية المجتمع متل كل مواطن ؟ \\
\hline & & & هل تتمنى أن تقضي معظم وقت فر اغلك مع الآخرين ؟ \\
\hline & & & هل تحترم رأي زملائك و تعمل به إذا كان رأيا صائبا ؟ \\
\hline & & & هل تشعر بتقدير الآخرين لأعمالك و إنجاز اتك ؟ \\
\hline & & & هل تعتذر لزميلك إذا تأخرت عن المو عد المحدد ؟ \\
\hline & & & هل تشعر بالو لاءو الإنتماء لأصدقائك ؟ \\
\hline & & & هل تشعر بالسعادة لأشياء قد يفرح بها الآخرون كثير ا؟ \\
\hline & & & هل تربطلك علاقات طيبة مع الزملاء و تحرص على إرضائهج؟ \\
\hline & & & هل يسعدك المشاركة في الحفلات و المناسبات الإجتماعية ؟ \\
\hline & & & هل تحرص على حقوق الآخرين بقدر حرصك على حقوقلك ؟ \\
\hline
\end{tabular}




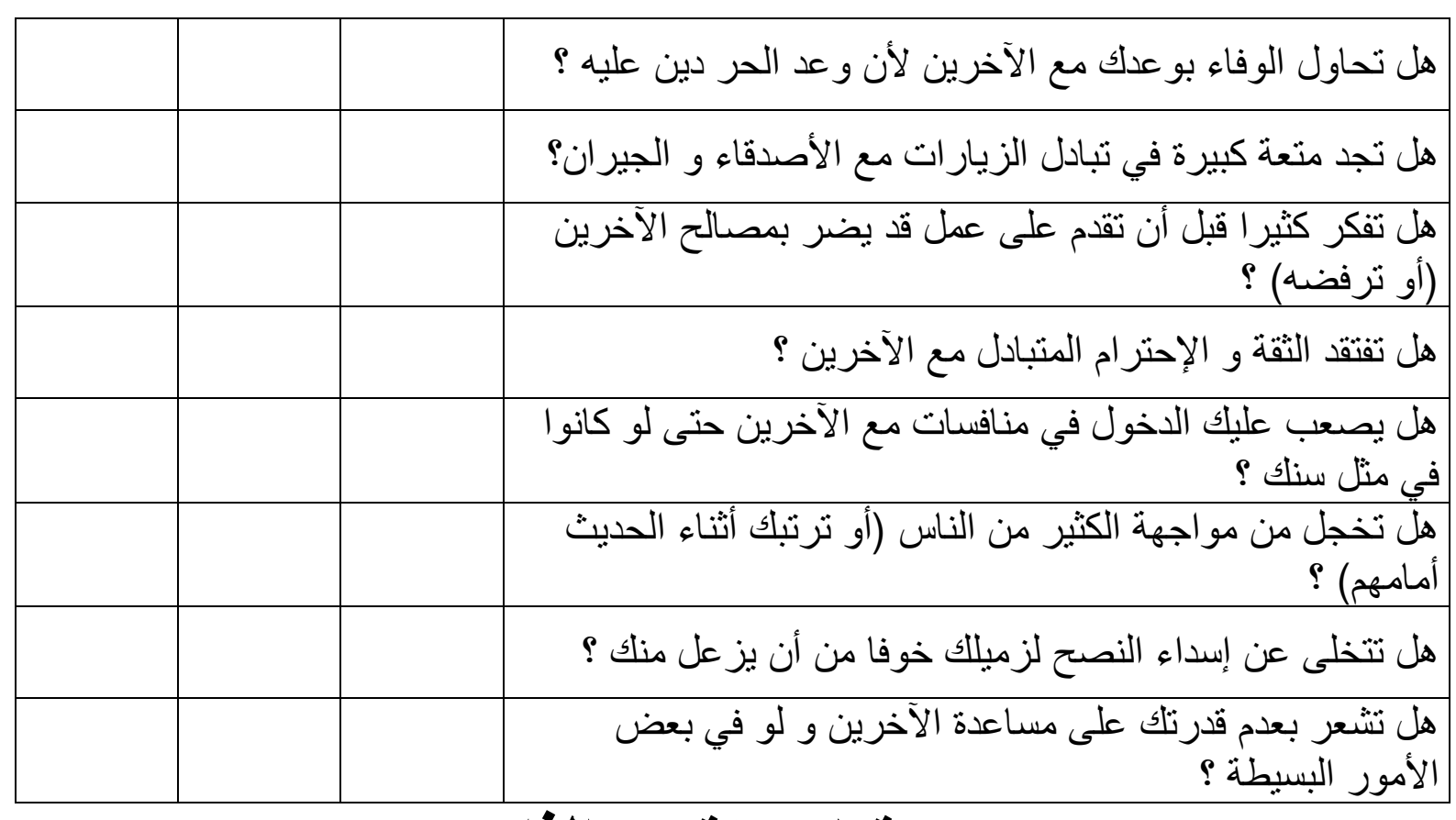

\section{مقياس تقدير الذات}

\begin{tabular}{|c|c|c|c|}
\hline لا لا (أبدا) & 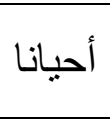 & 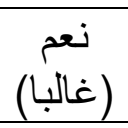 & 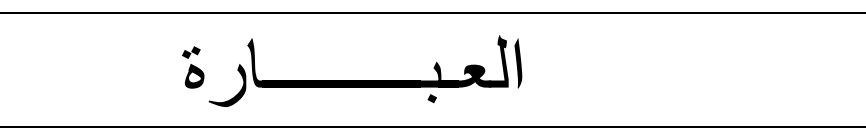 \\
\hline & & & تنقصني التقة بالنفس \\
\hline & & & أشعر بالرضا عن حياتي الاجتماعية \\
\hline & & & أشنعر بالرضا إزاء مستقبلي المشرق \\
\hline & & & إنني غير راض عن مجموعة أصدقائي \\
\hline & & & أثشعر بعدم الرضـا عن مظهري الثخصي \\
\hline & & & لا أحظى باحتر ام الناس بالدرجة التي تليق بي \\
\hline & & & أشعر أني عضو هام في أسرتي \\
\hline & & & إنني راض عن أي عمل أقوم به \\
\hline & & & أكره التو اضع الذي بشعرني الذلة \\
\hline & & & تلقى أفكاري تقدير و الدي \\
\hline & & & يبحث عني أصدقائي عندما أغيب عنهم \\
\hline & & & الإنتماعية مطئن إلى أني سأحقق مستقبلا ما أريده في حياتي \\
\hline & & & ينصت زملائي إلى ما أقوله باهتمام \\
\hline & & & أشعر بأنه لبس لوجودي قيمة كبيرة \\
\hline
\end{tabular}




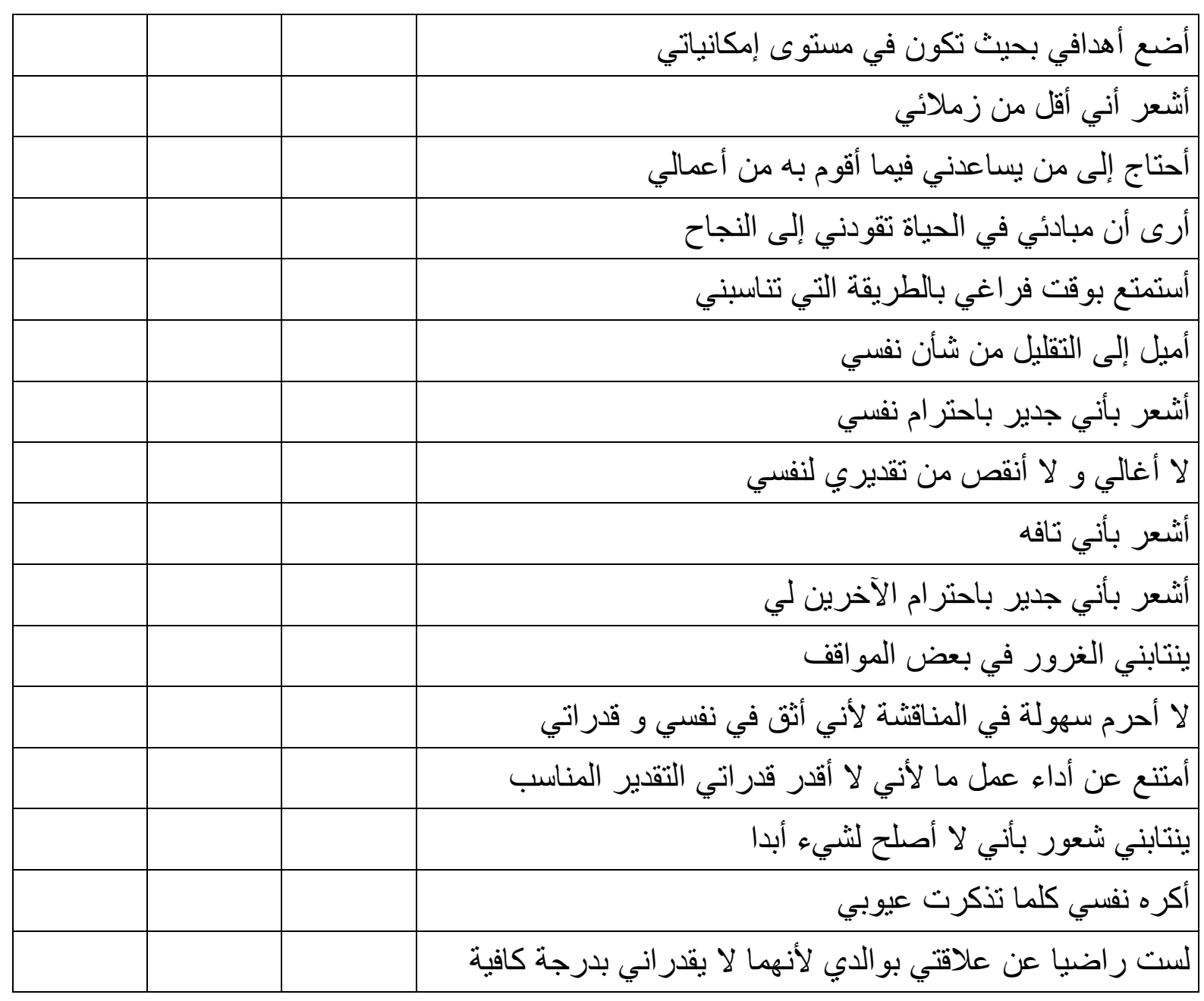


